\title{
Charakterisierung und Nutzung der mikrobiellen Diversität extremer Habitate der Kamtschatka-Region
}

\author{
Dissertation \\ zur Erlangung des Doktorgrades \\ der Mathematisch-Naturwissenschaftlichen Fakultäten \\ der Georg-August-Universität zu Göttingen
}

\author{
vorgelegt von \\ Jörg Schuldes \\ aus Aachen
}

Göttingen, 2008 
D7

Referent:

PD Dr. R. Daniel

Korreferent:

Prof. Dr. G. Gottschalk

Tag der mündlichen Prüfung: $\quad 30.04 .2008$ 


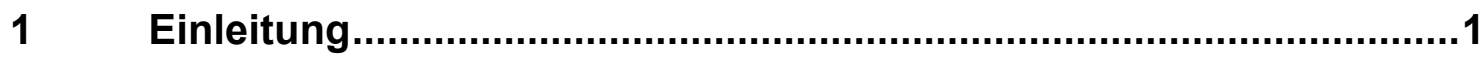

1.1 Analyse und Nutzung der mikrobiellen Diversität................................1

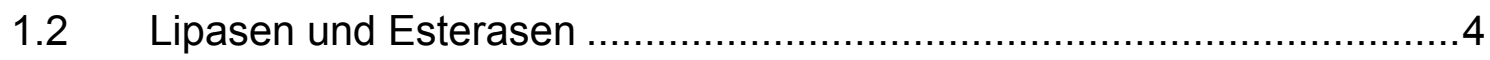

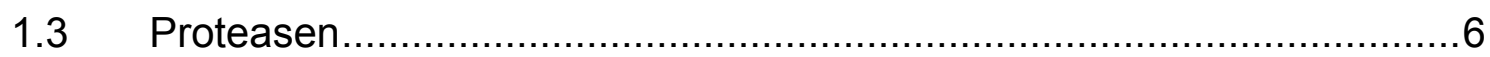

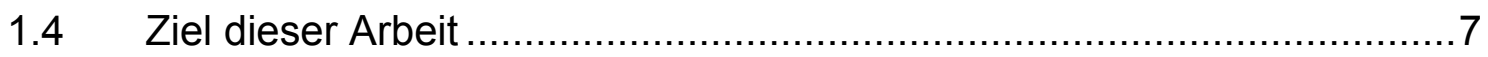

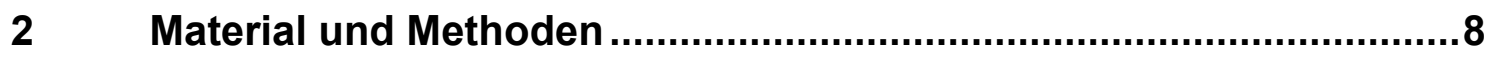

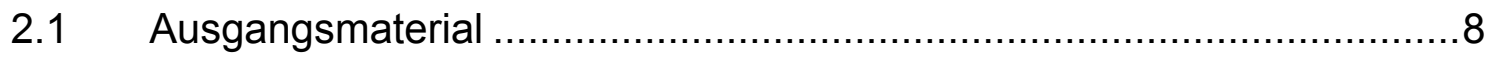

2.2 Organismen, Plasmide und Oligonukleotide .....................................

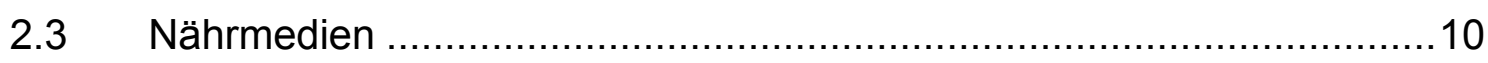

2.3.1 LB-(Luria-Bertani) Medium (SAMBROOK et.al., 1989) ...................11

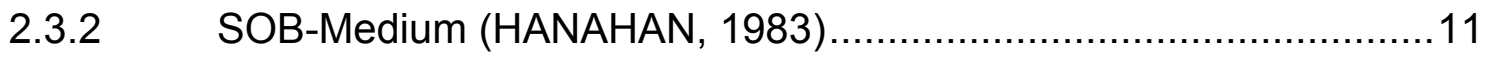

2.3.3 Spezifisches Plattentestverfahren zur Erkennung lipolytischer

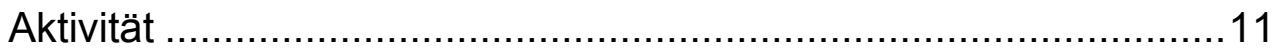

2.3.4 Spezifisches Plattentestverfahren zur Erkennung proteolytischer Aktivität

2.3.5 Spezifisches Plattentestverfahren zur Erkennung amyolytischer

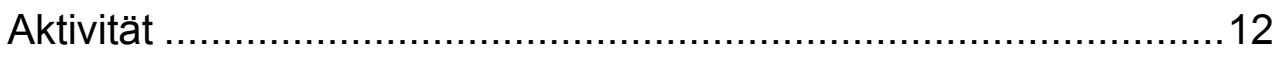

2.3.6 M9-Mineralmedium (MILLER, 1972; modifiziert) …......................12

2.3.7 Calaromator Viterbensis Medium ……….................................13

2.3.8 MacConkey-Agar (MacCONKEY, 1905; modfiziert).....................13

2.3.9 Spurenelementelösung SL-4 (PFENNIG und LIPPERT,1966)........14

2.3.10 Spurenelementelösung SL-9 (TSCHECH und PFENNIG; 1984) ....14

2.3.11 Vitaminlösung (WOLIN et al., 1964, modifiziert) ...........................15

2.3.12 Antibiotika und sonstige Medienzusätze ....................................15

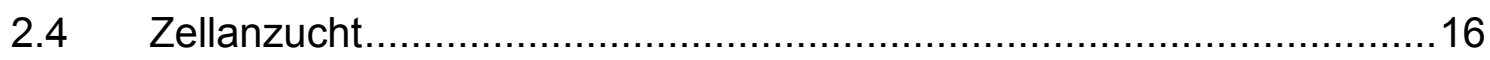

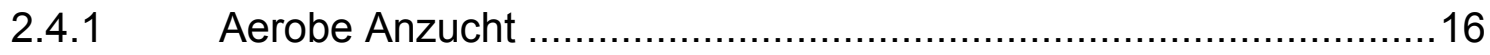

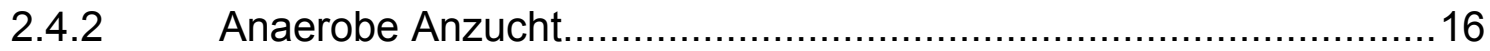

2.4.3 Anzucht von rekombinanten E. coli-Stämmen zur heterologen Genexpression 


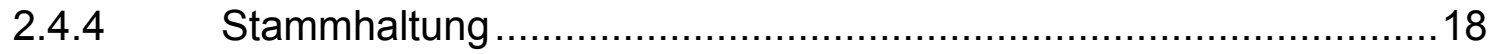

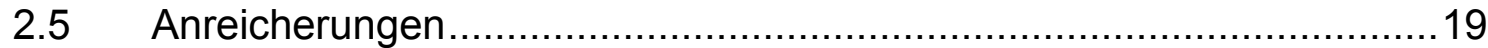

2.5.1 Aerobe Anreicherungen ......................................................... 19

2.5.2 Anaerobe Anreicherungen ...................................................19

2.6 Bestimmung von Wachstumsparametern ........................................19

2.6.1 Bestimmung der optischen Dichte................................................19

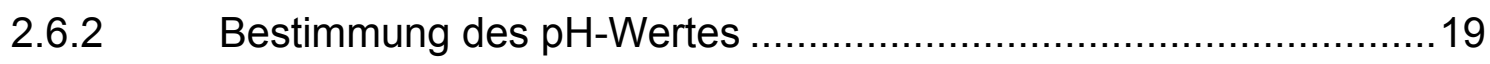

2.7 Standardtechniken für das Arbeiten mit Nukleinsäuren ......................20

2.7.1 Behandlung von Geräten und Lösungen....................................20

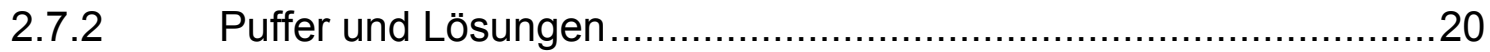

2.7.3 Fällung, Reinigung und Konzentration von Nukleinsäuren..............21

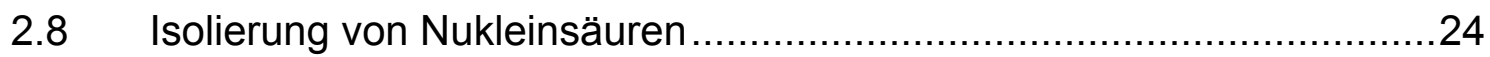

2.8.1 Isolierung von DNA aus Umweltproben (ZHOU et al., 1996) .........24

2.8.2 Isolierung von DNA aus Umweltproben mittels „Bead-

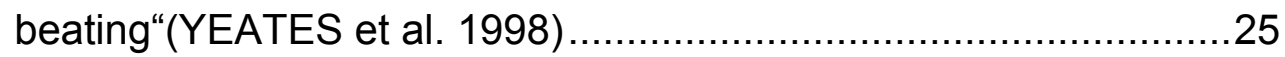

2.8.3 Reinigung von Umwelt-DNA (HENNE et al., 1999) ......................25

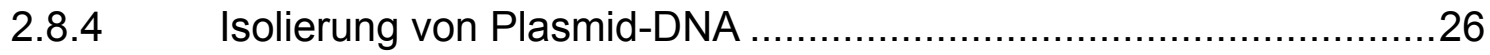

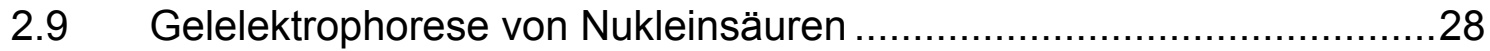

2.9.1 Standard-Agarose-Gelelektrophorese .....................................28

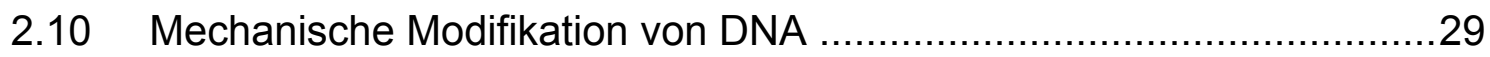

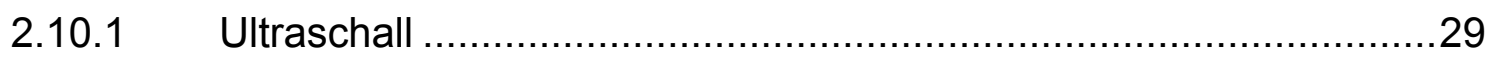

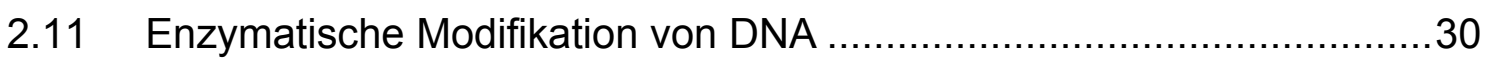

2.11.1 Schneiden von DNA durch Restriktionsendonukleasen ..................30

2.11.2 Voraussetzungen für das Klonieren von Umwelt-DNA mit dem „TOPO-TA-Cloning ${ }^{\circledR}$ “-Kit (s. 2.11.3) .............................................. 31

2.11.3 Ligation mit dem „TOPO-TA-Cloning ${ }^{\circledR}$ “-Kit .......................................

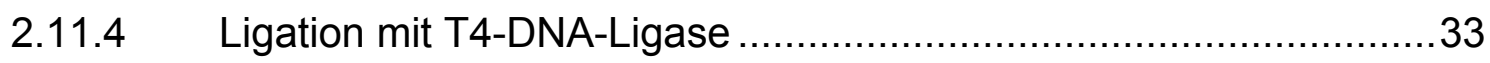

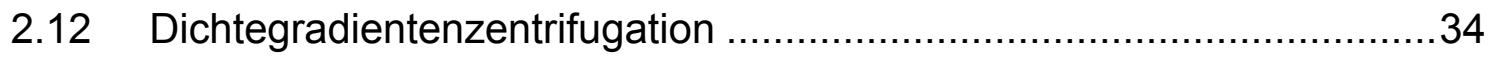

2.12.1 Saccharose-Dichtegradientenzentrifugation (SAMBROOK et al., 1989; modifiziert) 
2.12.2 Caesiumchlorid-Dichtegradientenzentrifugation (RADAJEWSKI et al. 2000).

2.13 Polymerasekettenreaktion (PCR) 35

2.14 Die Prozessierung von DNA-Sequenzen mit Hilfe des STADENSoftware-Packets, ARB und DOTUR 38

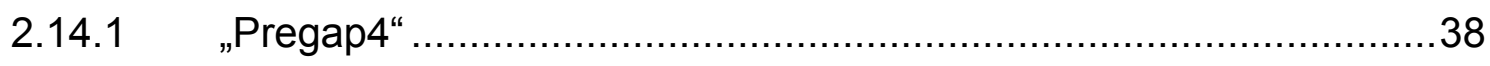

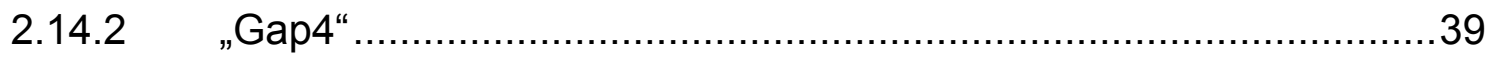

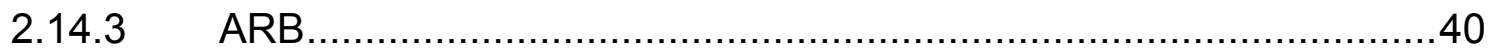

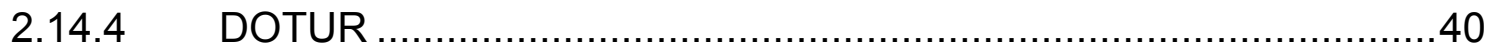

2.15 Untersuchung von 16S rRNA-Genen auf das Vorhandensein chimerer Sequenzen

2.16 Übertragung von DNA in E. coli und Selektion rekombinanter Klone....41

2.16.1 Hocheffiziente Transformation in E. coli (INOUE et al., 1990) .......41

2.16.2 Transformation in E. coli durch Elektroporation (DOWER et al., 1988) 42

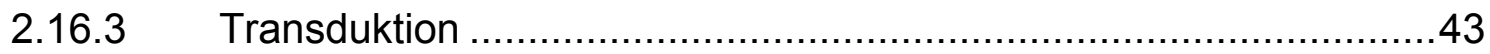

2.16.4 Der X-Gal-Test zur Selektion rekombinanter Klone .....................46

2.16.5 Screening auf lipolytische Aktivität ........................................46

2.16.6 Screening auf proteolytische Aktivität .................................. 47

2.16.7 Screening auf amyolytische Aktivität...................................47

2.17 Proteinbiochemische Methoden .............................................. 47

2.17.1 Proteinkonzentrationsbestimmung nach Bradford ......................47

2.17.2 Herstellung von Rohextrakten ........................................48

2.17.3 Konzentrierung und Umpufferung mit dem Vivaflow 200

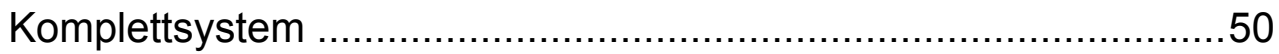

2.17.4 Bestimmung von Enzymaktivitäten .....................................50

2.17.5 Methoden zur Proteinanreicherung .......................................... 52

2.17.6 SDS-Polyacrylamid-Gelelektrophorese (SDS-PAGE) ..................53

2.17.7 Aktivitätsfärbung der Lipase (SOMMER et al., 1997).....................56

2.17.8 Nachweis proteolytischer Aktivität nach SDS-PAGE....................57

2.17.9 Western Blotting (TOWBIN et al., 1979, modifiziert) ....................57

2.18 Chemikalien, Enzyme und Gase ...............................................60 
3 Experimente und Ergebnisse

3.1 Isolierung von DNA aus verschiedenen Standorten. 63

3.2 Untersuchung der phylogenetischen Diversität mittels 16S rRNAGenanalysen

3.2.1 Konstruktion phylogenetischer Stammbäume für den Standort Avachinsky.

3.3 Konstruktion von Metagenombanken aus chromosomaler DNA verschiedener Standorte der Kamtschatka-Region in Escherichia coli .93

3.3.1 Konstruktion von Plasmid-Metagenombanken 93

3.3.2 Konstruktion einer Fosmid-Metagenombank aus metagenomischer DNA des Standortes Avachinsky .96

3.4 Screening der Standort-Genbanken auf lipolytische Aktivität. 98

3.4.1 Identifizierung eines ORFs mit lipolytischer Aktivität aus pFosJS1 durch Subklonierung und Sequenzierung .99

3.4.2 Identifizierung weiterer lipolytischer ORFs 109

3.5 Screening der Standort-Genbanken auf proteolytische Aktivität 115

3.5.1 Identifizierung der proteolytischen ORFs aus pFosJS5 und pFosJS6 durch Subklonierung und Sequenzierung 116

3.6 Isolierung von Mikroorganismen unter anaeroben Bedingungen und Glycerin als einzige Kohlenstoff und Energiequelle

4 Diskussion 129

4.1 DNA-Isolierung aus Umweltproben 129

4.2 Phylogenetische Untersuchung des thermophilen Habitates Avachinsky 131

4.3 Konstruktion von Metagenombanken

4.4 Identifizierung von Genen aus Metagenombanken, die lipolytische Aktivität vermitteln

4.4.1 Charakterisierung der lipolytischen ORFs. 146

4.5 Identifizierung von Genen aus Metagenombanken, die proteolytische Aktivität vermitteln 
4.5.1 Charakterisierung der proteolytischen ORFs 154

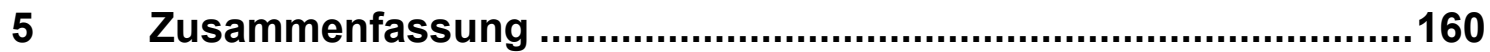

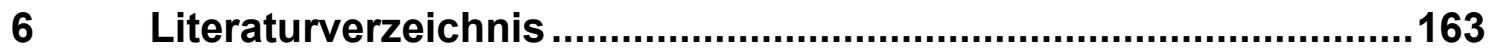

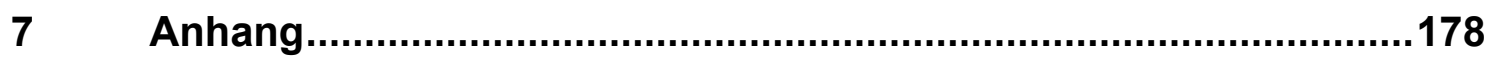




\begin{tabular}{|c|c|}
\hline A & Adenin \\
\hline Abb. & Abbildung \\
\hline Amp & Ampicillin \\
\hline APS & Ammoniumpersulfat \\
\hline ATP & Adenosin-5'-triphosphat \\
\hline AS & Aminosäure(n) \\
\hline BLAST & Basic Local Alignment Search Tool \\
\hline BLASTN & BLAST auf Nukleotidebene \\
\hline BLASTP & BLAST auf Proteinebene \\
\hline bp & Basenpaar(e) \\
\hline bzw. & beziehungsweise \\
\hline${ }^{\circ} \mathrm{C}$ & Grad Celcius \\
\hline C & Cytosin \\
\hline ca. & circa \\
\hline $\mathrm{cm}$ & Zentimeter \\
\hline C-terminal & carboxyterminal \\
\hline $\mathrm{Da}$ & Dalton \\
\hline d. h. & das heißt \\
\hline dest. & destilliert \\
\hline DNA & Desoxyribonukleinsäure \\
\hline dNTP & Desoxyribonukleotid-5'-triphosphat \\
\hline E. & Escherichia \\
\hline E-Cup & Eppendorf-Reaktionsgefäß \\
\hline EDTA & Ethylendiamintetraessigsäure \\
\hline et al. & et alteri, und andere \\
\hline $\mathrm{Fa}$. & Firma \\
\hline g & Gramm \\
\hline G & Guanin \\
\hline Gap & Genomassemblierungsprogramm, genome assembly program \\
\hline $\mathrm{GmbH}$ & Gesellschaft mit beschränkter Haftung \\
\hline$\times g$ & x-fache Erdbeschleunigung $(9,81 \mathrm{~m} / \mathrm{s} 2)$ \\
\hline $\mathrm{h}$ & Stunde \\
\hline
\end{tabular}




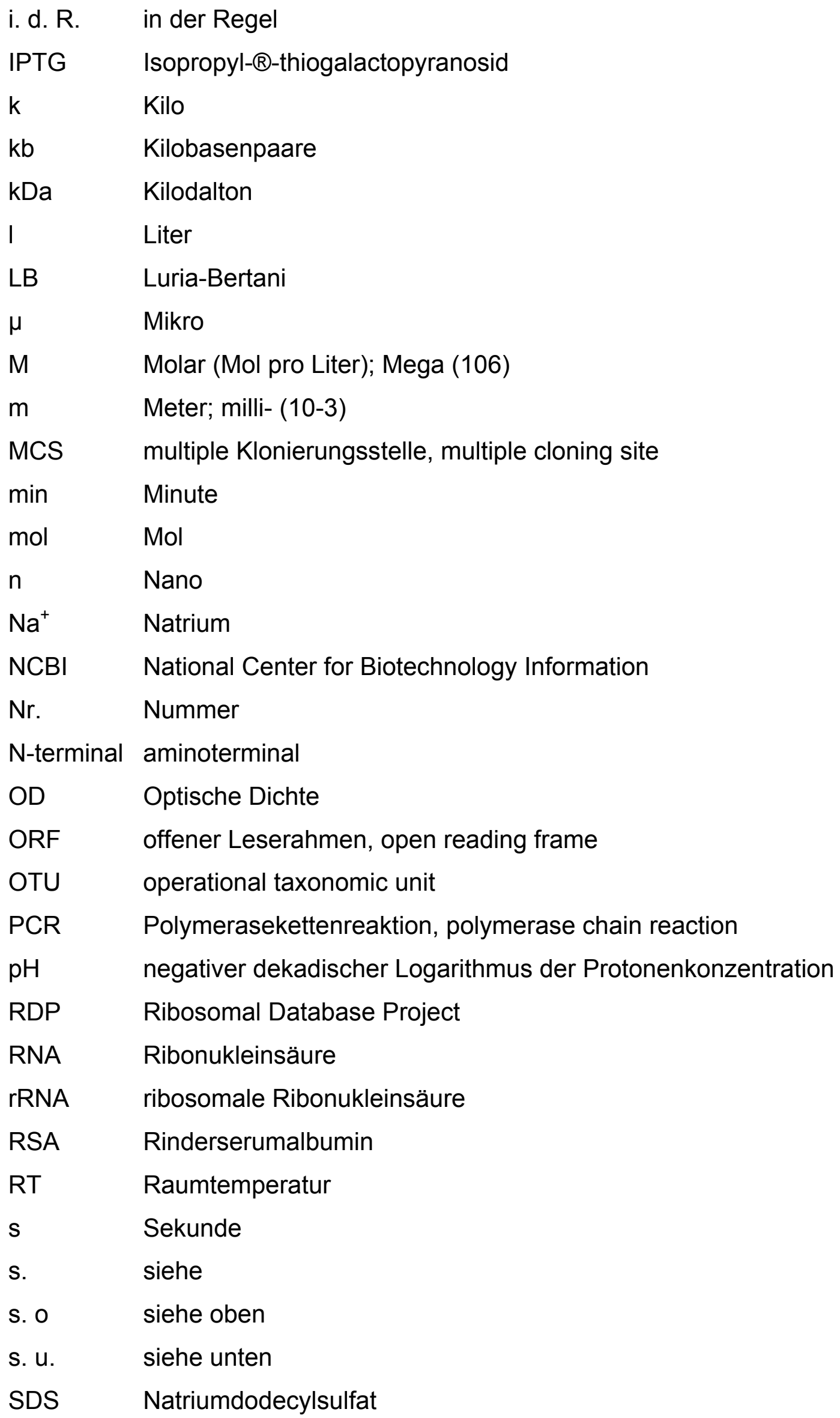




$\begin{array}{ll}\text { sp. } & \text { species } \\ \text { T } & \text { Thymin } \\ \text { TEMED } & \text { N, N, N', N'-Tetramethylethylendiamid } \\ \text { Tm } & \text { Schmelztemperatur } \\ \text { TM } & \text { transmembrane Helix/Helices } \\ \text { Tris } & \text { Tris-(hydroxymethyl-)aminomethan } \\ \text { U } & \text { Unit (Einheit der Enzymaktivität) } \\ \text { ü. N. } & \text { über Nacht } \\ \text { Upm } & \text { Umdrehungen pro Minute } \\ \text { v/v } & \text { Volumen pro Volumen } \\ \text { V } & \text { Volt } \\ \text { w/v } & \text { Masse pro Volumen } \\ \text { z. B. } & \text { zum Beispiel } \\ \text { X-Gal } & \text { 5-Brom-4-Chlor-3-Indolyl-D-Galactosid }\end{array}$

Abfürzungen für Aminosäuren

$\begin{array}{cccccc}\text { A } & \text { Ala } & \text { Alanin } & \text { M } & \text { Met } & \text { Methionin } \\ \text { C } & \text { Cys } & \text { Cystein } & \text { N } & \text { Asn } & \text { Asparagin } \\ \text { D } & \text { Asp } & \text { Aspartat } & \text { P } & \text { Pro } & \text { Prolin } \\ \text { E } & \text { Glu } & \text { Glutamat } & \text { Q } & \text { GIn } & \text { Glutamin } \\ \text { F } & \text { Phe } & \text { Phenylalanin } & \text { R } & \text { Arg } & \text { Arginin } \\ \text { G } & \text { Gly } & \text { Glycin } & \text { S } & \text { Ser } & \text { Serin } \\ \text { H } & \text { His } & \text { Histidin } & \text { T } & \text { Thr } & \text { Threonin } \\ \text { I } & \text { Ile } & \text { Isoleucin } & \text { V } & \text { Val } & \text { Valin } \\ \text { K } & \text { Lys } & \text { Lysin } & \text { W } & \text { Trp } & \text { Tryptophan } \\ \text { L } & \text { Leu } & \text { Leucin } & \text { Y } & \text { Tyr } & \text { Tyrosin }\end{array}$




\section{$1 \quad$ Einleitung}

\subsection{Analyse und Nutzung der mikrobiellen Diversität}

Mikroorganismen stellen mit etwa $60 \%$ den größten Anteil der Biomasse der Erde (WHITMAN et al. 1998). Man geht davon aus, dass etwa 1 bis 100 Millionen verschiedene prokaryotische Arten auf der Erde vorkommen (WILSON 1992, STRICKEBERGER 1996). Prokaryoten existieren vermutlich seit 3,8 Milliarden Jahren und sind in der Lage, unter den extremsten Umweltbedingungen zu wachsen. So konnten Mikroorganismen in heißen Quellen, Gletschern, Salinen oder der Tiefsee nachgewiesen werden. Ihre vielfältigen physiologischen, genetischen und metabolischen Eigenschaften erlauben es innen, sich diesen für den Menschen lebensfeindlich erscheinenden Bedingungen anzupassen. Aus diesem Grund stellen sie ein enormes Potential zur Erforschung neuartiger Stoffwechselwege, Biokatalysatoren und Wirksoffen dar (DANIEL, 2004, HANDELSMAN, 2004, STREIT und SCHMITZ, 2004).

Ein Ansatz zur Identifizierung neuer Enzyme aus bisher unbekannten Mikroorganismen beruht auf der Isolierung von Mikroorganismen unter selektiven Bedingungen. Dazu wird eine Umweltprobe mit selektiven Nährmedien kultiviert und Mikroorganismen, die in der Lage sind, unter den vorgegebenen Wachstumsbedingungen zu überleben, in Reinkultur gebracht (MILLER et al. 2000). Aus einer Reinkultur kann anschließend das gesuchte Enzym bzw. das entsprechende Gen isoliert und näher charakterisiert werden. Insgesamt handelt es sich bei dieser Methode der Identifizierung neuartiger Enzyme und Wirkstoffe um eine sehr zeit- und arbeitsaufwendige Methode. Ein weiterer, wesentlicher Nachteil ist jedoch die Notwendigkeit der Kultivierbarkeit der Mikroorganismen unter Laborbedingungen. Man geht davon aus, dass weniger als $1 \%$ der auf der Erde vorkommenden Mikroorganismen mit Standardmethoden kultivierbar sind (AMANN et al. 1995). Daraus folgt, dass die bisher kultivierten Mikroorganismen nur einen Bruchteil der tatsächlichen mikrobiellen Diversität ausmachen. Kultivierungsunabhängige Methoden, wie z.B. die 16S rRNA-Genanalyse ermöglichen die Untersuchung der mikrobiellen 
Diversität von Habitaten auf molekularbiologischer Ebene und geben einen Einblick in die tatsächliche mikrobielle Vielfalt. Die Entwicklung von Techniken zur Isolierung und Klonierung der gesamten mikrobiellen DNA eines Habitates sind Vorraussetzung für die Bestimmung der mikrobiellen Diversität von Habitaten (PACE et al. 1985). Durch phylogenetische Untersuchungen von $16 \mathrm{~S}$ rRNA-Gensequenzen konnten im Jahr 200352 verschiedene bakterielle Phyla identifiziert werden, von denen 26 nur durch 16S rRNA-Gensequenzen unkultivierter Mikroorganismen repräsentiert werden (HUGENHOLTZ et al. 2002, RAPPE und GIOVANNONI 2003). Abb. 1 gibt einen Überblick über diese 52 bakteriellen Phyla.

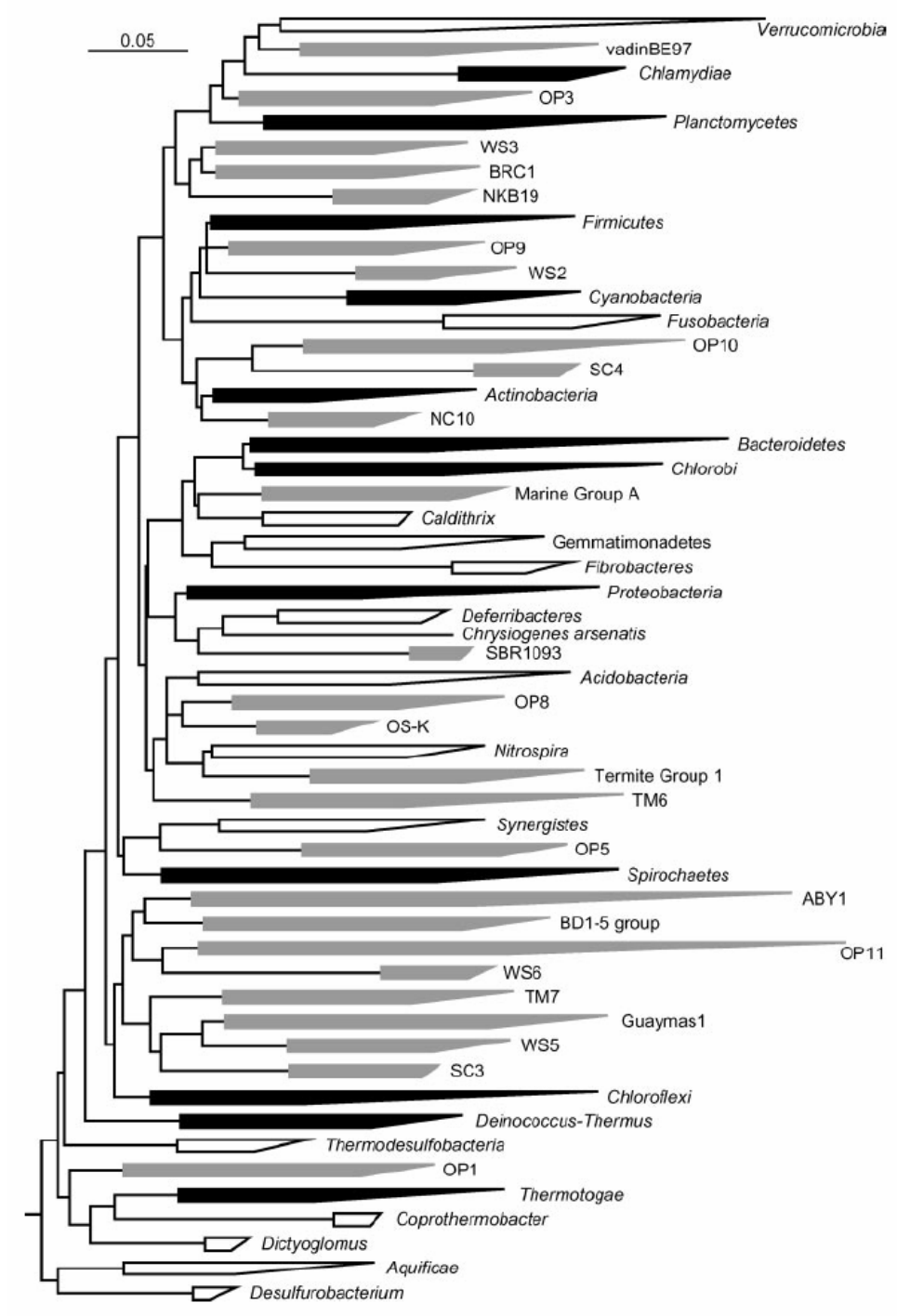

Abb. 1: 52 bakterielle Phyla nach RAPPE und GIOVANNONI 2003. Schwarz: 12 bakterielle Phyla nach WOESE 1987. Grau: 26 neue Phyla unkultivierter Mikroorganismen. Weiß: 14 neue Phyla kultivierter Mikroorganismen. 
Diese 52 bakteriellen Phyla konnten mittlerweile auf über 100 Phyla erweitert werden (DESANTIS et al. 2006). Aufgrund schlechter Kultivierbarkeit vieler Mikroorganismen bleibt ein beträchtlicher Teil des genetischen Potentials von Mikroorganismen bei der Suche nach neuartigen Biokatalysatoren und Wirkstoffen mit herkömmlichen Methoden ungenutzt. Im Jahr 1998 prägten HANDELSMANN et al. denn Begriff „Metagenom“ und bezeichneten damit die Gesamtheit aller mikrobiellen Genome eines Habitates. Die Erschließung und Nutzbarmachung des gesamten genetischen Potentials eines Habitates beruht auf Techniken die es erlauben, die gesamte mikrobielle DNA eines Habitates zu extrahieren, zu klonieren (RONDON et al. 2000) und in sogenannten „Metagenombanken“ zu konservieren. Die isolierte und gereinigte Umwelt-DNA wird fragmentiert und nach Größenselektion in geeigneten Vektoren kloniert. Die Wahl der Vektoren ist abhängig von der gewünschten Insert-Größe und der Qualität der klonierten DNA-Fragmente (SCHMEISSER et al. 2007, DANIEL 2005). Durch den Metagenomansatz konnte das Repertoire an neuartigen Biokatalysatoren um ein Vielfaches gesteigert werden (HONG et al. 2007, RANJAN et al. 2005, RHEE et al. 2005). Ein wichtiger Aspekt bei der Suche nach völlig neuen Enzymen mit besonderen Eigenschaften wie Thermo- oder pH-Stabilität ist die Wahl des Habitates. Phylogenetische Untersuchungen extremer Standorte wie heiße Quellen, der Tiefsee oder Salinen zeigen ein breites Spektrum an völlig unbekannten, unkultivierten Mikroorganismen (MOUSSARD et al. 2006, KANOKRATANA et al. 2004, HUGENHOLTZ et al. 1998). Zahlreiche Arbeiten belegen das hohe Potential solcher extremen Habitate als Quelle neuartiger Naturprodukte mit besonderen Eigenschaften (NIEHAUS et al. 1999, VIEILLE und ZEIKUS 2001, RHEE et al. 2006, TIRAWONGSAROJ et al. 2008). Verschiedenste sequenz- und aktivitätsbasierende Screeningverfahren ermöglichen die Durchmusterung dieser Metagenombanken nach biotechnologisch relevanten Biomolekülen (DANIEL 2005, STREIT et al. 2004). Als Ausgangsmaterial für diese Arbeit wurden Proben aus verschiedenen extremen Habitaten der KamtschatkaRegion verwendet. Kamtschatka befindet sich am äußerst östlichen Teil Russlands (s. Abb. 2). Es handelt sich um eine Halbinsel, welche von zahlreichen Vulkanen, heißen Quellen und Geysiren überzogen ist. Sie erstreckt sich über $1200 \mathrm{~km}$ bei einer Breite von $450 \mathrm{~km}$. In dieser Arbeit 
wurden zwei thermophile Habitate untersucht. Es handelt sich dabei zum einen um eine Bodenprobe in der Nähe des Vulkans bei Avachinsky, sowie um eine Sedimentprobe einer heißen Quelle bei Dachnie.

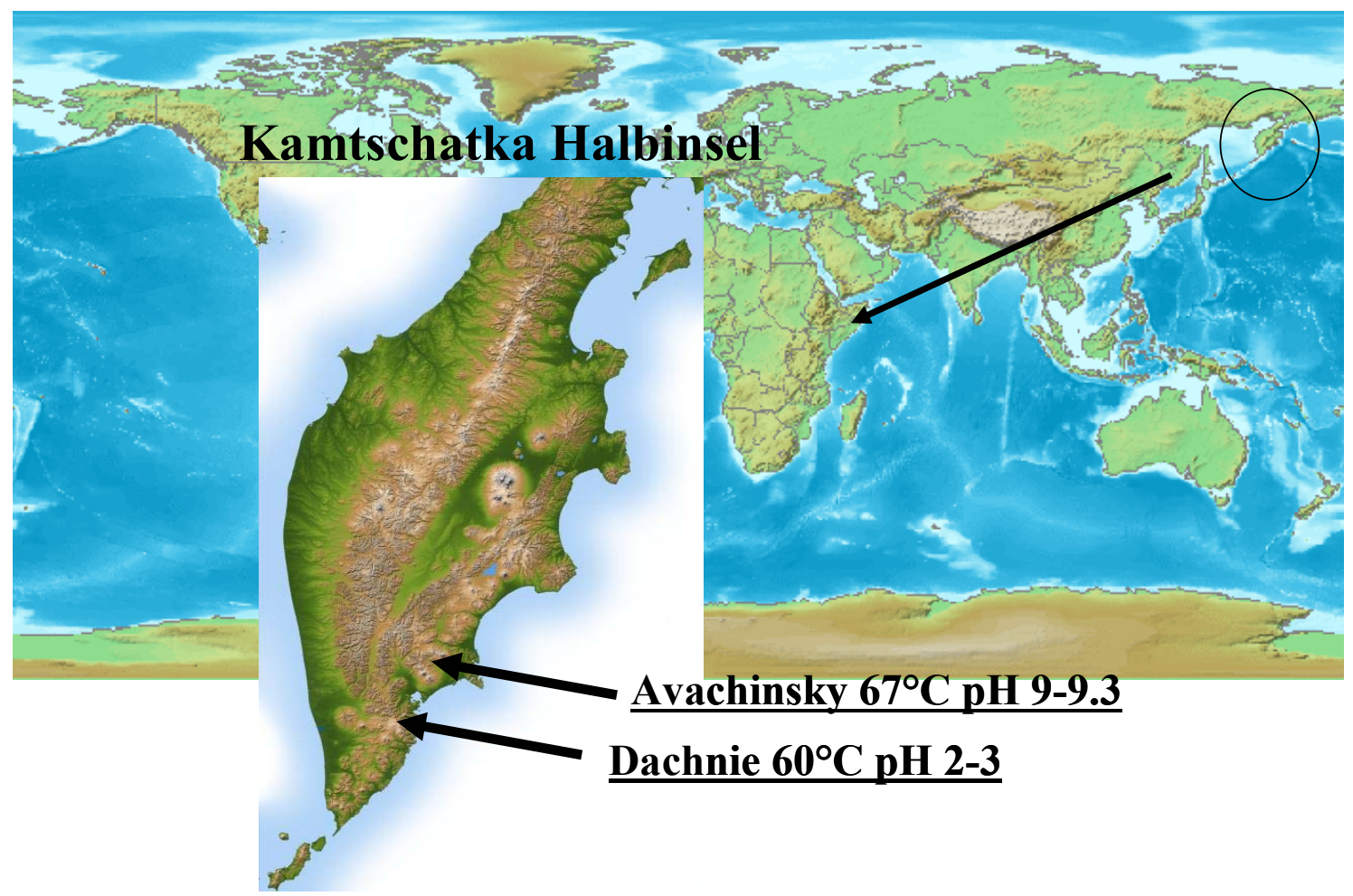

Abb. 2: Die Kamtschaka-Halbinsel. (Quelle Karten: http://www.Kamtschatkapeninsula.com)

\section{$1.2 \quad$ Lipasen und Esterasen}

Eine der wichtigsten Gruppen von Biokatalysatoren stellen Lipasen [3.1.1.3] und Carboxylesterasen [3.1.1.1] dar, welche in der Lage sind, die Hydrolyse und Synthese von Esterbindungen zu katalysieren. Sie gehören zur Superfamilie der $\alpha / \beta-H y d r o l a s e n$ und werden nach ARPIGNY und JÄGER (1999) in acht Familien eingeteilt. Ihr wichtigstes Merkmal ist die katalytische Triade Ser-His-Asp, wobei das Aspartat auch durch ein Glutamat ersetzt werden kann (SCHRAG et al. 1995, OLLIS et al. 1992). Der katalytische Serinrest liegt eingebettet in einem hochkonservierten Pentapeptid der Form Gly-X-Ser-X-Gly. Der Reaktionsmechanismus besteht aus vier Schritten (s. Abb. 3). Das Substrat wird durch einen nukleophilen Angriff des katalytischen Serins an dieses gebunden (1) und es kommt zur Bildung eines tetrahedralen Übergangszustandes. Das Histidin und Aspartat sowie Wasserstoffbrücken der 
Proteinhauptkette sorgen für die Stabilisierung (2). Durch Abspaltung des Alkoholrestes bildet sich ein Acyl-Enzym-Komplex. Nach der Hydrolyse (3) kommt es erneut zur Bildung eines tetrahedralen Übergangszustandes, aus welchem schließlich das Enzym und das Produkt wieder freigesetzt werden (4).
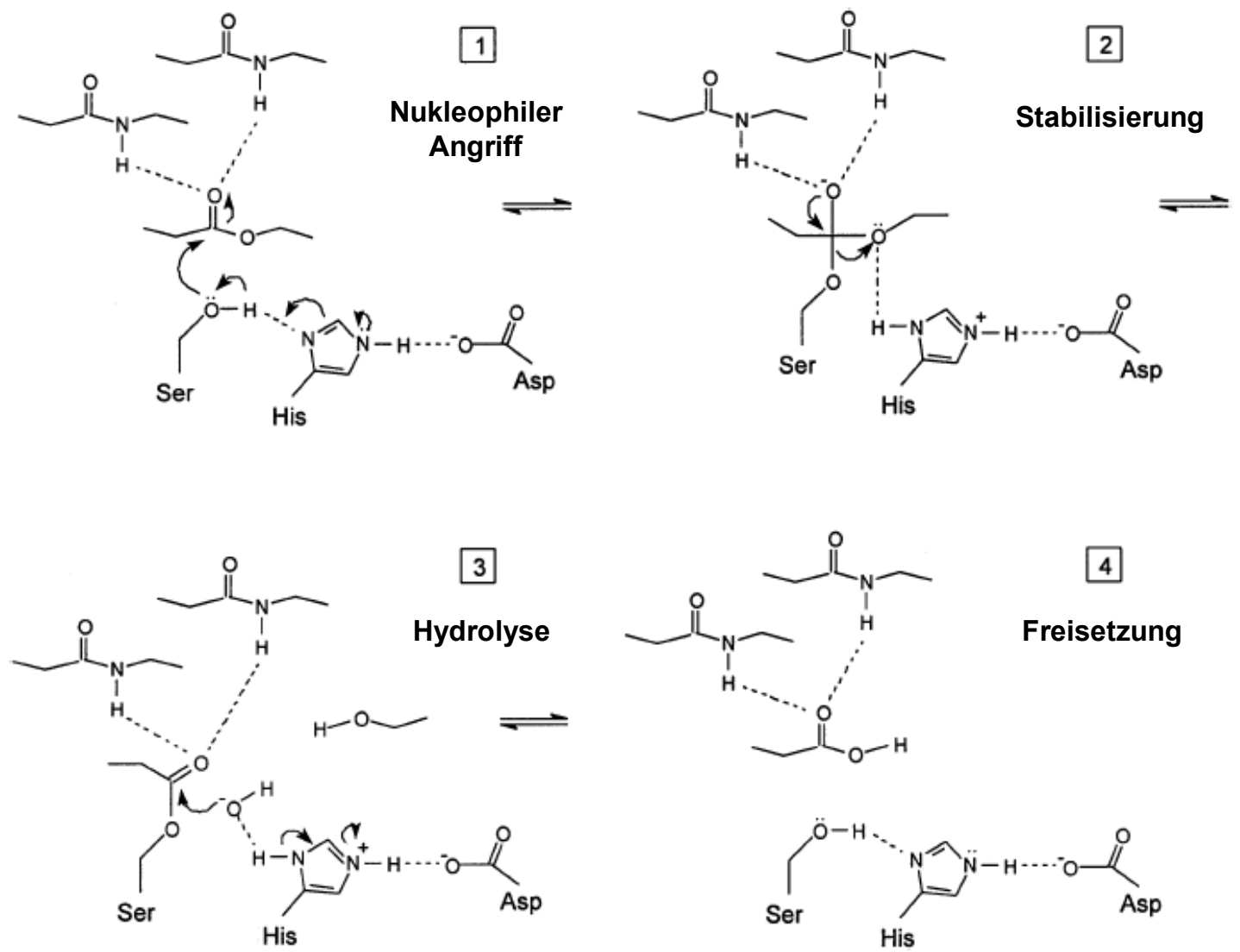

4

Freisetzung

Abb. 3 Reaktionsmechanismus von Lipasen nach JÄGER et al. 1999. Dargestellt sind die Reaktionsschritte der hydrolytischen Spaltung durch Lipasen. 1.: Bindung des Substrates durch nukleophilen Angriff. 2.: Stabilisierung des Übergangszustandes. 3.: Hydrolyse. 4.: Freisetzung von Produkt und Enzym.

Echte Lipasen bevorzugen als Substrate wasserunlösliche langkettige Triglyceride, während Carboxylesterasen wasserlösliche kurzkettige Triglyceride spalten. Echte Lipasen benötigen im Gegensatz zu Carboxylesterasen für ihre Aktivität eine Grenzfläche zwischen wässriger Phase und wasserunlöslichem Substrat. SARDA und DESUNELLA beschrieben das Phänomen der Grenzflächenaktivierung (SARDA und DESUNELLA 1958). Das Reaktionszentrum ist bei Lipasen unter einem Deckel (lid) aus ein oder zwei $\alpha$ Helices verborgen und somit für das Substrat unzugänglich. Durch die 
Anlagerung der Lipase an die Grenzfläche kommt es zu einer Konformationsänderung und der Deckel öffnet sich für das Substrat (JÄGER et al. 1994).

Aufgrund ihrer biochemischen Eigenschaften nehmen Lipasen und Esterasen einen wichtigen Platz in der industiellen Anwendung ein (JÄGER et al. 1999, GILBERT et al. 1993). Sie sind unabhängig von Co-Faktoren, stabil in Lösungsmitteln und zeigen eine hohe Regio- und Stereoselektivität. Sie finden Anwendung in der Herstellung von Pharmazeutika und Kosmetika, sowie in der Lebensmittel- und Waschmittelindustrie als Zusatz zur Fettlösung (JÄGER und EGGERT 2002).

\subsection{Proteasen}

Proteasen katalysieren die hydrolytische Spaltung von Proteinen und sind in jeder Zelle vorhanden. Sie können im Cytoplasma, membranverankert oder extrazellulär vorkommen. Biotechnologisch finden Proteasen z. B. Anwendung in der Waschmittelindustrie, wo sie als Zusatz bei der Entfernung von Eiweißflecken dienen. In der Nahrungsmittelindustrie zeigen tierische Proteasen Bedeutung in der Käseherstellung. Auch beim Vorgang des Gerbens in der Lederindustrie spielen Proteasen eine wichtige Rolle. Man unterscheidet Endound Exopeptidasen, sowie nach dem Aufbau ihres aktiven Zentrums Serin-, Cystein-, Aspartat- und Metalloproteasen (RAO et al. 1998):

Serin-Proteasen besitzen eine katalytische Triade mit Serin, Histidin und Aspartat im katalytischen Zentrum. Sie zeigen ihr Optimum an Aktivität im $\mathrm{pH}$-Bereich zwischen 7 und 11. Ihre molekulare Masse kann zwischen 18 kDa und $35 \mathrm{kDa}$ variieren. Serin-Proteasen lassen sich leicht durch die irreversible Hemmbarkeit mittels 3,4-Dichloroisocoumarin, Phenylmethylsufonylfluorid oder Diisopropylfluorophosphat erkennen. Beispiele für Serin-Proteasen sind Trypsin, Chymotrypsin und Elastase (SIEZEN et al. 2007, POLGAR 2005).

Aspartat-Proteasen werden auch als saure Proteasen bezeichnet, da sie die höchste Aktivität im pH-Bereich zwischen 3 und 4,5 zeigen. Es sind Endopeptidasen mit einem Aspartat-Rest im aktiven Zentrum. Die molekularen Massen liegen zwischen $30 \mathrm{kDa}$ und $45 \mathrm{kDa}$. Sie werden u. a. durch Pepstatin 
gehemmt. Typische Vertreter sind Pepsin oder Rennin (DANSER 2007, RAWLINGS et al. 1995).

Cystein-Proteasen kommen bei Prokaryoten und bei Eukaryoten vor und zeigen ein spezifisches Cystein und Histidin im aktiven Zentrum. Sie sind überwiegend bei neutralem pH-Wert aktiv. Die molekularen Massen liegen zwischen 25 kDa und 50 kDa. Ein bekanntes Beispiel ist Papain (WANG et al. 2007, GOSH et al. 2007).

Metallo-Proteasen sind nur in Gegenwart von zweiwertigen Metallionen wie z.B. $\mathrm{Zn}^{2+}$ oder $\mathrm{Ca}^{2+}$, aktiv. Aufgrund dieser Komplexbildung mit zweiwertigen Ionen wirkt EDTA hemmend auf die Proteaseaktivität. Typische Beispiele sind Thermolysin oder Collagenase (LUAN et al.2007, WATANABEet al. 1993).

Die MEROPS-Datenbank (www.merops.ac.uk) teilt Proteasen aufgrund struktureller und verwandtschaftlicher Eigenschaften im Hinblick auf die Aminosäuresequenz in Familien ein. Dabei können mehrere Familien zu sogenannten Clans zusammengefasst werden, wenn evolutionäre Verwandtschaft in Bezug auf die Tertiärstruktur zu erkennen ist. Die erste Einteilung erfolgt allerdings aufgrund der katalytischen Eigenschaften im aktiven Zentrum (RAWLINGS et al. 2004, 1993).

\section{$1.4 \quad$ Ziel dieser Arbeit}

Im Rahmen dieser Arbeit sollten mit metagenomischen Methoden verschiedene extreme Habitate der Kamtschatka-Region untersucht werden. Zum einen sollte eine phylogenetische Charakterisierung der mikrobiellen Diversität anhand von 16S rRNA-Genanlysen erfolgen, zum anderen sollten Metagenombanken aus Umwelt-DNA dieser Habitate konstruiert werden. Diese dienten als Quelle zur Identifizierung neuartiger Gene für lipolytische und proteolytische Enzyme. Im Weiteren sollten die im Rahmen der Durchmusterung erhaltenen Gene für Lipasen und Proteasen und die dazu korrespondierenden Genprodukte charakterisiert werden. 


\section{Material und Methoden}

\subsection{Ausgangsmaterial}

Tab. 1: Verwendete Proben

\begin{tabular}{lllll}
\hline Standort & Probenbezeichnung & Art der Probe & $\mathrm{pH}$ & $\begin{array}{l}\text { Temperatur } \\
{\left[{ }^{\circ} \mathrm{C}\right]}\end{array}$ \\
\hline Avachinsky & Avachinsky & $\begin{array}{l}\text { Bodenprobe } \\
\text { Kraterregion }\end{array}$ & $9-9,3$ & 67 \\
Dachnie & Dachnie & $\begin{array}{l}\text { Sediment } \\
\text { heiße Quelle }\end{array}$ & $2-3$ & 60 \\
\hline
\end{tabular}

\subsection{Organismen, Plasmide und Oligonukleotide}

Die im Rahmen dieser Arbeit verwendeten Organismen sind in Tab. 2 und die Plasmide in Tab. 3 aufgeführt.

Tab. 2: Verwendete Organismen

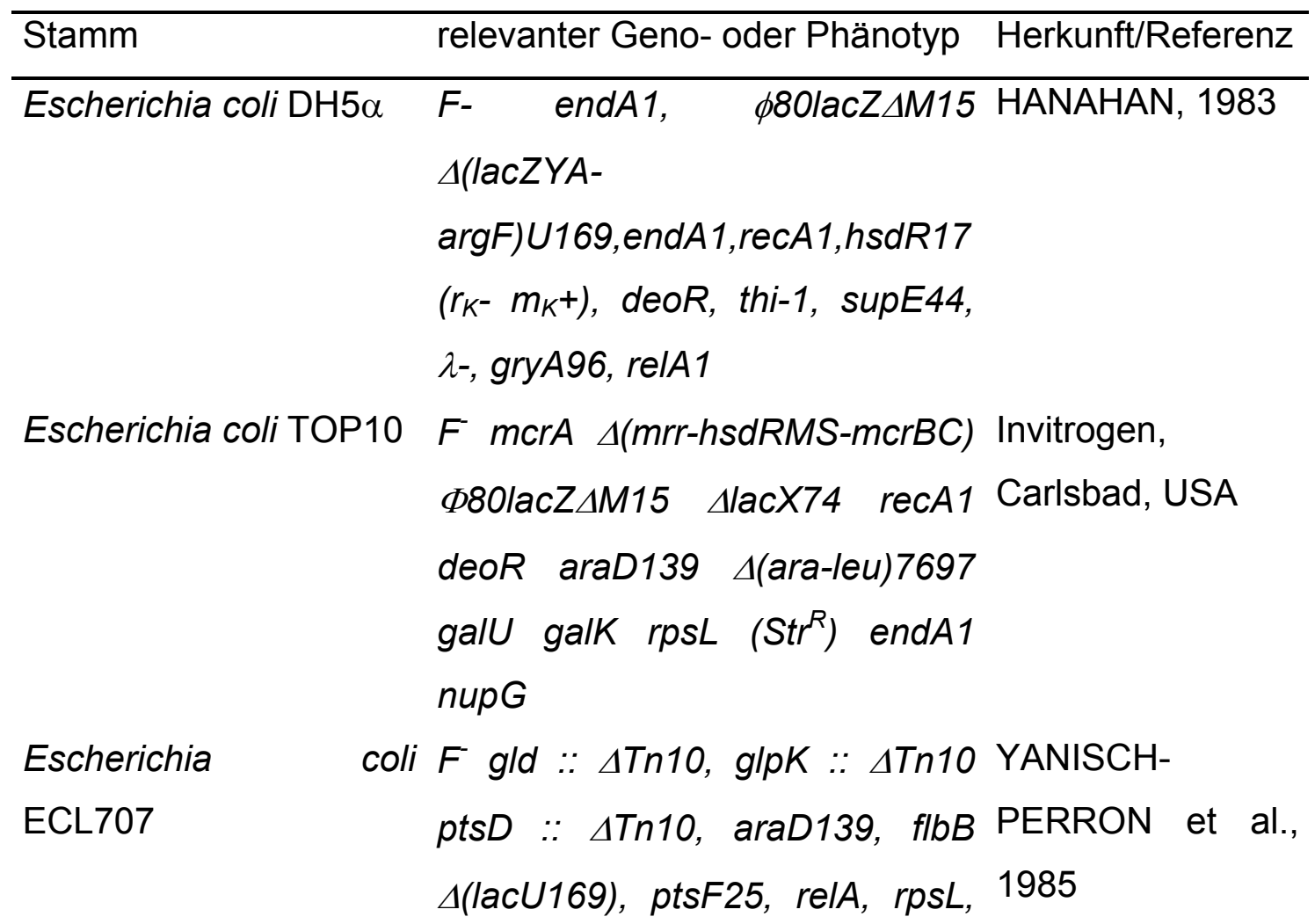


thi

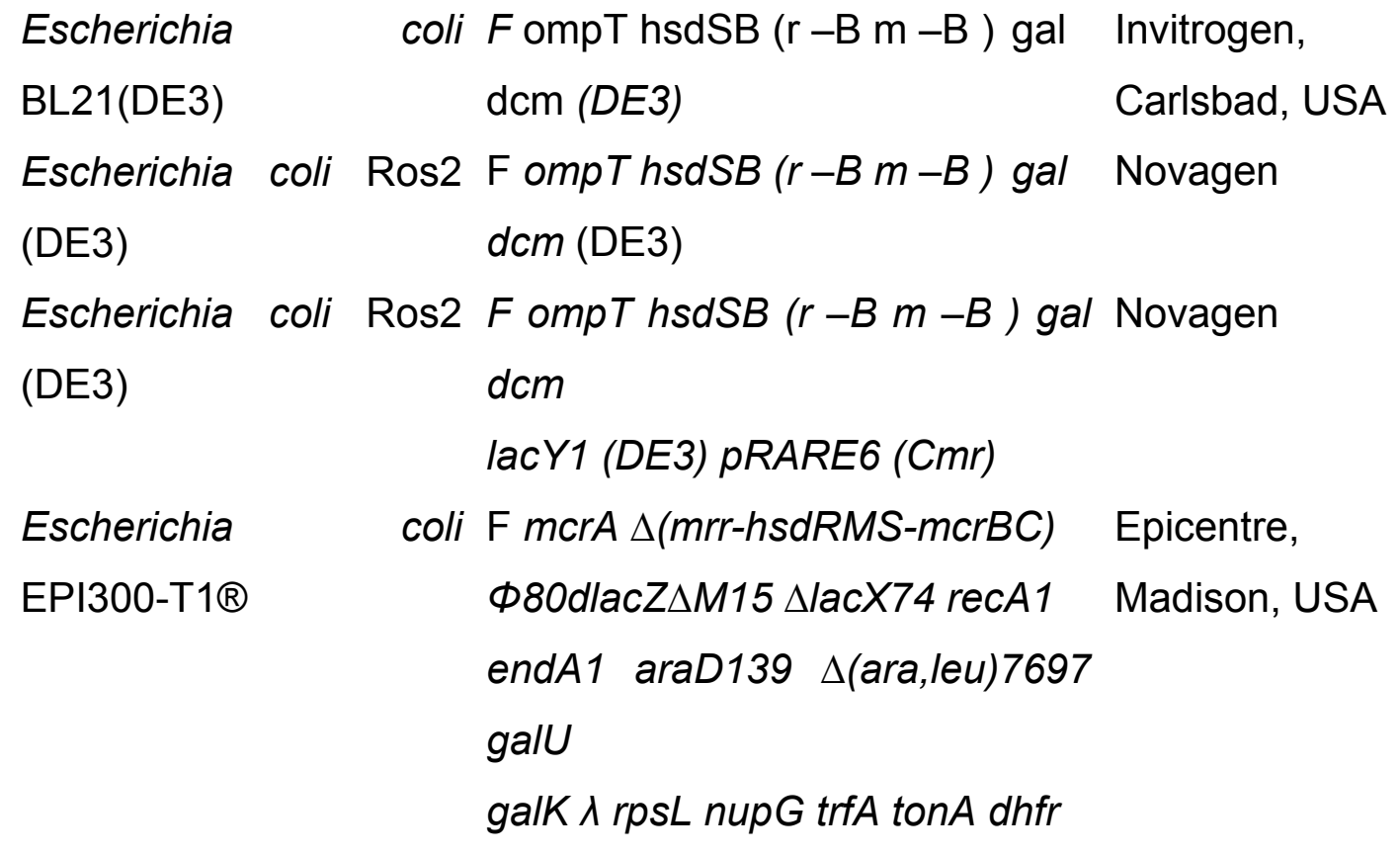

Tab. 3: Verwendete Plasmide

\begin{tabular}{|c|c|c|}
\hline Plasmid & relevantes Merkmal & Herkunft/Referenz \\
\hline pCR2.1-TOPO & $\mathrm{Ap}^{\mathrm{r}}, \mathrm{Kan}^{\mathrm{r}}, \mathrm{pMB1-Replikon}$ & $\begin{array}{l}\text { Invitrogen, } \\
\text { Carlsbad, USA }\end{array}$ \\
\hline pET101/D-TOPO & $\begin{array}{l}\text { Apr; His6-tag C-terminal, } \\
\text { V5-Epitop-tag }\end{array}$ & $\begin{array}{l}\text { Invitrogen, } \\
\text { Carlsbad, USA }\end{array}$ \\
\hline pBluescriptIISK+ & Ap', lacPOZ', pMB1-Replikon & $\begin{array}{ll}\text { Stratagene, } & \text { San } \\
\text { Diego, USA } & \end{array}$ \\
\hline pCR-XL-TOPO & $\mathrm{Kan}^{\mathrm{r}}, \mathrm{Zeo}^{r_{;}}$pMB1-Replikon & $\begin{array}{l}\text { Invitrogen, } \\
\text { Carlsbad, USA }\end{array}$ \\
\hline pCR4-TOPO & $A p^{r}, K n_{r}$, pMB1-Replikon & $\begin{array}{l}\text { Invitrogen, } \\
\text { Carlsbad, USA }\end{array}$ \\
\hline pCC1FOS & $\mathrm{Cm}^{\mathrm{r}}, \cos$ & $\begin{array}{l}\text { Epicentre, } \\
\text { Madison, USA }\end{array}$ \\
\hline
\end{tabular}


Tab. 4: Verwendete Oligonukleotide

\begin{tabular}{ll}
\hline Bezeichnung & Sequenz \\
\hline 16S-08 & 5'-AGAGTTTGATCATGGC-3' (MUYZER et al., 1992) \\
16S-1504 & 5'-TACCTTGTTACGACTT-3' (MUYZER et al., 1992) \\
A800F & 5'-GTAGTCGYGGCYGTAAAC-3'* \\
& (KOLGANOVA et al., 2001) \\
A1530R & 5'-GGAGGTGATCCAGCCG-3'* \\
& (ITOH et al., 2003) \\
349F & 5'-AGGCAGCAGTGGGGAAT-3'* \\
& (KOLGANOVA et al., 2001) \\
1492R & 5'-GGGTTGCGCTCGTTRC-3'* \\
& (KOLGANOVA et al., 2001) \\
EstJS1_for & 5'-CACCATGCCCAGGGTGAAGGTTAAC-3'* \\
EstJS1_rev & 5'-GTCCCTGCCGGAATGCCGTCTT-3'* \\
PepJS1_for & 5'-CACCATGAAACGATCTAGT-3'* \\
PepJS1_rev & 5'-CCGGAATATTAGCAAAATGA-3'* \\
PepJS2_for & 5'-CACCATGACATCCGCGCTGC-3'* \\
PepJS2_rev & 5'-CTGGGGTCTCTCCGTCAGCG-3** \\
\hline
\end{tabular}

\subsection{Nährmedien}

Alle aufgeführten Medien wurden durch 30 minütiges Autoklavieren bei $121^{\circ} \mathrm{C}$ sterilisiert. Die C-Quellen für Mineralmedien wurden separat autoklaviert und dem Medium unmittelbar vor dem Animpfen zugegeben. Zur Herstellung von Agarplatten wurde dem Medium vor dem Autoklavieren 1,5\% (w/v) Agar zugefügt.

Anaerobe Medien wurden nach der von COSTILOW (1981) beschriebenen Methode unter Begasung mit sauerstofffreiem Stickstoff hergestellt. 


\subsubsection{LB-(Luria-Bertani) Medium (SAMBROOK et.al., 1989)}

$\begin{array}{lll}\text { Trypton } & 10 & \mathrm{~g} \\ \text { Hefeextrakt } & 5 & \mathrm{~g} \\ \mathrm{NaCl} & 10 & \mathrm{~g} \\ \mathrm{H}_{2} \mathrm{O}_{\text {dest. }} & \mathrm{Ad} 1000 & \mathrm{ml}\end{array}$

\subsubsection{SOB-Medium (HANAHAN, 1983)}

$\begin{array}{lll}\text { Trypton } & 20 & \mathrm{~g} \\ \text { Hefeextrakt } & 5 & \mathrm{~g} \\ \mathrm{NaCl} & 0,58 & \mathrm{~g} \\ \mathrm{KCl} & 0,18 & \mathrm{~g} \\ \mathrm{MgCl}_{2} & 2 & \mathrm{~g} \\ \mathrm{MgSO}_{4} \times 7 \mathrm{H}_{2} \mathrm{O} & 2,5 & \mathrm{~g} \\ \mathrm{H}_{2} \mathrm{O}_{\text {dest. }} & \text { ad } 1000 & \mathrm{ml}\end{array}$

Nach dem Autoklavieren wurden je $10 \mathrm{ml}$ einer sterilfiltrierten Lösung aus $1 \mathrm{M}$ $\mathrm{MgCl}_{2}$ bzW. $1 \mathrm{M} \mathrm{MgSO}_{4}$ zugegeben (Endkonzentration jeweils $10 \mathrm{mM}$ ).

\subsubsection{Spezifisches Plattentestverfahren zur Erkennung lipolytischer Aktivität}

$\begin{array}{lll}\text { Trypton } & 10 & \mathrm{~g} \\ \text { Hefeextrakt } & 5 & \mathrm{~g} \\ \mathrm{NaCl} & 10 & \mathrm{~g} \\ \text { Agar } & 15 & \mathrm{~g} \\ \mathrm{H}_{2} \mathrm{O}_{\text {dest. }} & \text { ad } 1000 \mathrm{ml} \\ \text { Tributyrin } & 10 & \mathrm{ml}\end{array}$

LB-Medium (s.2.3.1) wurde mit $1 \%(\mathrm{v} / \mathrm{v})$ Tributyrin versetzt, auf $60^{\circ} \mathrm{C}$ erwärmt und mit einem Ultra-Turrax Homogenisator(Fa. Janke \& Kunkel KG) emulgiert. 


\subsubsection{Spezifisches Plattentestverfahren zur Erkennung proteolytischer} Aktivität

$\begin{array}{lll}\text { Trypton } & 10 & \mathrm{~g} \\ \text { Hefeextrakt } & 5 & \mathrm{~g} \\ \mathrm{NaCl} & 10 & \mathrm{~g} \\ \mathrm{Agar} & 15 & \mathrm{~g} \\ \mathrm{H}_{2} \mathrm{O}_{\text {dest. }} & \mathrm{ad} 1000 & \mathrm{ml} \\ \text { Skimmilk } & 20 & \mathrm{~g}\end{array}$

Die Skimmilk wurde in ca. $40 \mathrm{ml} \mathrm{H}_{2} \mathrm{O}_{\text {dest. }}$ Gelöst und getrennt autoklaviert

\subsubsection{Spezifisches Plattentestverfahren zur Erkennung amyolytischer} Aktivität

$\begin{array}{lll}\text { Trypton } & 10 & \mathrm{~g} \\ \text { Hefeextrakt } & 5 & \mathrm{~g} \\ \mathrm{NaCl} & 10 & \mathrm{~g} \\ \text { Agar } & 15 & \mathrm{~g} \\ \mathrm{H}_{2} \mathrm{O}_{\text {dest. }} & \mathrm{ad} 1000 & \mathrm{ml} \\ \text { Lösliche Stärke } & 10 & \mathrm{~g}\end{array}$

2.3.6 M9-Mineralmedium (MILLER, 1972; modifiziert)

$\begin{array}{lll}\mathrm{KH}_{2} \mathrm{PO}_{4} & 3,0 & \mathrm{~g} \\ \mathrm{Na}_{2} \mathrm{HPO}_{4} & 6,0 & \mathrm{~g} \\ \mathrm{NH}_{4} \mathrm{Cl} & 3,0 & \mathrm{~g} \\ \mathrm{NaCl} & 0,5 & \mathrm{~g} \\ \mathrm{MgSO}_{4} \times 7 \mathrm{H}_{2} \mathrm{O} & 0,05 & \mathrm{~g} \\ \mathrm{CaCl}_{2} \times 12 \mathrm{H}_{2} \mathrm{O} & 0,00 & \mathrm{~g} \\ & 2 & \\ \mathrm{FeSO}_{4} & 0,02 & \mathrm{~g} \\ \mathrm{Hefeextrakt} & 0,2 & \mathrm{~g} \\ \text { SL-4 } & 1 & \mathrm{ml} \\ \text { Vitaminlösung nach WOLIN } & 1 & \mathrm{ml} \\ \text { pH-Wert einstellen auf } & 7,4 & \end{array}$


Dem Medium wurde Glycerin in einer Endkonzentration von $100 \mathrm{mM}$ und Thiamin- $\mathrm{HCl}$ in einer Konzentration $10 \mathrm{mM}$ zugesetzt

\subsubsection{Calaromator Viterbensis Medium}

$\begin{array}{lll}\mathrm{KH}_{2} \mathrm{PO}_{4} & 2,0 & \mathrm{~g} \\ \left(\mathrm{NH}_{4}\right)_{2} \mathrm{SO}_{4} & 0,5 & \mathrm{~g} \\ \mathrm{NH}_{4} \mathrm{Cl} & 0,5 & \mathrm{~g} \\ \mathrm{NaCl} & 0,5 & \mathrm{~g} \\ \mathrm{MgCl}_{2} \times 6 \mathrm{H}_{2} \mathrm{O} & 0,04 & \mathrm{~g} \\ \mathrm{CaCl}_{2} \times 2 \mathrm{H}_{2} \mathrm{O} & 0,04 & \mathrm{~g} \\ \mathrm{NaHCO}_{3} & 4,2 & \mathrm{~g} \\ \mathrm{Cystein}^{\mathrm{HCl}} & 0,13 & \mathrm{~g} \\ \mathrm{Hefeextrakt} & 0,3 & \mathrm{~g} \\ \text { SL-9 } & 1 & \mathrm{ml} \\ \text { Vitaminlösung nach Wolin } & 1 & \mathrm{ml} \\ \text { pH-Wert einstellen auf } & 7,4 & \end{array}$

Das Medium wurde für 30 min mit $\mathrm{N}_{2}$ begast und mit einem ButylGummistopfen verschlossen. Anschließend wurde das Medium $20 \mathrm{~min}$ bei $121^{\circ} \mathrm{C}$ autoklaviert. Dem Medium wurde Glycerin in einer Endkonzentration von $100 \mathrm{mM}$ zugesetzt.

\subsubsection{MacConkey-Agar (MacCONKEY, 1905; modfiziert)}

$\begin{array}{lll}\text { Pepton aus Casein } & 15,3 & \mathrm{~g} \\ \text { Proteose-Pepton } & 3,6 & \mathrm{~g} \\ \mathrm{NaCl} & 5,0 & \mathrm{~g} \\ \text { Neutralrot } & 0,03 & \mathrm{~g} \\ \text { Kristallviolett } & 0,001 & \mathrm{~g} \\ \mathrm{CoCl}_{2}(50 \mathrm{mM}) & 0,085 & \mathrm{ml} \\ \text { Agar } & 15 & \mathrm{~g} \\ \mathrm{H}_{2} \mathrm{O}_{\text {dest. }} & \text { ad } 1000 & \mathrm{ml}\end{array}$


Dem Medium wurde Glycerin in einer Endkonzentration von 70 mM zugesetzt.

2.3.9 Spurenelementelösung SL-4 (PFENNIG und LIPPERT,1966)

$\begin{array}{lll}\mathrm{Na}_{2}-\mathrm{EDTA} & 5,0 & \mathrm{~g} \\ \mathrm{FeSO}_{4} \times 7 \mathrm{H}_{2} \mathrm{O} & 2,0 & \mathrm{~g} \\ \mathrm{ZnSO}_{4} \times 7 \mathrm{H}_{2} \mathrm{O} & 0,1 & \mathrm{~g} \\ \mathrm{MnCl}_{2} \times 4 \mathrm{H}_{2} \mathrm{O} & 0,03 & \mathrm{~g} \\ \mathrm{H}_{3} \mathrm{BO}_{4} & 0,3 & \mathrm{~g} \\ \mathrm{CoCl}_{2} \times 6 \mathrm{H}_{2} \mathrm{O} & 0,2 & \mathrm{~g} \\ \mathrm{CuCl}_{2} \times 2 \mathrm{H}_{2} \mathrm{O} & 0,01 & \mathrm{~g} \\ \mathrm{NiCl}_{2} \times 6 \mathrm{H}_{2} \mathrm{O} & 0,02 & \mathrm{~g} \\ \mathrm{NaMoO}_{4} \times 2 \mathrm{H} \mathrm{O} & 0,03 & \mathrm{~g} \\ \mathrm{H}_{2} \mathrm{O}_{\text {dest. }} & \mathrm{ad} 1000 & \mathrm{ml}\end{array}$

2.3.10 Spurenelementelösung SL-9 (TSCHECH und PFENNIG; 1984)

$\begin{array}{lll}\text { Titriplex } & 12,8 & \mathrm{~g} \\ \mathrm{FeCl}_{2} \times 4 \mathrm{H}_{2} \mathrm{O} & 2,0 & \mathrm{~g} \\ \mathrm{CoCl}_{2} \times 6 \mathrm{H}_{2} \mathrm{O} & 190 & \mathrm{mg} \\ \mathrm{MgCl}_{2} \times 2 \mathrm{H}_{2} \mathrm{O} & 100 & \mathrm{mg} \\ \mathrm{ZnCl}_{2} & 70 & \mathrm{mg} \\ \mathrm{H}_{3} \mathrm{BO}_{3} & 6 & \mathrm{mg} \\ \mathrm{NiCl}_{2} \times 6 \mathrm{H}_{2} \mathrm{O} & 24 & \mathrm{mg} \\ \mathrm{CuCl}_{2} \times 2 \mathrm{H}_{2} \mathrm{O} & 2 & \mathrm{mg} \\ \mathrm{Na}_{2} \mathrm{MoO}_{4} \times 2 \mathrm{H}_{2} \mathrm{O} & 36 & \mathrm{mg} \\ \mathrm{H}_{2} \mathrm{O}_{\text {dest. }} & \text { ad } 1000 & \mathrm{ml}\end{array}$




\subsubsection{Vitaminlösung (WOLIN et al., 1964, modifiziert)}

$\begin{array}{lll}\text { Biotin } & 2 & \mathrm{mg} \\ \text { Folsäure } & 2 & \mathrm{mg} \\ \text { Pyridoxin x HCl } & 10 & \mathrm{mg} \\ \text { Thiamin x HCl } & 15 & \mathrm{mg} \\ \text { Riboflavin } & 5 & \mathrm{mg} \\ \text { Nikotinsäure } & 5 & \mathrm{mg} \\ \text { Ca-Pantothenat } & 5 & \mathrm{mg} \\ \text { Vitamin } \mathrm{B}_{12} & 10 & \mu \mathrm{mg} \\ \text { p-Aminobenzoesäure } & 5 & \mathrm{mg} \\ \alpha \text {-Liponsäure } & 1 & \mathrm{mg} \\ \mathrm{H}_{2} \mathrm{O}_{\text {dest. }} & \text { ad } 1000 & \mathrm{ml}\end{array}$

\subsubsection{Antibiotika und sonstige Medienzusätze}

Für die Anzucht rekombinanter E. coli-Stämme wurden die in Tab. 5 aufgeführten Medienzusätze verwendet.

Tab. 5: Verwendete Medienzusätze und Konzentrationen

\begin{tabular}{lll}
\hline Medienzusatz & Stammlösung & Arbeitskonzentration \\
\hline Ampicillin & $50 \mathrm{mg} / \mathrm{ml} \mathrm{50} \%$ Ethanol & $50-100 \mu \mathrm{g} / \mathrm{ml}$ \\
Chloramphenicol & $25 \mathrm{mg} / \mathrm{ml}$ Ethanol & $12,5 \mu \mathrm{g} / \mathrm{ml}$ \\
Kanamycin & $25 \mathrm{mg} / \mathrm{ml} \mathrm{H}_{2} \mathrm{O}_{\text {dest }}$ & $50 \mu \mathrm{g} / \mathrm{ml}$ \\
IPTG & $25 \mathrm{mg} / \mathrm{ml} \mathrm{H}_{2} \mathrm{O}_{\text {dest. }}$ & $50 \mu \mathrm{g} / \mathrm{ml}$ \\
X-Gal & $20 \mathrm{mg} / \mathrm{ml}$ Dimethylformamid & $40 \mu \mathrm{g} / \mathrm{ml}$ \\
\hline
\end{tabular}

Die IPTG-Stammlösung wurde steril-filtriert.

Die Zugabe der Komponenten erfolgte erst nach dem Abkühlen der autoklavierten Medien auf mindestens $60^{\circ} \mathrm{C}$. Die Lagerung erfolgte bei $-20^{\circ} \mathrm{C}$. 


\section{$2.4 \quad$ Zellanzucht}

\subsubsection{Aerobe Anzucht}

Die aerobe Anzucht von E. coli erfolgte in Reagenzgläsern oder Erlenmeyerkolben. Das Kulturvolumen betrug ca. $20 \%$ des Füllvolumens der Reagenzgläser bzw. Erlenmeyerkolben. Die Kulturen wurden unter Schütteln bei $30^{\circ} \mathrm{C}$ oder $37^{\circ} \mathrm{C}$ inkubiert.

\subsubsection{Anaerobe Anzucht}

Anaerobe Kulturen wurden mit einem 1 bis $10 \%$ igen (v/v) Inokulum aus einer Stammkultur (s. 2.4.4) oder aus einer anaeroben Vorkultur beimpft. Für Kulturen mit einem Volumen bis zu $10 \mathrm{ml}$ wurden Hungate-Röhrchen (Anaerobe Test Tubes, Hungate Type, $16 \times 125$ mm, Fa. Bellco Glass Inc., Vineland, New Jersey, USA) und für Anzuchten bis $50 \mathrm{ml}$ 125-ml-Serumflaschen („Hypovials”, Fa. Pierce, Rockford, England) verwendet. Bei einem Kulturvolumen von bis zu $500 \mathrm{ml}$ fanden 1-I-Serumflaschen (Fa. Müller und Krempel AG, Bülach, Schweiz) Verwendung. Für das Überimpfen wurden sterile Einwegspritzen benutzt.

\subsubsection{Anzucht von rekombinanten E. coli-Stämmen zur heterologen Genexpression}

\subsubsection{Expression mit dem "pET Directional TOPO® Expression"-Kit}

Der "pET Directional TOPO® Expression"-Kit (Fa. Invitrogen, Carlsbad, USA) nutzt die Klonierungsstrategie des "TOPO-Cloning" (s. Abb. 4 und detaillierte Erklärung des Grundprinzips unter 2.11.2), um blunt-end-PCR-Produkte gerichtet in einen "high-level"-Expressionsvektor zu klonieren. 


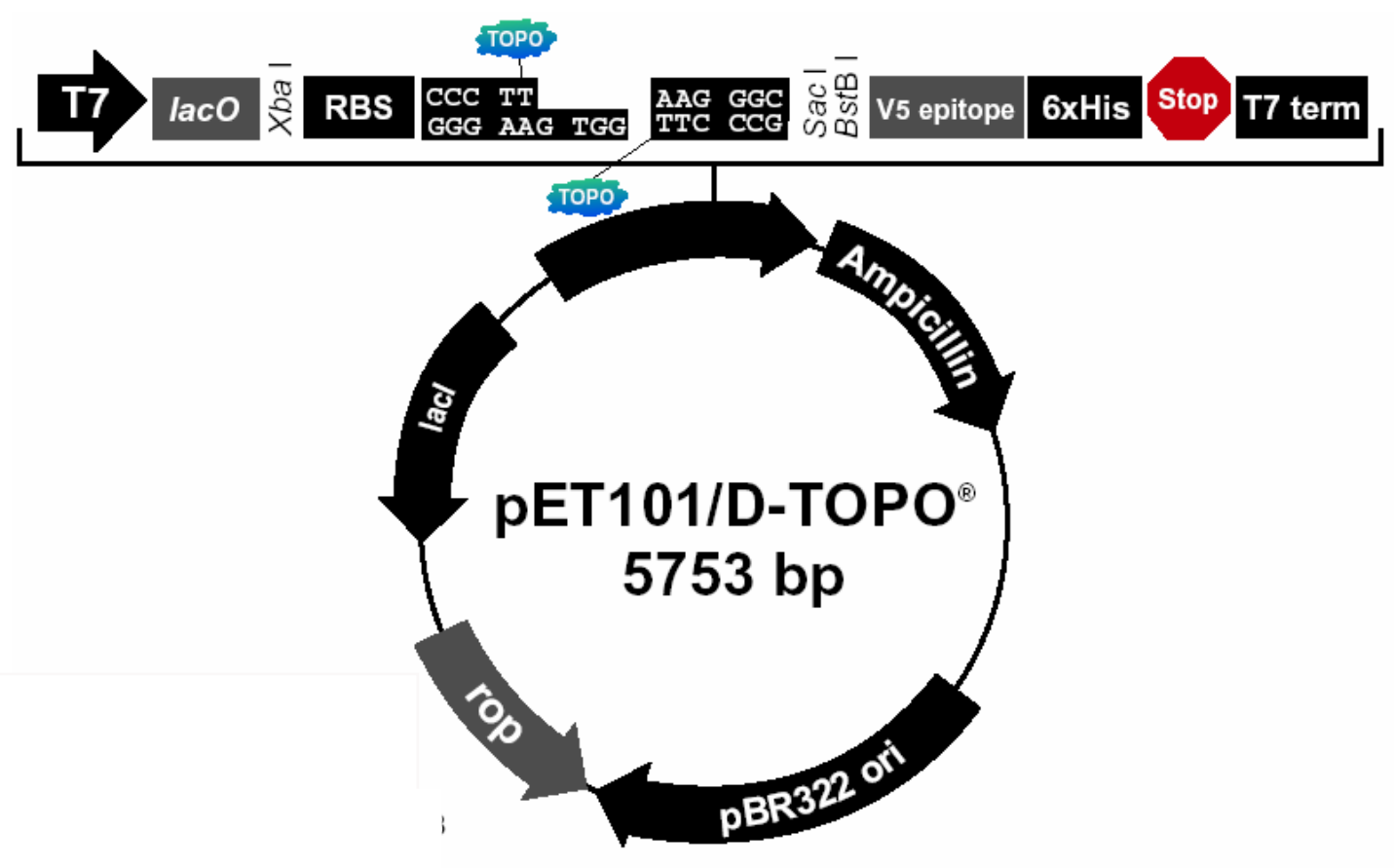

Abb. 4: Physikalische Karte des Expressionsvektors pET101/D

Außerdem besteht die Möglichkeit, das Zielgen N- oder C-terminal mit einem Tag (u. a. His ${ }^{-}$-Tag) zu versehen, der später eine einfache Detektion mit Antikörpern oder die Reinigung des gebildeten Proteins ermöglicht. Die physikalische Karte des verwendeten Vektors pET101/D-TOPO ist in Abb. 4 dargestellt. Die gerichtete TOPO-Klonierung (s. Abb. 5) wurde durch das Anhängen einer spezifischen Sequenz $\left(5^{\prime}-C A C C\right)$ an das durch PCR amplifizierte Zielgen erreicht, die komplementär ( $\left.3^{\prime}-G T G G\right)$ als EinzelstrangÜberhang auf dem Vektor vorhanden war. Dieser Überhang drang in das 5'Ende des PCR-Produkts ein und stabilisierte so die korrekte Orientierung des inserierten Gens.

Das pET-Expressionssystem macht sich die hohe Aktivität und Spezifität der T7-RNA-Polymerase zu Nutze. Dies ermöglicht ausgehend vom T7-Promotor eine regulierte Expression von heterologen Genen in E. coli (ROSENBERG et al., 1987; STUDIER und MOFFATT, 1986; STUDIER et al. 1990). Für die Expression wird der E. coli-Stamm BL21 Star ${ }^{\mathrm{TM}}$ (DE3) herangezogen. Dieser Stamm trägt den defekten, lysogenen $\lambda$-Phagen DE3, der folgende Elemente chromosomal kodiert enthält: den Lac-Repressor, lacl, die T7-RNA- 
Polymerase-Gene unter der Kontrolle des lacUV5-Promotors und einen Teil des lacZ-Gens.

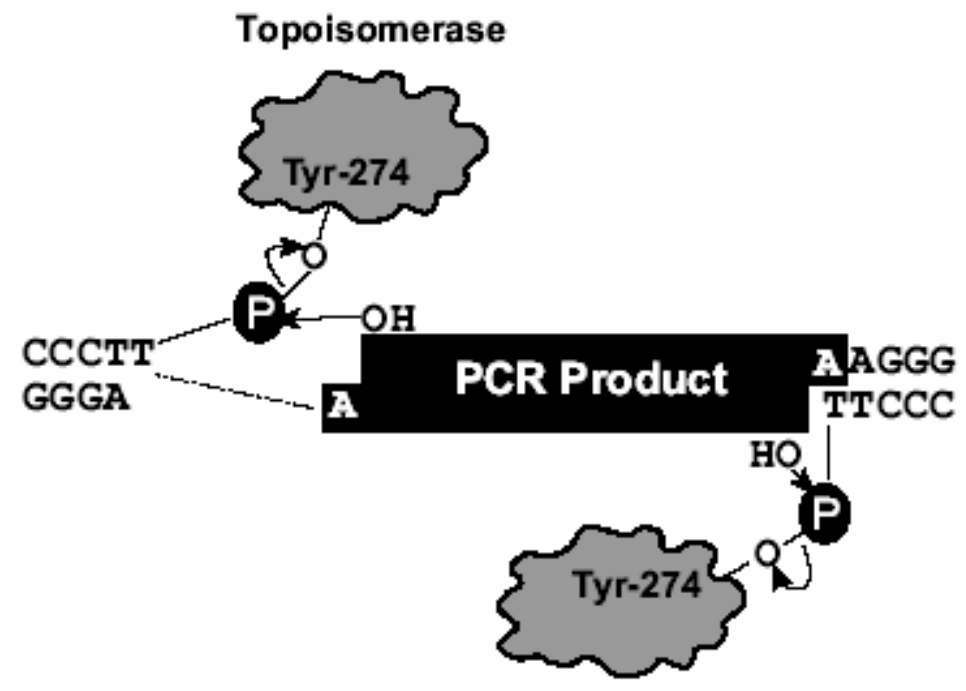

Topoisomerase

Abb. 5: Schematische Darstellung der gerichteten TOPO-Klonierung

Wenn dieser Vektor in einem DE3-lysogenen Stamm etabliert wurde, wirkte der gebildete lac-Repressor zum einen an dem lacUV5-Promotor im Wirtschromosom und reprimierte dort die Expression der T7-Polymerase und zum anderen am T7-Promotor des Vektors. Letzteres verhinderte die Expression der inserierten Gene. Die Expression der T7-RNA-Polymerase und der inserierten Gene ließ sich somit durch die Zugabe von IPTG induzieren.

\subsubsection{Stammhaltung}

Agarplatten mit E. coli konnten maximal 8 Wochen bei $4{ }^{\circ} \mathrm{C}$ gelagert werden. Zur längerfristigen Konservierung wurden Stammkulturen angelegt. Dazu wurden diese bei $30{ }^{\circ} \mathrm{C}$ in LB-Medium (s. 2.3.1) angezogen. In der logarithmischen Wachstumsphase wurden dann 0,75 $\mathrm{ml}$ Zellsuspension entnommen, mit 0,25 ml Glycerin (87 \%, (v/v)) versetzt und bei $-70{ }^{\circ} \mathrm{C}$ gelagert. Eine weitere Methode der Konservierung von E. coli Stämmen sind Mikrotiterplatten. Die Klone werden in den Titerplatten in LB-Medium angezogen und mit $10 \%$ (v/v) DSMO versetzt. Die Lagerung fand ebenfalls bei $-70{ }^{\circ} \mathrm{C}$ statt. 


\section{$2.5 \quad$ Anreicherungen}

\subsubsection{Aerobe Anreicherungen}

Die aerobe Anreicherung von Standortproben erfolgte in Erlenmeyerkolben. Dazu wurden $100 \mathrm{ml}$ Thermus-Medium mit $10 \%$ (w/v) der Standortprobe als Inokulum angeimpft und bei $60^{\circ} \mathrm{C}$ für 7 Tage inkubiert.

\subsubsection{Anaerobe Anreicherungen}

Anaerobe Anreicherungen erfolgten bei $65^{\circ} \mathrm{C}$ für 7 Tage und wurden in $125-\mathrm{ml}-$ Serumflaschen ("Hypovials", Fa. Pierce, Rockford, England) durchgeführt. Dazu wurden $50 \mathrm{ml}$ mit $10 \%$ (w/v) Standortprobe beimpft.

\subsection{Bestimmung von Wachstumsparametern}

\subsubsection{Bestimmung der optischen Dichte}

Die Bestimmung der optischen Dichte (OD) erfolgte anhand von Trübungsmessungen bei einer Wellenlänge von $600 \mathrm{~nm}$ gegen sterile Nährlösung in einem Spektralphotometer (UV-VIS Spektrophotometer V-550, Fa. Jasco, Jena) in Plastikküvetten mit einer Schichtdicke von $1 \mathrm{~cm}$. Bei Zelldichten $\mathrm{OD}_{600}>0,3$ wurden die Proben mit steriler Nährlösung entsprechend verdünnt. Die Messungen erfolgten gegen Medium als Leerwert.

\subsubsection{Bestimmung des $\mathrm{pH}-$ Wertes}

Der pH-Wert wurde mit einem WTW pH-Meter pH 526 (Fa. WTW GmbH, Weilheim) und einer Glas-Calomel-Elektrode (Fa. Cahn-Ingold, Frankfurt) bestimmt. Vor den Messungen wurde das Gerät für den entsprechenden Messbereich mit Eichlösungen (pH 4,0, pH 7,0 und pH 10,0 der Fa. Riedel de Haen AG, Hannover) geeicht. 


\subsection{Standardtechniken für das Arbeiten mit Nukleinsäuren}

\subsubsection{Behandlung von Geräten und Lösungen}

Alle hitzestabilen Lösungen und Geräte wurden zur Inaktivierung von Nukleasen für 20 min bei $121^{\circ} \mathrm{C}$ autoklaviert. Hitzelabile Geräte wurden mit $96 \%$ (v/v) Ethanol gewaschen und Metalloberflächen abgeflammt. Hitzelabile Biochemikalien wurden sterilfiltriert.

\subsubsection{Puffer und Lösungen}

Im Folgenden sind die Zusammensetzungen einiger Puffer und Lösungen aufgeführt, die im nachfolgenden Text nicht näher erläutert werden. Die Herstellung niedrigerer Pufferkonzentrationen erfolgte durch Verdünnung des Puffers mit $\mathrm{H}_{2} \mathrm{O}_{\text {dest. }}$

$\begin{array}{lll}10 \times \text { TE-Puffer } & & \\ 1 \mathrm{M} \text { Tris-Puffer }(\mathrm{pH} \mathrm{8,0}) & 100 & \mathrm{ml} \\ 0,5 \mathrm{M} \text { EDTA }(\mathrm{pH} 8,0) & 10 & \mathrm{ml} \\ \mathrm{H}_{2} \mathrm{O}_{\text {dest }} & \text { ad } 1000 \mathrm{ml}\end{array}$

$50 \times$ TAE-Puffer

$\begin{array}{lll}\text { Tris } & 242 & \mathrm{~g} \\ \text { Eisessig } & 57 & \mathrm{ml} \\ 0,5 \mathrm{M} \text { EDTA }(\mathrm{pH} \mathrm{8,0)} & 100 & \mathrm{ml} \\ \mathrm{H}_{2} \mathrm{O}_{\text {dest }} & \mathrm{ad} 1000 \mathrm{ml}\end{array}$




\subsubsection{Fällung, Reinigung und Konzentration von Nukleinsäuren}

\subsubsection{Fällung von Nukleinsäuren}

Die Konzentration von Nukleinsäuren erfolgte durch Fällung mit Ethanol oder

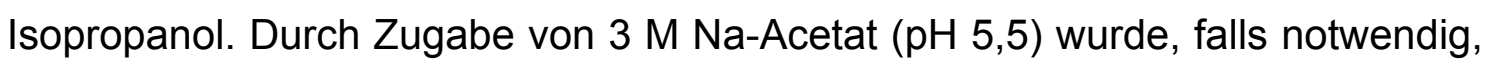
die lonenstärke erhöht (Endkonzentration 0,3 M). Zur Präzipitation der Nukleinsäuren erfolgte die Zugabe von 2 Vol. Ethanol (96 \%) bzw. 1 Vol. Isopropanol (96\%). Die Ethanolfällung erfolgte durch Inkubation bei Raumtemperatur für mindestens $1 \mathrm{~h}$, bei Isopropanol wurde über Nacht bei Raumtemperatur inkubiert. Die Nukleinsäuren wurden durch Zentrifugation (13000 bis $16000 \times \mathrm{g}, 4{ }^{\circ} \mathrm{C}$ oder RT, $30 \mathrm{~min}$ ) pelletiert. Das Pellet wurde mit 1 $\mathrm{ml}$ eiskaltem Ethanol $(70 \%, \mathrm{v} / \mathrm{v})$ gewaschen, getrocknet und in dem gewünschten Volumen sterilem $\mathrm{H}_{2} \mathrm{O}$ aufgenommen.

\subsubsection{DNA-Fällung nach Saccharose-Dichtegradientenzentrifugation}

Ziel dieser Fällung war die Abtrennung von Saccharose nach der SaccharoseDichtegradientenzentrifugation (s. 2.12.1). Dazu wurde jedes Aliquot aus dem Gradienten mit 0,5 Vol. PEG-NaCl-Lösung (20\% PEG 6000, 2,5 M NaCl) versetzt und über Nacht bei RT inkubiert. Anschließend erfolgte eine Zentrifugation der Lösungen (30 min, 22650 x g, RT). Der Überstand wurde abgenommen, das Pellet mit 0,5 ml Ethanol (70\% (v/v), RT) versetzt und nochmals unter den gleichen Bedingungen zentrifugiert. Wiederum wurde der Überstand abgenommen, das Pellet getrocknet und in $20-30 \mu \mathrm{l}$ sterilem $\mathrm{H}_{2} \mathrm{O}_{\text {dest }}$ aufgenommen. Alle Schritte wurden bei RT durchgeführt, da bei Einsatz niedrigerer Temperaturen das Polyethylenglykol ausfällt.

\subsubsection{Mikrodialyse von DNA}

Zur Entfernung von Salzen aus kleinen Probe-Volumen wie Ligationsansätzen wurde eine Mikrodialyse durchgeführt. Die Dialyse wurde in einer kleinen 
Petrischale gegen steriles $\mathrm{H}_{2} \mathrm{O}_{\text {dest }}$ als Dialysepuffer durchgeführt. Zunächst wurden kleine Membranfilterscheiben (Porengröße 0,025 $\mu \mathrm{m}$, Fa. Milipore, Eschborn) mit der glänzenden Seite nach oben auf die Wasseroberfläche gegeben. Dann wurden mit einer Pipette vorsichtig 5 bis $10 \mu \mathrm{l}$ der Probe auf die Dialysemembran aufgetragen. Nach 30 min konnten die dialysierten Proben abgenommen werden.

\subsubsection{Dialyse von Umwelt-DNA}

Enthielt die aus den Standort-Proben isolierte DNA zu hohe Salzkonzentrationen, mußte sie vor einer weiteren Reinigung zunächst einer Dialyse unterzogen werden. Zu diesem Zweck wurden 20 bis $30 \mathrm{~cm}$ lange Dialyseschlauchstücke in TE-Puffer autoklaviert. Anschließend wurde die DNALösung in die Schläuche eingefüllt, die an beiden Enden mit DialyseschlauchKlammern verschlossen wurden. Die DNA-Lösung wurde dann 24 h gegen TEPuffer dialysiert. Nach etwa 4 bis $5 \mathrm{~h}$ wurde der Puffer ausgewechselt. Anschließend erfolgte eine Fällung der DNA mit Ethanol (s. 2.7.3.1).

\subsubsection{Konzentrationsbestimmung von Nukleinsäuren}

Die Bestimmung der Konzentration von Nukleinsäuren in wässriger Lösung erfolgte photometrisch bei einer Wellenlänge von $260 \mathrm{~nm}$.

Eine Extinktion von 1 entspricht etwa:

$50 \mu \mathrm{g} / \mathrm{ml}$ doppelsträngiger DNA, $40 \mu \mathrm{g} / \mathrm{ml}$ einzelsträngiger DNA oder

$30 \mu \mathrm{g} / \mathrm{ml}$ einzelsträngiger Oligonukleotide.

Die Reinheit von Nukleinsäure-Lösungen konnte durch das Verhältnis $\mathrm{OD}_{260} \mathrm{zu}$ $\mathrm{OD}_{280}$ bestimmt werden. Bei reinen DNA-Lösungen sollte dieser Wert zwischen 1,8 und 2,0 liegen (SAMBROOK et al., 1989), niedrigere Werte weisen auf Verunreinigungen mit Proteinen hin. 


\subsubsection{Bestimmung der DNA Konzentration mittels NanoDrop® ND-1000}

Die DNA Konzentration wurde mit dem NanoDrop ${ }^{\circledR}$ ND-1000 bestimmt. Durch die Nutzung dieses Gerätes entfallen der Gebrauch von Küvetten und die Herstellung großer Verdünnungen. Die Konzentration einer Probe mit einem Volumen von $1 \mu \mathrm{l}$ kann ebenso wie deren Reinheit hiermit sofort bestimmt werden (s. ND-1000 Spektrophotometer V3.3 User`s manual).

\subsubsection{Isolierung von DNA-Fragmenten mittels „QIAquick Gel Extraction"-Kit}

Zur Isolierung von DNA-Fragmenten aus Agarosegelen wurde der "QIAquick Gel Extraction"-Kit (Fa. Qiagen $\mathrm{GmbH}$, Hilden) herangezogen. Die Methode beruht auf der Bindung der DNA an eine Silica-Membran in Gegenwart von hohen Salzkonzentrationen. Das Kit kann zur Extraktion von DNA-Fragmenten von einer Größe von 0,1 bis $10 \mathrm{kBp}$ genutzt werden. Die Extraktion erfolgte nach den im Herstellerprotokoll beschriebenen Arbeitsschritten. Die DNA wurde mit $\mathrm{H}_{2} \mathrm{O}_{\text {dest. }}$ eluiert und bis zur weiteren Verwendung bei $-20^{\circ} \mathrm{C}$ aufbewahrt.

\subsubsection{Reinigung von DNA-Fragmenten mittels „QIAquick PCR Purification"-Kit}

Zur Reinigung von PCR-Produkten und anderen linearen DNA-Fragmenten wurde der „QIAquick PCR Purification“-Kit (Fa. Qiagen GmbH, Hilden) genutzt. Wie auch beim „QIAquick Gelextraction“-Kit (s. 2.7.3.7.) wird die DNA bei hohen Salzkonzentrationen an eine Silica-Membran gebunden. Die Reinigung wurde nach den Anweisungen des Herstellers durchgeführt. Die Elution der DNA erfolgte mit $\mathrm{H}_{2} \mathrm{O}_{\text {dest. }}$. Die so gereinigten PCR-Produkte wurden bis zu ihrer weiteren Verwendung bei $-20^{\circ} \mathrm{C}$ gelagert. 


\subsection{Isolierung von Nukleinsäuren}

\subsubsection{Isolierung von DNA aus Umweltproben (ZHOU et al., 1996)}

Diese Methode der DNA-Isolierung aus Bodenproben beruht auf der direkten Lyse der Zellen, so dass sie vor dem Aufschluß nicht von den Bodenpartikeln abgetrennt werden müssen. Weiterhin wird so die zusätzlich im Boden frei vorliegende DNA erhalten.

Zur DNA-Isolierung wurden $50 \mathrm{~g}$ Boden mit $135 \mathrm{ml}$ DNA-Extraktionspuffer (DEP) und $1 \mathrm{ml}$ Proteinase $\mathrm{K}(10 \mathrm{mg} / \mathrm{ml})$ versetzt und für $30 \mathrm{~min}$ bei $37{ }^{\circ} \mathrm{C}$ horizontal geschüttelt (225 Upm). Nach der Zugabe von $15 \mathrm{ml} 20$ \% SDS (oder $30 \mathrm{ml} 10 \%$ ) wurde das Gemisch für $2 \mathrm{~h}$ bei $65^{\circ} \mathrm{C}$ inkubiert und dabei alle 15 bis 20 min vorsichtig geschüttelt.

Zur Trennung der bereits gelösten DNA von der Bodenmatrix wurde anschließend zentrifugiert (10 min, 7000 Upm, Rotor GS3, Sorvall Zentrifuge, Fa. Du Pont Instruments, Newton, USA, RT) und der Überstand in einen GS3Zentrifugenbecher überführt. Das Pellet wurde noch zweimal in je $45 \mathrm{ml}$ DEP und $5 \mathrm{ml} 20 \%$ SDS suspendiert und nach einer 10-minütigen Inkubation bei $65^{\circ} \mathrm{C}$ wie oben beschrieben zentrifugiert.

Zur Extraktion der DNA wurde den gesammelten Überständen 1 Vol. Chloroform/lsoamylalkohol (24:1) zugesetzt und für $10 \mathrm{~min}$ bei $7000 \mathrm{Upm}$ (Rotor GS3, Sorvall Zentrifuge, Fa. Du Pont Instruments, Newton, USA) und RT zentrifugiert.

Die Fällung der DNA erfolgte durch Zugabe von 0,6 Vol. Isopropanol für $1 \mathrm{~h}$ bei RT. Nach einer Zentrifugation bei 9000 Upm für 20 min bei RT wurde das Pellet mit eiskaltem Ethanol (70\% v/v) gewaschen und in 4 bis $5 \mathrm{ml}$ sterilem $\mathrm{H}_{2} \mathrm{O}$ aufgenommen. 


$\begin{array}{lll}\text { DNA-Extraktionspuffer (DEP) } & \\ \text { Tris } & 100 & \mathrm{mM} \\ \text { EDTA } & 100 & \mathrm{mM} \\ \mathrm{Na}_{2} \mathrm{HPO}_{4} & 100 & \mathrm{mM} \\ \mathrm{NaCl} & 1,5 & \mathrm{M} \\ \mathrm{CTAB} & 1 & \%\end{array}$

$\mathrm{pH} 8,0$

\subsubsection{Isolierung von DNA aus Umweltproben mittels „Bead- beating"(YEATES et al. 1998)}

Die Methode der DNA-Isolierung mittels „Bead-beating“ beruht auf der Kombination der Methode von ZHOU et al. 1996. Neben der direkten Lyse der Zellen wurde ein 30 sekundiger „Bead-beating“-Schritt eingebaut.

\subsubsection{Reinigung von Umwelt-DNA (HENNE et al., 1999)}

Bei den verwendeten Methoden zur Isolierung von DNA aus Standortproben (s. 2.8.1 und 2.8.2) wurden neben der DNA auch Huminsäuren gefällt, die in nachfolgenden Klonierungsschritten Restriktionsenzyme und Ligase inhibieren können. Durch Reinigung über das „Wizard ${ }^{\mathrm{TM}}$ Plus Minipreps DNA Purification System" (Fa. Promega Deutschland GmbH, Mannheim) konnten die Huminsäuren zum größten Teil abgetrennt werden. Jedoch ist diese Methode mit einem hohen Verlust an DNA verbunden.

Der erste Reinigungsschritt erfolgte nacheinander über zwei Minisäulen. Dazu wurden $150 \mu \mathrm{l}$ DNA-Lösung mit $150 \mu \mathrm{l} \mathrm{H}_{2} \mathrm{O}$ verdünnt, mit 1 ml „DNA Purification Resin" versetzt und auf den Säulenkörper gegeben. Nach dem Waschen mit $2 \mathrm{ml}$ „Wash”-Puffer wurde zum Trocknen des Säulenmaterials bei 2000 Upm für 2 min zentrifugiert. Die Elution der DNA aus der Säulenmatrix erfolgte mit jeweils $50 \mu \mathrm{lTE}$-Puffer $\left(65-70^{\circ} \mathrm{C}\right)$. Da bei dieser Methode die Bindekapazität des Säulenmaterials stark überschritten wird, wurde die Elution sechsmal wiederholt. Das vereinigte Eluat wurde wieder mit $1 \mathrm{ml}$ Resin versetzt und auf die zweite Säule aufgetragen. Die Elution wurde viermal wiederholt. 


\subsubsection{Isolierung von Plasmid-DNA}

\subsubsection{Plasmidschnellpräparation (HOLMES \& QUIGLEY, 1981)}

Diese Methode diente vor allem zum schnellen Nachweis und zur Charakterisierung von Klonierungsergebnissen. $1,5 \mathrm{ml}$ einer über Nacht gewachsenen Kultur wurden geerntet (5000 x g, 5 min, RT) und in $350 \mu$ STETPuffer suspendiert. Nach Zugabe von $25 \mu$ Lysozym-Lösung $(10 \mathrm{mg} / \mathrm{ml})$ und einer kurzen Inkubation des Ansatzes bei RT erfolgte anschließend eine Denaturierung für $1 \mathrm{~min}$ bei $100^{\circ} \mathrm{C}$. Zellreste und denaturierte Proteine wurden nach Zentrifugation (16000 x g, 10 min) mit einem sterilen Zahnstocher entfernt. Nach der Zugabe von $40 \mu \mathrm{l}$ Na-Acetat $(2,5 \mathrm{M}, \mathrm{pH} 5,2)$ und $420 \mu \mathrm{l}$ Isopropanol wurde das Plasmid durch Zentrifugation (16000 x g, $5 \mathrm{~min}$ ) pelletiert. Das enthaltene Pellet wurde mit Ethanol $(70 \%,(v / v))$ gewaschen, getrocknet und in $50 \mu \mathrm{H}_{2} \mathrm{O}_{\text {dest. }}$ suspendiert.

STET-Puffer

$\begin{array}{lll}\mathrm{NaCl} & 100 & \mathrm{mM} \\ \text { Tris-HCl } & 10 & \mathrm{mM} \\ \text { EDTA } & 1 & \mathrm{mM} \\ \text { Triton } \mathrm{X}-100 & 5 & \% \\ \text { pH } 8,0 & & \end{array}$

\subsubsection{Minipräparation von Plasmiden mittels „QIAprep Spin Miniprep Kit“"}

Zum Erhalt von sehr sauberer Plasmid-DNA wurde der "QIAprep Spin Miniprep Kit“ (Fa. Qiagen) genutzt. 1,5 ml einer 5-ml-Übernachtkultur wurden für $5 \mathrm{~min}$ bei $6000 \times$ g zentrifugiert und das Zellpellet in $250 \mu \mathrm{l}$ Puffer P1 suspendiert. Es folgte die Zugabe von $250 \mu \mathrm{l}$ Puffer P2, Schwenken bis zum Aufklaren der Lösung und Neutralisation durch Zusatz von $350 \mu \mathrm{l}$ Puffer N3. Durch Zentrifugation (10 min, $13000 \mathrm{x} \mathrm{g}$ ) wurden die ausgefällten Proteine und Zelltrümmer sedimentiert. Der Überstand wurde anschließend auf eine QIAprep 
Säule aufgetragen, die eine Silica-Gel-Membran für die selektive Adsorption von Plasmid-DNA enthält. Durch Zentrifugation (1 min, $13000 \times \mathrm{g}$ ) erfolgte die Bindung der DNA an die Membran, der Durchfluß wurde verworfen. Nach einem Waschschritt mit $750 \mu \mathrm{l}$ Puffer PE und dem Trocknen durch Zentrifugation (1 $\mathrm{min}, 13000 \mathrm{x}$ g) wurde die Plasmid-DNA mit 30 bzw. $50 \mu \mathrm{l}$ $\mathrm{H}_{2} \mathrm{O}_{\text {dest. }}$ Eluiert. Alle verwendeten Puffer wurden vom Hersteller mitgeliefert.

\subsubsection{Minipräparation von Plasmiden mittels „NucleoSpinPlasmid“-Kit}

Alternativ zur Plasmid-Präparation mit dem "QIAprep Spin Miniprep Kit” wurde auch der „NucleoSpinPlasmid“-Kit der Firma Macherey und Nagel genutzt. Prinzip und Vorgehen dieses Kits entsprechen denen des „QIAprep Spin Miniprep Kits“. Es entsprechen sich dabei die Puffer A1 und P1, A2 und P2, A3 (von diesem wurden abweichend $300 \mu$ l eingesetzt) und N3, AW und PB sowie A4 (von diesem wurden alternativ $600 \mu$ l eingesetzt) und PE. Alle verwendeten Puffer wurden vom Hersteller mitgeliefert.

\subsubsection{Minipräparation von Fosmiden}

Die Präparation von Fosmiden erfolgte analog 2.8.4.3. Es wurde allerdings die doppelte Puffermenge verwendet.

\subsubsection{Präparative Plasmidisolierung über Anionenaustausch- Chromatographie}

Die Isolierung größerer Mengen an Plasmid-DNA erfolgte nach alkalischer Lyse mit den Puffern P1, P2 und P3 über Anionenaustauschchromatographie (Qiagen Plasmid Midi-Kit, Fa. Qiagen). $25 \mathrm{ml}$ Zellkultur wurden bei einer $\mathrm{OD}_{600}$ von 1 bis 1,5 geerntet und in $4 \mathrm{ml} \mathrm{P1-Puffer} \mathrm{suspendiert.} \mathrm{Es} \mathrm{folgte} \mathrm{die} \mathrm{Zugabe}$ von $4 \mathrm{ml} \mathrm{P2-Puffer} \mathrm{und} \mathrm{eine} \mathrm{Inkubation} \mathrm{für} 5 \mathrm{~min}$ bei RT. Anschließend wurden $4 \mathrm{ml} \mathrm{P3-Puffer} \mathrm{zugefügt} \mathrm{und} \mathrm{für} 30 \mathrm{~min}$ auf Eis inkubiert. Nach Zentrifugation (30 min, $16000 \times \mathrm{g}, 4{ }^{\circ} \mathrm{C}$ ) wurde der Überstand abgenommen und zur vollständigen Aufklarung erneut für 15 min zentrifugiert. Der dabei erhaltene 
Überstand konnte dann auf eine mit $4 \mathrm{ml}$ QBT-Puffer äquilibrierte Quiagen-tip100 Säule aufgetragen werden. Es folgte ein Waschschritt mit $20 \mathrm{ml} \mathrm{QC-Puffer}$ und die Elution der Plasmid-DNA durch Zugabe von $5 \mathrm{ml}$ QF-Puffer. Die DNA wurde mit 0,7 Vol. Isopropanol gefällt und durch Zentrifugation (30 min, $\left.16000 \times \mathrm{g}, 4{ }^{\circ} \mathrm{C}\right)$ pelletiert. Das Pellet wurde anschließend mit Ethanol $(70 \%$, v/v) gewaschen und getrocknet und in 100 bis $200 \mu \mathrm{l} \mathrm{H}_{2} \mathrm{O}_{\text {dest }}$ aufgenommen. Für die Isolierung von Plasmid-DNA aus größeren Kulturvolumina als $100 \mathrm{ml}$ wurde die Menge an P1, P2 und P3 entsprechend erhöht. Die Anionenaustauschchromatographie erfolgte dann in mehreren Durchgängen, wobei die Säule nach jeder Elution mit $4 \mathrm{ml}$ QBT-Puffer neu äquilibriert wurde. Auf diese Weise wurde Plasmid-DNA aus Kulturvolumina bis $250 \mathrm{ml}$ isoliert. Alle verwendeten Puffer wurden vom Hersteller mitgeliefert.

\section{$2.9 \quad$ Gelelektrophorese von Nukleinsäuren}

\subsubsection{Standard-Agarose-Gelelektrophorese}

Zur analytischen Auftrennung von DNA-Fragmenten diente die StandardAgarose-Gelelektrophorese (SAMBROOK et al., 1989). Es wurden Gele mit einem Volumen von 10 bis $25 \mathrm{ml}$ gegossen. Die Agarosekonzentration variierte zwischen 0,8 und 1,5\%. Die Proben wurden vor dem Auftragen mit 0,2 Vol. Stop-Mix versetzt, um sie zu beschweren und um die Lauffront zu markieren. Als Elektrophoresepuffer wurde 1-fach TAE-Puffer verwendet. Die Elektrophorese wurde bei einer konstanten Spannung zwischen 25 und $120 \mathrm{~V}$ durchgeführt, wodurch sich je nach Gelgröße eine Laufzeit von 1 bis $7 \mathrm{~h}$ ergab. Nach Beendigung der Elektrophorese wurden die Agarosegele in einem Ethidiumbromidbad (1 $\left.\mu \mathrm{g} / \mathrm{ml} \quad \mathrm{H}_{2} \mathrm{O}_{\text {dest }}\right)$ für 10 bis $30 \mathrm{~min}$ angefärbt und anschließend mit einer Geldokumentationsanlage (Image Quant 100) analysiert. Dabei wurde die DNA mittels UV-Licht durch das eingelagerte Ethidiumbromid sichtbar gemacht und fotografisch dokumentiert. Die Bestimmung der Größe von DNA-Fragmenten erfolgte an Hand eines mit aufgetrennten internen Größenstandards. 
$10 \times$ DNA-Probenpuffer

50 x TAE-Puffer:
$125 \mathrm{mg}$ Bromphenolblau

16, $5 \mathrm{ml}$ Tris $(150 \mathrm{mM}, \mathrm{pH} 7,6)$

$30 \mathrm{ml}$ Glycerol

3, $5 \mathrm{ml} \mathrm{H} \mathrm{O}_{\text {dest }}$

$2 \mathrm{M}$ Tris

$50 \mathrm{mM} \mathrm{Na}{ }_{2}$ EDTA

$5,71 \%$ Essigsäure

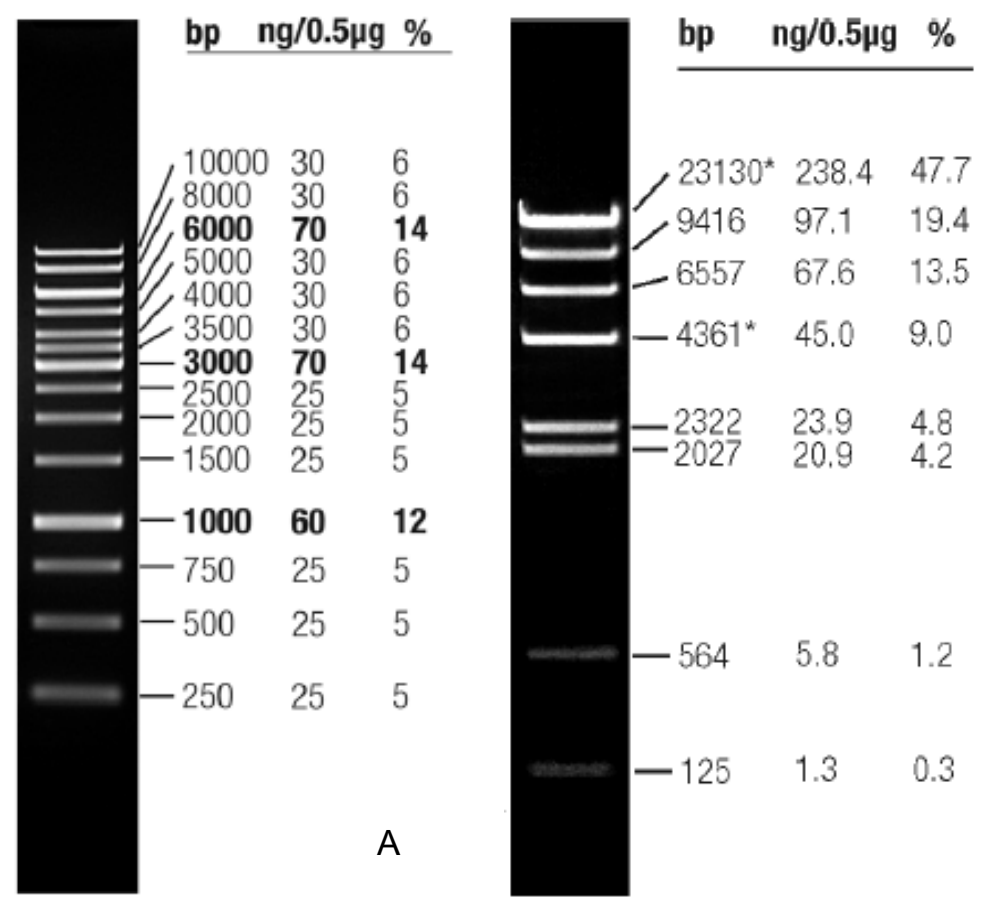

B

Abb. 6: A/B DNA-Ladder. A - 1 kb DNA Ladder, B - $\lambda$ Hind III Ladder (Abb. aus http://www.fermentas.com/catalog/electrophoresis/index.html)

\subsection{Mechanische Modifikation von DNA}

\subsubsection{Ultraschall}

Die unter 2.8 isolierten bzw. gereinigten Nukleinsäuren konnten mit Hilfe des Ultraschalls auf unspezifische Größen fragmentiert werden. Dazu wurde die DNA in entsprechende Puffer aufgenommen und zwischen 3 und $10 \mathrm{~s}$ im Eisbad beschallt (20\%ige Amplitude, Cycle 0,5). 


\subsection{Enzymatische Modifikation von DNA}

\subsubsection{Schneiden von DNA durch Restriktionsendonukleasen}

DNA lässt sich durch Restriktionsendonukleasen an definierten Stellen spalten. Man unterscheidet hierbei Typ1 und Typ2 Restriktionsendonukleasen. Jene vom Typ1 erkennen eine jeweils definierte Nukleotidsequenz, schneiden aber unspezifisch außerhalb dieser Erkennungssequenz, weshalb sie für die meisten molekularbiologischen Methoden ungeeignet sind. Typ2 Restriktionsendonukleasen schneiden an definierter Stelle innerhalb der Erkennungssequenz. Je nach verwendetem Enzym können Spaltprodukte mit glatten oder klebrigen Enden entstehen. Bei den Produkten mit klebrigen Enden muss man zudem zwischen solchen mit $3^{\wedge}$ Überhängen und solchen mit $5^{`}$ Überhängen unterscheiden, da dies von entscheidender Bedeutung für die Verwendbarkeit von diesen Restriktionsendonukleasen für bestimmte Methoden ist. Die Spaltprodukte können dann gelelektrophoretisch aufgetrennt werden, was eine Größenabschätzung und die Isolierung einzelner Fragmente ermöglicht. Unit (U) stellt die standardisierte Einheit für Restriktionsendonukleasen dar, wobei eine Unit die Menge Enzym ist, die ein $\mu \mathrm{g} \lambda$-DNA in einer Stunde verdaut. Die eingesetzte Menge Restriktionsenzym sollte dementsprechend an die Anzahl der Schnittstellen pro DNA-Molekül und auf die Anzahl der zu schneidenden Moleküle angepasst werden. Für einen analytischen Verdau wurde standardmäßig meist $1 \mu$ l (i.d.R. 1 U) eingesetzt. Der Verdau erfolgte in einem vom Hersteller mitgelieferten und auf die entsprechenden Enzyme abgestimmten Puffer. Die partielle Spaltung von chromosomaler bzw. von Standort-DNA wurde zeitlimitiert durchgeführt. Es wurde routinemäßig mit $1 \cup$ Restriktionsenzym gearbeitet. Die Verdauung wurde in bestimmten Zeitabständen durch Zugabe von EDTA (20 mM) und Inkubation auf Eis gestoppt. 


\section{Analytischer Restriktionsverdau}

$x \mu$ I DNA (bis zu $1 \mu \mathrm{g}$ )

$1,5 \mu \mathrm{l} 10 \mathrm{x}$ Puffer

$x \mu l$ Restriktionsenzym(e)

ad $20 \mu \mathrm{l} \mathrm{H}_{2} \mathrm{O}_{\text {dest }}$

\section{Präparativer Restriktionsverdau}

$x \mu l$ DNA (bis zu $10 \mu g$ )

$5 \mu \mathrm{l} 10$ x Puffer

$x \mu l$ Restriktionsenzym(e)

ad $50 \mu \mathrm{H} \mathrm{H}_{2} \mathrm{O}_{\text {dest }}$

\subsubsection{Voraussetzungen für das Klonieren von Umwelt-DNA mit dem

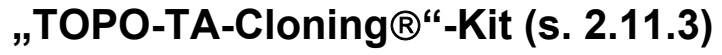

\subsubsection{AuffülIreaktion von gereinigter und größenfraktionierter Umwelt-DNA durch Behandlung mit T4-DNA-Polymerase}

Mit Hilfe der T4-DNA-Polymerase wurde größenfraktionierte und gereinigte Umwelt-DNA auf „blunt-end“ aufgefüllt. Dazu wurden $5 \mu \mathrm{g}$ DNA aus einer Saccharosegradientenzentrifugation (s. 2.12.1) bzw. CaesiumchloridDichtegradienten-Zentrifugation (s. 2.12.2) verwendet.

Ansatz:

$\begin{array}{ll}\text { Standort-DNA } & 5 \mu \mathrm{g} \\ \text { T4-Polymerase } & 5 \mathrm{U} \\ \text { Reaktionspuffer } & 10 \mu \mathrm{l} \\ \text { dNTP-Mix } & 10 \mathrm{mM} \\ \mathrm{H}_{2} \mathrm{O}_{\text {dest. }} & 50 \mu \mathrm{l}\end{array}$

Es erfolgte eine Inkubation von $1 \mathrm{~h}$ bei Raumtemperatur mit anschließender Reinigung mittels QIAquick PCR Purification“-Kit (s.2.7.3.8). 


\subsubsection{Anhängen von dATP an „blunt-end-DNA“}

Mit Hilfe der Taq-DNA-Polymerase wurde ein Desoxyadenosin an „blunt-endDNA“ angehängt.

Ansatz:

$\begin{array}{ll}\text { „blunt-end-DNA“ } & 50 \mu \mathrm{l} \\ \text { dATP } & 2 \mathrm{mM} \\ \text { Taq-DNA-Polymerase } & 2 \mathrm{U} \\ \mathrm{MgCl}_{2} & 6 \mu \mathrm{l} \\ \text { Reaktionspuffer } & 7 \mu \mathrm{l} \\ \mathrm{H}_{2} \mathrm{O}_{\text {dest. }} & 7 \mu \mathrm{l}\end{array}$

Es erfolgte eine Inkubation von 20 min bei $72{ }^{\circ} \mathrm{C}$ mit anschließender Reinigung mittels „QIAquick PCR Purification“-Kit (s. 2.7.3.8).

\subsubsection{Dephosphorylierung von DNA-Fragmenten}

Um eine Insertion der Umwelt-DNA-Fragmente in den Vektor pCR2.1-TOPO oder pCR-XL-TOPO zu ermöglichen, müssen die Enden dephosphoryliert werden, da an den Vektor eine Topoisomerase kovalent über eine 3'Phosphotyrosylbindung gebunden ist. Zu dem Ansatz aus 2.11.2.2 wurde $1 \mathrm{U}$ alkalische Phosphatase pro $\mu \mathrm{g}$ DNA (Fa MBI Fermentas $\mathrm{GmbH}$ ) zugesetzt und für $30 \mathrm{~min}$ bei $37^{\circ} \mathrm{C}$ inkubiert.

\subsubsection{Ligation mit dem „TOPO-TA-Cloning ${ }^{\circledR}$ “-Kit}

Für eine besonders effektive Klonierung von PCR-Produkten, die mit der TaqDNA-Polymerase in einer Polymerasekettenreaktion (s. 2.13) amplifiziert wurden, wurde das "TOPO-TA-Cloning®"-Kit (Fa. Invitrogen) verwendet. Für diese Art der Klonierung wird keine Ligase benötigt. 
Die Taq-DNA-Polymerase besitzt eine von der Matrize unabhängige terminale Transferase-Aktivität und hängt an die 3'-Enden von PCR-Produkten einzelne Desoxyadenosine $(A)$ an. Der im Kit vorhandene, bereits linearisierte Vektor pCR2.1-TOPO besitzt analog dazu an den 3'-Enden einzelne DesoyxthymidinReste (T). Dies erlaubt eine Ligation nach der sogenannten TA-Methode. Des Weiteren besitzt der Vektor die kovalent gebundene Topoisomerase I des Vaccinia-Virus. Die Topoisomerase I bindet an spezifische Sequenzen doppelsträngiger DNA und spaltet dort das Phosphordiester-Gerüst stromabwärts der Sequenz 5'-CCCTT in einem Strang (SHUMAN, 1991). Die Energie dieser Spaltungsreaktion wird durch Ausbildung einer kovalenten Bindung zwischen dem 3'-Phosphat des gespaltenen Stranges und dem Tyrosin-274 der Topoisomerase I konserviert. Die Reaktion zwischen DNA und Protein kann durch den Angriff des 5'-Hydroxyl-Restes umgekehrt werden, was dann zur Abspaltung der Topoisomerase I führt (SHUMAN, 1994). Dieses Prinzip wird zur effizienten Klonierung von PCR-Produkten genutzt (s. Abb. 7).

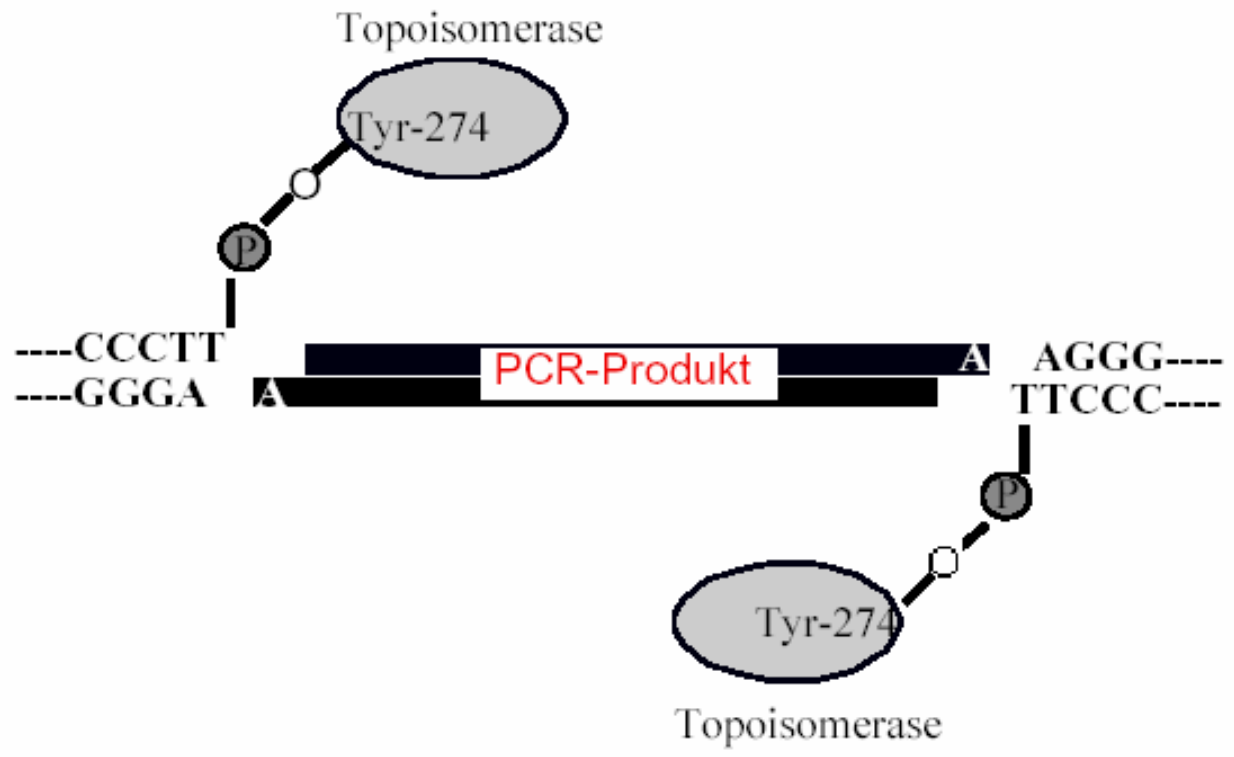

Abb. 7: Schematische Darstellung der TOPO-TA-Klonierung.

\subsubsection{Ligation mit T4-DNA-Ligase}

Zur Verknüpfung von linearisierter, dephosphorylierter Vektor- und Insert-DNA wurde T4-DNA-Ligase eingesetzt, die in Anwesenheit von ATP eine 
Phosphordiesterbindung zwischen $3^{\prime}-\mathrm{OH}$ - und $5^{\prime}-\mathrm{PO}_{4}$-Enden von Nukleinsäuren katalysiert. Die Ligationen wurden in einem Volumen von $20 \mu \mathrm{l}$ durchgeführt. Es wurden jeweils 0,2 bis $1 \mu \mathrm{g}$ Vektor- bzw. Insert-DNA eingesetzt. Der Ansatz enthielt weiterhin $1 \cup$ T4-DNA-Ligase und in 1-facher Konzentration den vom Hersteller mitgelieferten Reaktionspuffer. Die Ligationsansätze mit kohäsiven Enden wurden über Nacht bei $16{ }^{\circ} \mathrm{C}$, für 2 bis $4 \mathrm{~h}$ bei Raumtemperatur oder für $48 \mathrm{~h}$ bei $4{ }^{\circ} \mathrm{C}$ inkubiert. Zur Ligation glatter Enden wurden $2 \mathrm{U}$ Ligase eingesetzt und die Ansätze für $1 \mathrm{~h}$ bei $37{ }^{\circ} \mathrm{C}$ inkubiert.

\subsection{Dichtegradientenzentrifugation}

\subsubsection{Saccharose-Dichtegradientenzentrifugation (SAMBROOK et al., 1989; modifiziert)}

Die Größenfraktionierung von Fragmenten partiell verdauter, chromosomaler DNA, die zur Klonierung eingesetzt werden sollte, erfolgte mittels einer Saccharose-Dichtegradientenzentrifugation. Bei dieser sehr schonenden Methode werden die verschiedenen Fragmentgrößen entsprechend ihrer Schwebedichte im Saccharosegradienten getrennt. Zunächst wurde ein Saccharose-Stufengradient $(10-40 \%)$ in $10 \mathrm{ml}$-Zentrifugenröhrchen (Sorvall Polyallomer 3699, Fa. Du Pont de Nemours Deutschland $\mathrm{GmbH}$, Dreieich) hergestellt. Dazu wurden je 1,9 ml $40 \%, 32,5 \%, 25 \%, 17,5 \%$ und $10 \%$ Saccharose (jeweils w/v in $1 \mathrm{M} \mathrm{NaCl}, 20 \mathrm{mM}$ Tris-HCl, $5 \mathrm{mM}$ EDTA, pH 8,0) beginnend mit der höchsten Konzentration übereinandergeschichtet und nach jeder Stufe eingefroren. Auf den fertigen Gradienten wurde $100-200 \mu \mathrm{g}$ partiell verdaute chromosomale DNA aufgetragen. Die Zentrifugation erfolgte in einem „swing-out”-Rotor (Sorvall TH641, Fa. Du Pont de Nemours) in einer Ultrazentrifuge (Sorvall OTD 55 B, 27000 Upm, 24 h, $20{ }^{\circ} \mathrm{C}$ ). Zur Ernte des Gradienten wurden vorsichtig je $400 \mu \mathrm{l}$ von oben beginnend abgenommen. Anschließend erfolgte eine DNA-Fällung mit PEG/NaCl aus Saccharose (s. 2.7.3.2). $10 \mu$ jeder dritten Fraktion wurden durch Agarosegelelektrophorese (s. 2.9.1) auf Größe und Qualität hin überprüft. 


\subsubsection{Caesiumchlorid-Dichtegradientenzentrifugation (RADAJEWSKI et al. 2000)}

Eine weitere Methode zur Reinigung von Umwelt-DNA ist die CaesiumchloridDichtegradientenzentrifugation. Dabei wird eine Caesiumchlorid-Lösung (1 g Caesiumchlorid/ml TE-Puffer (s. 2.7.2)) mit $500 \mu l$ Umwelt-DNA versetzt, in $6 \mathrm{ml}$ Ultrazentrifugenröhrchen (Typ 6ML Polyallomer, Sorvall USA, Newtown) gefüllt und mit $150 \mu \mathrm{l}$ Ethidiumbromidlösung [10 $\mathrm{mg} / \mathrm{ml} \mathrm{H}_{2} \mathrm{O}_{\text {dest. }}$ ] versetzt. Aufgefüllt werden die Röhrchen erneut mit Caesiumchloridlösung [1 g/ml TE-Puffer] und mit dem "Crimper“, einem Spezialgerät der Firma Du Pont de Nemours Deutschland, Bad Homburg, luftblasenfrei verschlossen. Die Dichtegradientenzentrifugation erfolgte in einer Sorvall-Ultrazentrifuge OTD 75 in dem Rotor T 865.1 (Du Pont de Nemours Deutschland, Bad Homburg) für 26 h bei 42000 Upm. Nach Beendigung der Zentrifugation konnte die unter UVLicht sichtbare DNA-Bande mit einer sterilen Einwegspritze abgenommen werden, nachdem zuvor am oberen Rand des Röhrchens mittels steriler Kanüle ein Druckausgleich erfolgte. Das in der DNA-Lösung verbliebene Ethidiumbromid wurde durch achtmaliges Ausschütteln mit wassergesättigtem Butanol (1 Volumen), das Caesiumchlorid durch Dialyse (s. 2.7.3.4) gegen TEPuffer entfernt. Abschließend erfolgte eine Ethanolfällung (s. 2.7.3.1) und die Konzentration der DNA wurde ermittelt (s. 2.7.3.6).

\subsection{Polymerasekettenreaktion (PCR)}

Die Mitte der achtziger Jahre entwickelte Polymerasekettenreaktion ist ein wichtiges und nicht mehr wegzudenkendes Hilfsmittel in der DNA-Analytik geworden. Mit der PCR ist es möglich, DNA Fragmente, von denen die Sequenz zumindest teilweise bekannt ist, zu amplifizieren. Dies ermöglicht einerseits den präparativen Einsatz der PCR zur Herstellung großer DNAMengen, die kloniert, sequenziert oder als Matrize für in vitro Transkriptionen verwendet werden können, andererseits kann die PCR-Methode auch für analytische Zwecke eingesetzt werden. Ihre hohe Sensitivität erlaubt die Detektion sehr geringer DNA Mengen. 
Für die Automatisierung des Vorgangs bedient man sich hitzestabiler DNAPolymerasen. Im ersten Schritt wird die als Matrize (= Template) fungierende DNA durch Erhitzen denaturiert, woraufhin sich im folgenden Schritt die Primer spezifisch an die DNA-Einzelstränge anlagern können (= Annealing). Auf die Hybridisierung der Oligonukleotide folgt die Synthesereaktion, in der die DNAPolymerase ausgehend von den 3' OH-Enden der Primer die DNA-Stränge verlängert. Der Zyklus aus Denaturieren, Primer-Hybridisierung und DNASynthese wird 20-30 mal durchlaufen, wobei jeder neu synthetisierte Strang im folgenden Zyklus als Template dienen kann, so dass die gewünschte Sequenz theoretisch exponentiell vermehrt wird.

Im Rahmen dieser Arbeit wurde die PCR eingesetzt, um DNA-Sequenzen zu amplifizieren. Damit das Fragment über die passenden Restriktionsschnittstellen für eine nachfolgende Klonierung verfügt, wurden die Primer so synthetisiert, dass das Amplifikat nach der Reaktion einen entsprechenden Restriktionsverdau erlaubte. Als DNA-Polymerase wurde entweder eine Taq-Polymerase oder Pfu-Polymerase eingesetzt. Letztere besitzt aufgrund ihrer 3'-5'-Exonukleaseaktivität eine geringere Fehlerrate beim Baseneinbau als die Taq-Polymerase.

\section{Reaktionsansatz:}

10-50 ng Template-DNA

$0,5 \mu \mathrm{M}$ je Primer

$200 \mu \mathrm{M}$ dNTPs

$10 \mu l$ 10x Taq- bzw. Pfu-Reaktionspuffer

1 - 2,5 U der DNA-Polymerase

ad $50 \mu \mathrm{H} \mathrm{H}_{2} \mathrm{O}_{\text {dest }}$

Die Reaktion wurde in einem programmierbaren Mastercycler Gradient (Fa. Eppendorf, Hamburg) durchgeführt. 


\section{PCR-Programm:}

$5 \min 95^{\circ} \mathrm{C}$ (Denaturierung)

25-30 Zyklen: 1 min $95^{\circ} \mathrm{C}$ (Denaturierung)

30 s $50-60{ }^{\circ} \mathrm{C}$ (Primer Annealing)

45 s $72{ }^{\circ} \mathrm{C}$ (DNA-Synthese)

$10 \min 72^{\circ} \mathrm{C}$ (finale Extension)

Das PCR-Programm wurde, entsprechend der Schmelztemperatur $(\mathrm{Tm})$ von den verwendeten Primern, variiert. Dabei liegt die Annealing-Temperatur um 5 $10{ }^{\circ} \mathrm{C}$ unter der Tm der Primer.

PCR-Produkte, die für Klonierungszwecke bestimmt waren, wurden im Anschluss an eine erfolgreiche Klonierung sequenziert, um eventuelle, durch die PCR entstandene Mutationen auszuschließen.

\section{Primerdesign:}

Für optimale Amplifizierung eines Gens sollten Primer mit einer Länge von 1830 Basenpaaren gewählt werden. Der GC-Gehalt sollte sich auf 40-60 \% belaufen. Zudem sollten Dimere, Hairpins und Loops möglichst vermieden werden. Die Annealing-Temperatur sollte $5-10{ }^{\circ} \mathrm{C}$ unter der Schmelztemperatur (Tm) der Primer liegen.

Die Tm, die bei beiden Primern ähnlich sein sollte, errechnet sich nach folgender Formel:

$\mathrm{Tm}=\left[2{ }^{\circ} \mathrm{C} \times(\right.$ Anzahl $\left.\mathrm{A}+\mathrm{T})\right]+\left[4^{\circ} \mathrm{C}(\right.$ Anzahl $\left.\mathrm{G}+\mathrm{C})\right]$

Mit entsprechenden Primerdesign Programmen können schnell und sicher optimale Primerbedingungen bestimmt werden. 


\subsection{Die Prozessierung von DNA-Sequenzen mit Hilfe des STADEN- Software-Packets, ARB und DOTUR}

Das STADEN-Software-Packet beinhaltet verschiedene Programme zum Selektieren, Aufbereiten, Assemblieren und Editieren von DNA-Sequenzen (STADEN et al., 2000). Es würde den Rahmen dieser Arbeit sprengen, auf die Struktur und Funktionsweise der einzelnen Programme einzugehen. Hier soll nur ein Überblick über die Anwendung des Software-Packetes gegeben werden. Eine ausführliche Dokumentation kann unter http://www.mrcImb.cam.ac.uk/pubseq/staden_home.html abgerufen werden. Im Wesentlichen wurden zur Prozessierung der DNA-Sequenzen die Programme „Pregap4“ und „Gap4“ genutzt.

\subsection{1 „Pregap4“}

Bevor DNA-Sequenzen in das Genomassemblierungsprogramm "Gap4" eingespeist werden können, müssen diese durch diverse Prozesse geleitet werden, welche das Programm "Pregap4“ leistet (BONFIELD \& STADEN, 1996):

- Screening auf Vektor-Kontaminationen: Sequenzen, die den VektorSequenzen (pBluescriptIISK+ bzw. pCR2.1-TOPO) entsprechen, fallen aus der Datenbank heraus.

- Screening auf Kontamination mit E. coli DNA: Bei der Herstellung der Genbank kann es zu Kontaminationen mit der DNA des Wirtsstammes (E. coli DH5 $\alpha$ ) kommen. Diese Daten müssen ebenfalls entfernt werden.

- Qualitätskontrolle: Sequenzen mit einer geringen Qualität fallen aus der Datenbank heraus.

- „Vektor-Clipping“: Es werden die Basen einer Sequenz maskiert, die im Übergang zum Insert der Vektor-Sequenz entsprechen.

- Umformatierung in ein neues Dateiformat: Zur Assemblierung benötigt "Gap4“ ein anderes Dateiformat („experiment files“).

Zur Erleichterung der Prozessierung der Rohdaten wurden im Göttinger Genomanalyselabor Computerskripte entwickelt, die hier nicht näher erläutert werden sollen. Prinzipiell bewerkstelligten solche Skripte das Umbenennen von 
Dateinamen, das Einleiten der Rohsequenzen in „Pregap4“ und das Sortieren der Ausgabe von „Pregap4“ in mehrere Listen („Failed, Passed, ScreenVector“, etc.).

Bei der Prozessierung der 16S rRNA-Gensequenzen wurde aufgrund der großen Ähnlichkeiten dieser Gene auch zu denen von E. coli auf das Screening nach $E$. coli-Kontaminationen verzichtet.

\subsection{2 "Gap4“}

Gap4 ist ein Genomassemblierungsprogramm; es kann aber auch wie in diesem Projekt für kleinere DNA-Abschnitte wie Cosmide oder große Plasmide verwendet werden (BONFIELD et al., 1995). Neben der Assemblierung kann das Programm auch zur Editierung der Sequenzen benutzt werden. Gap4 ist des Weiteren unerlässlich beim sogenannten „Finishing“, dem Schließen von Sequenzlücken in einem Sequenzierungsprojekt.

Assemblierung: Mit Hilfe von Algorithmen („PHRAP“, http://bozeman.mbt. washington.edu/phrap.docs/phrap.html) werden Sequenzüberlappungen ausfindig gemacht. Sequenzläufe (,readings“), die solche Sequenzüberlappungen aufweisen, werden dann passend zueinander ausgerichtet („Alignment“) und zu zusammenhängenden DNA-Abschnitten, den sogenannten Contigs, zusammengefasst. Aus den „alignten“ Sequenzen innerhalb eines Contigs bildet das Programm dann eine Consensus-Sequenz.

„Editierung“: Ziel ist es hierbei, die Qualität der Consensus-Sequenz eines Contigs zu verbessern und Fehler in der Assemblierung zu detektieren und aufzulösen. Dabei wurden entsprechende Einzelsequenzen markiert, aus dem Contig extrahiert und dann manuell in den Datensatz zu passenden Contigs zurücktransferiert. Die Fehlerrate sollte nicht höher als 1 in 10000 Basen betragen. Dabei lässt sich die Qualität jeder einzelnen Base in der ConsensusSequenz über deren „Base Confidence“-Wert überprüfen.

„Finishing“: In „Gap4“ können zwei (oder mehrere) Contigs anhand der Lage und Orientierung der enthaltenden „readings“ zueinander geordnet werden, was eine Hilfe zur Überwindung von Sequenzlücken zwischen Contigs ist. 
Gegebenenfalls können Contigs dann semi-manuell mit Hilfe der Funktion „Join Contigs" miteinander verbunden werden.

\subsubsection{ARB}

Mit Hilfe des Programmes ARB können phylogentische Beziehungen von 16S rRNA-Gene erstellt werden. Zunächst kann in einem Editierungs-Feld ein Alignment aller 16S rRNA Gensequenzen einer Datenbank erstellt werde. Anschließend können die Daten in phylogentische Stammbäume über verschiedene Methoden integriert werden. Eine ausführliche Beschreibung des Programmes ARB kann unter www.arb-home.de abgerufen werden.

\subsubsection{DOTUR}

Mit Hilfe des Programmes DOTUR lassen sich 16S rRNA Gensequenzen eines Habitates in sogenannte OTUs umrechnen. Ein OTU entspricht dabei allen $16 \mathrm{~S}$ rRNA Gensequenzen, welche sich untereinander nicht mehr als $3 \%$ unterscheiden. Eine ausführliche Beschreibung kann unter www. plantpath.wisc.edu/fac/joh/dotur.html abgerufen werden.

\subsection{Untersuchung von 16S rRNA-Genen auf das Vorhandensein chimerer Sequenzen}

Die Sequenzen der 16S rRNA-Gene wurden mit den Programmen „CHIMERA_CHECK version 2.7“ des „Ribosomal Database Project“ (RDP; LARSEN et al., 1993) unter der Internetadresse http:rdp.cme.msu.edu/cgis/chimera.cgi und dem Programm „Bellerophon chimera detection programm“ unter der Internetadresse http:foo.math.uq.au/ huber/bellerophon.pl auf das Vorhandensein von Chimeren überprüft. Das Programm „CHIMERA_CHECK version 2.7“ überprüft, ob es einen möglichen Schnittpunkt in der zu untersuchenden Sequenz gibt, der die Sequenz in zwei Teile teilt, die jeweils zu einer anderen Sequenz aus 
der RDP-Datenbank die größte Übereinstimmung haben. Dabei macht das Programm „CHIMERA_CHECK version 2.7“ keine definitive Aussage darüber, ob eine Sequenz ein Chimer ist, so dass bei jeder Sequenz im Einzelnen auf das Vorhandensein von Artefakten entschieden werden muss. Das Programm „Bellerophon chimera detection programm“ berechnet dagegen zwei mögliche Stammbäume mit dem Anfang und dem Ende aller Sequenzen. Ergeben sich dabei unterschiedliche Verzweigungen, ist dies ein Anzeichen dafür, dass es sich bei den entsprechenden Sequenzen um Chimere handelt.

\subsection{6 Übertragung von DNA in E. coli und Selektion rekombinanter Klone}

\subsubsection{Hocheffiziente Transformation in E. coli (INOUE et al., 1990)}

Zur Herstellung hocheffizienter Transformanten wurde $E$. coli aus einer Stammkultur auf eine LB-Agar-Platte ausgestrichen und über Nacht bei $37{ }^{\circ} \mathrm{C}$ inkubiert. Aus 10 bis 12 Einzelkolonien wurde eine $5 \mathrm{ml}$ Vorkultur angeimpft. Diese diente als Inokulum für $250 \mathrm{ml}$ SOB-Medium (s. 2.3.2). Diese Kultur wurde bei $16{ }^{\circ} \mathrm{C}$ schüttelnd bis zu einer $\mathrm{OD}_{600}$ von 0,6 inkubiert. Nach einer Inkubation für $10 \mathrm{~min}$ auf Eis wurden die Zellen zentrifugiert (10 min, 2500 x g, $4{ }^{\circ} \mathrm{C}$ ), in $80 \mathrm{ml}$ eiskalter TB-Lösung suspendiert und für $10 \mathrm{~min}$ auf Eis abgekühlt. Es folgte eine Zentrifugation der Zellen (10 min, $2500 \times$ g, $4{ }^{\circ} \mathrm{C}$ ) und Suspension in $20 \mathrm{ml}$ TB-Lösung mit DMSO (Endkonzentration 7 \%, v/v). Nach einer Inkubation für 10 min auf Eis wurden Aliquots von $200 \mu$ in flüssigem $\mathrm{N}_{2}$ eingefroren und direkt zur Transformation eingesetzt oder bei $-70{ }^{\circ} \mathrm{C}$ gelagert. Zur Transformation wurden $200 \mu \mathrm{l}$ Zellsuspension auf Eis aufgetaut und nach der Zugabe von 1 bis $20 \mu$ l DNA-Lösung (ca. 10 bis $500 \mathrm{ng}$ ) für 30 min auf Eis inkubiert. Es folgte ein Hitzeschock für 1 min bei $42^{\circ} \mathrm{C}$, eine kurze Inkubation auf Eis und die Zugabe von 0,8 ml LB-Medium. Zur Ausprägung der plasmidkodierten Antibiotikaresistenz wurden die Ansätze für 60 min bei $37{ }^{\circ} \mathrm{C}$ inkubiert und anschließend die Suspension auf LB-Agarplatten mit entsprechendem Antibiotikum ausplattiert. 
TB-Lösung

$\begin{array}{lll}\text { Pipes } & 10 & \mathrm{mM} \\ \mathrm{MnCl}_{2} & 55 & \mathrm{mM} \\ \mathrm{CaCl}_{2} & 15 & \mathrm{mM} \\ \mathrm{KCl} & 250 & \mathrm{mM}\end{array}$

$\mathrm{pH} 6,7$

Das $\mathrm{MnCl}_{2}$ wurde ungelöst und separat autoklaviert.

\subsubsection{Transformation in E. coli durch Elektroporation (DOWER et al., 1988)}

Diese Methode beruht auf der Permeabilisierung der Zellmembran durch Elektroschock. Dieser verursacht einen kurzfristigen reversiblen lokalen Zusammenbruch des Membranpotentials bzw. eine Desorganisation der Membranstruktur (CHASSY et al., 1988) und erleichert damit die Aufnahme von Makromolekülen wie z. B. Plasmid-DNA in die Zelle.

Zur Herstellung elektrokompetenter Zellen wurde eine 5-ml-Übernachtkultur in $250 \mathrm{ml}$ LB-Medium (s. 2.3.1) überimpft und bei $30{ }^{\circ} \mathrm{C}$ unter Schütteln bis zu einer $\mathrm{OD}_{578}$ von 0,5 bis 1,0 inkubiert. Die Kultur wurde für 15 bis 30 min auf Eis gehalten und danach für $10 \mathrm{~min}$ bei $5000 \times \mathrm{g}$ und $4{ }^{\circ} \mathrm{C}$ zentrifugiert. Das Pellet wurde dann zweimal mit 1 Volumen $\mathrm{H}_{2} \mathrm{O}_{\text {dest. }}$ gewaschen und anschließend noch einmal mit $10 \mathrm{ml}$ Glycerin (10 \%, (v/v)). Abschließend erfolgte die Suspendierung in 0,5 ml Glycerin $(10 \%,(\mathrm{v} / \mathrm{v}))$. Aliquots der Suspension wurden bei $-70^{\circ} \mathrm{C}$ gelagert.

Pro Ansatz wurden $40 \mu \mathrm{l}$ Zellsuspension auf Eis aufgetaut, in eine sterile vorgekühlte Elektroporationsküvette (Elektrodenabstand $0,2 \mathrm{~cm}$ ) überführt und mit 1 bis $5 \mu$ dialysierter DNA-Lösung versetzt. Die Elektroporation erfolgte in einem Gene Pulser TM (Bio-Rad Laboratories GmbH, München) bei $25 \mu \mathrm{F}, 200$ $\Omega$ und 2,5 kV, wodurch eine Feldstärke von $12,5 \mathrm{kV} / \mathrm{cm}$ und eine Zeitkonstante von 3,5 bis 4,5 ms erreicht wurde. Nach dem Stromimpuls wurden die Zellen sofort in $1 \mathrm{ml}$ LB-Medium aufgenommen, $60 \mathrm{~min}$ bei $37{ }^{\circ} \mathrm{C}$ inkubiert und anschließend auf LB-Agarplatten mit den entsprechenden Antibiotika ausplattiert. 


\subsubsection{Transduktion}

Um relativ große Fagmente (30 bis $40 \mathrm{kBp}$ ) chromosomaler DNA zu klonieren, wurden Fosmide als Vektoren verwendet. Diese können dann, sofern sie ausreichend große Inserts tragen, in vitro in die Köpfe des Phagen $\lambda$ verpackt und in entsprechende E. coli-Stämme transduziert werden. In dieser Arbeit wurde das CopyControl ${ }^{\mathrm{TM}}$ Fosmid Library Production Kit von EPICENTRE ${ }^{\circledR}$ Biotechnologies verwendet.

\subsubsection{Konstruktion einer Fosmidgenbank}

Die zu klonierende chromosomale DNAwurde nicht zusätzlich geschert, da die DNA während des Präparationsvorganges schon ausreichend geschert wurde. Die Größe wurde anhand eines 0,4\%igem Agarosegels (s. 2.9.1) überprüft und die Konzentration mittels Nanodrop (s. 2.7.3.6) bestimmt. Anschließend erfolgte der „End Repair“, um die entstandenen 5'phosphorylierten DNA Enden zu glatten Enden aufzufüllen.

\section{„End Repair"-Reaktion}

$x \mu \mathrm{H} \mathrm{H}_{2} \mathrm{O}_{\text {dest }}$

$8 \mu \mathrm{l} 10 \times$ End Repair Puffer

$8 \mu \mathrm{l} 2,5 \mathrm{mM}$ dNTP Mix

8 l $10 \mathrm{mM}$ ATP

bis zu $20 \mu \mathrm{g}$ gescherte Insert DNA (ungefähr $0,5 \mu \mathrm{g} / \mu \mathrm{l}$ )

$4 \mu \mathrm{l}$ End-Repair Enzym-Mix

ad $80 \mu \mathrm{l}$

Die Reaktion wurde für 2-3 h bei RT inkubiert. Anschließend wurde der EnzymMix für 10 min bei $70^{\circ} \mathrm{C}$ inaktiviert.

Die aufgefüllte DNA wurde dann mit einer Sure-Clean-Lösung (Bioline) gefällt. Dazu wurden $80 \mu \mathrm{l}$ Bioline-Lösung zu den $80 \mu \mathrm{l}$ Reaktionsansatz gegeben und 10 min bei RT inkubiert. Im Anschluss erfolgte die Fällung für 10 min bei 
11000 Upm (Biofuge fresco, Heraeus instruments). Das Pellet wurde dann zweimal mit $70 \%$ Ethanol (v/v) gewaschen (8 min, $11000 \mathrm{rpm}$ ), getrocknet und mindestens $3 \mathrm{~h}$ in $\mathrm{H}_{2} \mathrm{O}_{\text {dest }}$ resuspendiert.

Von der DNA wurde dann mittels Nanodrop (s. 2.7.3.6) die Konzentration bestimmt und dann in eine Ligations-Reaktion eingesetzt.

\section{Ligations-Reaktion}

$x \mu \mathrm{l} \mathrm{H}_{2} \mathrm{O}_{\text {dest }}$

$1 \mu \mathrm{l} 10 \times$ Fast-Link Ligations-Puffer

$1 \mu \mathrm{l} 10 \mathrm{mM}$ ATP

$1 \mu \mathrm{l}$ CopyControl pCC1Fos Vektor

$x \mu l$ konzentrierte Insert DNA $(0,25 \mu \mathrm{g})$

$1 \mu \mathrm{l}$ Fast-Link DNA Ligase

ad $10 \mu \mathrm{l}$

Die Ligation erfolgte 2-3 $\mathrm{h}$ bei RT. Anschließend wurde die Fast-Link-Ligase bei $70{ }^{\circ} \mathrm{C}$ für 10 min hitzeinaktiviert. Der Ansatz wurde bei $-20^{\circ} \mathrm{C}$ gelagert, oder für die sofortige Weiterverarbeitung auf Eis aufbewahrt.

Nach der Ligation wurden die CopyControl Fosmid Klone mittels MaxPlax Lambda Packaging Extracts in Phagen verpackt. Als Wirtsstamm diente E. coli EPI300-T1®.

Dieser Stamm wurde als $5 \mathrm{ml}$ Vorkultur ü.N. angezogen. Am Tag der Verpackungsreaktion wurden $50 \mathrm{ml} \mathrm{LB}-$ Medium $+10 \mathrm{mM} \mathrm{MgSO}_{4}$ mit dieser Vorkultur angeimpft und bis zu einer $\mathrm{OD}_{600} \mathrm{~nm}$ von $0,8-1$ bei $37{ }^{\circ} \mathrm{C}$ und 150 Upm (Infors HT, Bottmingen, $\mathrm{CH}$ ) inkubiert.

Währenddessen wurde ein Reaktionsansatz des MaxPlax Lambda Packaging Extracts pro $10 \mu \mathrm{l}$ Ligations-Reaktion auf Eis aufgetaut. Ein halber Phagenansatz $(25 \mu \mathrm{l})$ wurde zur Ligations-Reaktion dazupipettiert, vorsichtig gemischt und die restlichen Phagen wurden sofort wieder bei $-70{ }^{\circ} \mathrm{C}$ weggefroren. Die Verpackungsreaktion wurde dann 90 min bei $30{ }^{\circ} \mathrm{C}$ inkubiert. Danach wurden die restlichen $25 \mu$ Phagenextrakt dazugeben und die Reaktion erneut für $90 \mathrm{~min}$ bei $30^{\circ} \mathrm{C}$ inkubiert. 
Nach der 3-stündigen Inkubation wurde der Ansatz auf ein Volumen von $1 \mathrm{ml}$ mit Phagen Verdünnungspuffer (Phagen Dilution Buffer) aufgefüllt und $25 \mu \mathrm{l}$ Chloroform dazupipettiert. Nach vorsichtigem Mischen wurde die Reaktion bei 4 ${ }^{\circ} \mathrm{C}$ aufbewahrt.

Im darauffolgenden Schritt wurde der Phagentiter bestimmt. Dazu wurden folgende Verdünnungen aus der $1 \mathrm{ml}$ Reaktion mit dem Phagen Dilution Buffer (PDB) hergestellt:

Tab. 6: Verdünnungen zur Bestimmung des Phagentiters

\begin{tabular}{|c|c|c|c|}
\hline Verdünnung & Volumen & Verdünnungsstufe & PDBvol \\
\hline & & $\mathrm{ml}$ & \\
\hline $1: 10^{2}$ & $10 \mu l$ & Phagenreaktion & $990 \mu \mathrm{l}$ \\
\hline $1: 10^{4}$ & $10 \mu \mathrm{l}$ & aus $1: 10^{2}$ & $990 \mu \mathrm{l}$ \\
\hline $1: 10^{5}$ & $100 \mu \mathrm{l}$ & aus $1: 10^{4}$ & $990 \mu \mathrm{l}$ \\
\hline $1: 10^{6}$ & $100 \mu \mathrm{l}$ & aus $1: 10^{5}$ & $990 \mu \mathrm{l}$ \\
\hline
\end{tabular}

Aus den einzelnen Verdünnungen wurden je $10 \mu$ l Reaktionsansatz zu je $100 \mu \mathrm{l}$ vorbereiteten $\mathrm{EPI} 300-\mathrm{T} 1^{\circledR}$ Zellen pipettiert und diese 40 min bei $37^{\circ} \mathrm{C}$ inkubiert. Danach wurden die infizierten Zellen auf $\operatorname{LB}_{\mathrm{cm}}(12,5 \mu \mathrm{g} / \mathrm{ml})$ Platten ausgestrichen und ü.N. bei $37{ }^{\circ} \mathrm{C}$ im Brutschrank (HT TR 225, Infors AG) inkubiert.

Anhand der Anzahl der Kolonien wurde nun der Phagentiter bestimmt:

(\# Kolonien) (Verdünnungsfaktor) $(1000 \mu \mathrm{l} / \mathrm{ml})$

$$
=\mathrm{cfu} / \mathrm{ml}
$$

(Vol. ausplattierter Verdünnungsstufe $[\mu l]$ )

PDB (Phage Dilution Buffer):10 mM Tris/HCl, $\mathrm{pH} 8,3$

$$
\begin{aligned}
& 100 \mathrm{mM} \mathrm{NaCl} \\
& 10 \mathrm{mM} \mathrm{MgCl}_{2}
\end{aligned}
$$




\subsubsection{Der X-Gal-Test zur Selektion rekombinanter Klone}

Bei Klonierungen ist es entscheidend, Klone, die nach Übertragung von DNA nur den Vektor enthalten, von denjenigen die ein Plasmid mit Insert tragen, zu unterscheiden. Aus diesem Grund wurde ein zusätzliches Screeningsystem neben der plasmidkodierten Antibiotikaresistenz benutzt. Plasmide der pBluescript-Reihe enthalten neben dem Promotor- und Operator-Bereich des lac-Operons auch das 5'-Ende des lacZ-Genes (VIEIRA und MESSING, 1982). Dieses kodiert für das sogenannte $\alpha$-Peptid, welches die inaktive $\beta$ Galaktosidase von Wirtsstämmen wie E. coli DH5 $\alpha$ komplementieren kann. Da sich die multiple Klonierungsstelle der verwendeten Vektoren innerhalb des aminoterminalen Bereichs des lacZ-Gens befindet, ist eine $\alpha$-Komplementation nur möglich, wenn das Plasmid kein Insert besitzt. Der Nachweis der aktiven $\beta$ Galaktosidase auf Agarplatten erfolgte durch Zugabe des Induktors IPTG (Isopropyl-ß-thiogalaktopyranosid) und des Substrats X-Gal (5-Brom-4-chlorindoyl- $\beta$-D-galaktosid), welches durch das Enzym gespalten wurde. Dabei entstand in Anwesenheit von Sauerstoff der blaue Farbstoff 5-Brom-4-chlorindigo, welcher der Indikator für rekombinante E. coli-Stämme ist, die ein Plasmid ohne Insert tragen.

\subsubsection{Screening auf lipolytische Aktivität}

Die rekombinanten Klone wurden mit Hilfe eines spezifischen Lipase-Testagars (s. 2.3.3) auf lipolytische Aktivität getestet. Der Agar enthält neben LB-Medium Tributyrin, welches den Abbau kurzkettiger Triglyceride durch Bildung eines klaren Hofes um die Kolonie detektiert.

Für das Screening wurde E. coli Top10 nach der Transformation (s. 2.16) in ensprechender Verdünnung auf die Testagarplatten ausplattiert bzw. direkt aus Mikrotiterplatten gestempelt. Die Platten wurden 2 bis 5 Tage bei $37{ }^{\circ} \mathrm{C}$ und anschließend ü. $\mathrm{N}$. bei $60{ }^{\circ} \mathrm{C}$ inkubiert, um gegebenenfalls thermostabile Lipasen zu aktivieren. 


\subsubsection{Screening auf proteolytische Aktivität}

Der Nachweis proteolytischer Aktivität bei rekombinanten E. coli Stämmen fand auf LB-Agar statt, der mit Skim-Milk (2\% w/v) versehen war. Die Skim-Milk wurde zuvor in etwas $\mathrm{H}_{2}$ Odest. gelöst, getrennt vom Medium autoklaviert und nach dem Autoklavieren zum Medium zugegeben. Proteolytische Aktivität führt zur Hydolyse der Skimmilk, welche dadurch deutlich aufklart. Für das Sreening wurden E. coli Top10-Zellen transformiert und geeignete Verdünnungen auf Skim-Milk-Agar ausplattiert bzw. direkt aus Mikrotiterplatten gestempelt. Positive Klone konnten nach 2 bis 5 Tagen Wachstum bei $37{ }^{\circ} \mathrm{C}$ mit anschließender Inkubation bei $60{ }^{\circ} \mathrm{C}$ ü. $\mathrm{N}$. durch eine deutliche Hofbildung (Aufklarung) um die Kolonie detektiert werden.

\subsubsection{Screening auf amyolytische Aktivität}

Der Nachweis amyolytischer Aktivität bei rekombinaten E. coli Stämmen fand auf LB Agar statt, der mit 0,5\% (w/v) löslicher Stärke versehen war. Nach Inkubation bei $37^{\circ} \mathrm{C}$ für 2 bis 3 Tage und einer zusätzlichen Inkubation bei 60 ${ }^{\circ} \mathrm{C}$ ü. N., erfolgte eine Anfärbung der Platten mit Lugolscher Lösung. Ein Abbau der Stärke mache sich durch einen klaren Hof um die Kolonie bemerkbar.

\subsection{Proteinbiochemische Methoden}

\subsubsection{Proteinkonzentrationsbestimmung nach Bradford}

Die Bestimmung der Proteinkonzentration erfolgte in modifizierter Form nach der Methode von BRADFORD (1976).

Es wurden $20 \mu \mathrm{l}$ einer Probe zu $1 \mathrm{ml}$ Bradford-Reagenz gegeben. Wenn nötig konnte die Probe mit $\mathrm{H}_{2} \mathrm{O}_{\text {dest }}$. verdünnt werden. Nach einer Inkubation für 10 min bei RT wurde die Absorption bei einer Wellenlänge von $580 \mathrm{~nm}$ gegen einen Leerwert gemessen. Zur Konzentrationsbestimmung wurde eine Eichgerade mit Rinderserumalbumin in einem Bereich von 0 bis $10 \mu \mathrm{g} / \mathrm{ml}$ aufgenommen. 
Bradford-Reagenz:

$\begin{array}{lll}\text { Serva Blau G-250 } & 70 & \mathrm{mg} \\ \text { Ethanol }(96 \%,(\mathrm{v} / \mathrm{v})) & 50 & \mathrm{ml} \\ \mathrm{H}_{3} \mathrm{PO}_{4}(85 \%,(\mathrm{v} / \mathrm{v})) & 100 & \mathrm{ml} \\ \mathrm{H}_{2} \mathrm{O}_{\text {dest. }} & \text { ad } 1000 & \mathrm{ml}\end{array}$

Nach vollständigem Lösen des Farbstoffs in Ethanol und Zugabe der übrigen Bestandteile erfolgte eine Filtration durch einen Faltenfilter. Das Reagenz wurde lichtgeschützt gelagert und war ca. 1 Jahr haltbar.

\subsubsection{Herstellung von Rohextrakten}

\subsubsection{Zellaufschluß mit der Frenchpress}

Für die Herstellung von Rohextrakten mit der Frenchpresse wurde von einem Kulturvolumen mit mindestens $25 \mathrm{ml}$ ausgegangen. Zunächst wurden die Zellen durch Zentrifugation (6000 Upm, $10 \mathrm{~min}, 4{ }^{\circ} \mathrm{C}$, GS3-Rotor, Sorvall RC-5BZentrifuge, Fa. Du Pont de Nemours $\mathrm{GmbH}$ ) geerntet und das Pellet in einem geeigneten Puffer aufgenommen. Die Zellsuspension wurde dann in eine vorgekühlte French-Press-Apparatur (Fa. SLM Aminco, Urbana, USA) gefüllt. Der Aufschluß der Zellen fand bei einem Druck von 140 MPa statt. Der Vorgang wurde zweimal wiederholt, wobei vor dem ersten Mal eine Spatelspitze DNase I (Fa. Boehringer, Mannheim) zugegeben wurde. Anschließend erfolgte eine Zentrifugation bei $15000 \mathrm{Upm}$ und $4{ }^{\circ} \mathrm{C}$ für 30 min (SS34-Rotor, Sorvall RC-5BZentrifuge, Fa. Du Pont de Nemours GmbH). Der erhaltene Extrakt wurde als Rohextrakt bezeichnet und konnte bis zur weiteren Verwendung bei $-20{ }^{\circ} \mathrm{C}$ gelagert werden. 


\subsubsection{Zellaufschluß durch Ultraschallbehandlung}

Zum Zellaufschluss durch Ultraschall wurden die geernteten Zellen (6000 Upm, 10 min, $4{ }^{\circ} \mathrm{C}$, GS3-Rotor, Sorvall RC-5B-Zentrifuge, Fa. Du Pont de Nemours $\mathrm{GmbH}$ ) zunächst in einem geeigneten Puffer aufgenommen. Das Gefäß mit der Zellsuspension wurde in die Halterung des Ultraschallgerätes (Ultraschallprozessor UP200S, Fa. Dr. Hielscher GmbH, Stahndorf) eingespannt. Um eine zu hohe Erwärmung der Zellsuspension zu vermeiden, wurde das Gefäß während der gesamten Prozedur durch ein Eisbad gekühlt. Es wurde viermal mit einer Amplitude von 80 Micron beschallt. Zwischen den Beschallungen wurde jeweils für eine halbe Minute pausiert. Nach der Ultraschallbehandlung wurde der Extrakt für $30 \mathrm{~min}$ bei 15000 Upm und bei 4 ${ }^{\circ} \mathrm{C}$ in einem SS34-Rotor (Sorvall RC-5B-Zentrifuge, Fa. Du Pont de Nemours $\mathrm{GmbH})$ zentrifugiert, um intakte Zellen abzutrennen. Die erhaltenen Extrakte konnten bis zur weiteren Verwendung bei $-20^{\circ} \mathrm{C}$ gelagert werden.

\subsubsection{Gewinnung der periplasmatischen Fraktion}

Die Gewinnung der periplasmatischen Fraktion erfolgte über das Kälteosmotischer- Schock Verfahren. Hierzu wurde eine ü. N. Kultur abzentrifugiert $\left(4000 \times \mathrm{g}, 20 \mathrm{~min}, 4^{\circ} \mathrm{C}\right)$. Der Überstand wurde verworfen und das Pellet in $10 \mathrm{ml}$ pro $0,1 \mathrm{~g}$ Zellen Tris-HCl (30 mM, $20 \%$ Sucrose, $\mathrm{pH}$ 8.0) resuspendiert. $\mathrm{Zu}$ dieser Zelllösung wurde EDTA in einer finalen Konzentration von $1 \mathrm{mM}$ gegeben und unter Schwenken für 10 Minuten bei RT inkubiert. Im Anschluss folgte eine Zentrifugation (8000 Upm , $4{ }^{\circ} \mathrm{C}, 10 \mathrm{~min}$ ). Der Überstand wurde abgenommen und verworfen. Das Pellet wurde danach in eiskaltem $5 \mathrm{mM}$ $\mathrm{MgSO}_{4}(10 \mathrm{ml}$ pro $0,1 \mathrm{~g}$ Zellen) aufgenommen. Es folgte eine Inkubation für 10 min unter Schütteln im Eis-Wasser-Bad. Nach einer weiteren Zentrifugation (8000 Upm , $4{ }^{\circ} \mathrm{C}, 10 \mathrm{~min}$ ) konnte der Überstand gewonnen werden, der die periplasmatische Fraktion darstellte. 


\subsubsection{Konzentrierung und Umpufferung mit dem Vivaflow 200 Komplettsystem}

Um größere Volumen (z. B. die Kulturüberstände der ProteaseExpressionskulturen) einzuengen, wurde das Vivaflow 200 Komplettsystem (Fa. Sartorius, Göttingen) komplementiert mit einer PES (Polyethersulfon)-Membran (Ausschlussgröße: 30 kDa; Fa. Sartorius, Göttingen) eingesetzt. Damit konnten einerseits innerhalb von ca. 1 bis 2 Stunden 2 I Kulturüberstand auf ca. $30 \mathrm{ml}$ eingeengt werden. Andererseits konnte das System auch zur Umpufferung der konzentrierten Proteinlösung benutzt werden. Alle Schritte wurden nach Angaben des Herstellers durchgeführt.

\subsubsection{Bestimmung von Enzymaktivitäten}

Enzymaktivitäten wurden im Bereich der linearen Abhängigkeit der Reaktionsgeschwindigkeit bestimmt und in $U$ angegeben. Ein $U$ entspricht dabei dem Umsatz von $1 \mu \mathrm{mol}$ Substrat pro Minute.

Die Volumenaktivität [U/ml] wurde nach folgender Formel berechnet:

$$
\mathrm{U} / \mathrm{ml}=\frac{\Delta \mathrm{E} / \mathrm{min} \times \mathrm{V}}{\mathrm{E} \times \mathrm{d} \times \mathrm{v}}
$$

$\Delta \mathrm{E} / \mathrm{min}=$ Extinktionsänderung pro Minute

$\mathrm{V} \quad=$ Gesamtvolumen des Testansatzes

$\varepsilon \quad=$ Extinktionskoeffizient $[\mathrm{mM}-1 \mathrm{x} \mathrm{cm}-1]$

$\mathrm{V} \quad=$ Probenvolumen

d $\quad=$ Schichtdicke der Küvette

Die spezifische Enzymaktivität [U/mg Protein] ergab sich aus der Division der Volumenaktivität [U/ml] durch die Proteinkonzentration [mg/ml] (s. 2.17.1). 


\subsubsection{Bestimmung der lipolytischen Aktivität (WINKLER und STUCKMANN et al. 1979)}

Der quantitative Nachweis der lipolytischen Aktivität wurde mit emulgiertem para-Nitrophenyl-Palmitat (pNP-Palmitat) durchgeführt. Die Esterhydrolyse wird bevorzugt durch Lipase, aber auch mit geringeren Umsatzraten durch Esterasen katalysiert. Die enzymatische Abspaltung des gelben Chromogens pNitrophenol konnte photometrisch verfolgt und quantifiziert werden.

Lösung A: $\quad \mathrm{Na}-/ \mathrm{K}-\mathrm{PO}_{4}$-Puffer

\begin{tabular}{|c|c|}
\hline (56 $\mathrm{mMNa}_{2} \mathrm{HPO}_{4} / \mathrm{KH}_{2} \mathrm{PO}_{4}, \mathrm{pH} 8$ & 90 \\
\hline Na-Desoxycholat & 200 \\
\hline Gummi Arabicum & 200 \\
\hline p-Nitrophenyl-Palmitat* & 30 \\
\hline Isopropanol & 10 \\
\hline
\end{tabular}

Unmittelbar vor Gebrauch wurden Lösung A und B gemischt und im Dunkeln aufbewahrt. Das Gemisch war ca. 2 h stabil. Pro Reaktionsansatz wurden 1,2 $\mathrm{ml}$ Substratemulsion kurz vorgewärmt und schließlich mit dem zu testenden Enzym $10 \mathrm{~min}$ bei entsprechender Temperatur inkubiert. Danch wurde die Hydrolyse durch Messung der $\mathrm{OD}_{410}$ (Extinktionkoeffizient $\varepsilon=15 \mathrm{mM}^{-1} \mathrm{~cm}^{-1}$ ) bestimmt.

\subsubsection{Bestimmung der proteolytischen Aktivität mit Azocasein als Substrat (SECADES und GUIJARRO et al. 1999)}

Für die Bestimmung proteolytischer Enzymaktivitäten wurden $120 \mu \mathrm{l}$ der zu bestimmenden Proteinlösung in Eppendorf-Cups vorgelegt und $10 \mathrm{~min}$ bei derentsprechenden Temperaturpräinkubiert. Anschließend wurden $480 \mu \mathrm{l}$ Azocaseinlösung hinzugegeben und der Testansatz $2 \mathrm{~h}$ bei $80{ }^{\circ} \mathrm{C}$ (ermitteltes Temperaturoptimum) inkubiert. Durch die Zugabe von $600 \mu$ l Trichloressigsäure (10 \% w/v) wurde die Reaktion gestoppt. Nach 20 min Inkubation bei Raumtemperatur wurde der Ansatz für 10 min bei 13000 Upm zentrifugiert. 
$800 \mu \mathrm{l}$ des Überstandes wurden mit $200 \mu \mathrm{l} \mathrm{NaOH}(1,8 \mathrm{M})$ versetzt und die Absorption in einer Küvette bei $420 \mathrm{~nm}$ gemessen. Eine Enzymaktivität von $1 \mathrm{U}$ wurde definiert als eine Absorptionsänderung von 0,0025 in $2 \mathrm{~h}$.

Azocaseinlösung: 1 \% (w/v) Azocasein in 50 mM Phosphatpuffer ( $\mathrm{pH} 7$ )

\subsubsection{Methoden zur Proteinanreicherung}

\subsubsection{Reinigung löslicher Proteine mit Protino ${ }^{8}$ Ni-Säulen (Fa. Macherey-Nagel, Düren)}

Das Prinzip der Proteinaufreinigung mit Hilfe dieser Säulen entspricht dem der Metall-Chelat-Affinitätschromatographie. Das hier eingesetzte Trägermaterial sind Silica-Kügelchen, die als Chelatgruppe TED (Triscarboxymethylethylendiamin) binden. TED bindet 5 der 6 Koordinationsstellen des Nickels, so dass nur noch eine für das rekombinante Protein zur Verfügung steht. Damit soll sowohl ein Auswaschen des Metalls verhindert als auch eine spezifischere Bindung des aufzureinigenden Proteins verbessert werden. Im Gegensatz zu auf Agarose-basierendem Trägermaterial soll durch weniger Seitenketten unspezifischen Bindungen entgegengewirkt werden. Die Aufreinigung erfolgte nach Herstellerangaben.

\subsubsection{Proteinreinigung über FPLC}

Bei einer säulenchromatographischen Proteinreinigung mittels FPLC (Fast Protein Liquid Chromatography) wird das zu trennende Substanzgemisch in Lösung (mobile Phase) über eine Säule aus einer festen, porösen Matrix (stationäre Phase) geschickt. Die Wechselwirkungen der gelösten Bestandteile mit der stationären Phase verzögern die Wanderungsgeschwindigkeit durch die Matrix in substanzspezifischer Weise. Auf diesem Wege wird im Idealfall z.B. der hitzegefällte Rohextrakt in separate Fraktionen reiner Proteine aufgetrennt. 
Durchführung:

Alle Puffer und Proben wurden vor dem Auftragen filtriert, um eine Verunreinigung des Säulenmaterials mit Staubpartikeln zu vermeiden. Die Filtration der Proben erfolgte durch Einweg-Sterilfilter (Minisart 0,2 $\mu \mathrm{m}$, Sartorius). Die Puffer wurden mit $\mathrm{H}_{2} \mathrm{O}_{\text {dest. }}$. hergestellt und anschließend mit einer Vakuumpumpe (Savant) durch Cellulosenitrat-Filter $(0,45 \mu \mathrm{m}$, Schleicher \& Schuell, Dassel) filtriert. Um das Eindringen von Luftblasen in das Säulenmaterial zu verhindern, wurden alle Anschlüsse drop to drop verbunden. Die Säulen werden in 20 \%igem (v/v) Ethanol gelagert. Direkte Umpufferung der Säulen von Ethanol zu einem salzhaltigen Puffer oder umgekehrt sollte durch Spülen mit MilliQ-Wasser vermieden werden.

Die verwendete ÄKTA-FPLC-Anlage besteht aus folgenden Komponenten (alle Amersham Biosciences, Freiburg):

Geräte: Monitor UPC-900

Pumpe P-920

In-line Mixer M-925

Motor Valve INV-907

Fraction Collector Frac-900

$10 \mathrm{ml}$ und $50 \mathrm{ml}$ Superloop, $1 \mathrm{ml}$ und $250 \mu \mathrm{l}$ Probenschleifen

Säulen: His-Trap

\subsubsection{SDS-Polyacrylamid-Gelelektrophorese (SDS-PAGE)}

Bei der SDS-Gelelektrophorese wandert der SDS-Protein-Komplex im elektrischen Feld zur Anode. Die meisten Proteine binden SDS zu negativ geladenen SDS-Protein-Komplexen mit konstantem Ladungs- zu MasseVerhältnis (1,4 g SDS/g Protein in $1 \%$ SDS-Lösungen). Durch SDS und vorherige Reduktion mit ß-Mercaptoethanol werden die Proteine denaturiert und 
Protein-Protein-Wechselwirkungen aufgelöst. Die SDS-Protein-Komplexe verschiedener Proteine unterscheiden sich damit nur noch in ihrer Größe und haben vergleichbare hydrodynamische Eigenschaften. Der Molekularsiebeffekt einer porösen Polyacrylamidmatrix trennt so die SDS-Protein-Komplexe nach ihrem Stokes-Radius und damit nach ihrem Molekulargewicht (MG) auf. Im Rahmen dieser Arbeit wurde das diskontinuierliche Laemmli-System mit TrisGlycin-Puffern verwendet, bei dem ein Trenngel von einem Sammelgel überschichtet wird (LAEMMLI, 1970). Je nach Proteingröße wurde die Porengröße des Trenngels variiert. Für Proteine mit einem MG von 10-60 kDa wurden 15 \%ige Trenngele, für Proteine vom MG 30-120 KDa 10 \%ige Gele und für Proteine mit einem MG 50 - 200 kDa 8 \%ige Gele verwendet.

In der folgenden Tabelle ist das Pipettierschema eines $10 \%$ igen SDS-Gels dargestellt.

$\begin{array}{lll}\text { Lösung } & 10 \% \text { Trenngel } & 3 \% \text { Sammelgel } \\ \text { AA }(40 \%(w / v)) & 1 \mathrm{ml} & 0,2 \mathrm{ml} \\ \text { Trenngel } & 1 \mathrm{ml} & - \\ \text { Sammelgel } & - & 0,48 \mathrm{ml} \\ \text { APS } & 30 \mu \mathrm{l} & 15 \mu \mathrm{l} \\ \text { TEMED } & 3 \mu \mathrm{l} & 2 \mu \mathrm{l} \\ \mathrm{H}_{2} \mathrm{O}_{\text {Bidest }} & 2 \mathrm{ml} & 1,32 \mathrm{ml}\end{array}$

Die zu analysierenden Proben wurden mit 4 x SDS-Probenpuffer versetzt und durch 10-minütiges Erhitzen bei $95^{\circ} \mathrm{C}$ denaturiert. Die Elektrophorese wurde in einer mit 1 x SDS-Laufpuffer gefüllten Mini-Elektrophorese-Kammer von BioRad (Protean ${ }^{\circledR}$ Mini cell) durchgeführt. Zum Sammeln der Proben wurde für $10 \mathrm{~min}$ eine Stromstärke von 15 mA pro Gel angelegt (Power Pac 300, BioRAD). Anschließend wurden die Proben für 40 min bei $30 \mathrm{~mA}$ pro Gel aufgetrennt.

Die Bestimmung von Proteingrößen erfolgte im Vergleich zur Laufstrecke eines im gleichen Gel aufgetrennten Standards. 
Tab. 7: Protein Molecular Weight Marker (Fa. MBI Fermentas)

\begin{tabular}{llr}
\hline Protein & Herkunft & kDa \\
\hline B-Galaktosidase & E. coli & 116 \\
BSA & Rinderserum & 66 \\
Ovalbumin & Hühnereiweiß & 45 \\
Laktat-Dehydrogenase & Schweinemuskel & 35 \\
RE Bsp981 & E. coli & 25 \\
ß-Laktoglobulin & Kuhmilch & 18 \\
Lysozym & Hühnereiweiß & 14 \\
\hline
\end{tabular}

Acrylamid-Stammlösung: Acrylamid/Bisacrylamid-Lösung (24:1)

\begin{tabular}{|c|c|}
\hline & $40 \%(w / v)(A A)$ \\
\hline \multirow[t]{3}{*}{ Sammelgelpuffer: } & 0,5 M Tris/HC \\
\hline & $0,4 \%$ SDS \\
\hline & $\mathrm{pH} 6,8$ \\
\hline \multirow[t]{3}{*}{ Trenngelpuffer } & 1,5 M Tris/HCl \\
\hline & $0,4 \%$ SDS \\
\hline & $\mathrm{pH} 8,8$ \\
\hline \multirow[t]{3}{*}{$10 \times$ SDS-Laufpuffer } & $144,1 \mathrm{~g}$ Glycin \\
\hline & $30,4 \mathrm{~g}$ Tris \\
\hline & ad 1 Liter $\mathrm{H}_{2} \mathrm{O}_{\text {dest }}$ \\
\hline \multirow[t]{5}{*}{$4 \times$ SDS-Probenpuffer } & $20 \mathrm{mM}$ Tris/HCl pH 6,8 \\
\hline & $1,2 \mathrm{~g} \mathrm{SDS}$ \\
\hline & 7,5 ml Glycerol (87 \%) \\
\hline & 0,001 \% Bromphenolblau \\
\hline & erst vor Gebrauch: $10 \%$ ß-ME \\
\hline APS & $10 \%$ APS (w/v) in $\mathrm{H}_{2} \mathrm{O}_{\text {dest }}$ \\
\hline
\end{tabular}




\subsubsection{Coomassie-Färbung}

Nach Beendigung der Elektrophorese wurden die Gele kurz mit $\mathrm{H}_{2} \mathrm{O}_{\text {dest. }}$ gespült und dann für $60 \mathrm{~min}$ in die Coomassie-Färbelösung gelegt. Nach Spülen mit $\mathrm{H}_{2} \mathrm{O}_{\text {dest }}$. wurde das $\mathrm{Gel}$ entfärbt, wobei die Entfärbelösung mehrfach gewechselt wurde. Bei guter Transparenz des Hintergrundes konnten die Gele ausgewertet werden und in Fixierlösung aufbewahrt werden.

Coomassie-Färbelösung:

Entfärbelösung:

Coomassie-Blau G-250

$0,08 \% \quad(v / v) \quad$ Methanol

$33 \% \quad(\mathrm{v} / \mathrm{v})$

Coomassie-Blau R-250 $0,08 \%$

(v/v) Eisessig $10 \% \quad(\mathrm{v} / \mathrm{v})$

Methanol $45 \%$ $(\mathrm{v} / \mathrm{v})$

Fixierlösung:

Eisessig $10 \%$

$(\mathrm{v} / \mathrm{v})$ Eisessig

$10 \% \quad(v / v)$

\subsubsection{Aktivitätsfärbung der Lipase (SOMMER et al., 1997)}

Der Nachweis der Lipase erfolgte nach Auftrennung im SDS-Polyacrylamidgel. Das Testsystem beruht aud der Umsetzung des in den LipaseaktivitätsTestagar emulgierten Triglycerids (Tributyrin bzw Tricaprylin) zu Glycerin und freien Fettsäuren. Die Substrathydrolyse führt zur Aufklarung des weißlichen Testagars.

Nach der SDS-PAGE (s.2.17.6) wurde das SDS-Polyacrylamidgel $20 \mathrm{~min}$ in $20 \%$ igen (v/v) Isopropanol und zweimal 10 min in $\mathrm{H}_{2} \mathrm{O}_{\text {dest }}$ gewaschen. Anschließend wurde es auf dem Lipaseaktivitäts-Testagar für $16 \mathrm{~h}$ bei entsprechender Temperatur (RT bis $55^{\circ} \mathrm{C}$ ) inkubiert.

Lipaseaktivitäts-Testagar:

$\begin{array}{lll}\text { Tris } & 20 & \mathrm{mM} \\ \mathrm{CaCl}_{2} & 5 & \mathrm{mM} \\ \text { Triglycerid } & 1 & \%(\mathrm{v} / \mathrm{v}) \\ \text { Agar } & 1,3 & \%(\mathrm{v} / \mathrm{v}) \\ \mathrm{pH} & 8,0 & \end{array}$




\subsubsection{Nachweis proteolytischer Aktivität nach SDS-PAGE}

Für den Nachweis proteolytischer Aktivität auf einem SDS-Gel wurde zunächst ein 12 \%iges SDS-Gel hergestellt. Die Zusammensetzung von Trenn- und Sammelgel erfolgte laut 2.17.6 mit der Ausnahme, dass beim Trenngel $1 \mathrm{ml}$ $\mathrm{H}_{2} \mathrm{O}_{\text {dest }}$ durch $1 \mathrm{ml} \mathrm{0,65 \% (w/v)} \mathrm{Casein-Lösung} \mathrm{ersetzt} \mathrm{wurden.} \mathrm{Nach} \mathrm{der}$ Elektrophorese wurde das Gel für $30 \mathrm{~min}$ bei RT in Phosphatpuffer ( $50 \mathrm{mM}$, $\mathrm{pH} 7$ ) geschwenkt, um die Renaturierung der Proteine zu gewährleisten. Anschließend wurde das Gel mit auf $50^{\circ} \mathrm{C}$ vorgewärmten Phosphatpuffer (50 $\mathrm{mM}, \mathrm{pH}$ 7) versetzt und eine Stunde bei $50{ }^{\circ} \mathrm{C}$ inkubiert. Anschließend wurde das Gel mit Coomassie angefärbt.

Casein-Lösung: 0,65 \% (w/v) Casein in $50 \mathrm{mM}$ Phosphatpuffer $(\mathrm{pH} 7)$

\subsubsection{Western Blotting (TOWBIN et al., 1979, modifiziert)}

Die Methode des elektrophoretischen Proteintransfers auf Blot-Membranen (TOWBIN et al., 1979) wurde für den spezifischen Nachweis von Proteinen mit His $_{6}$-Tag bzw. V5-Epitop angewandt. Der Western-Blot wurde in einer Mini-BlotApparatur („Mini Trans-Blot $\circledast$ Electrophoretic Transfer Cell“, Fa. Bio-Rad Laboratories $\mathrm{GmbH}$, München) durchgeführt. Nach der SDS-PAGE wurde das Gel sowie auf Gelgröße zugeschnittene zwei Lagen Whatman Papier (Whatman $3 \mathrm{MM}$, Schleicher und Schuell GmbH, Dassel) und die NitrocelluloseMembran (Hybond ECL Nitrocellulose Membrane; Fa. Amersham Biosciences, Freiburg) zusammen mit den beiden Glasfiberpads $10 \mathrm{~min}$ in gekühltem Transfer-Puffer getränkt. Anschließend wurde der Blot luftblasenfrei in der Gelhalterungskassette auf der Anodenseite aufgebaut und durch Andrücken der Kathodenseite auf die Anodenseite fest verschlossen. 


Anode $(+)$
\[ \begin{array}{l}\text { Glasfiberpad } \\ 1 \text { Lage Whatman } \\ \text { Blot-Membran } \\ \text { SDS-Polyacrylamidgel } \\ 1 \text { Lage Whatman } \\ \text { Glasfiberpad }\end{array} \]

Kathode (-)

Transferpuffer:

Tris $25 \quad \mathrm{mM}$

Glycin $192 \quad \mathrm{mM}$

Methanol $200 \quad \mathrm{ml}$

$\mathrm{H}_{2} \mathrm{O}_{\text {dest }}$ Ad $1000 \mathrm{ml}$

$\mathrm{pH} 8,1$ bis 8,4

Der $\mathrm{pH}-$ Wert des Transfer-Puffers durfte nicht mit Säure oder Base eingestellt werden; lag der pH-Wert außerhalb dieses Bereichs, wurde der Puffer neu angesetzt. Bei der vor dem Western-Blot durchgeführten SDS-PAGE wurde ein sogenannter „Prestained Marker“ (peqGOLD prestained Protein Marker; Fa. PeqLab, Erlangen) verwendet. Anhand dieser bereits gefärbten Banden konnte der Proteintransfer überprüft werden. Dadurch entfiel ein Färbeschritt mit Ponceau S. Die Membran konnte direkt nach dem Western-Blot der gewünschten Färbung unterzogen werden. Als Alternative zur Benutzung von Nitrocellulose-Membranen wurden auch hydrophobe PolyvinylidendifluoridMembranen (PVDF-Membranen, Fa. Amersham Biosciences, Freiburg) eingesetzt. Dabei musste darauf geachtet werden, dass diese zunächst in Methanol voräquilibriert wurden. 


\subsubsection{Immunodetektion von Proteinen auf Blot-Membranen}

Geblottete Antigene bieten die Möglichkeit, sie mit Konjugaten oder Antikörpern anfärben zu lassen. Bei der Verwendung von Antikörpern hängt die Spezifität der Immunfärbung von der Spezifität des primären und sekundären Antikörpers und deren eingesetzten Konzentrationen ab. In dieser Arbeit wurde die Immunodetektion eingesetzt, um mit carboxyterminalen $\mathrm{His}_{6}-$ bzw. V5-Epitopen versehene Fusionsproteine nachzuweisen. Folgende primären- und sekundären Antikörper kamen dabei zum Einsatz.

\section{Antikörper:}

Anti-V5-Ap Antikörper (Fa. Invitrogen, Carlsbad, USA); monoklonaler, mit alkalischer Phospatase konjugierter Antikörper aus Maus gerichtet gegen das V5-Epitop aus Paramyxovirus, Verdünnung: 1:2000 in TBS-T Puffer.

\section{Durchführung:}

Alle Inkubationen erfolgten, wenn nicht anders beschrieben, beiRaumtemperatur auf einem Schüttler. Nach dem elektrophoretischen Transferder Proteine von dem SDS-Polyacrylamidgel auf die NC-Membran wurde diese zur Absättigung unspezifischer Bindungsstellen 60 min in der Blocklösung inkubiert und anschließend dreimal für je $10 \mathrm{~min}$ in TBS-T gewaschen. Zum spezifischen Nachweis von Proteinen wurde die Membran für 2 Stunde mit dem Anti-V5-Alkalische-Phosphatase Konjugat inkubiert und anschließend dreimal für je 15 min mit TBS-T gewaschen.

\section{Detektion:}

Für die Immunodetektion der mit alkalischer Phosphatase gekoppelten Antikörper wurde das BCIP/NBT Color Development Substrat (Fa. Promega, Mannheim) eingesetzt. Die Substratfärbung wurde nach Angaben des Herstellers durchgeführt. 


\begin{tabular}{lcclll} 
TBS-Puffer (10X) & \multicolumn{5}{c}{ TBS-T Puffer (10x) } \\
Tris- $\mathrm{HCl}$ & 0,1 & $\mathrm{M}$ & Tris- $\mathrm{HCl}$ & 0,1 & $\mathrm{M}$ \\
$\mathrm{NaCl}$ & 1,4 & $\mathrm{M}$ & $\mathrm{NaCl}$ & 1,4 & $\mathrm{M}$ \\
$\mathrm{pH} 7,4$ & & & Tween 20 & 0,1 & $\%(\mathrm{w} / \mathrm{v})$ \\
& & & $\mathrm{pH} \mathrm{7,4}$ & &
\end{tabular}

Blocklösung: $\quad 5 \%$ in TBS-T Puffer (1X)

\subsection{Chemikalien, Enzyme und Gase}

Es wurden Chemikalien des handelsüblichen Reinheitsgrades der Firmen Boehringer (Mannheim), Fluka (Buchs, Schweiz), Merck (Darmstadt), Riedel de Haen (Hannover), Serva (Heidelberg) und Sigma (Taufkirchen) verwendet. Des Weiteren wurde mit Biochemikalien, Enzymen etc. folgender Firmen gearbeitet:

Amersham Pharmacia, Freiburg:

Nylonmembranen, HMW Calibration-Kit, PD10-Säulen

Bio-Rad Laboratories, München:

Prestained SDS-PAGE Standard Low Range

Biozym GmbH, Hess. Oldendorf:

Elektroporationsküvetten

Dr. Rieks $\mathrm{GmbH}$, Uetersen:

L-Erythrulose

Eppendorf, Wesseling-Berzdorf:

Elektroporationsküvetten

Eurogentec, Seraing, Belgien:

Agarose

Gerbu Biotechnik GmbH, Gaiberg:

IPTG, X-Gal, Ampicillin, Proteinase $\mathrm{K}$

Invitrogen, Carlsbad, CA, USA:

pET Directional TOPO Expression Kit, TOPO TA Cloning Kit

Macherey-Nagel, Düren: 
Nucleo Spin Plasmid, Protino ${ }^{\circledR} \mathrm{Ni}-$ Säulen

MBI Fermentas $\mathrm{GmbH}$, St. Leon-Rot:

Taq-DNA-Polymerase, Pfu-DNA-Polymerase T4-DNA-Ligase, Ladder-Mix, Nukleotide, Restriktionsendonukleasen

Messer Griesheim GmbH, Kassel:

Stickstoff

Metabion, Martiensried:

Oligonukleotide

Millipore, Eschborn:

Mikrodialyse-Filter

New-England Biolabs $\mathrm{GmbH}$, Freiburg:

Restriktionsendonukleasen

Novagen, Darmstadt:

KOD Hifi DNA Polymerase

PeqLab Biotechnologie $\mathrm{GmbH}$, Erlangen:

peqGold Protein-Marker, peqGold Protein-Marker IV (Prestained)

Promega, Deutschland $\mathrm{GmbH}$, Mannheim:

WizardTM Plus Minipreps DNA Purificaton System, Pfu-DNA-Polymerase, APSystem

Qiagen $\mathrm{GmbH}$, Hilden:

Plasmid Midi-Kit, QIAprep Spin Miniprep Kit, Qiaquick PCR-Purification-Kit;

Qiaquick Gel Extraction Kit, RNA/DNA Maxi Kit

Sartorius AG, Göttingen:

Sterilfilter

Sigma Chemie $\mathrm{GmbH}$, Deisenhofen:

D-Erythrose, Erythrit, Glycerin-3-Phosphat-Dehydrogenase

Stratagene, USA:

Gigapack® III Gold Packaging Extract

Whatman, Maidstone, England:

Whatman-Filterpapier3MM 


\section{Experimente und Ergebnisse}

Der Bedarf an neuartigen biotechnologisch relevanten Biokatalysatoren ist in den letzten Jahren verstärkt angestiegen. Dabei wurden zunächst traditionelle Methoden, wie die zielgerichtete Anreicherung und Isolierung von Mikroorganismen mit anschließender Identifizierung der Zielgene, verwendet. Da aber weniger als $1 \%$ der Mikroorganismen der Erde mit Laborstandardtechniken kultivierbar sind (AMMAN et al. 1995), rückte bald der Begriff Metagenom in den Vordergrund. Durch direktes Klonieren von DNA aus Umweltproben steht dabei ein weitaus größerer Pool an genetischem Material zur Erforschung neuartiger Biokatalysatoren und Wirkstoffen zur Verfügung. Durch den Einsatz der Metagenomforschung konnte bereits eine Reihe neuartiger biotechnologische relevanter Enzyme und Wirkstoffe, wie z.B. Lipasen/Esterase (LEE et al 2004, HENNE et al. 2000), Amylasen (YUN et al. 2004), Cellulasen (VOGET et al. 2005), Oxidoreduktasen (Knietsch et al. 2003 a/b), Proteasen (GUPTA et al. 2002) oder Antibiotika (BRADY et al. 2000) entdeckt werden. Ein limitierender Faktor bei der Untersuchung von Metagenomen stellt aber die Methode der DNA-Isolierung aus Umweltproben dar (Daniel 2005). Bei der Konservierung der mikrobiellen Diversität während der DNA-Isolierung und der Klonierung spielen Faktoren, wie z. B. das Auftreten von Scherkräften oder die Sauberkeit der DNA, eine entscheidende Rolle.

Ziel dieser Arbeit war es durch den Einsatz verschiedener DNA-IsolierungsMethoden die mikrobielle Diversität verschiedener Habitate der KamtschatkaRegion zu erschließen und mittels 16S rRNA-Genalysen zu untersuchen. Des Weiteren sollte, durch Konstruktion und Screening von Metagenombanken neuartige Enzyme isoliert und anschließend charakterisiert werden. Abb. 8 gibt einen Überblick über die im Rahmen dieser Arbeit durchgeführten Schritte. 

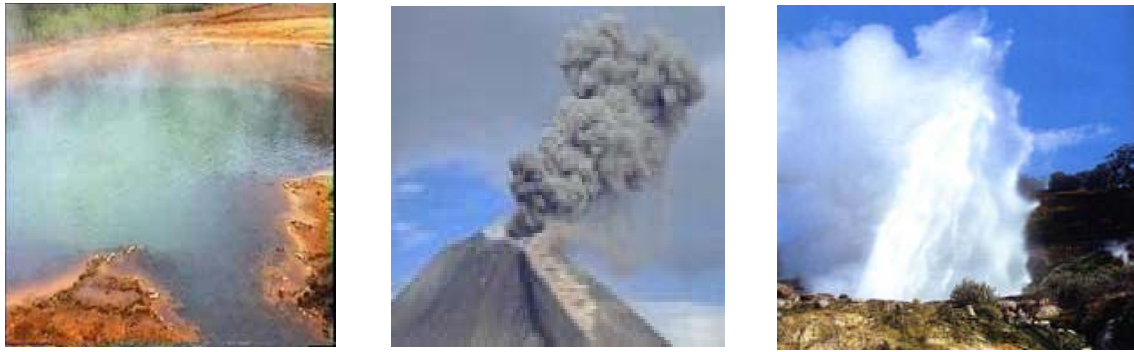

Mikrobielle Lebensgemeinschaft: Heiße Quellen, Geysire, Vulkane

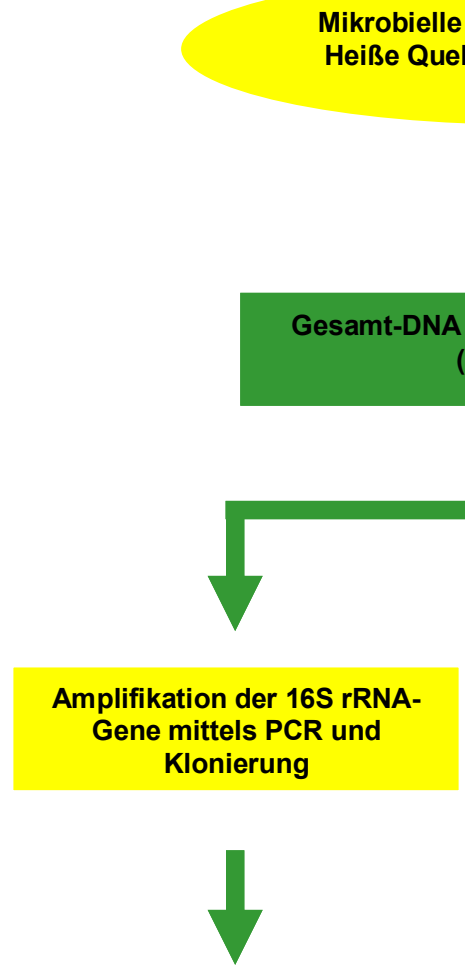

DNA-Isolierung

Sequenzierung und Konstruktion

Screening nach biotechnologisch interessanten phylogenetischer Stammbäume

Abb. 8: Schematische Darstellung der im Rahmen dieser Arbeit durchgeführten Schritte. (Quelle: http://www.Kamtschatkapeninsula.com)

\subsection{Isolierung von DNA aus verschiedenen Standorten}

Für 16S rRNA-Genanalysen und zur Konstruktion von Metagenombanken wurden zwei Habitate der Kamtschatka-Region ausgewählt. Es handelt sich dabei um Sedimentproben einer heißen Quelle in der Region Dachnie sowie um Bodenmaterial aus der Kraterregion bei Avachinsky. Bei der Entnahme wurden die Temperatur und der pH-Wert der Probe bestimmt (s. Tab. 8). 
Tab. 8: Umweltparameter der untersuchten Habitate

\begin{tabular}{lllll}
\hline Standort & Probenbezeichnung & Art der Probe & $\mathrm{pH}$ & $\begin{array}{l}\text { Temperatur } \\
{\left[{ }^{\circ} \mathrm{C}\right]}\end{array}$ \\
\hline Avachinsky & Avachinsky & $\begin{array}{l}\text { Bodenprobe } \\
\text { Kraterregion }\end{array}$ & $9-9,3$ & 67 \\
Dachnie & Dachnie & $\begin{array}{l}\text { Sediment } \\
\text { heiße Quelle }\end{array}$ & $2-3$ & 60 \\
& & &
\end{tabular}

Es handelt sich bei beiden Standorten um thermophile Habitate, welche den größten Unterschied in ihrem pH-Wert zeigen. Bei Dachnie handelt es sich um einen thermoacidophilen Standort, bei Avachinsky um einen thermoalkaliphilen. Für die Untersuchung der mikrobiellen Diversität anhand der 165 rRNAGensequenzen und die Konstruktion von Metagenombanken aus thermophilen Proben der Kamtschatka-Region musste zunächst die chromosomalen DNA aus den Habitaten isoliert werden. Dazu war es notwendig, verschiedene Methoden auszuprobieren, um die Ausbeute an DNA so groß wie möglich zu halten und gleichzeitig den Anteil an mitisolierten Matrixbestandteilen, wie z. B. Huminsäuren (TEBBE et al. 1993, MOREIRA 1998), welche enzymatische Reaktionen behindern, so klein wie möglich zu halten. Ein weiteres Problem bestand darin, chromosomale DNA aus für diese Standorte charakteristischen Archaeen zu isolieren, da diese sich durch ihre äußerst stabile Zellwand auszeichnen und nicht jede Methode zum Aufbrechen dieser Strukturen geeignet ist. Folgende Methoden wurden getestet:

1. Die Methode der direkten Lyse der Zellen (ZHOU et al. 1996)

2. Die "freeze-thaw" Methode (BARNS et al. 1994)

3. "Bead-beating" (YEATES et al. 1998)

4. Nykodenz-Dichtegradienten-Zentrifugation zum Abtrennen der mikrobiellen Fraktion von der Matrix (LINDAHL et al. 1994)

Um eine hohe Ausbeute an DNA zu bekommen und somit die mikrobielle Diversität der Habitate weitestgehend zu erhalten wurde die Methode der direkten Lyse nach Zhou et al. (1996) in Kombination mit "Bead-Beating" angewendet. Das Auftreten von höheren Scherkräften und somit eine geringere Ausbeute an hochmolekularer DNA bei der Methode des Bead-Beatings wurde 
zu Gunsten des Erhalts der mikrobiellen Diversität in Kauf genommen. Bei der Methode der direkten Lyse der Zellen von Zhou et al. (1996) gelang der Zellaufschluß durch eine ausgedehnte Hitzeinkubation in Gegenwart eines Hochsalzextraktionspuffers, SDS, CTAB, EDTA und Proteinase K. Der Zellaufschluß wurde gesteigert durch „Bead-Beating“ für 30 s (s. 2.8.2). Nach Abtrennung der Zell- und Substratbestandteile durch Zentrifugation wurde die DNA mit Chloroform/Isoamylalkohol extrahiert und schließlich mit Isopropanol gefällt. Falls nötig, wurde die DNA über Nacht gegen TE-Puffer (s. 2.7.3.4) dialysiert, um gegebenenfalls auskristallisierte Salze zu entfernen. Anschließend wurde die DNA erneut gefällt (s. 2.7.3.1). Koextrahierte Matrixbestandteile wie Huminsäuren mussten entfernt werden, da sie Enzymaktivitäten hemmen können und somit eine anschließende Klonierung der DNA erschweren. Mittels Caesiumchlorid-EthidiumbromidDichtegradientenzentrifugation wurden diese Bestandteile entfernt (s. 2.12.2). In Abb. 9 sind die Reinigungsschritte der metagenomischen DNA am Beispiel des Standortes Avachinsky dargestellt. Die metagenomische DNA des Standortes Dachnie wurde in gleicher Weise isoliert und gereinigt.
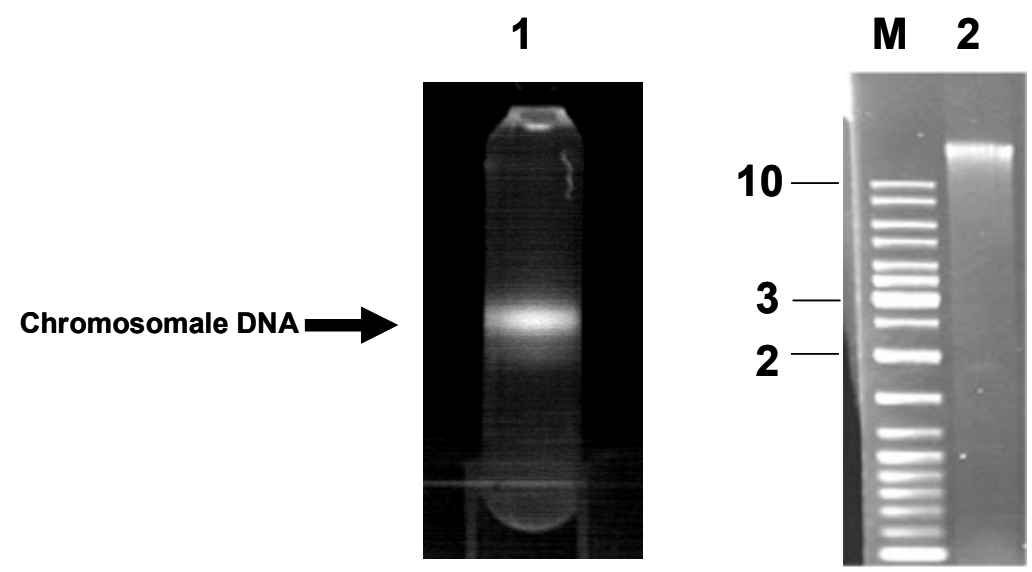

Abb. 9: DNA-Isolierung und Reinigungsschritte der metagenomischen DNA des Standortes Avachinsky. 1: metagenomische DNA nach CsCl-Zentrifugation (2.12.2). 2: gereinigte metagenomische DNA (2.12.2). M: Längenstandard 


\subsection{Untersuchung der phylogenetischen Diversität mittels 16S rRNA- Genanalysen}

Die Untersuchung der mikrobiellen phylogenetischen Diversität des Standortes Avachinsky erfolgte durch partielle oder gesamte Amplifikation der 16S rRNAGene mittels PCR (s. 2.13). Es folgte eine Klonierung der Fragmente über TOPO-TA-Klonierung (s. 2.11.3) und anschließender Sequenzierung. Als Template diente die wie unter 3.1 isolierte DNA. In den PCRs wurden Oligonukleotidpaare, welche gegen die $16 \mathrm{~S}$ rRNA-Gene von Bakterien und Archaeen gerichtet sind, eingesetzt. Die verschiedenen Kombinationen sind in Tab. 4 wiedergegeben. Die erhaltenen PCR-Produkte wurden durch Agarosegelelektrophorese auf die entsprechende Größe hin analysiert und anschließend gereinigt (s. 2.9.1, 2.7.3.8). Es folgte eine Klonierung der PCRProdukte in den Vektor pCR2.1-TOPO. Diese Ansätze wurden schließlich in $E$. coli TOP10 Zellen transformiert und auf LB-Ampicillin Platten mit X-Gal und IPTG ausplattiert (s. 2.3.1). Die inserttragenden (weißen) Kolonien wurden in Mikrotiterplatten konserviert. Die Sequenzierung der Plasmid-Inserts erfolgte durch das "Göttingen Genomics Laboratory“. Des Weiteren wurden 16S rDNAGenbanken durch die Firma Qiagen (Hilden) angelegt und sequenziert. Die Prozessierung der Rohsequenzen erfolgte durch das STADEN-SoftwarePacket. Mit dem Programm „Pregap4“ wurden die Rohsequenzen vorbearbeitet, während die eigentliche Bearbeitung erfolgte im Programm "Gap4" (s. 2.14). Die bearbeiteten Sequenzdaten wurden nun auf das vorhanden sein von so genannte Chimeren hin untersucht. Es handelt sich dabei um Artefakte die bei der PCR entstehen können. Dabei kann es durch unvollständige Elongation oder durch den Einsatz an zu kleiner Template DNA zur Entstehung von PCR Produkten kommen, die sich aus der 16S rDNA zweier verschiedener Mikroorganismen zusammensetzt (LIESACK et al 1991, WANG und WANG 1996). Putative chimere Sequenzen wurden wie unter 2.15 beschrieben ermittelt und entfernt. Die so bearbeiteten Sequenzdaten wurden anschließend zur weiteren Analyse und zur Konstruktion von phylogentischen Stammbäumen in das Programm „ARB“ eingespeist. Bei dem Programm handelt es sich um ein Sequenzanalyse-Programm zur Erstellung phylogenetischer Stammbäume (s. 2.14.3) 


\subsubsection{Konstruktion phylogenetischer Stammbäume für den Standort Avachinsky}

Für die Untersuchung der phylogenetischen Diversität des Habitates Avachinsky wurden insgesamt 594 16S rRNA-Gensequenzen analysiert. Davon wurden 234 bakterielle und 42 archelle 16S rRNA-Gensequenzen für die Konstruktion phylogenetischer Stammbäume genutzt. Zunächst wurde mit Hilfe des Programmes „ARB“ (2.14.3) ein Stammbaum konstruiert, welcher einen Überblick über die verschiedenen Phyla des Standortes Avachinsky gibt (s. Abb. 10). Von mittelerweile über 100 identifizierten Phyla der Bakterien und Archaeen (DESANTIS et al. 2006) konnten 16S rRNA-Gene vollständig oder partiell von insgesamt 20 Phyla amplifiziert werden. Es konnten 16S rRNAGene von nahezu allen Klassen der Proteobacteria erhalten werden. Es wurden Vertreter der Cyanobacteria, der Nitrospirae, der Acido- und Actinobacteria, der Planctomycetes, der Gemmatimonadetes und auch der Bacteroidetes gefunden werden. Außerdem konnte eine große Anzahl an 16S rRNA-Genen amplifiziert werden, welche bisher nur unbekannten oder unkultivierten Mikroorganismen bzw. Phyla zugeordnet werden konnte. Das Phylum oder der nächstverwandte Mikroorganismus wird also nur durch 16S rRNA-Gensequenzen repräsentiert. Auch von typischen Vertretern für thermophile Standorte der Phyla Aquificae, Thermotogae oder Chloroflexi konnten 16S rRNA-Gene amplifiziert werden. 201 der erhaltenen 16S rRNA-Gensequenzen wurden den Archaeen zugeordnet. Aufgrund hoher Identitäten untereinander wurden schließlich 42 archaelle Sequenzen für die Konstruktion phylogenetischer Stammbäume verwendet. Es wurden sowohl Vertreter der Crenarchaeota als auch der Euryarchaeota gefunden. 


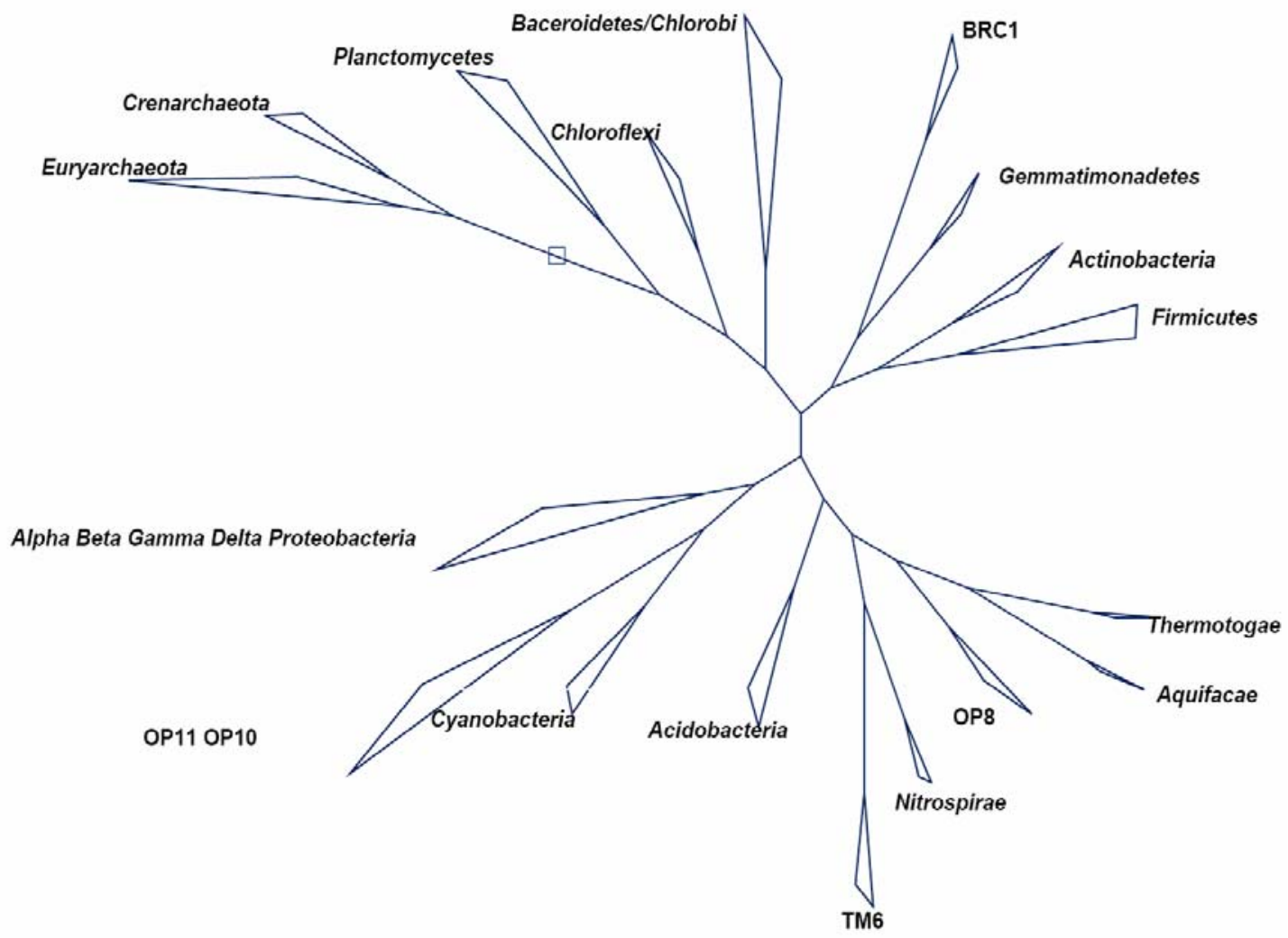

Abb. 10 :Stammbaum aller durch 16S rRNA-Genanalyse repräsentierten Phyla des Standortes Avachinsky.

Die insgesamt 594 16S rRNA-Gensequenzen wurden einer sogenannten DOTUR (s. 2.14.4) Analyse unterzogen. Dabei werden die $16 S$ rRNAGensequenzen eines Standortes gegeneinander alignt und in OTUs (operational taxonomic units) eingeteilt. Ein OTU steht dabei für alle 16S rRNAGensequenzen, welche sich untereinander nicht mehr als $3 \%$ in ihrer Sequenz unterscheiden. Die 594 16S rRNA-Gensequenzen des Standortes Avachinsky wurden in 214 OTUs eingeteilt. Davon sind 186 bakteriell OTUs und 28 archaelle OTUs.

Im Folgenden sind die enthaltenen Phyla separat dargestellt und geben einen Einblick in die mikrobielle Diversität des Standortes Avachinsky. 


\subsubsection{Analyse der archaellen 16S rRNA-Gensequenzen des Standortes Avachinsky}

Die phylogentischen Stammbäume wurden mit dem Programm „ARB“ unter Verwendung der „Maximum-Parsimony“-Methode und 100facher „Bootstrap“ Analyse angefertigt. Insgesamt wurden 42 16S rRNA-Gene der Phyla Euryarchaeota und Crenarchaeota für die Konstruktion von Stammbäumen verwendet. 15 16S rRNA-Gensequenzen lassen sich dabei in drei verschiedene Ordnungen der Euryarchaeota einteilen (Abb. 11). Dabei konnten die Sequenzen A05_kaa18, A01_kaa01 und H11_kaa05 den Thermoplasmatales und G04_kaa10 den Halobacteriales zugeordnet werden. Die nächsten Nachbarn entstammen Habitaten wie heißen Quellen [AF52660], Sediment aus der Antarktis [AF424536], Ölkontaminierten Böden [AB161336] oder Bioreaktoren [AY323219], werden aber nur durch 16S rRNA-Gensequenzen repräsentiert. Der überwiegende Teil (E01_kaa18, B03_kaa10, H02_kaa10, D05_kaa01, D10_kaa10, H11_kaa10, A09_kaa10, F10_kaa10, B03_kaa18, H10_kaa18, B02_kaa10) der 16S rRNA-Gensequenzen der Euryarchaeota zeigte die größte Identität zu $16 S$ rRNA-Genen von bisher völlig unbekannten und unkultivierten Euryarchaeota. Auffällig hierbei, dass bis auf H10_kaa18, allen anderen kein direkter Nachbar zugeordnet werden konnte bzw. dieser phylogentisch weit entfernt liegt. Sie zeigen die größte Identität $(87,8$ bis $88,2 \%)$ zu einer $16 \mathrm{~S}$ rRNA-Gensequenz amplifiziert aus einer Goldmine in Südafrika [AB050212]. H10_kaa18 hingegen zeigt eine Identität von 97,6 \% zu der 16S rRNA-Gensequenz AB050211, welche ebenfalls dieser Goldmine entstammt (TAKAl et al. 2001). 


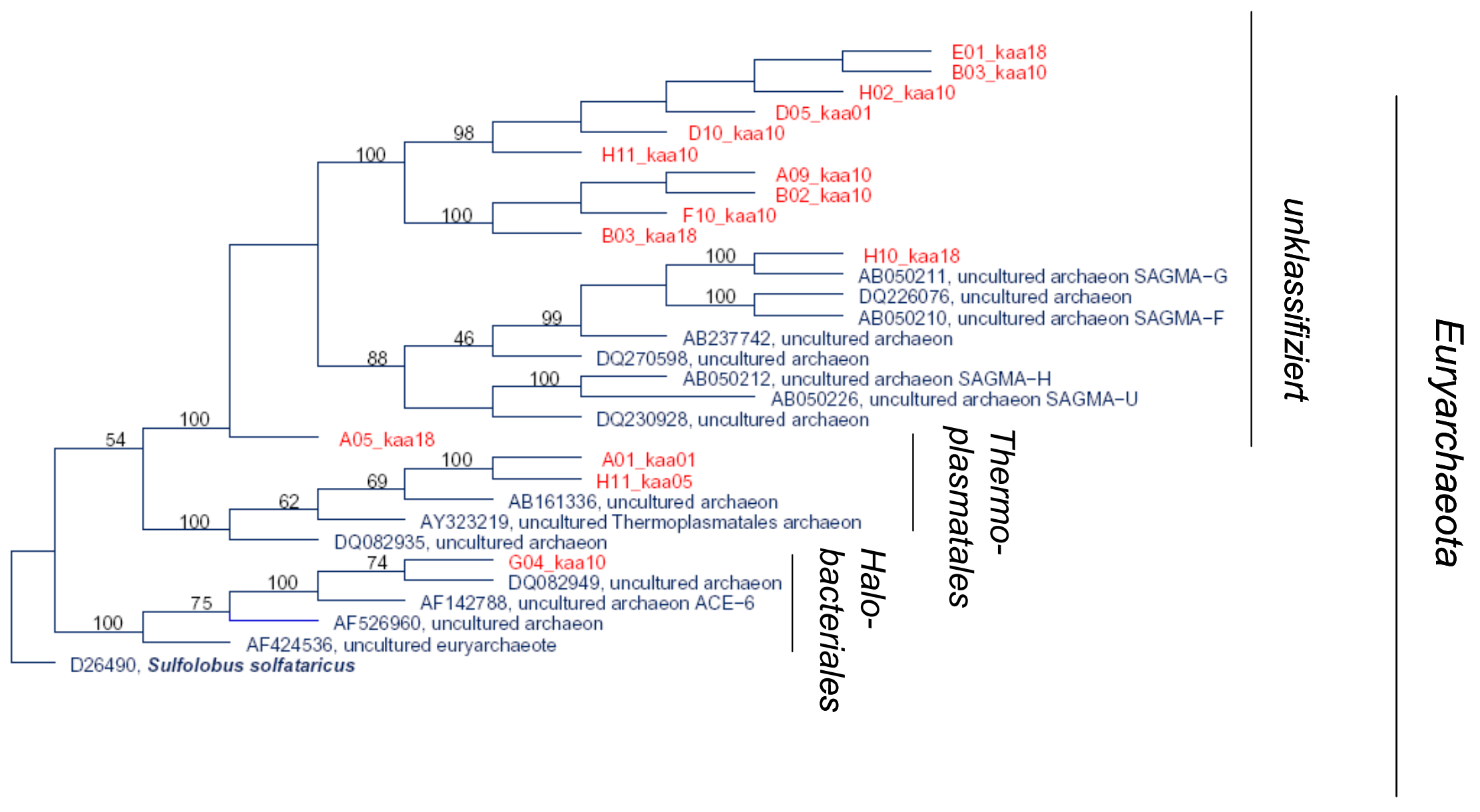

Abb. 11: Phylogenetischer Stammbaum der Euryarchaeota des Standortes Avachinsky. Der Stammbaum wurde mit dem Programm ARB (s. 2.14.3) unter Verwendung der „Maximum-Parsimony-Methode“ und 100-facher „Bootstrap“-Analyse konstruiert. Die "Outgroup" wird durch Methanosaeta thermophila repräsentiert 


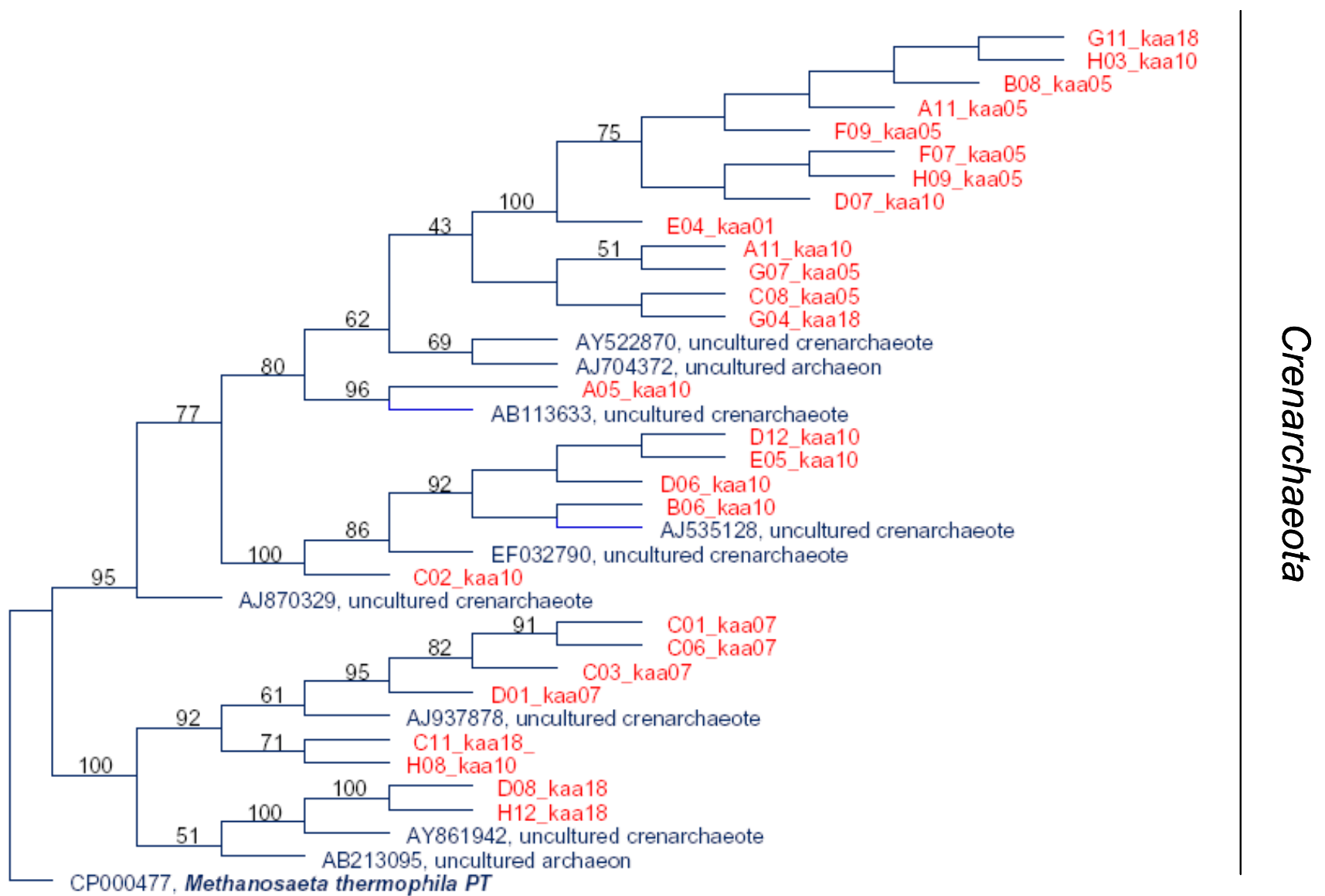

Abb. 12: Phylogenetischer Stammbaum der Crenarchaeota des Standortes Avachinsky. Der Stammbaum wurde mit dem Programm ARB (s. 2.14.3) unter Verwendung der "Maximum-Parsimony-Methode“ und 100-facher "Bootstrap“-Analyse konstruiert. Die „Outgroup" wird durch Methanosaeta thermophila repräsentiert 
27 partiell amplifizierte 16S rRNA-Gene, welche dem Phylum der Crenarchaeota zugeordnet werden konnten, wurden ebenfalls in drei Ordnungen eingeteilt (s. Abb. 12). Allerdings setzen sich diese Ordnungen ausschließlich aus 16S rRNA-Gensequenzen von bisher unkultivierten Crenarchaeota zusammen. Eine Gruppe von 13 16S rRNA-Gensequenzen (G11_kaa18, H03_kaa10, B08_kaa05, A11_kaa05, F09_kaa05, F07_kaa05, H09_kaa05, D07_kaa10, E04_kaa01, A11_kaa10, G07_kaa05, C08_kaa05, G04_kaa18) zeigt Identitäten zwischen 93,5 und 95,2 \% zu einer 16S rRNAGensequenz amplifiziert aus einem Ackerboden in Wisconsin (USA) [AY522870] (SLIWINSKI et al. 2004). Phylogenetische Verwandtschaft zeigte sich außerdem zu 16S rRNA-Gensequenzen des Yellowstone Nationalparks [AY861942] (SPEAR et al. 2005), heißen Quellen des Mariana-Grabens [AB213095] und einer Goldmine in Japan [AB113633] (NUNOURA et al. 2005). Insgesamt zeigen alle 42 archaellen 16S rRNA-Gensequenzen des Standortes Avachinsky engste phylogentische Verwandtschaft zu bisher unkultivierten Archaeen. 11 (26 \%) der 16S rRNA-Gensequenzen der Euryarchaeota und alle 27 (65 \%) 16S rRNA-Gensequenzen der Crenarchaeota, also $91 \%$ aller archaellen 16S rRNA-Gensequenzen des Stanortes Avachinsky, können dabei nur in Ordnungen völlig unbekannter Archaeen eingeteilt werden.

Abb. 13 gibt einen Überblick über die prozentuale Verteilung der $16 S$ rRNAGensequenzen des Standortes Avachinsky, welche im Rahmen dieser Arbeit für die Konstruktion der phylogenetischen Stammbäume der Crenarchaeota und Euryarchaeota verwendet wurden. 


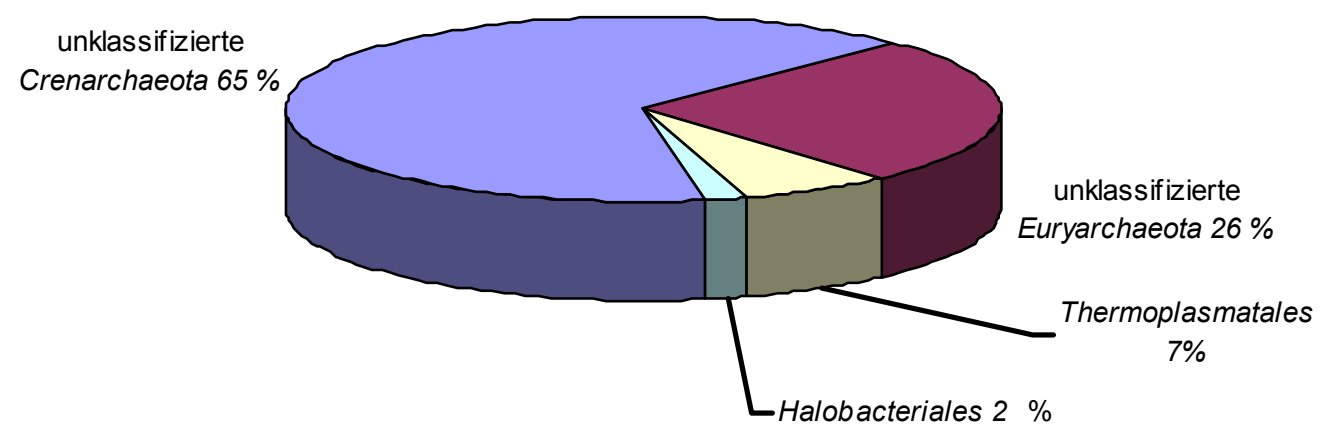

Abb. 13: Prozentuale Verteilung der amplifizierten 16S rRNA-Gene in die Phyla Euryarchaeota und Crenarchaeota des Standortes Avachinsky. Insgesamt wurden 42 archaelle 16S rRNA Gensequenzen des Standortes Avachinsky für die Konsrtuktion phylogentischer Stammbäume verwendet. $65 \%$ konnten unbekannte Ordnungen der Crenarchaeota zugeordnet werden (blau). $35 \%$ entfielen auf das Phylum Euryarchaeota, davon $7 \%$ auf die Thermoplasmatales (gelb), $2 \%$ auf die Halobacteriales (grün) und $26 \%$ auf eine unbekannte Ordnung der Euryarchaeota (rot).

\subsubsection{Ergebnisse der Analyse der bakteriellen 16S rRNA-Gensequenzen des Standortes Avachinsky}

55 amplifizierte 16S rRNA-Gensequenzen des Standortes Avachinsky können den Alpha-Proteobakterien zugeordnet werden. Sie werden in drei Stammbäumen beschrieben. Wie Anhand der drei Stammbäume der AlphaProteobakterien zu erkennen ist, lassen sich diese 16S rRNA-Gensequenzen in vier Ordnungen einteilen: Rhizobiales (Abb. 14), Caulobacteriales (Abb. 14), Sphingomonadales (Abb. 16) und eine Ordnung von bisher unklassifizierten $16 S$ rRNA-Genen (Abb. 15). 17 der 16S rRNA-Gensequenzen also ca. $31 \%$ der insgesamt den Alpha-Proteobakterien zugeordneten Sequenzen gehören zu dieser unklassifizierten Ordnung. Die Sequenz B02_kab11 zeigt in dieser Ordnung mit 99,6 \% die höchste Identität zu einer 16S rRNA-Gensequenz amplifiziert aus einem Silage-Bunker [AY921758] (TRINGE et al. 2005). Die geringste Identität mit 88,4 \% zeigt die Sequenz D11_kab19. Der direkte Nachbar [EF032744] wurde aus einer vulkanischen Probe aus Hawaii amplifiziert. In allen Ordnungen werden viele der direkten Nachbarn nur durch 
ihre $16 \mathrm{~S}$ rRNA-Gensequenzen vertreten. D. h. es konnte noch kein Mikroorganismus zu diesem 16S rRNA-Gen kultiviert werden. 36\% der partiell ampifizierten 16S rRNA-Gensequenzen konnten den Rhizobiales und Caulobacteriales zugeteilt. Die 16S rRNA-Gensequenzen der Rhizobiales des Standortes Avachinsky zeigen Identitäten zwischen 91,5 und $100 \%$ zu ihren direkten Nachbarn. $100 \%$ Identität zeigt die 16S rRNA-Gensequenz B07_kab11 zu einer 16S rRNA-Gensequenz amplifiziert aus einer Bodenprobe in Schottland [AF078225] (MCCAIG et al. 1999). 33\% der 16S rRNAGensequenzen der Alpha-Proteobakterien des Standortes Avachinsky werden den Sphingomonadales zugeordnet. Diese Sequenzen zeigen im Allgemeinen sehr hohe Identitäten zu ihren direkten Nachbarn, welche hier größtenteils bereits kultivierte Mikroorganismen sind. Sie liegen mit einer Ausnahme zwischen 98,7 und 99,9 \%. Die direkten Nachbarn entstammen Habitaten wie der Tiefsee [DQ396092], Proben einer Textilfabrik [DQ855091] oder schwermetallbelasteten Böden [AF105023]. E05_kab02 zeigt mit 87,4 \% Identität zu einer 16S rRNA-Gensequenz der Sargasso See [AY162053] (ZENGLER et al. 2002) die geringste Identität. 


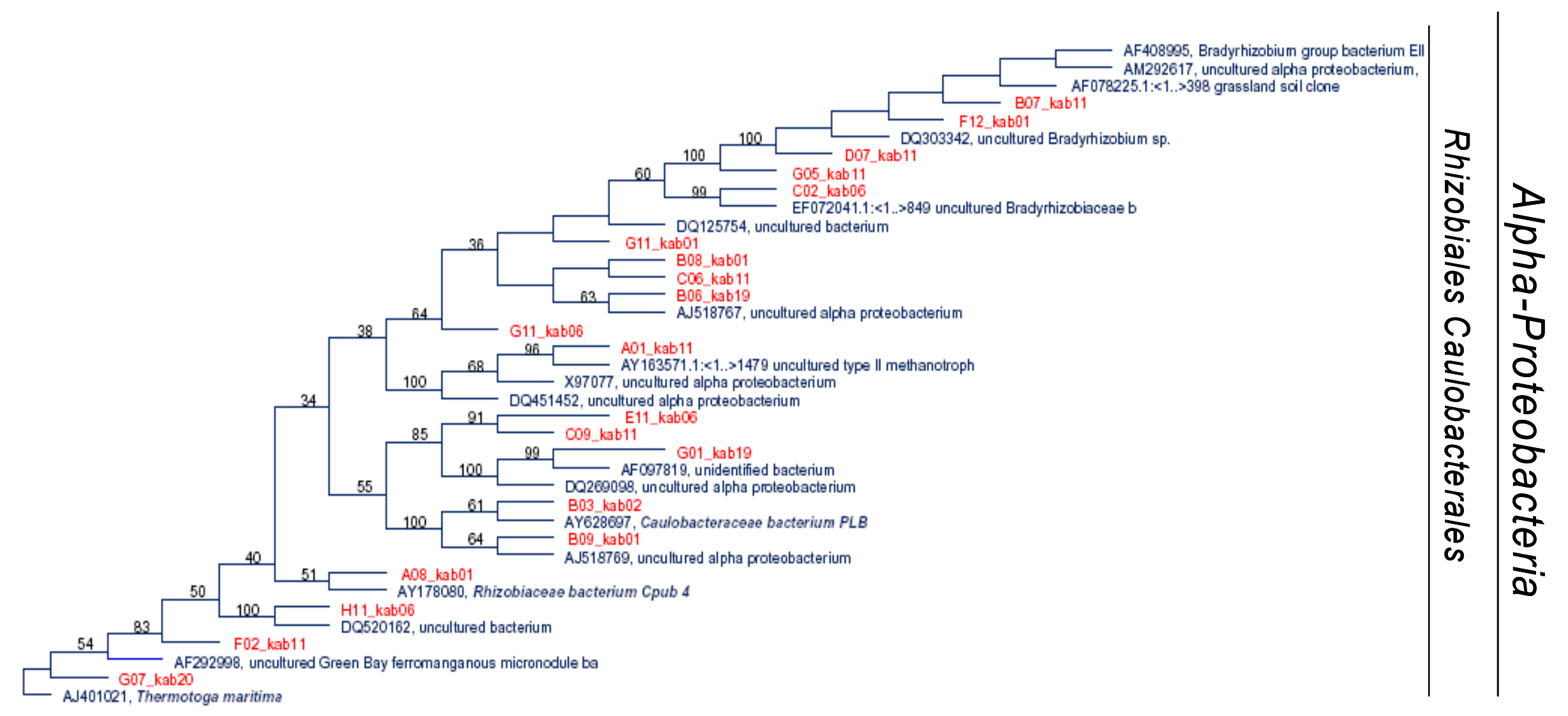

Abb. 14: 1. Phylogenetischer Stammbaum der Alpha-Proteobacteria des Stanortes Avachinsky. Der Stammbaum wurde mit dem Prorgamm ARB (s.2.14.3) unter Verwendung der "Maximum-Parsimony-Methode“ und 100-facher "Bootstrap"-Analyse konstruiert. Die "Outgroup" wird durch Thermotoga maritima repräsentiert. 


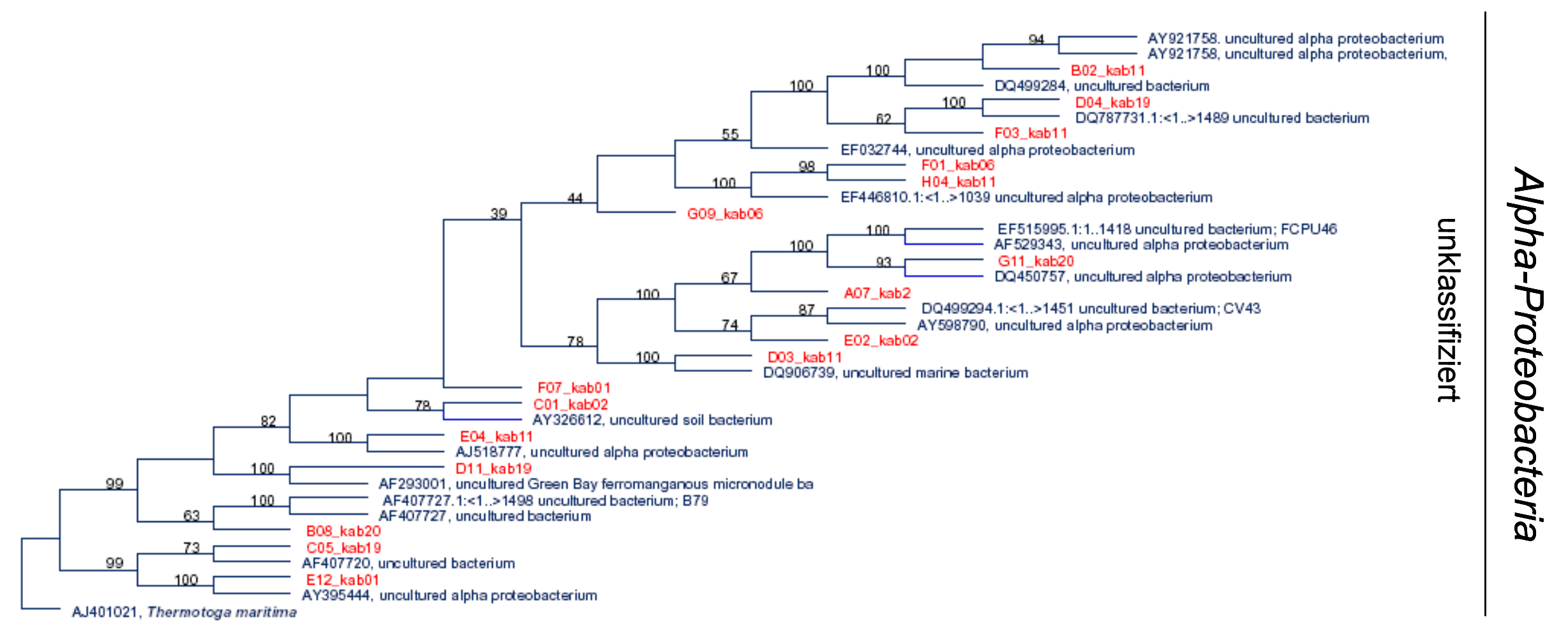

Abb. 15: 2. Phylogenetischer Stammbaum der Alpha-Proteobacteria des Standortes Avachinsky. Der Stammbaum wurde mit dem Programm ARB unter Verwendung der „Maximum-Parsimony-Methode“ und 100-facher „Bootstrap"-Analyse konstruiert. Die „Outgroup“ wird durch Thermotoga maritima repräsentiert. 


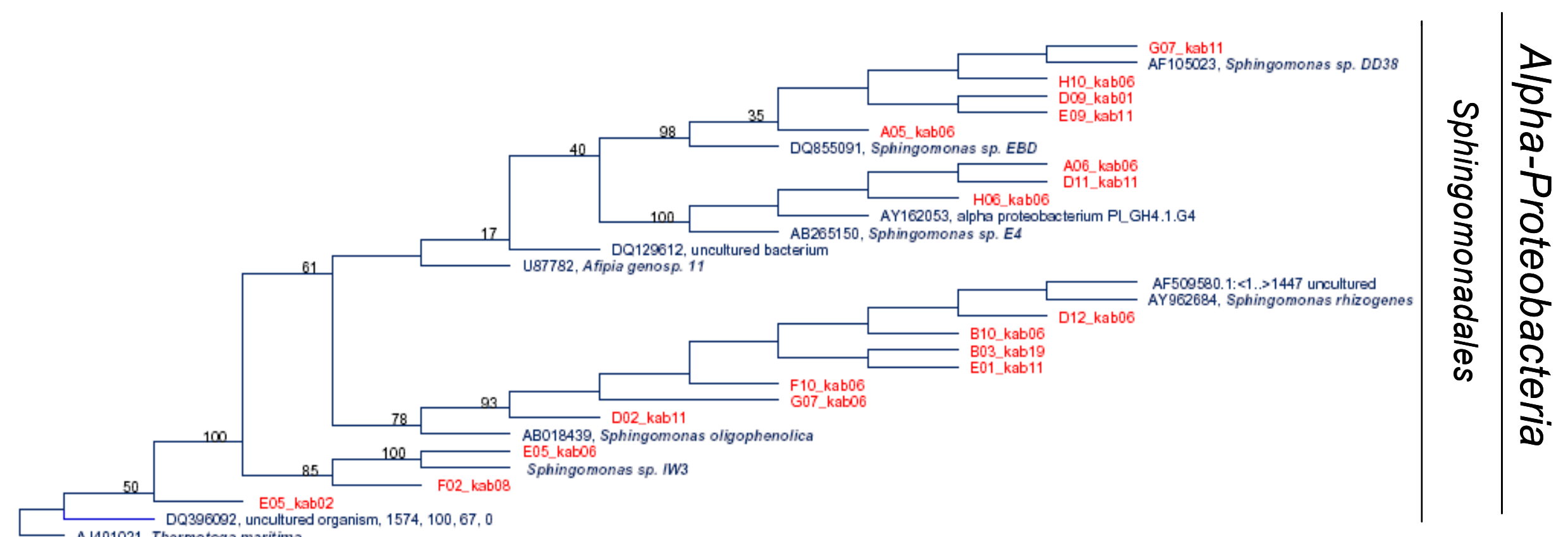

Abb. 16: 3. Phylogentischer Stammbaum der Alpha-Proteobacteria des Standortes Avachinsky. Der Stammbaum wurde mit dem Programm ARB unter Verwendung der „Maximum-Parsimony-Methode“ und 100-facher "Bootstrap"-Analyse konstruiert. Die "Outgroup" wird durch Thermotoga maritima repräsentiert. 
In Abb. 17 sind die phylogenetischen Beziehungen der Beta-Proteobakterien des Standortes Avachinsky dargestellt. 33 16S rRNA-Gensequenzen konnten diesem Phylum zugeordnet werden. Sie lassen sich innerhalb dieses Phylums in weitere 4 Ordnungen einteilen: Nitrosomonadales, Methylophilales, Rhodocyclales und die Burkholderiales. Damit sind vier der insgesamt fünf Ordnungen der Beta-Proteobakterien vertreten. Der Ordnung Neisseriales konnte kein 16S rRNA-Gen des Standortes Avachinsky zugeordnet werden. Wie auch schon bei den Alpha-Proteobakterien beobachtet werden konnte, wird mit einer Außnahme der nächste Nachbar nur durch 16S rRNA-Gensequenzen repräsentiert. Nur die Sequenz E05_kab19 zeigt eine Identität von 94,6 \% zu dem Organismus Dechlorosoma sp. [AY171616] isoliert aus einer perchloratkontaminierten Probe. Drei 16S rRNA-Gensequenzen (A04_kab06, A08_kab11, F05_kab11) der Rhodocyclales amplifiziert aus Avachinsky zeigen mit ca. $95 \%$ Identität phylogenetische Beziehung zu einer 16S rRNAGensequenz aus einer Wasserprobe der Kalahariwüste in Südafrika [DQ223206]. Desweiteren konnten phylogentische Beziehungen zu Sequenzen aus Habitaten wie heißen Quellen [DQ390446], chlorethanhaltigen Gewässern [DQ196633] oder dem "Großen Artesischen Becken“ in Australien [AF407711] hergestellt werden. 14 der insgesamt 33 16S rRNA-Gensequenzen der BetaProteobakterien des Standortes Avachinsky zeigen weniger als $3 \%$ Unterschied in zu der 16S rRNA-Gensequenz ihres direkten Nachbarn. 


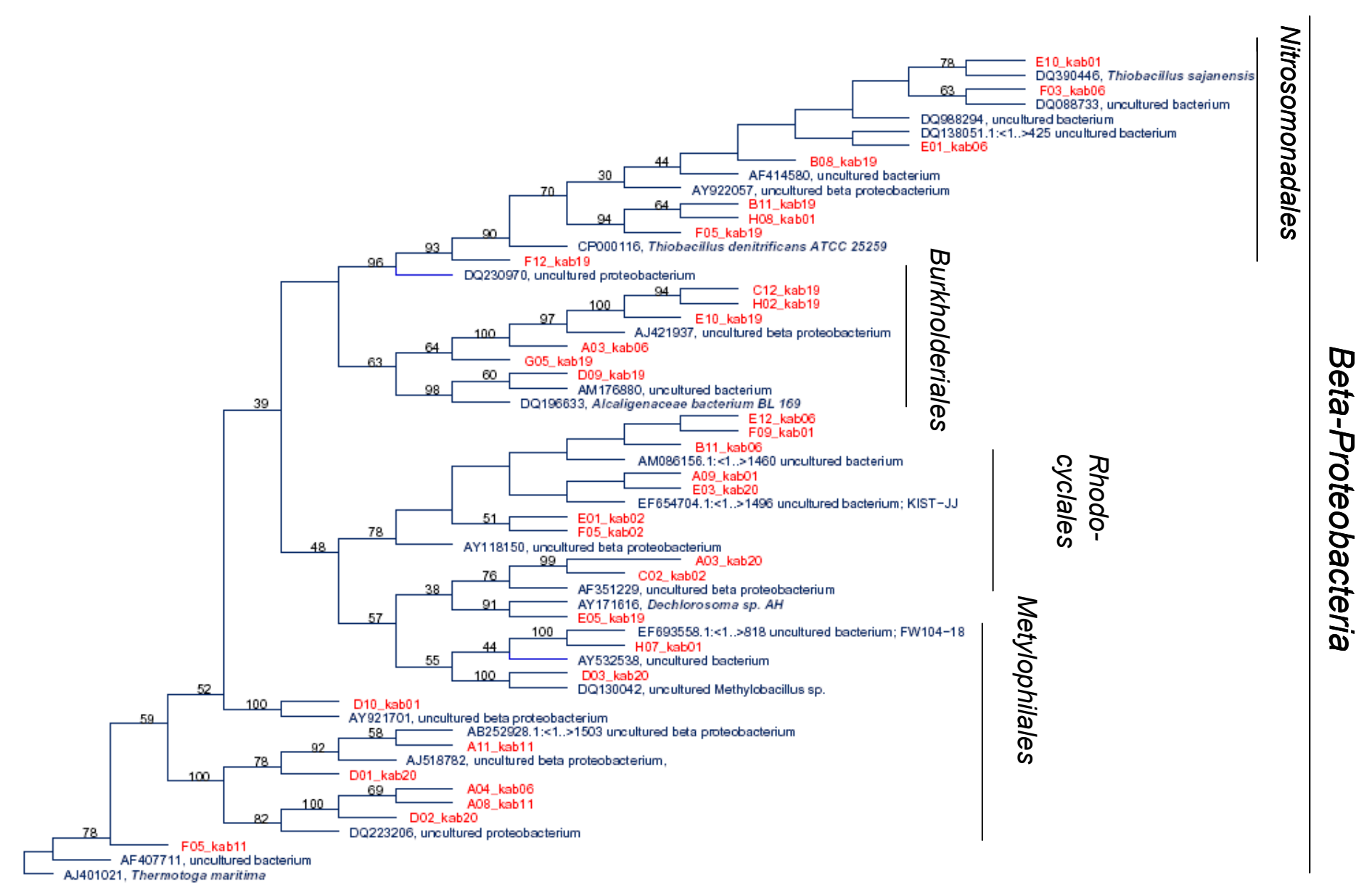

Abb. 17: Phylogenetischer Stammbaum der Beta-Proteobacteria des Standortes Avachinsky. Der Stammbaum wurde mit dem Programm ARB unter Verwendung der "Maximum-Parsimony-Methode“ und 100-facher "Bootstrap"-Analyse konstruiert. Die "Outgroup" wird von Thermotoga maritima repräsentiert. 


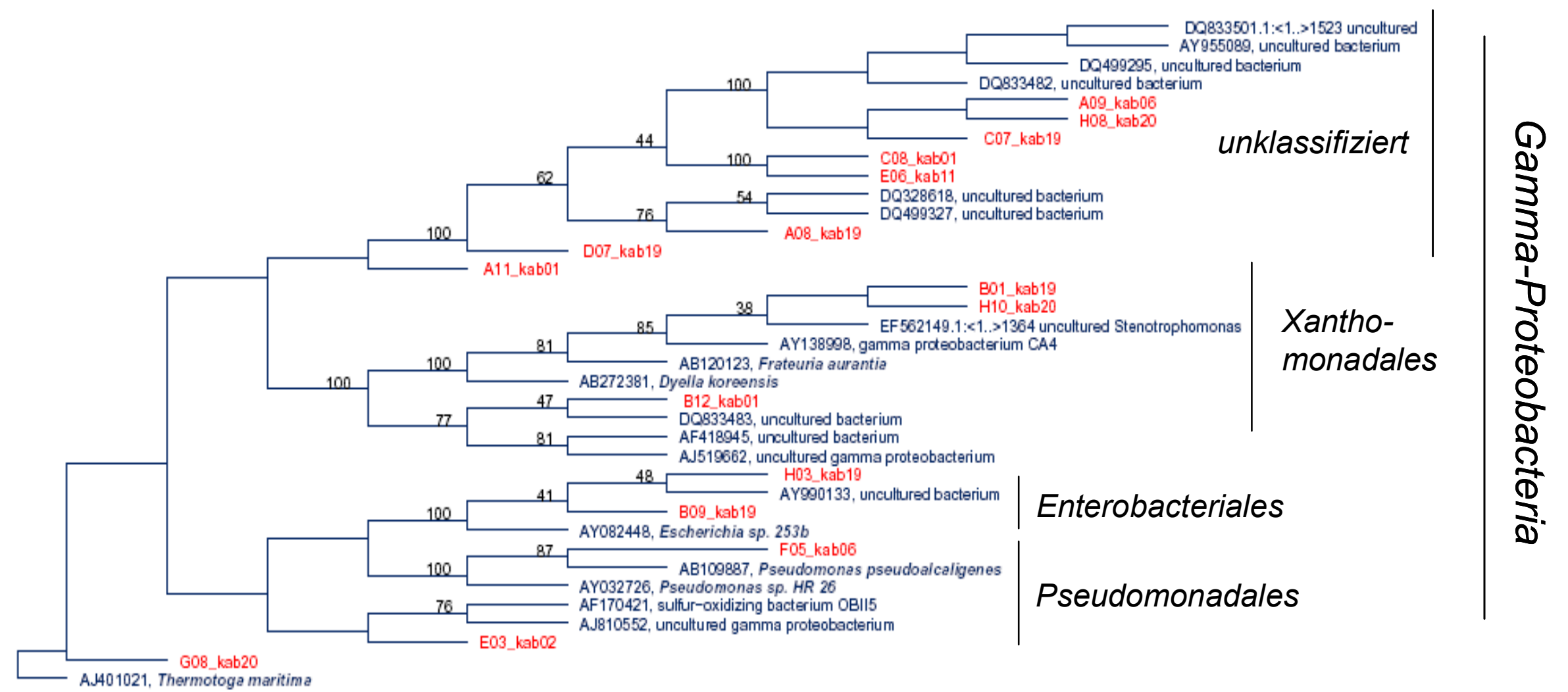

Abb. 18: Phylogenetischer Stammbaum der Gamma-Proteobacteria des Standortes Avachinsky. Der Stammbaum wurde mit dem Programm ARB unter Verwendung der "Maximum-Parsimony-Methode" und 100-facher "Bootstrap"-Analyse konstuiert. Die "Outgroup" wird von Thermotoga maritima repräsentiert. 
Für die Gamma-Proteobakterien konnte ein phylogenetischer Stammbaum konstruiert werden, welcher sich aus vier Ordnungen zusammensetzt (Abb. 18): Xanthomonadales, Pseudomonadales, Enterobacteriales und eine Ordnung ohne direkte Zugehörigkeit eines Mikroorganismus. Insgesamt konnten $1616 \mathrm{~S}$ rRNA-Gensequenzen aus dem Standort Avachinsky diesem Phylum zugeteilt werden. 8 Sequenzen wurden der unklassifizierten Ordnung zugeordnet, deren direkte Nachbarn durch 16S rRNA-Gensequenzen aus z. B Sedimenten repräsentiert werden [DQ833501, DG328618]. 5 dieser 16S rRNAGensequenzen des Standortes Avachinsky zeigen Identitäten zwischen 85,3 98,8 \% zu einer 16S rRNA-Gensequenz amplifiziert aus einem Wasserreservoir in China [AY955089]. Den Xanthomonadales konnte drei Sequenzen zugeordnet werden (B01_kab19, H10_kab20, B12_kab01). Ihre phylogentischen Nachbarn werden durch Frateuria aurantia, Dyella koreensis und einem unkultivierten Stenotrophomonas repräsentiert, welche aus granithaltigen Sedimenten [EF562149] und Böden in Indonesien [AB120123] isoliert wurden. Die den Pseudomonadales zugeordneten $16 \mathrm{~S}$ rRNAGensequenzen aus dem Standort Avachinsky zeigen phylogenetische Verwandtschaft zu 16S rRNA-Genen aus heißen Quellen [AF170421] (G08_kab20) oder sizilianischen Hafensedimenten [AJ810552] (E03_kab02).

Die Delta-Proteobakterien des Standortes Avachinkys werden durch $2416 S$ rRNA-Gensequenzen vertreten. Sie können in zwei Ordnungen eingeteilt werden (Abb. 19). Dabei entfallen 14 Sequenzen auf die Ordnung der Desulfovibrionales und zehn auf eine bisher unbekannte Ordnung. Die Desulfovibrionales werden durch Mikroorganismen wie Geobacter sp. oder Bdellovirio sp. sowie unkultivierte Mikroorganismen vertreten. 4 16S rRNAGensequenzen (D06_kab06, B10_kab01, F09_kab11, D12_kab11) aus Avachinsky zeigen direkte Verwandtschaft zu dem Organismus Geobacter sp. [AASH01000049]. Die Identitäten liegen dabei zwischen 81,9 und 95,1 \%. Den 16S rRNA-Gensequenzen G04_kab06 und B11_kab11 konnte eine Sequenz amplifiziert aus einer heißen Quelle des Yellowstone Nationalparks als direkten Nachbarn zugeordnet werden [AY862012] (SPEAR et al. 2005). Desweiteren konnten phylogenetische Beziehungen zu 16S rRNA-Genen amplifiziert aus Habitaten wie z. B. aus chinesischem Waldböden [AY963493] oder Sedimenten [AY521561] nachgewiesen werden. Die Ordnung der unkultivierten 
Mikroorganismen entstammt Habitaten wie hawaiianischen Lavaschluchten [EF032746], thermale Regionen in Tibet [EF205525], chlorreichen Sedimenten in Japan [AB187504] oder einer uranhaltigen Mine in Johanngeorgenstadt in Sachsen [AJ518795, AJ518801]. 
EF032749.1:1... $>1484$ uncultured EF032749, uncultured delta proteckacteriun

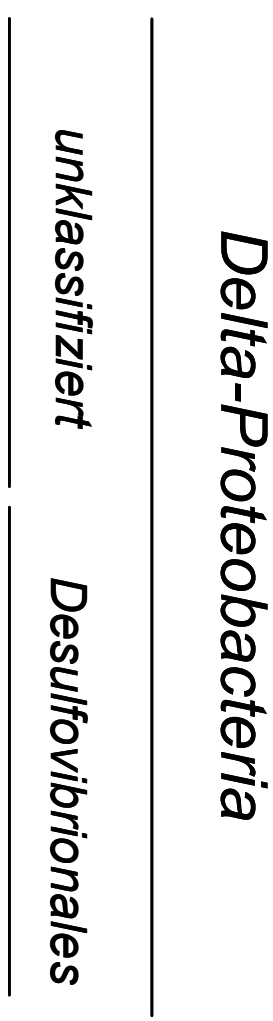

Abb. 19: Phylogentischer Stammbaum der Delta-Proteobacteria des Standortes Avachinsky. Der Stammbaum wurde mit dem Programm ARB unter Verwendung der "Maximum-Parsimony-Methode“ und 100-facher „Bootstrap“-Analyse konstruiert. Die „Outgroup“ wird durch Thermotogales str. BH180 139 repräsentiert. 


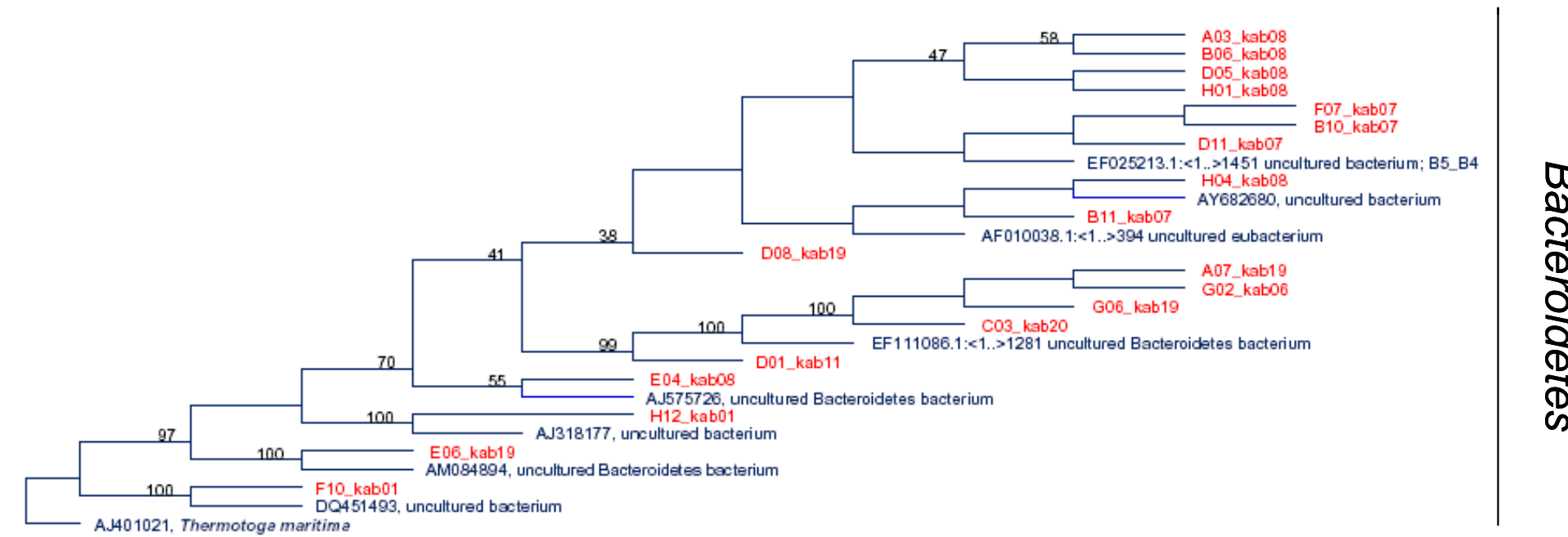

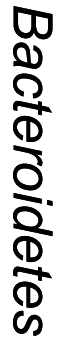

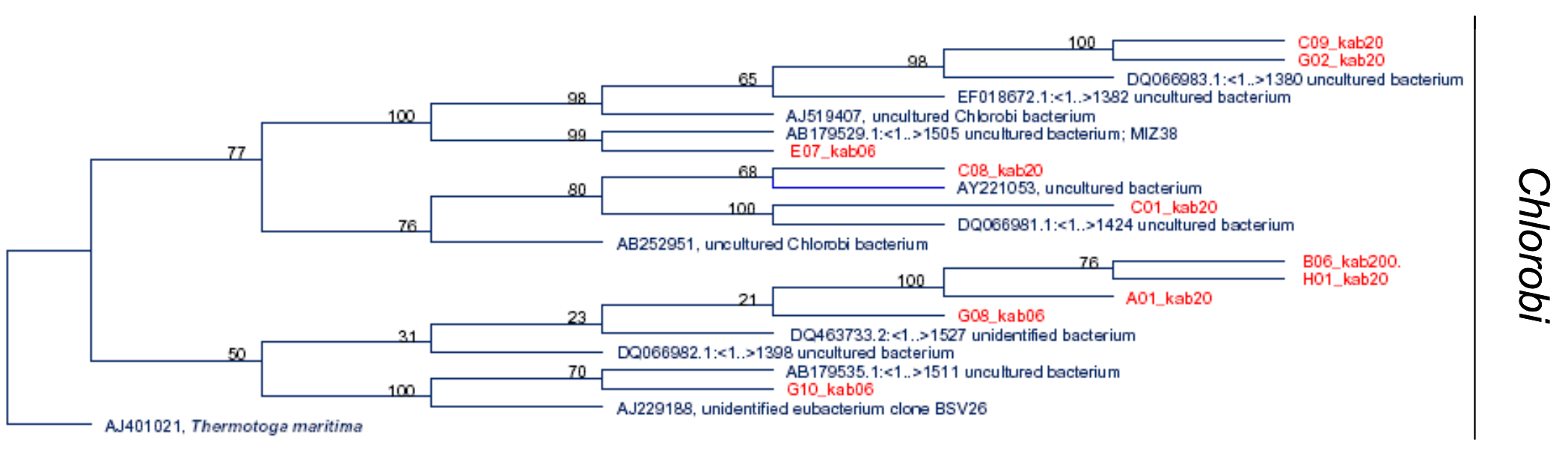

Abb. 20: Phylogentische Stammbäume der Bacteroidetes und der Chlorobi des Standortes Avachinsky. Die Stammbäume wurden mit dem Programm ARB unter Verwendung der „Maximum-Parsimony-Methode“ und 100-facher „Bootstrap“-Analyse konstruiert. Die „Outgroups" werden durch Thermotoga maritima repräsentiert. 
Die aus dem Standort Avachinsky amplifizierten 16S rRNA-Gensequenzen, welche den Phyla Bacteroidetes und Chloribi (Abb. 20) zugeordnet werden können zeigen keinerlei phylogentische Beziehung zu bereits kultivierten Mikroorganismen. Sieben von 19 16S rRNA-Gensequenzen aus Avachinsky (F07_kab07, D11_kab07, D08_kab19, B06_kab08, A03_kab08, D05_kab08, E04_kab08) zeigen direkte phylogenetische Beziehungen zu einer 16S rRNAGensequenz, welche aus einem Truthahndarm stammt [EF025213]. Sie gehören dem Phylum Bacteroidetes an. Weitere fünf $16 \mathrm{~S}$ rRNA-Gensequenzen (G06_kab19, G02_kab06, A07_kab19, D01_kab11, C03_kab20) lassen sich mit einer 16S rRNA-Gensequenz amplifiziert aus einem Flusssediment in Bogota in phylogenetischen Zusammenhang bringen. Acht von Zehn $16 S$ rRNAGensequenzen der Chlorobi aus Avachinsky zeigen direkte phylogenetische Beziehung zu einer Sequenz amplifiziert aus dem „Lake Washington“ in Seattle (USA) [DQ066981-3]. Die Identitäten liegen dabei zwischen 87,5 und $94 \%$. Insgesamt 12 16S rRNA-Gensequenzen, amplifiziert aus dem Standort Avachinsky, können den Planctomycetes bzw. den Gemmatimonadetes zugeteilt werden (Abb. 21). Sie zeigen jedoch keine direkte Verwandtschaft zu bereits kultivierten Mikroorganismen Sechs gehören zu den Planctomycetes, von denen vier als direkten Nachbarn eine 16S rRNA-Gensequenz aus einem extrem acidophilen Biofilm in Italien [DQ499298] (MACALADY et al. 2007) haben. Die Identitäten liegen hierbei zwischen 78,9 und 90,5 \%. Die Gemmatimonadetes aus Avachinsky zeigen mit durchschnittlich $94 \%$ im Allgemeinen höhere Identitäten zu ihren direkten Nachbarn. Diese wurden mit zwei Außnahme aus einem Silagebunker in Minnesota (USA) amplifiziert [AY921771, AY921931, AY 921895] (TRINGE et al. 2005).

Das Phylum Firmicutes (Abb. 22) enthält 12 16S rRNA-Gensequenzen aus Avachinsky. Es beinhaltet Mikroorganismen wie Caloramator sp. [AF286863], isoliert aus einer heißen Quelle des Yellowstone Nationalparks, oder Thermobrachium celere [DQ207958]. Dies sind typische Vertreter der Ordnung Clostridiales. Acht 16S rRNA-Gensequenzen (C01_kab19, F11_kab01, E07_kab01, A03_kab19, E04_kab02, H05_kab20, B01_kab20, C07_kab06) aus Avachinsky zeigen direkte phylogenetische Verwandtschaft zu diesen Organismen. 
Die Phyla unkultivierter Mikroorganismen OP8, TM6 und BRC1 (Abb. 22) enthalten 16S rRNA-Gensequenzen, welche aus typischen thermophilen Habitaten wie heißen Quellen des Yellowstone Nationalpark (OP8) [AF027067] oder vulkanischen Tiefseen (TM6) [AY592384] stammen. Aber auch 16S rRNAGensequenzen amplifiziert aus Waldboden (TM6) [AY043958] oder anaerobe Sedimente (BRC1) [AY114315] zählen zu diesen Phyla. Sieben 16S rRNASequenzen aus Avachinsky konnte diesen Phyla zugeordnet werden. 


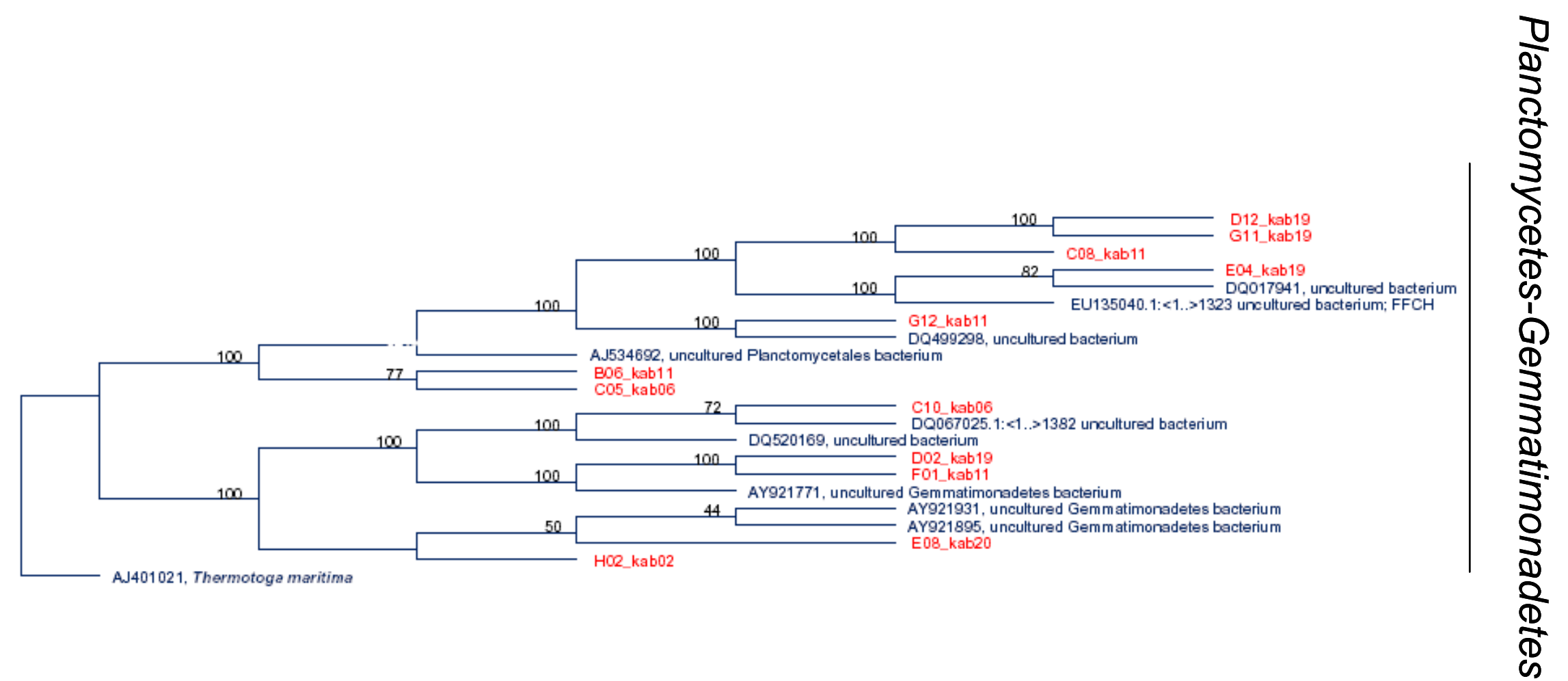

Abb. 21: Phylogentischer Stammbaum der Planctomycetes und Gemmatimonadetes des Standortes Avachinsky. Der Stammbaum wurde mit dem Programm ARB unter Verwendung der "Maximum-Parsimony-Methode“ und 100-facher "Bootstrap"-Analyse konstruiert. Die "Outgroup“ wird durch Thermotoga maritima repräsentiert. 

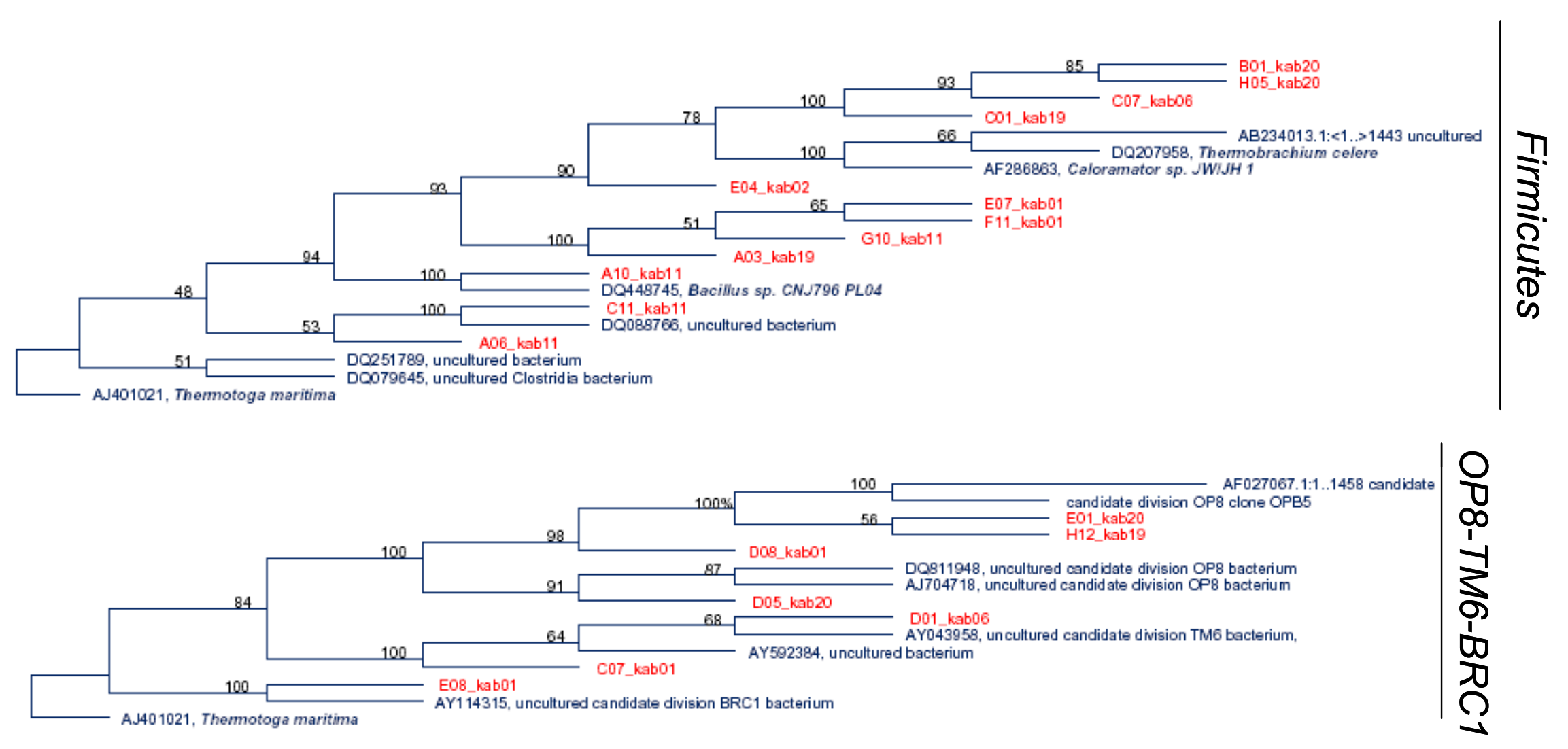

Abb. 22: Phylogentische Stammbäume der Firmicutes, OP8, TM6 und BRC1 des Standortes Avachinsky. Der Stammbaum wurde mit dem Programm ARB unter Verwendung der „Maximum-Parsimony-Methode“ und 100-facher „Bootstrap“-Analyse konstruiert. Die „Outgroups" werden durch Thermotoga maritima repräsentiert. 
Abb. 23 zeigt die Phylogentischen Beziehungen der Phyla Acidobacteria und Nitrospirae des Habitates Avachinsky. Insgesamt 30 also etwa 12,5\% der $16 \mathrm{~S}$ rRNA-Gensequenzen aus dem Habitat Avachinsky konnten diesen Phyla zugeordnet werden. Phylogenetische Beziehungen konnten allerdings nur zu bisher unkultivierten Mikroorganismen festgestellt werden. Diese zeigen allerdings eine hohe Diversität, was die Herkunft ihrer Habitate betrifft. Bei der Herkunft handelt es sichi bei den Acidobacteria um thailändische heiße Quellen [AY555791], Prärieboden aus Oklahoma [EU131963] oder dem „Großen Artesischen Becken“ [AF407714]. Die 16S rRNA-Gensequenzen der direkten Nachbarn der Nitrospirae entstammen Habitaten wie Uranabfällen [AY532568, AJ534638], Sediment [EF069279] oder chinesischen Ölfeldern [DQ097680]. Abb. 24 sind die Phyla Actinobacteria, Cyanobacteria, Chloroflexi, Thermotogae, Aquificae sowie OP10 und OP11 des Standortes Avachinsky dargestellt. 20 aus Avachinsky amplifizierte 16S rRNA-Gensequenzen konnten diesen Phyla zugeordnet werden. Diesen Phyla werden überwiegend Mikroorganismen aus thermophilen Habitaten zugeordnet. Mikrooranismen wie z. B. Aquifex oder Thermotoga konnten aus solchen Habitaten isoliert werden. Aber auch die 16S rRNA-Gensequenzen bisher unkultivierter Mikroorganismen, welche hier den Phyla OP10 und OP11 zugewiesen wurden, entstammen Habitaten wie z. B. vulkanischen Gebieten der Inselgruppe Hawaii [EF032775] oder heißen Quellen Kamtschatkas [AF453508], wie auch die 16S rRNAGensequenzen dieser Arbeit. Die 16S rRNA-Gensequenzen des Phylums Actinobacteria zeigen Verwandtschaft zu 16S rRNA-Genen amplifiziert aus tropischen Regenwäldern Afrikas [AY513962], die der Chloroflexi zu 16S rRNAGenen aus Mangrovenwäldern [DQ811858]. Klon DQ675048 des Phylum Thermotogae entstammt einem Ölfeld. 


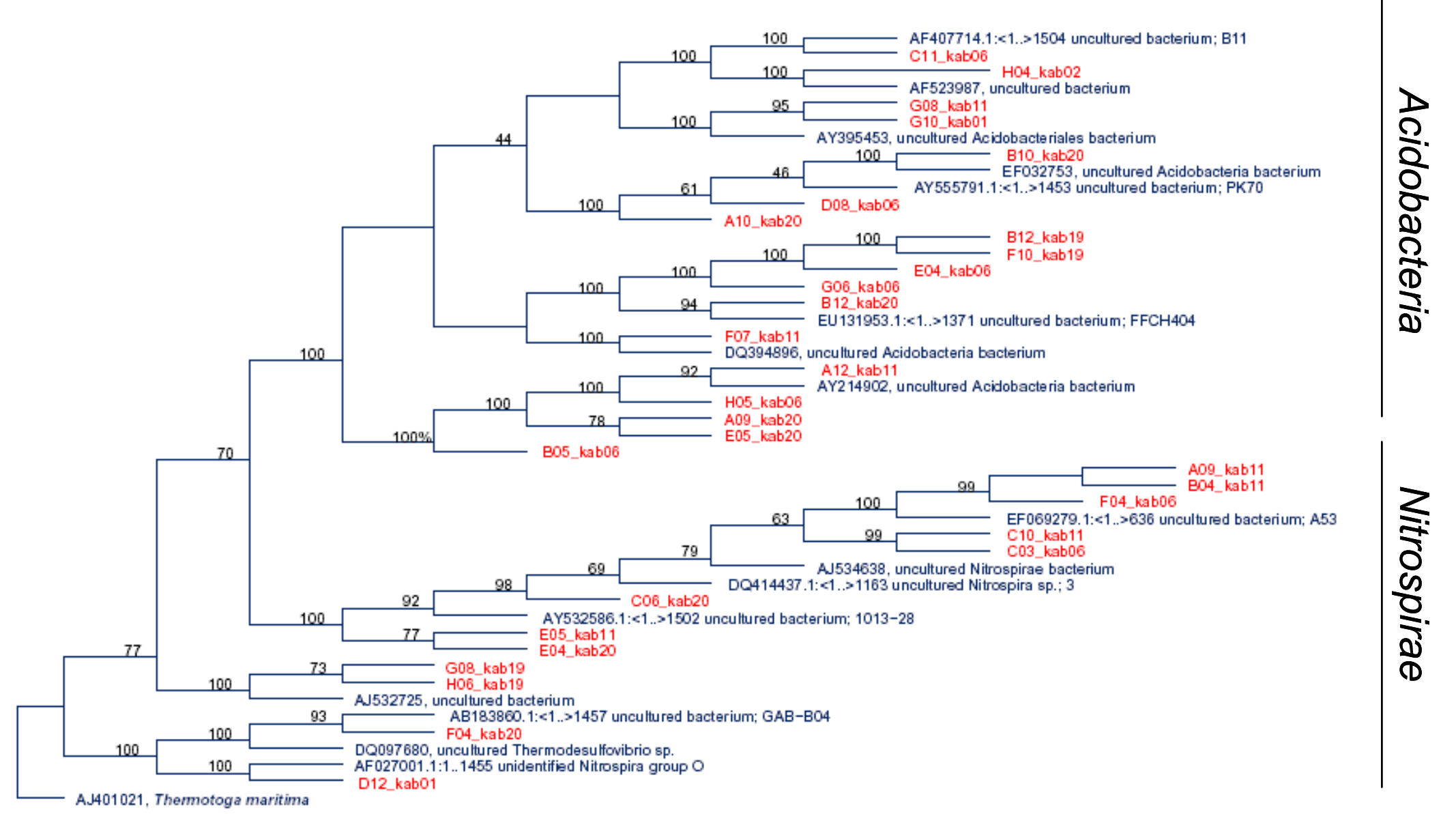

Abb. 23: Phylogentischer Stammbaum der Acidobacteria und Nitrospirae des Standortes Avachinsky. Der Stammbaum wurde mit dem Programm ARB unter Verwendung der „Maximum-Parsimony-Methode“ und 100-facher „Bootstrap“-Analyse konstruiert. Die „Outgroup“ wird durch Thermotoga maritima repräsentiert. 


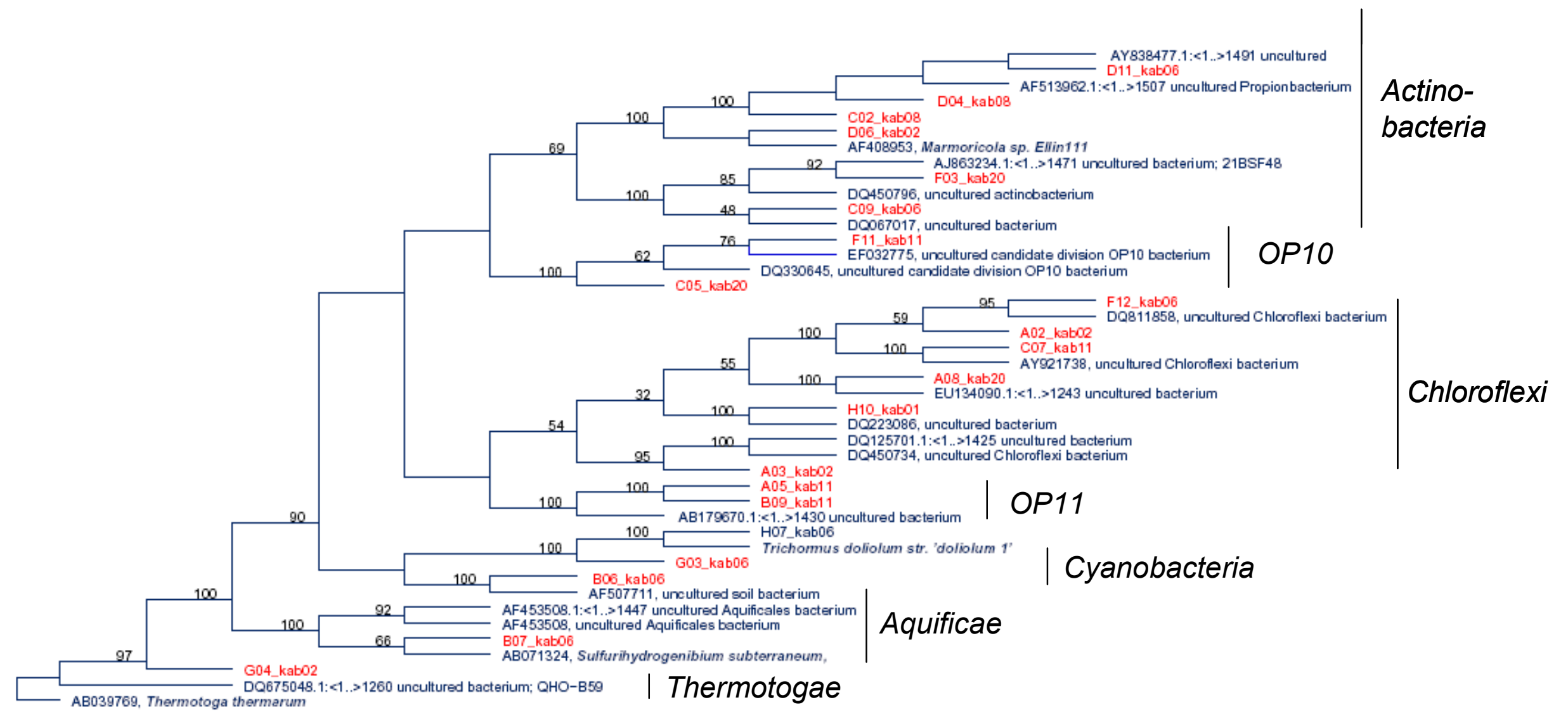

Abb. 24: Phylogentischer Stammbaum der Phyla Actinobacteria, Chloroflexi, Cyanobacteria, Aquificae, Thermotogae sowie der unklassifizierten Phyla OP10 und OP11 des Standortes Avachinsky. Der Stammbaum wurde mit dem Programm ARB unter Verwendung der "Maximum-ParsimonyMethode“ und 100-facher „Bootstrap“-Analyse konstruiert. Die „Outgroup“ wird durch Thermotoga thermarum repräsentiert. 
Abb. 25 zeigt einen Überblick über die prozentuale Verteilung der amplifizierten 16S rRNA-Gensequenzen des Standortes Avachinky in die entsprechenden Phyla. Der Größte Anteil der im Rahmen dieser Arbeit amplifizierten 16S rRNAGensequenzen des Standortes Avachinsky konnte dabei den Proteobakterien zugeordnet werden. Über 50 \% entfallen auf dieses Phylum. Davon stellen die Alpha-Proteobakterien mit $24 \%$ den größten Anteil. Die Phyla Bacteroidetes, Acidobacteria, Firmicutes und Nitrospirae haben einen Anteil zwischen 5 und $8 \%$. Alle anderen vertretenen Phyla liegen unter $5 \%$.
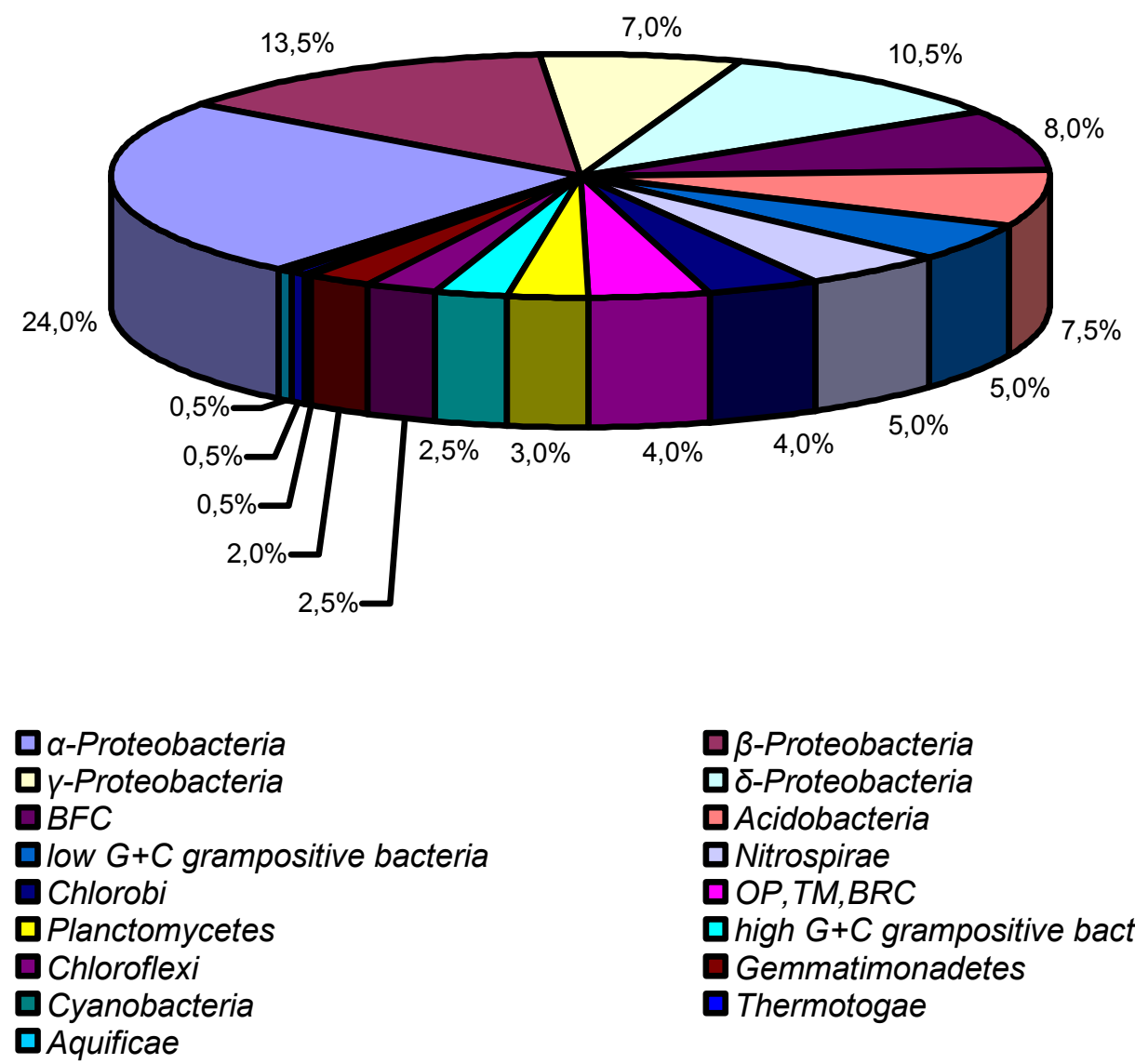

Abb. 25: Prozentuale Verteilung der 234 bakteriellen 16S rRNA Gensequenzen in die entsprechenden Phyla der Bacteria des Standortes Avachinsky. 
Insgesamt zeigt die Analyse der $16 \mathrm{~S}$ rRNA-Gensequenzen des Standortes Avachinsky, dass einige Sequenzen große Ähnlichkeit zu bereits bekannten 16S rRNA-Gensequenzen aufweisen. Teilweise sogar $100 \%$ Identität zeigen. Die überwiegende Mehrheit zeigt aber weniger als $97 \%$ Identität zu ihren direkten phylogenetischen Nachbarn. 95,5\% der direkten Nachbarn werden dabei nur durch 16S rRNA-Gensequenz unkultivierter Mikroorganismen vertreten. Die für die phylogenetischen Stammbäume berechneten Matrixen, welche die phylogenetischen Abstände der einzelnen 16S rRNAGensequenzen in den entsprechenden Phyla angeben, befinden sich im Anhang.

\subsection{Konstruktion von Metagenombanken aus chromosomaler DNA verschiedener Standorte der Kamtschatka-Region in Escherichia coli}

\subsubsection{Konstruktion von Plasmid-Metagenombanken}

Für die Konstruktion von Plasmid-Genbanken war es notwendig die zuvor isolierte hochmolekulare chromosomale DNA (s. 3.1) der Standorte Avachinsky und Dachnie auf eine Größe zwischen 2 und $10 \mathrm{kbp}$ zu schneiden. Dazu wurde die DNA zeitlimitiert mit dem Restriktionsenzym Bsp143I partiell verdaut (s. 2.11.1). Dieses Restriktionsenzym besitzt eine Erkennungssequenz von 4 Basen ( $\downarrow$ GATC) und schneidet deshalb sehr häufig. Dadurch sollte eine gleichmäßige Verteilung aller vorkommenden DNA-Fragmente erreicht werden. Der Verdau wurde zeitlimitiert über einen Zeitraum von 5 min durchgeführt. Zu verschiedenen Zeiten wurden Aliquots abgenommen und der Verdau mit EDTA abgestoppt. Nach Analyse des Verdaues durch Agarosegelelektrophorese (Abb. 26 A) wurde die DNA mittels Saccharose-Dichtegradienten-Zentrifugation größenfraktioniert (s. 2.12.1). Die DNA wurde gefällt (s. 2.7.3.2), analysiert (Abb. $26 \mathrm{~B}$ ) und DNA-Fragmente zwischen 2 und $10 \mathrm{kbp}$ wurden für anschließende Klonierungen eingesetzt. Abb. 26 zeigt die Analyse des partiellen Verdaus sowie der Saccharose-Dichtegradienten-Zentrifugation anhand der DNA des Standortes Avachinsky. Die DNA des Standortes Dachnie wurde auf die gleiche Weise behandelt. 
A)

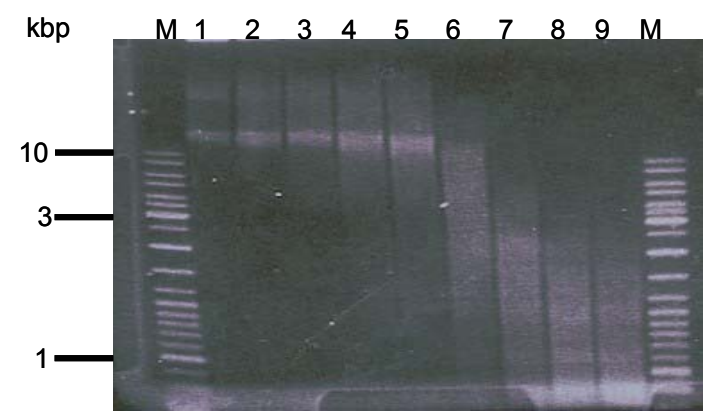

B)

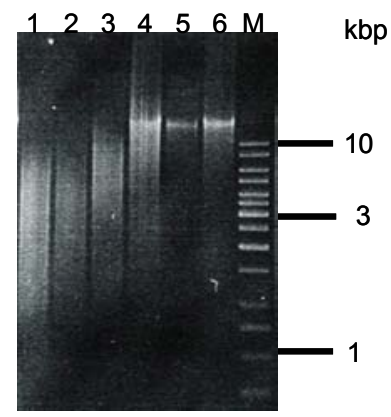

Abb. 26: Elektrophoretische Trennung partiell verdauter und durch SaccharoseDichtegradienten-Zentrifugation größenfarktionierte metagenomische DNA des Standortes Avachinsky. A) Partieller Verdau metagenomischer DNA des Standortes Avachinsky mit dem Restriktionsenzym Bsp143I (s. 2.11.1). Spur 1-9: Dauer des partiellen Verdaus. Spur 1: 20 Sekunden partieller Verdau. Spur 2: 40 Sekunden partieller Verdau. Spur 3: 60 Sekunden partieller Verdau. Spur 4: 90 Sekunden partieller Verdau. Spur 5: 120 Sekunden partieller Verdau. Spur 7:150 Sekunden partieller Verdau. Spur 8: 180 Sekunden partieller Verdau. Spur 9: 240 Sekunden partieller Verdau. B) Fraktionen metagenomischer DNA nach Saccharose-Dichtegradienten-Zentrifugation (s. 2.12.1). Spur 1: Fraktion 17. Spur 2: Fraktion 20. Spur 3: Fraktion 24. Spur 4: Fraktion 27. Spur 5: Fraktion 30. Spur 6: Fraktion 33.

\subsubsection{Konstruktion einer Plasmid-Genbank aus metagenomischer DNA des Standortes Avachinsky mittels T4-Ligase}

Für die Herstellung einer Plasmid-Genbank mit Hilfe der T4-Ligase (Fermentas) wurde der Vektor pBlueskript II SK ${ }^{+}$ausgewählt, welcher in E. coli in hoher Kopienzahl gebildet wird und sich deshalb für spätere enzymaktivitätsbasierende Screenings gut eignet, da auch die Detektion von schwach exprimierten Fremdgenen ermöglicht wird. Über eine Ampicillinresistenz war es möglich, Transformanten zu selektieren und über das ebenfalls vektorkodierte lacZ-Gen konnten rekombinate Plasmide durch den XGal-Test (s. 2.16.4) identifiziert werden. Dieser Vektor wurde mit dem Restriktionsenzym BamHI linearisiert und mit alkalischer Phosphatase dephosphoryliert, um eine Religation des Vektors in größerem Umfang zu verhindern (s. 2.11.2.3). Saccharose-Dichtegradienten-Zentrifugationsfraktionen mit DNA Fragmenten zwischen 2 und $10 \mathrm{kbp}$ wurden nun mit Hilfe der T4Ligase in den Vektor pBlueskript II SK ${ }^{+}$ligiert (s. 2.11.4). Die Ligationsansätze wurden anschließend in E. coli Top10 bzw. E. coli DH5 $\alpha$ transformiert und auf LB-Ampicillin-Agar mit X-Gal und IPTG ausplattiert (s. 2.3.1). Zur Charakterisierung der Genbank wurde das das Verhältnis von inserttragenden 
zu insertlosen Plasmiden bestimmt. Außerdem wurden die Plasmide von 30 Kolonien präpariert und mit dem Restriktionsenzym EcoRI verdaut (s. 2.11.1). Dadurch konnte die durchschnittliche Insertgröße der Plasmidgenbank ermittelt werden. Es konnte eine Genbank bestehend aus 20000 inserttragenden Klonen konstruiert werden. Die Eigenschaften der konstruierten Metagenombank ist in Tab. 9 zusammengefasst. Zur Konservierung der Genbank wurden die Klone von den Platten abgeschwemmt, die Plasmide isoliert und bei $-20^{\circ} \mathrm{C}$ gelagert.

\subsubsection{Konstruktion von Plasmid-Genbanken aus metagenomischer DNA der Standorte Avachinsky und Dachnie mit Hilfe des TOPO-TA- Systems}

Eine weitere Methode zur Herstellung von Plasmid-Genbanken stellt das TOPO-TA-Klonierungs-System der Firma Invitrogen (Carlsbad) dar. Die Verwendung des „TOPO-TA-Cloning $®$ “-Kits (s. 2.11.3) zur Klonierung der Standort-DNA setzte jedoch das Vorhandensein eines einzelnen Desoxyadenosin (A) am 3'-Ende der DNA voraus, da der bereits linearisierte Vektor pCR2.1-TOPO bzw. PCR-XL-TOPO an seinen 3'-Enden ein Desoxythymidin-Rest (T) besitzt. Aus diesem Grund wurden die größenfraktionierten DNA-Fragmente (s. 2.12.1) an ihren Enden „blunt-end“ aufgefüllt (s. 2.11.2.1) und anschließend ein Desoxyadenosin am 3'-Ende angehängt (s. 2.11.2.2). Abschließend wurde die DNA dephosphoryliert (s. 2.11.2.3) und in den Vektor pCR2.1-TOPO bzw. pCR-XL-TOPO inseriert (s. 2.11.3). Nach Transformation in Escherichia coli TOP10 (s. 2.16.1/2) wurden die Zellen auf LB-Ampicillin- bzw. Kanamycin-Platten mit IPTG und X-Gal ausplattiert. Zur Ermittlung der durchschnittlichen Insertgrößen wurden pro Genbamk 30 Klone in LB-Ampicillin-Medium angezogen und deren Plasmide isoliert (s. 2.8.4). Mittels Restriktionsverdau konnte die durchschnittliche Insertgröße bestimmt werden. Zur Konservierung wurden die Klone von den Platten abgeschwemmt, deren Plasmide isoliert und bei $-20^{\circ} \mathrm{C}$ gelagert. Für den Standort Avachinsky konnten auf diese Weise 98000 rekombinaten Plasmide konstruiert werden. Für den Standort Dachnie 21000. Die Eigenschaften dieser Metagenombanken sind in Tab. 9 zusammengefasst. 


\subsubsection{Konstruktion einer Fosmid-Metagenombank aus metagenomischer DNA des Standortes Avachinsky}

Für die Klonierung von sehr großen DNA Fragmenten ab $25 \mathrm{kbp}$ wurde das "CopyControl ${ }^{\mathrm{TM}}$ Fosmid Library Production Kit" der Firma Epicentre (Madison, USA) ausgewählt. Die Klonierung von sehr großen DNA Fragmenten bietet den Vorteil des Screenings nach ganzen Genclustern bzw. liefert nach Sequenzierungsarbeiten einen Einblick in die Organisation verschiedener Gene im Genom des noch unbekannten Organismus. Das "CopyControl ${ }^{\mathrm{TM}}$ Fosmid Library Production Kit" der Firma Epicentre ermöglicht die Klonierung von DNA Fragmenten einer Größe zwische 25 und 40 kbp.

Die wie unter 3.1 beschrieben isolierte metagenomische DNA des Standortes Avachinsky musste für diese Klonierung allerdings nicht größenfraktioniert werden, da sie durch das Auftreten von Scherkräften bei der Isolierung die DNA ausreichend fragmentiert war. Die Klonierung wurde wie unter 2.16.3.1 durchgeführt. Zunächst wurde die DNA „blunt-end“ aufgefüllt, in den Fosmidvektor pCC1FOS ligiert und in Phagenköpfe verpackt. Nach Transduktion des E. coli Stammes EPI300-T1R durch die Phagen wurden die Ansätze auf LB-Chloramphenicol-Agarplatten ausplattiert. Für die Charakterisierung der Fosmid-Genbank wurden 15 Klone in LBChloramphenicol angezogen und die Fosmide präpariert (s. 2.8.4.4). Die Fosmide wurden mit dem Restriktionsenzym EcoRI verdaut, um eine durchschnittliche Insertgröße zu ermitteln und die Diversität der Fosmide zu bestätigen.

Diese Fosmid-Genbank umfasst eine Größe von 5200 Klonen mit einer durchschnittlichen Insertgröße von $35 \mathrm{kbp}$ (s Tab. 9) und wurde zur Konservierung in mit LB-Chloramphenicol-Medium versetzten Mikrotiterplatten gepickt, über Nacht bei $37^{\circ} \mathrm{C}$ inkubiert, mit $10 \%(\mathrm{v} / \mathrm{v})$ DMSO versetzt und bei $-70^{\circ} \mathrm{C}$ gelagert. 
Tab. 9 Aufstellung aller im Rahmen dieser Arbeit konstruierten Umweltgenbanken und ihre Charakteristika

\begin{tabular}{|c|c|c|c|c|c|c|}
\hline Standort & Klonierungsvektor & Genbankbezeichnung & $\begin{array}{c}\text { Anzahl } \\
\text { rekombinanter } \\
\text { Klone }\end{array}$ & Ø Insertgröße & Inserthäufigkeit & $\begin{array}{c}\text { Gesamt } \\
\text { DNA [Mbp] }\end{array}$ \\
\hline Avachinsky & pBlueskript II SK $^{+}$ & A1 & 20000 & $2 \mathrm{kbp}$ & $90 \%$ & 40 \\
\hline Avachinsky & $\mathrm{pCR} 2.1$ & A2 & 23000 & $2,5 \mathrm{kbp}$ & $90 \%$ & 57,5 \\
\hline Avachinsky & $\mathrm{pCR}-\mathrm{XL}$ & A3 & 75000 & $3,5 \mathrm{kbp}$ & $70 \%$ & 262,5 \\
\hline Dachnie & pCR2.1 & $\mathrm{D} 1$ & 21000 & $1,5 \mathrm{kbp}$ & $80 \%$ & 31,5 \\
\hline Avachinsky & pCC1FOS & FosA & 5200 & $35 \mathrm{kbp}$ & $100 \%$ & 182 \\
\hline \multicolumn{3}{|c|}{ Zusammenfassung aller Genbanken: } & 144200 & $8,9 \mathrm{kbp}$ & $86 \%$ & 573,5 \\
\hline
\end{tabular}


Insgesamt wurden im Rahmen dieser Arbeit 5 Metagenombanken konstruiert. Es konnten vier „small-insert“ Genbanken in unterschiedlichen Klonierungsvektoren konstuiert werden. Drei von ihnen entstammen dem Standort Avachinsky und eine dem Standort Dachnie. Die durchschnittlichen Insertgrößen liegen zwischen 1,5 kbp und 3,5 kbp. Die umfangreichste PlasmidMetagenombank wurde aus metagenomischer DNA des Stanortes Avachinsky konstruiert und umfasst 75000 rekombinante Plasmide und einer durchschnittlichen Insertgröße von 3,5 kbp. Zusätzlich konnte eine Fosmidgenbank des Standortes Avachinsky konstruiert werden. Sie besteht aus 5200 rekombinaten Fosmiden mit einer durchschnittlichen Insertgröße von 35 kbp. Insgesamt wurden 573,5 Mbp metagenomischer DNA der Standorte Avachinsky und Dachnie kloniert.

Die konstruierten Metagenombanken dienten der Suche nach neuartigen Genen, welche lipolytische- oder proteolytische Aktivität vermitteln.

\subsection{Screening der Standort-Genbanken auf lipolytische Aktivität}

Um das genetische Potential der konstruierten Metagenombanken zu untersuchen bzw. zu nutzen, um neuartige Biokatalysatoren zu entdecken, wurden verschiedene Aktivitäts-Screenings durchgeführt. Ein Ziel dieser Arbeit war das Screening nach Enzymen mit lipolytischer Aktivität. Die hierzu verwendete Screeningmethode erfolgte durch Aufstempeln der 5200 FosmidKlone oder Transformation der zur Konservierung präparierten PlasmidGenbanken in E. coli TOP10 und Ausplattieren auf LB-Agarplatten (s. 2.3.3) mit $1 \%$ (v/v) Tributyrin als Indikator (LAWRENCE et al.1967). Die Platten wurden bei $37{ }^{\circ} \mathrm{C}$ für 1-2 Tage inkubiert gefolgt von einer Inkubation bei $60{ }^{\circ} \mathrm{C}$ über Nacht. Die lipolytische Aktivität zeigte sich durch eine Hofbildung um den entsprechenden Klon (s.Abb. 27). 


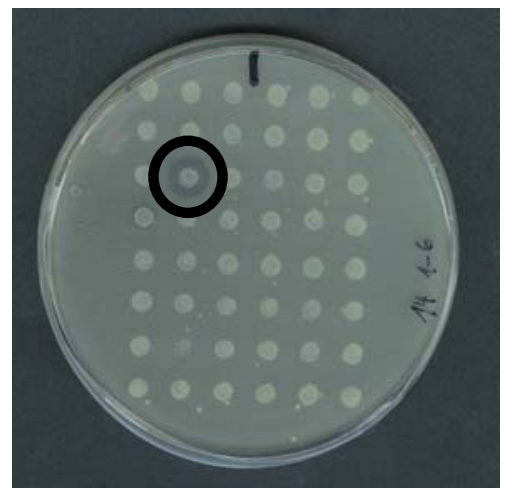

Abb. 27: Plattentestverfahren zur Erkennung lipolytischer Aktivität (s. 2.16.5). Der Kreis markiert einen rekombinanten $E$. coli Stamm der Fosmidgenbank FosA, welcher lipolytische Aktivität zeigt.

Die Durchmusterung der 5200 Fosmidklone ergab vier Treffer. Aus den Plasmid-Genbanken konnte kein positiver Klon ermittelt werden. Die Fosmide dieser vier Klone wurden anschließend präpariert. Mittels Restriktionsverdau wurde überprüft, ob es sich tatsächlich um unterschiedliche Fosmidklone handelte. Des Weiteren ergaben sich für die Klone, welche fortlaufen als pFosJS1-4 bezeichnet werden Insertgrößen zwischen 20 und $45 \mathrm{kbp}$.

Nach Retransformation der Fosmide in E. coli EPI300-T1R zeigten alle Klone einen stabilen lipolytischen Phänotyp.

\subsubsection{Identifizierung eines ORFs mit lipolytischer Aktivität aus pFosJS1 durch Subklonierung und Sequenzierung}

Durch Subklonierung des Fosmides pFosJS1 mit BamHI bzw. Bsp143I in die Vektoren pBlueskript II SK+ und pCR4-TOPO konnten vier aktive Subklone ermittelt werden. Die Plasmidinserts der gescreenten Subklone wurden ansequenziert und durch anschließendes „Primer-walking“ konnte ein ORF von 816 bp und einem GC-Gehalt von 60,7 ermittelt werden. Dieser wurde als estJS1 bezeichnet. Der ORF kodiert für 271 Aminosäuren mit einer Molekularmasse von 30,03 kDa und einem isoelektrischen Punkt von 6,86. Ein Datenvergleich mittels blastp in der NCBI-Datenbank ergab eine Identität von $45 \%$ im Bereich der Aminosäuren 1 bis 264 zu dem Protein BioH aus dem Organismus Kurthia sp. 538-KA26. Die komplette Nukleotid- und 
Aminosäuresequenz ist in Abb. 28 gezeigt. In der Aminosäuresequenz von estJS1 findet man die für Esterasen bzw. Lipasen typischen KonsensusSequenzen Gly-X-Ser-X-Gly, die das aktive Serin umgeben. In diesem Fall findet man die Aminosäuresequenz Gly-Val-Ser-Met-Gly (s. Abb. 28). Nach ARPIGNY und JÄGER (1999) lässt sich das Protein EstJS1 somit in die Familie V der Esterasen und Lipasen einteilen. Abb. 29 zeigt ein Alignment von EstJS1 mit BioH aus Kurthia sp. 538-KA26. Dort sind die Aminosäuren der katalytischen Triade und die putativen konservierten Bereiche der Esterasen bzw. Lipasen der Familie V dargestellt.

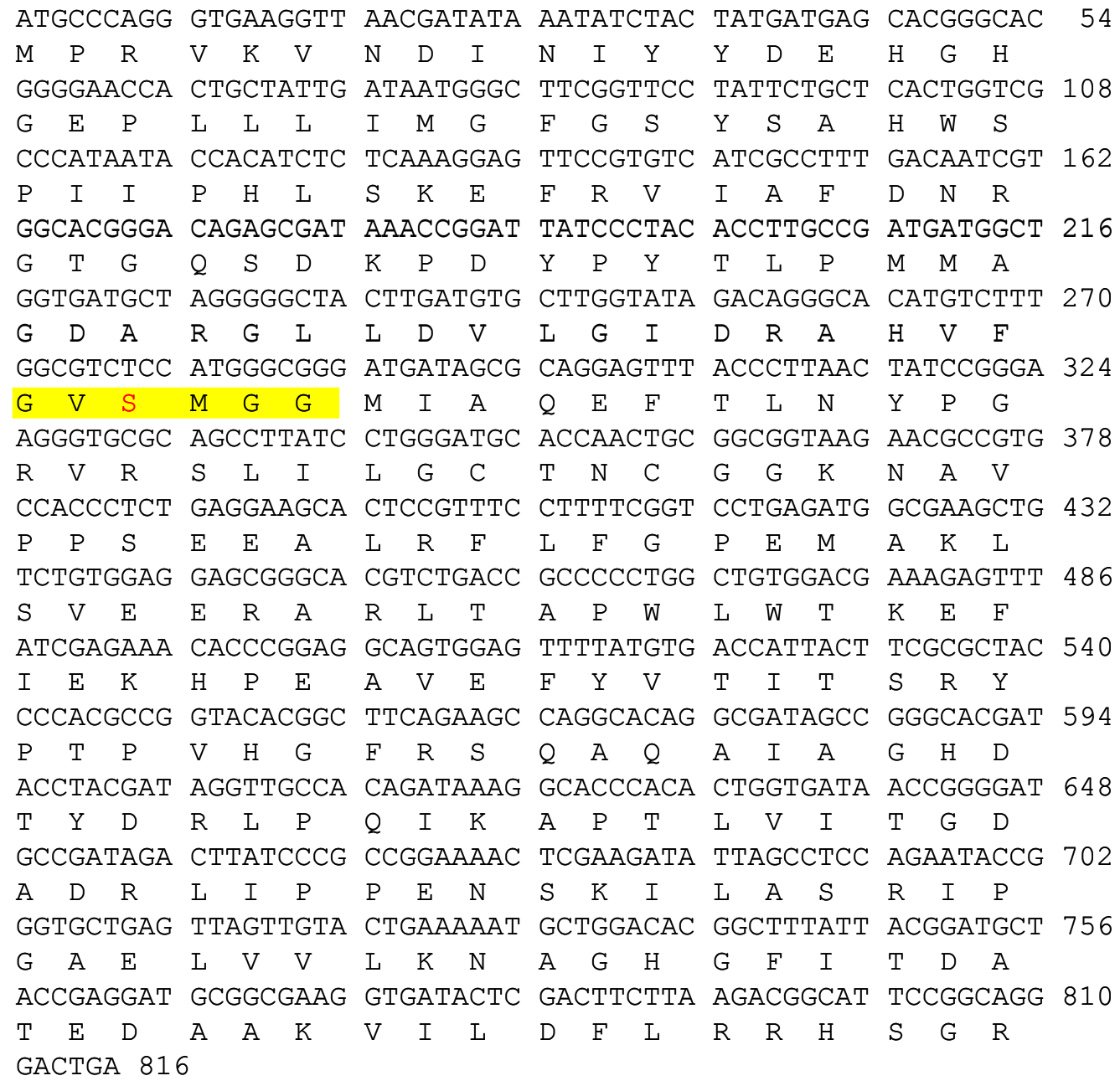

Abb. 28: Nukleotid- und Aminosäuresequenz von EstJS1. Das für Esterasen und Lipasen der Familie $V$ typische Strukturmotiv G-V-S-M-G-G ist gelb hintelegt. Rot kennzeichnet das aktive Serin. 


\begin{tabular}{|c|c|c|}
\hline $\mathrm{BioH}$ & 1 & ---MPFVNHDNESLYYEVHGQGDPLLLIMGLGYNSLSWH- \\
\hline EstJS1 & 1 & ---MPRVKVNDINIYYDEHGHGEPLLLIMGFGSYSAHWS- \\
\hline $\mathrm{BioH}$ & 37 & RTVPTLAKRFKVIVFDNRGVGKSSKPEQ-------PYSIE \\
\hline EstJS1 & 37 & PI IPHLSKEFRVIAFDNRGTGQSDKPDY-------PYTLP \\
\hline $\mathrm{BioH}$ & 70 & MMAEDARAVLDAVSVDSAHVYGISMGGMIAQRLAITYPER \\
\hline EstJS1 & 70 & MMAGDARGLLDVLGIDRAHVFGVSMGGMIAQEFTLNYPGR \\
\hline $\mathrm{BiOH}$ & 110 & VRSLVLGCTTAGGTTHIQPSPEISTLMVSRASLTGSPRDN \\
\hline EstJS1 & 110 & VRSLILGCTNCGGKNAVPPSEEALRFLFGPEMAKLSVEER \\
\hline $\mathrm{BioH}$ & 150 & AWLAAPIVYSQAFIEKHPELIQEDIQKRIEIITP--PSAY \\
\hline EstJS1 & 150 & ARLTAPWLWTKEFIEKHPEAVEFYVTITSRYPTP--VHGF \\
\hline $\mathrm{BioH}$ & 188 & LSQLQACLTHDTSNELDKINI PTLI I HGDADNLVPYENGK \\
\hline EstJS1 & 188 & RSQAQAIAGHDTYDRLPQIKAPTLVITGDADRLI PPENSK \\
\hline $\mathrm{BioH}$ & 228 & MLAERIQGSQFHTVS-CAGHIYLTEAAKEANDKVIQFLAH \\
\hline EstJS1 & 228 & ILASRIPGAELVVLK-NAGHGFITDATEDAAKVILDFLRR \\
\hline $\mathrm{BioH}$ & 267 & L------------- 267 \\
\hline EstJS1 & 267 & HSGRD--------- 271 \\
\hline
\end{tabular}

Abb. 29: Mittels ClustalW erstelltes Alignment von EstJS1 mit BioH aus Kurthia sp. 538KA26. Putative Aminosäuren der katalytischen Triade sind rot dargestellt. Putative konservierte Bereiche für Esterasen und Lipasen der Familie $V$ im Bereich der katalytischen Triade sind gelb umrahmt (G-X-S-X-G-G, P-T-X-X-X-X-G-X-X-D, G-H ARPIGNY und JÄGER 1999).

\subsubsection{Heterologe Expression des estJS1-Gens}

Zur heterologen Expression, Reinigung und biochemischen Charakterisierung wurde der ORF estJS1 in den Expressionsvektor pET101/D-TOPO kloniert. Nach erfolgreicher Klonierung und heterologer Expression sollte das Genprodukt mit einem C-terminalen $\mathrm{His}_{6}$-Tag und einem V5-Epitop versehen sein (s. 2.4.3). Die Expression des Proteins konnte dann durch spezifische $\mathrm{His}_{6}{ }^{-}$ bzw. V5-Antikörper in Western-Blot Analysen nachgewiesen werden. Die Reinigung sollte schließlich mittels Nickel-TED-Affinitätschromatographie (s. 2.17.5.1) erfolgen. Der ORF estJS1 wurde mit den Primern ESTJS1_for und ESTJS1_rev (s Tab. 4) durch den Einsatz der Pfu-DNA-Polymerase amplifiziert, in den Vektor pET101/D-TOPO kloniert, in den E. coli Stamm TOP10 transformiert (s. 2.16.1) und auf LB-Ampicillin-Agarplatten ausplattiert. Zur Überprüfung der Klonierung wurden aus 10 Klonen die Plasmide präpariert (s. 2.8.4). Die richtige Orientierung des DNA-Fragments in dem Vektor wurde mittels Restriktionverdau überprüft. Zusätzlich erfolgte ein Sequenzierung des Inserts durch das „Göttingen Genomic Laboratory“. 
Für die Expression wurde dieses Konstrukt in den E. coli Stamm BL21 transformiert und der Stamm mit E. coli/BL21/estJS1 bezeichnet. Der Ansatz wurde zunächst auf LB-Ampicillin-Agarplatten mit IPTG und Tributyrin als Indikator ausplattiert (s. 2.3.3). Durch Bildung eines Hofes um die Kolonien konnte die lipolytische Aktivität des produzierten Proteins bestätigt werden. Zusätzlich erfolgte eine Kontrolle der Expression durch eine Western-BlotAnalyse (s. 2.17.8). Zunächst wurde der Rohextrakt der Expressionskultur elektrophoretisch durch SDS-PAGE (s. 2.17.6) aufgetrennt, anschließend auf eine Nitrocellulosemembran geblottet und die Expression durch Immunodetektion mittels Anti-V5-AP-Antikörper bestätigt. Das Ergebnis ist in Abb. 30 dargestellt.

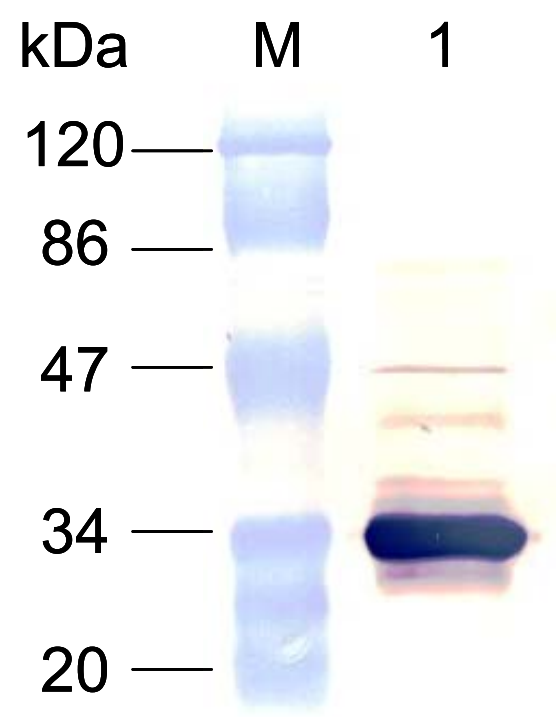

Abb. 30: Nachweis der heterologen Expression von EstJS1 durch Western-Blot-Analyse (2.17.9). M: Größenstandard 1:Ein Rohextrakt von E. coli/BL21/estJS1 wurde elektrophoretisch durch SDS-PAGE (s. 2.17.6) aufgetrennt, auf Nitocellulose-Membran geblottet und durch Immunodetektion mittels Anti-V5-Antikörper nachgewiesen (s. 2.17.8).

Bei etwa 34 kDa zeigt sich die deutliche Detektion eines Proteins. Addiert man zu EstJS1 den C-terminalen $\mathrm{His}_{6}$-Tag und das V5-Epitop kommt man auf eine Molekularmasse von 33,57 kDa, was in etwa dieser deutlichen Bande 
entspricht. Die Expression des Proteins konnte also mittels Western-Blot Analyse bestätigt werden. Nun erfolgte die Reinigung des Proteins über NickelTED-Affinitätschromatographie (s. 2.17.5.1). Dazu wurde 1 L LB-Medium mit einer Vorkultur des E. coli/BL21/estJS1-Stammes beimpft und bis zu einer $\mathrm{OD}_{600}$ bei $37{ }^{\circ} \mathrm{C}$ (s. 2.4.1) inkubiert. Danach erfolgte die Induktion mit 0,1 mM IPTG. Nach weiteren 6 Stunden Inkubation wurden die Zellen geerntet. Mittels French-Press-Apparatur wurde ein Rohextrakt hergestellt (s. 2.17.2). EstJS1 wurde dann mittels Nickel-TED-Affinitätschromatographie (s. 2.17.5.1) über eine Protino 2000 Säule aufgereinigt. Die Reinigungsschritte wurden durch eine SDS-PAGE dokumentiert. Die Ergebnisse sind in Abb. 31 dargestellt. Spur 1 zeigt den Durchlauf der Rohextraktes von E. coli/BL21/estJS1 durch die Protino 2000 Säule, bzw. das nicht an die Säule gebundene Protein. Spur 2 zeigt die Waschfraktion und Spur 3 und 4 stellen die Elutionfraktionen dar. Es wurde zweimal mit jeweils $2 \mathrm{ml}$ Elutionpuffer (s. 2.17.5.1) und $250 \mathrm{mM}$ Imidazol eluiert. In Spur 3 und 4 zeigt sich eine Bande bei ca. 34 kDa. Dies entspricht der Molekularmasse von EstJS1 nach heterologer Expression in E. coli BL21.

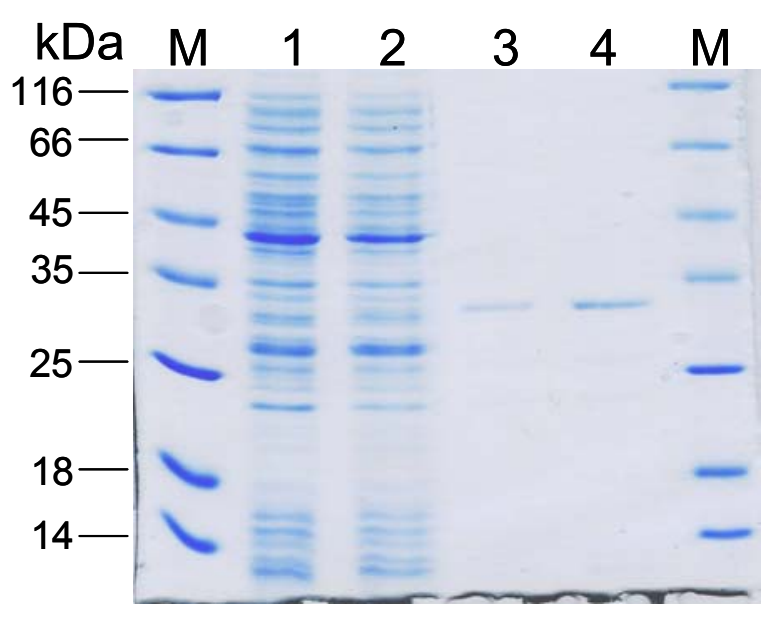

Abb. 31: Aufreinigungsschritte von EstJS1 über Nickel-TED-Affinitätschromatographie. M: Proteinmarker, Spur 1 zeigt den Durchlauf der Rohextraktes von E. coli/BL21/estJS1 durch die Protino 2000 Säule, bzw. das nicht an die Säule gebundene Protein. Spur 2 zeigt die Waschfraktion und Spur 3 und 4 stellen die Elutionfraktionen dar. Es wurde zweimal mit jeweils $2 \mathrm{ml}$ Elutionpuffer (50 mM Na-Phosphatpuffer, $250 \mathrm{mM}$ Imidazol s 2.17.5.1) eluiert 


\subsubsection{Nachweis von EstJS1 mittels Aktivitätsgelelektrophorese}

Die zuvor ermittelte Molekularmasse von EstJS1 konnte ebenfalls durch SDSPAGE mit anschließendem Aktivitätsnachweis bestätigt werden. Dazu erfolgte zunächst die Auftrennung des unter 3.4.1 gereinigten Proteins im 12\%igen SDS-Polyacrylamidgel. Anschließend wurde das Gel wie unter 2.17.7 beschrieben mit Isopropanol und zweimal mit $\mathrm{H}_{2} \mathrm{O}_{\text {dest. }}$ gewaschen und schließlich für wenigstens 16 Stunden bei RT auf einem LipaseaktivitätsTestagar inkubiert. Der Marker und eine weitere Spur, auf welcher EstJS1 aufgetrennt wurde, wurden mit Coomasie gefärbt (s. 2.17.6). Das Ergebnis der Aktivitätsfärbung ist in Abb. 32 dargestellt.

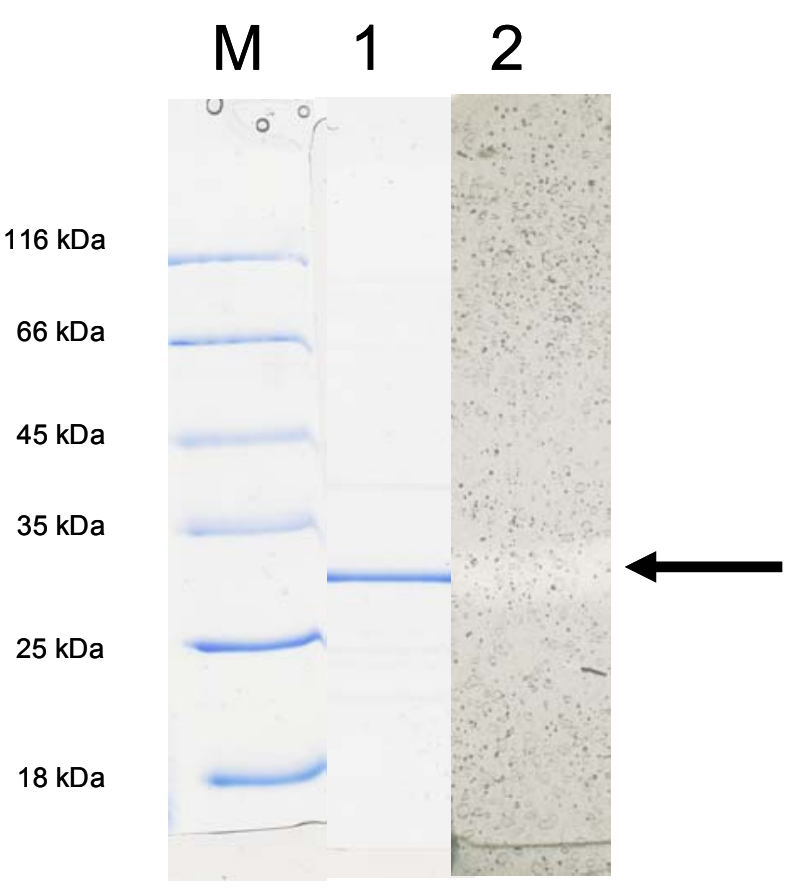

Abb. 32: Aktivitätsfärbung von EstJS1. M: Proteinstandard, 1 Coomassie-Färbung der gereinigten Proteins EstJS1, 2 Aktivitätsfärbung von EstJS1. Der Pfeil markiert die Aufklarung des Testagars (2.17.7) durch lipolytische Aktivität von EstJS1

Durch Inkubation des aufgetrennten Proteins auf dem Testagar kam es zur Aufklarung auf der Höhe des Comassie-gefärbten Proteins. Die Bande lag bei ca. $34 \mathrm{kDa}$. Dies entspricht der Molekularmasse von EstJS1 nach heterologer Expression in E. coli BL21. 


\subsubsection{Bestimmung der lipolytischen Aktivität von EstJS1 in Abhängigkeit der Temperatur}

Die lipolytische Aktivität von EstJS1 wurde wie unter 2.17.4.1 beschrieben mit pNP-Caprylat als Substrat durchgeführt. Die Puffersubstratmischung sowie EstJS1 wurden dafür bei Temperaturen zwischen 10 und $70{ }^{\circ} \mathrm{C}$ für $5 \mathrm{~min}$ getrennt vorinkubiert. Die Reaktion wurde durch Zugabe des Enzyms zum Substratpuffergemisch gestartet und dauerte $10 \mathrm{~min}$. Der gesamte Verlauf ist in Abb. 33 dargestellt. Es zeigte sich Aktivität über einen weiten Temperaturbereich mit einem Optimum von $23 \mathrm{U} / \mathrm{mg}$ bei ca. $37^{\circ} \mathrm{C}$. Bei $60{ }^{\circ} \mathrm{C}$ konnte noch ca. $24 \%$ der maximalen Aktivität gemessen werden. Bei $70{ }^{\circ} \mathrm{C}$ waren es nur noch eine geringe Aktivität von ca. $7 \%$. Zwischen 10 und $50{ }^{\circ} \mathrm{C}$ wurden mindestens $50 \%$ der maximalen lipolytischen Aktivität erreicht.

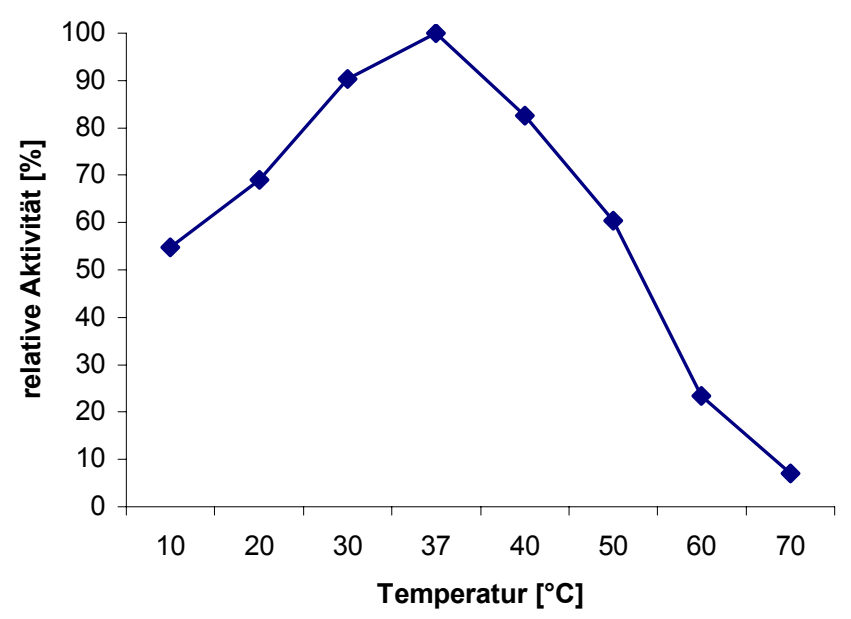

Abb. 33: Abhängigkeit der lipolytischen Aktivität von EstJS1 von der Temperatur. Die Substratenzympuffergemische wurde für $10 \mathrm{~min}$ bei den verschiedenen Temperaturen inkubiert und die Aktivität wie unter 2.17.4.1 beschrieben bestimmt. Als $100 \%$ wurde die spezifische Aktivität von EstJS1 von $23 \mathrm{U} / \mathrm{mg}$ bei $37^{\circ} \mathrm{C}$ gesetzt.

\subsubsection{Bestimmung der Temperaturstabilität von EstJS1}

Für die Ermittlung der Temperaturstabilität wurde das Enzym 2,5 $\mathrm{h}$ bei Temperaturen zwischen $45{ }^{\circ} \mathrm{C}$ und $60{ }^{\circ} \mathrm{C}$ inkubiert und es wurde in regelmäßigen Abständen die Restaktivität ermittelt (s. 2.17.4.1). Die jeweils größte spezifische Aktivität wurde dabei als $100 \%$ festgelegt. Bei $45{ }^{\circ} \mathrm{C}$ lag sie 
bei $23,7 \mathrm{U} / \mathrm{mg}$, bei $50{ }^{\circ} \mathrm{C}$ bei $18,2 \mathrm{U} / \mathrm{mg}$ und bei $60{ }^{\circ} \mathrm{C}$ bei $5 \mathrm{U} / \mathrm{mg}$. Als Substrat diente dabei pNP-Caprylat. Es zeigte sich, dass EstJS1 bei Temperaturen zwischen $45{ }^{\circ} \mathrm{C}$ und $50{ }^{\circ} \mathrm{C}$ über den gesamten Zeitraum von 2,5 h 20-30\% seiner Gesamtaktivität einbüßt, dann aber relativ stabil bleibt. Nach weiteren 2,5 h Inkubation zeigte sich bei diesen Temperaturen immer noch eine Restaktivität von ca. $50 \%$ (Daten nicht gezeigt). Bei $60{ }^{\circ} \mathrm{C}$ hingegen konnte schon nach 60 min nur noch $40 \%$ der Gesamtaktivität ermittelt werden und nach 2,5 h zeigte sich nur noch eine geringe Restaktivität von 20 \% im Vergleich zur größten spezifischen Aktivität bei $60{ }^{\circ} \mathrm{C}$. Der Verlauf der Messungen ist in Abb. 34 gezeigt.

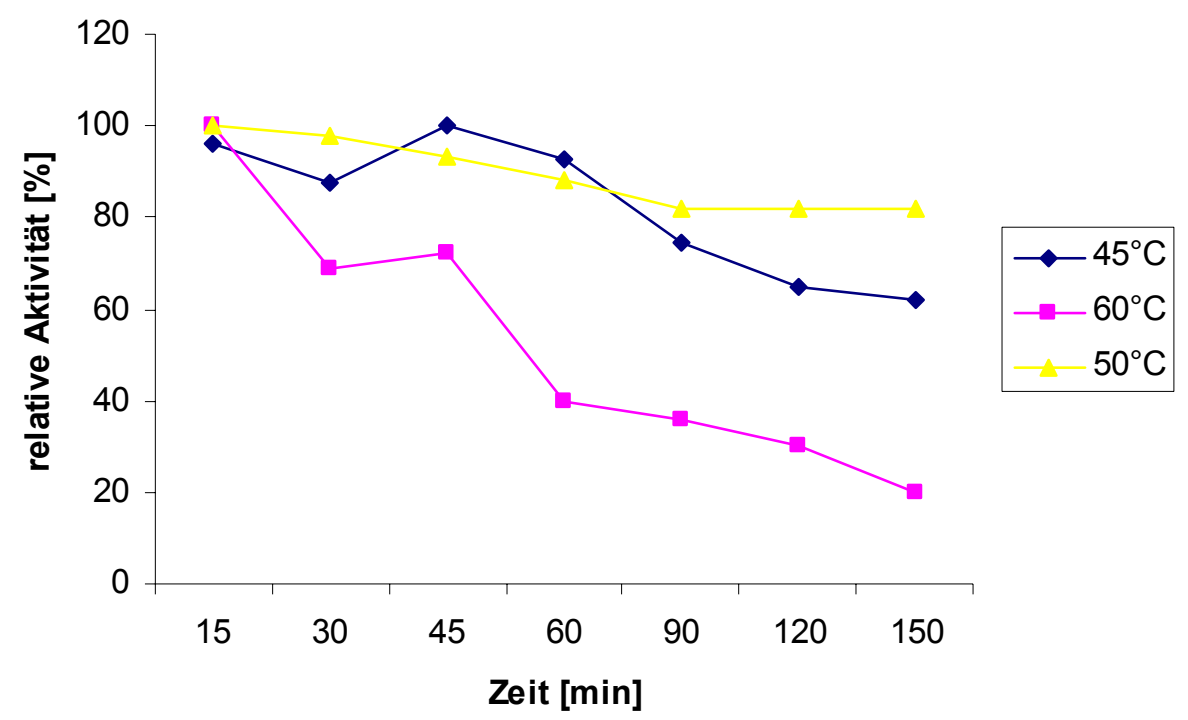

Abb. 34: Relative Aktivität von EstJS1 in Abhängigkeit der Zeit bei 45,50 und $60{ }^{\circ} \mathrm{C}$. Die Substratenzympuffergemische wurden für $2,5 \mathrm{~h}$ bei den verschiedenen Temperaturen inkubiert und Aktivität wie unter 2.17.4.1 beschrieben bestimmt. Als $100 \%$ wurde die jeweils größte spezifische Aktivität von EstJS1 festgelegt. Bei $45^{\circ} \mathrm{C}$ lag sie bei $23,7 \mathrm{U} / \mathrm{mg}$, bei $50{ }^{\circ} \mathrm{C}$ bei 18,2 $\mathrm{U} / \mathrm{mg}$ und bei $60^{\circ} \mathrm{C}$ bei $5 \mathrm{U} / \mathrm{mg}$

\subsubsection{Bestimmung der Aktivität von EstJS1 in Abhängigkeit der Substratkettenlänge}

Für die Ermittlung der spezifischen Aktivität von EstJS1 wurden verschiedene para-Nitrophenyl-Acylester verwendet, welche sich in der Kettenlänge des Fettsäurerestes unterscheiden. Die Aktivität wurde spektrophotometrisch wie 
unter 2.17.4.1 beschrieben bei $37^{\circ} \mathrm{C}$ gemessen. Die Ergebnisse sind in Abb. 35 dargestellt.

Substratspektrum

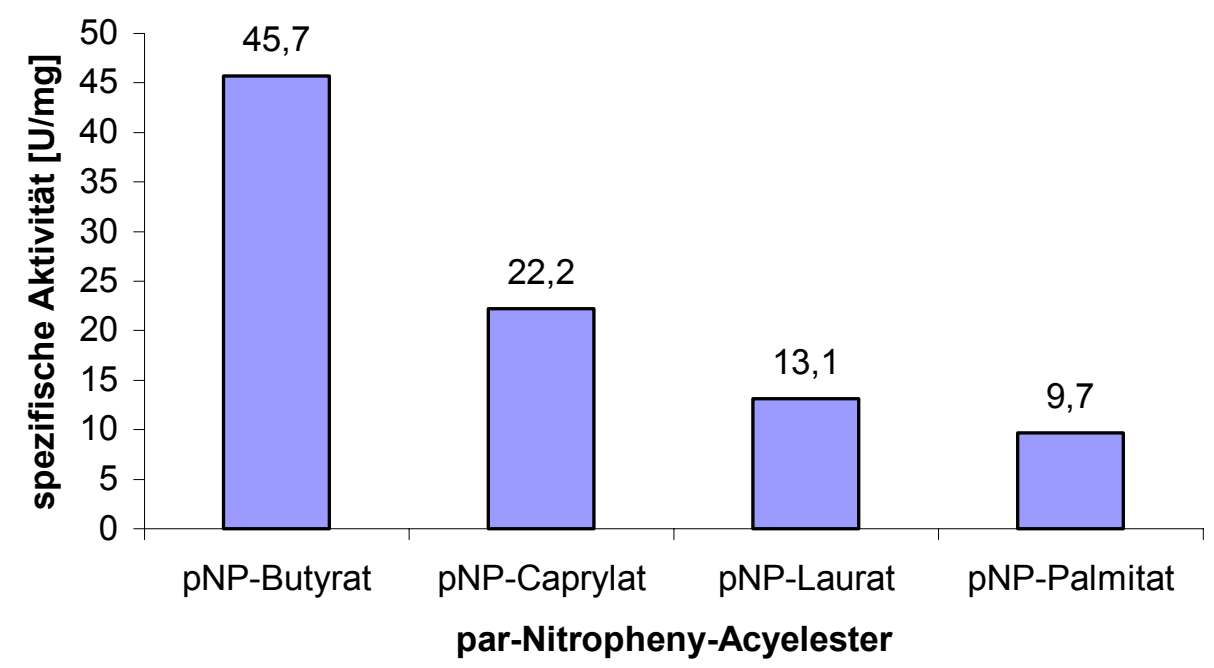

Abb. 35: Spezifische Aktivität von EstJS1 in Abhängigkeit der Substratkettenlänge. Das Substratenzympuffergemisch wurde bei $37^{\circ} \mathrm{C}$ für 10 min inkubiert und die Aktivität wie unter 2.17.4.1 beschrieben bestimmt.

Die größte Aktivität konnte bei kurzkettigen Fettsäureresten ermittelt werden. Für Butyrat (C4) waren es 45,7 U/mg und etwa die Hälfte konnte noch für Laurat (C6) ermittelt werden. Etwa ein Viertel an maximaler Aktivität konnte für das Substrat Caprylat (C8) und etwa ein Fünftel für Palmitat (C10) gemessen werden. Die Ermittlung der Substratkettenspezifität deutet darauf hin, dass es sich bei EstJS1 um eine Esterase handelt und nicht um eine Lipase, da Esterasen bevorzugt kurzkettige Fettsäuren spalten.

\subsubsection{Bestimmung des pH-Stabilität von EstJS1}

Die Aktivität in Abhängigkeit des pH-Wertes von EstJS1 wurde im pH Bereich von 2 bis 12 bestimmt. Dazu wurden verschiedene Puffer Systeme ausgewählt. Die Aktivität von EstJS1 im pH-Bereich zwischen 2 bis 4 sowie 9 bis 12 wurden in Glycin-Puffer (50 mM) durchgeührt. Von pH 3 bis 7 in Natriumphosphat- 
Puffer $(50 \mathrm{mM})$ und $\mathrm{pH} 6$ bis 10 in Tris-Puffer $(50 \mathrm{mM})$. EstJS1 wurde mit den jeweiligen Puffern auf eine Konzentration von 0,03 $\mu \mathrm{g} / \mu$ l eingestellt und bei RT inkubiert. Die Aktivität wurde nach 2 und $48 \mathrm{~h}$ mit para-Nitrophenyl-Caprylat als Substrat und Inkubation für $10 \mathrm{~min}$ bei $37^{\circ} \mathrm{C}$ wie unter 2.17.4.1 beschrieben gemessen und verglichen. Die Ergebnisse sind in den Abb. 36 dargestellt.

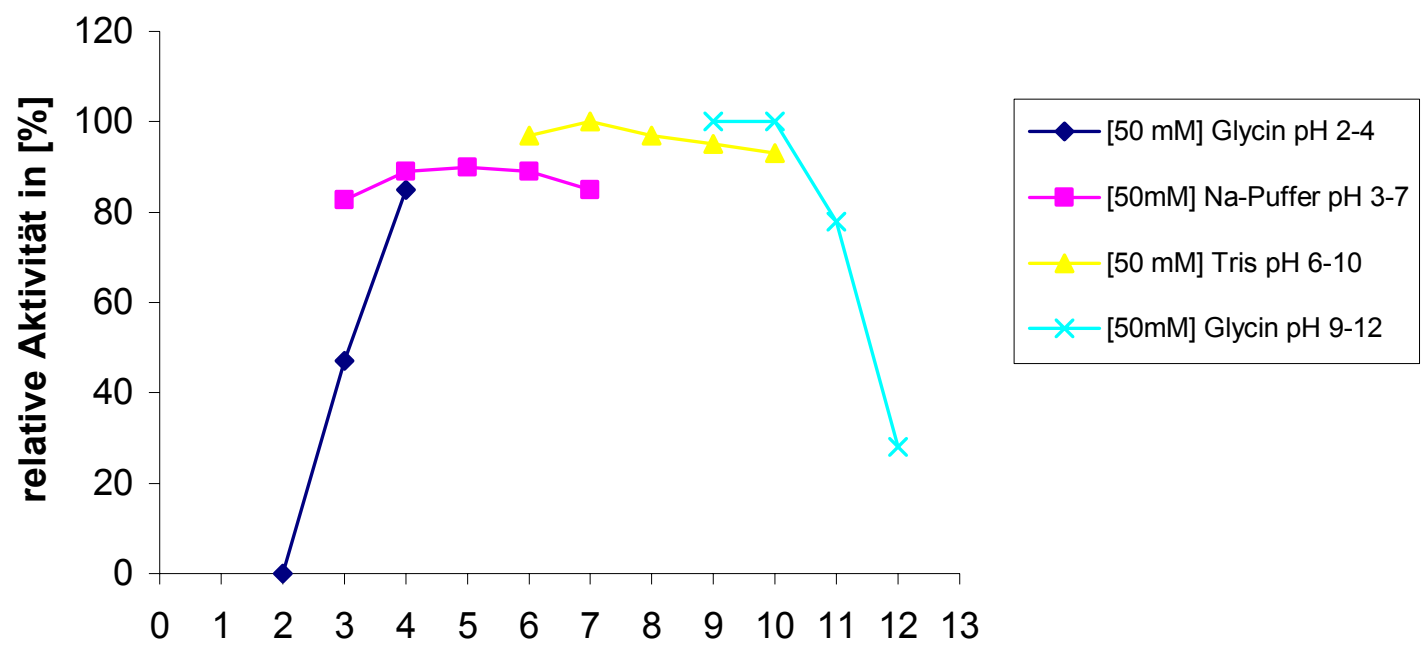

Abb. 36: Relative Aktivität von EstJS1 in Abhängigkeit des pH-Wertes. Die Aktivität wurde nach $2 \mathrm{~h}$ Inkubation bei RT mit para-Nitrophenyl-Caprylat als Substrat und Inkubation für $10 \mathrm{~min}$ bei $37{ }^{\circ} \mathrm{C}$ wie unter 2.17.4.1 beschrieben gemessen Die Aktivität von EstJS1 im pH-Bereich zwischen 2 bis 4 sowie 9 bis 12 wurden in Glycin-Puffer $(50 \mathrm{mM})$ durchgeührt. Von pH 3 bis 7 in Natriumphosphat Puffer $(50 \mathrm{mM})$ und pH 6 bis 10 in Tris-Puffer $(50 \mathrm{mM})$. Als $100 \%$ wurde eine spezifische Aktivität von $11 \mathrm{U} / \mathrm{mg}$ bei pH 10 und 11 festgelegt.

Wie in Abb. 36 zu erkennen ist, ist die höchste Aktivität im pH-Bereich zwischen 10 und 11 gemessen worden. Sie liegt dort nach $2 \mathrm{~h}$ Inkubation bei RT und Aktivitätsmessung bei $37^{\circ} \mathrm{C}$ bei $11 \mathrm{U} / \mathrm{mg}$. Auch bei pH 7 konnte eine nahezu maximale Aktivität bestimmt werden. Rapide nahm jedoch die Aktivität bei $\mathrm{pH}$ Werten über $11 \mathrm{ab}$. Dort konnte nur noch eine Restaktivität von ca. $25 \%$ gemessen werden. Ähnliches zeigte sich bei $\mathrm{pH}-$ Werten unter 4, wo sich die Aktivität pro pH-Einheit halbierte und bei $\mathrm{pH} 2$ schließlich bei nahezu $0 \%$ angekommen war. Insgesamt ziegt sich ein Optimum an Aktivität zwischen $\mathrm{pH}$ 3 und 10. Nach $48 \mathrm{~h}$ Inkubation bei RT und entsprechenden $\mathrm{pH}$-Bereichen konnten jeweils noch Restaktivitäten von wenigstens $90 \%$ im Vergleich zu $2 \mathrm{~h}$ Inkubation bei RT ermittelt werden. Bei pH-Werten unter 5 war fast keine 
Aktivität von EstJS1 zu erkennen. Bei pH 12 waren es nur noch ca. $30 \%$. EstJS1 zeigt insgesamt eine hohe pH-Stabilität im pH-Bereich von 5 bis 11.

\subsubsection{Identifizierung weiterer lipolytischer ORFs}

Wie unter 3.4 beschrieben konnten insgesamt vier lipolytisch aktive Fosmidklone identifiziert werden. Aus zwei weiteren (pFosJS2 und pFosJS3) dieser vier Fosmide konnten bereits die lipolytischen ORFs identifiziert und teilweise charakterisiert werden. Sie wurden mit estJS2 und estJS3 bezeichnet. Die Fosmide der jeweiligen Klone wurden wie unter 2.8.4.4 beschrieben präpariert und mittels Ultraschall (s. 2.10.1) in unspezifisch große Bruchstücke fragmentiert. Über Agarosegelelektrophorese (s. 2.9.1) wurden diese Bruchstücke größenfraktioniert und Fragmente zwischen 3 und $8 \mathrm{kbp}$ wie unter 2.11.2/3 beschrieben in den Vektor pCR-XL-TOPO ligiert und in E. coli TOP10 transformiert (s. 2.16.2). Die erhaltenen Subklone wurden in Mikrotiterplatten konserviert (s. 2.4.4) und diese erneut auf lipolytische Aktivität überprüft. Für pFosJS2 konnten neun Subklone und für pFosJS3 sechs Subklone mit lipolytischer Aktivität ermittelt werden. Die Inserts dieser Subklone wurden ansequenziert und über weiteres „Primer-walking“ und Bearbeitung der Subklon-Sequenzen mit dem Programm „Gap4“ konnten die lipolytischen ORFs estJS2 und estJS3 identifiziert werden. Abb. 37 zeigt die Nukleotid- und Aminosäuresequenz von estJS2. Für estJS2 konnte ein offener Leserahmen von 1503 bp mit einem GC-Gehalt von 86,6 festgelegt werden. Dies entspricht 500 Aminosäuren und einer Molekularmasse des abgeleiteten Proteins von $54,29 \mathrm{kDa}$. Ein Datenvergleich mittels blastp in der NCBI Datenbank (www.ncbi.nlm.nih.gov) ergab eine Identität von $36 \%$ im Bereich der Aminosäuren 31 bis 490 zu einer extrazellulären Carboxylesterase Typ B aus Chlorobium ferrooxidans DSM13031. Bei EstJS2 findet man das für Esterasen bzw. Lipasen typische Pentapeptid Gly-X-Ser-X-Gly, welches das aktive Serin beinhaltet. Zusätzlich findet man den für Esterasen/Lipasen der Familie IV typischen konservierten Bereich His-Gly-Gly-Gly. 
1 ATGGGCTCAC CGACCCTTGA ACTGCCCACA CGGTGGTGGT ACAATCAGCC AAAACCGCAA $\begin{array}{lllllllllllllllllllll}M & G & S & P & \text { T } & \text { L } & E & \text { L } & P & \text { T } & \text { R } & \text { W } & \text { W } & \text { Y } & \text { N } & Q & P & K & P & Q\end{array}$

61 AAGGAGAATG AAATGGCACT GAGTGACCCC ATAATGACCG ATTCCGGACC CGTGTCCGGC $\begin{array}{llllllllllllllllllll}K & E & N & E & M & A & L & S & D & P & \text { I } & M & T & D & S & G & P & \text { V } & S & G\end{array}$

121 GTGGTGCTGG GGGAGCCGGG GAAGGAGGTT CATGTCTACC GCTCCATCCC CTACGCCGCC $\begin{array}{lllllllllllllllllllll}V & V & L & G & E & P & G & K & E & V & H & V & Y & R & S & I & P & Y & A & A\end{array}$

181 CCGCCCCTGG GCGAGCTGCG CTGGAAGCCG CCGCAGCCGC TTTCGCCATG GAGGCGCATC $\begin{array}{llllllllllllllllllllll}\mathrm{P} & \mathrm{P} & \mathrm{L} & \mathrm{G} & \mathrm{E} & \mathrm{L} & \mathrm{R} & \mathrm{W} & \mathrm{K} & \mathrm{P} & \mathrm{P} & \mathrm{Q} & \mathrm{P} & \mathrm{L} & \mathrm{S} & \mathrm{P} & \mathrm{W} & \mathrm{R} & \mathrm{R} & \mathrm{I}\end{array}$

241 CGCGATTGCA CCCCACCCTC CAAGCCCTGC CCGCAGGTGG AGAGGCCGTT CTGCCCCGGT $\begin{array}{lllllllllllllllllllll}R & D & C & T & P & P & S & K & P & C & P & Q & V & E & R & P & F & C & P & G\end{array}$

301 CCCTACAGCG AGGACTGCCT CTATCTGGTG GTGATGACGC CGGCAAAGAA AGCGAACGAG $\begin{array}{lllllllllllllllllllllll}P & Y & S & E & D & C & L & Y & L & V & V & M & T & P & A & K & K & A & N & E\end{array}$

361 CGGCTGCCGG TGATGGTCTG GTTCCACGGC GGCGGCTATA GCATCGGCAG CGGCGGCATG $\begin{array}{llllllllllllllllllllll}R & \text { L } & P & V & M & V & W & F & H & G & G & G & Y & S & I & G & S & G & G & M\end{array}$

421 GCGCCCTGGG GCACCTCGCT GGCGCTGGCA CAGCAGGGCG TGGTGCTGGT CAGCGTCACC $\begin{array}{lllllllllllllllllllll}A & P & W & G & \text { T } & S & \text { L } & \text { A } & \text { L } & \text { A } & Q & Q & \text { Q } & G & \text { V } & \text { V } & \text { L } & \text { V } & \text { S } & \text { V } & \text { T }\end{array}$

481 CACCGCCTTG GTCCCCTGGG CTGCCTGGCA CTGCCGGCGC TCTCTAAGGA GTCGCCCGAA $\begin{array}{llllllllllllllllllll}H & R & L & G & P & L & G & C & L & A & \text { L } & P & A & L & S & K & E & S & P & E\end{array}$

541 GGCGTCTCCG GGAACTACCT GTTCCTCGAT TGCATCGCTG CCCTCAAGTG GGTGCAGCGC $\begin{array}{lllllllllllllllllllll}G & V & S & G & N & Y & \text { L } & F & \text { L } & \text { D } & \text { C } & \text { I } & A & A & \text { L } & K & \text { W } & \text { V } & Q & R\end{array}$

601 AACATCGCCA ACTTCGGCGG CAACCCCGAC TGCGTCACCA TCTTCGGCGA GTCCGGCGGC $\begin{array}{llllllllllllllllllll}\mathrm{N} & \mathrm{I} & \mathrm{A} & \mathrm{N} & \mathrm{F} & \mathrm{G} & \mathrm{G} & \mathrm{N} & \mathrm{P} & \mathrm{D} & \mathrm{C} & \mathrm{V} & \mathrm{T} & \mathrm{I} & \mathrm{F} & \mathrm{G} & \mathrm{E} & \mathrm{S} & \mathrm{G} & \mathrm{G}\end{array}$

661 GCCGGCAAGT GCGATGCCCT GATGGCTTCC CCCATGGCTA AGGGCTTGTT CCACCGCGTC $\begin{array}{llllllllllllllllllllll}\text { A } & G & K & \text { C } & \text { D } & \text { A } & \text { L } & \text { M } & \text { A } & \text { S } & \text { P } & \text { M } & \text { A } & \text { K } & \text { G } & \text { L } & \text { F } & \text { H } & \text { R } & \text { V }\end{array}$

721 ATCCTGGAGA GCGGCGCCAA CGGCGGCACA GGCGAGCAGG CACGCCTGGT GGTCACCCTC $\begin{array}{llllllllllllllllllllllll} & I & L & E & S & G & A & N & G & G & T & G & E & Q & A & R & L & V & V & T & L\end{array}$

781 AAGGACGCCG AGGCGCTGGG CGAAAGGCTG GTCACCCAGT ATTTGAATAT GGATCCCAGC $\begin{array}{llllllllllllllllllll}K & D & A & E & A & L & G & E & R & \text { L } & V & T & Q & Y & L & N & M & D & P & S\end{array}$

841 GACCTGGCGG CACTGCGCAA ACTCCCCGCC GAGCAACTGG TCAGGGCGGC AGCCAAGCTC $\begin{array}{llllllllllllllllllll}D & L & A & A & \text { L } & R & K & \text { L } & P & A & E & Q & L & V & R & A & A & A & K & L\end{array}$

901 ACCCAGGACA TGGCGGTGGA GCGCCCCGA GGCGTCACCG CCACCGATAC CTTGAAGGTG $\begin{array}{lllllllllllllllllllll}T & Q & D & M & A & V & E & R & P & E & G & V & T & A & T & D & T & L & K & V\end{array}$

961 GACGGCTACT TCATGCCCGA CTTCCCCGAC AACATCTTCC GCGCCGGCAG GCAGAACAAC $\begin{array}{lllllllllllllllllllllll}D & G & Y & F & M & P & D & F & P & D & N & I & F & R & A & G & R & Q & N & N\end{array}$

1021 GTCCCGCTGA TAACCTGCGC CAACCTCGGC GAGCTCATCG CCGAGAAGAC GCTCCTCAAG $\begin{array}{lllllllllllllllllllll}V & P & \text { L } & \text { I } & \text { T } & \text { C } & A & \text { A } & \text { L } & G & \text { E } & \text { L } & \text { I } & \text { A } & \text { E } & \text { K } & \text { T } & \text { L } & \text { L } & \text { K }\end{array}$

1081 ATGCCCGGCA TCATCAAGGC ATATGTCACC AGGCTGGAGA GCTGCCACAG GCTGGGCACC $\begin{array}{lllllllllllllllllllll}M & P & G & I & I & K & A & Y & V & T & R & L & E & S & C & H & R & L & G & T\end{array}$

1141 AAGGGCTTCG GCTGCATCTT CAGCCACGTG CCCACAAAGT GGCGGGCTGA GGGGGTGATG $\begin{array}{llllllllllllllllllllll}K & G & F & G & C & I & F & S & H & V & P & T & K & W & R & A & E & G & V & M\end{array}$

1201 GCATACCACG GCATCGAGCT GATGTACCTG TTCGGCGTCT ATAAGGTCAT CGGCAACCCG $\begin{array}{llllllllllllllllllllll}A & Y & H & G & \text { I } & E & \text { L } & \text { M } & \text { Y } & \text { L } & \text { F } & G & \text { V } & \text { Y } & \text { K } & \text { V } & \text { I } & G & \text { N } & \text { P }\end{array}$

1261 GCGCACTTCA TCGGCTTCGC CCAGCCCTCG GGCGCCTCCT CGCCCGATGC CGGCATCACC $\begin{array}{llllllllllllllllllllll}A & H & F & I & G & F & A & Q & P & S & G & A & S & S & P & D & A & G & I & T\end{array}$

1321 GATGAGGACA GGCTGGTCTC CGAGGCGATG ATGGCGATGT GGGTGCAGTT TGCCAGGAGC $\begin{array}{lllllllllllllllllllll}D & E & D & R & \text { L } & V & S & E & A & M & M & A & M & W & V & Q & F & A & R & S\end{array}$

1381 GGCGACCCCA ATGTCAAGGG GTTAATCAAA TGGCCCACCT GGGAGCCGGC AAGCGACCAG $\begin{array}{llllllllllllllllllllllllll}G & D & P & N & V & K & G & \text { L } & I & K & W & P & T & W & E & P & A & S & D & Q\end{array}$

1441 TACCTCGATA TCGCCTGGCC CCTGCAGGTG AGGTCGGGCT ATTCCAGGGT CGCCGGTGGC $\begin{array}{lllllllllllllllllllll} & \text { I } & \text { L } & \text { D } & \text { I } & \text { A } & \text { W } & \text { P } & \text { L } & \text { Q } & \text { V } & \text { R } & \text { S } & G & \text { Y } & \text { S } & \text { R } & \text { V } & \text { A } & G & G\end{array}$ 1501 TAA

Abb. 37: Nukleotid- und Aminosäuresequenz von estJS2. Die für Esterasen/Lipasen typische Konsensussequenz G-X-S-X-G ist gelb, die für die Esterasen und Lipasen der Familie IV H-G-G-G-X ist grün dargestellt. Die putativen Aminosäuren der katalytischen Triade sind rot unterlegt (ARPIGNY und JÄGER 1999). 
Das estJS3-Gen umfasst 1548 bp mit einem GC-Gehalt von 63,2 \% und kodiert für 515 Aminosäuren. Es wurde eine Molekularmasse des abgeleiteten Proteins von 56,17 kDa und ein isoelektrischen Punkt von 7,14 berechnet. Blastp mit der Datenbank der NCBI ergab eine Identität von 42 \% im Bereich der Aminosäuren 7 bis $504 \mathrm{zu}$ einer extrazellulären Carboxylesterase Typ B aus Bacillus coagulans 36D1. Die für Esterasen/Lipasen typische Konsensus-Sequenz GlyX-Ser-X-Gly, die konservierten Bereiche der Esterasen/Lipasen der Familie IV und die putativen Aminosäuren der katalytischen Triade wurden in Abb. 38 gekennzeichnet. Die Suche nach einem Signalpeptid mit dem Programm „SignalP 3.0“ (http://www.cbs.dtu.dk/services/SignalP/) blieb erfolglos Bei weiteren Sequenzierungen stromaufwärts von estJS3 konnten stattdessen Sequenzbereiche identifiziert werden, welche mit denen von ABC-Transportern übereinstimmen (Daten nicht gezeigt). Abb. 39 zeigt die Orientierung von diesem möglichen ABC-Transporter zu estJS3. 
AtgGtTgAAg CTACACCAgC AAtCGTCGAg ACtACtgCAg GgAAAATCGA GgGtgTtTtC $\begin{array}{lllllllllllllllllllll}M & V & E & A & T & P & A & I & V & E & T & T & A & G & K & I & E & G & V & F\end{array}$

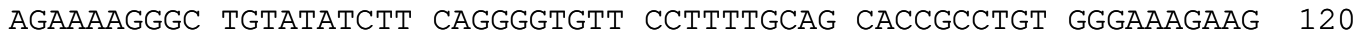
$\begin{array}{lllllllllllllllllllllll}R & K & G & L & Y & I & F & R & G & V & P & F & A & A & P & P & V & G & K & K\end{array}$

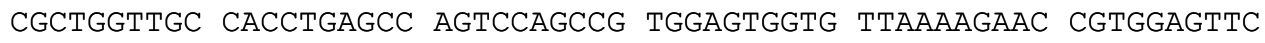
$\begin{array}{llllllllllllllllllllll}R & W & \mathrm{~L} & \mathrm{P} & \mathrm{P} & \mathrm{E} & \mathrm{P} & \mathrm{V} & \mathrm{Q} & \mathrm{P} & \mathrm{W} & \mathrm{S} & \mathrm{G} & \mathrm{V} & \mathrm{K} & \mathrm{R} & \mathrm{T} & \mathrm{V} & \mathrm{E} & \mathrm{F}\end{array}$ GGGGCCACCT GCCCTCAGGT GCCCATGGAA GTGGCGTTAC TTAATCCACC CGAGCAACAG $\begin{array}{llllllllllllllllllllllll}G & A & T & C & P & Q & V & P & M & E & V & A & L & L & N & P & P & E & Q & Q\end{array}$ CCACAGAGCG AGGACTGCCT CTATCTCAAC ATCTGGACGC CAgGgCTTGA CAATGCCAAA 300

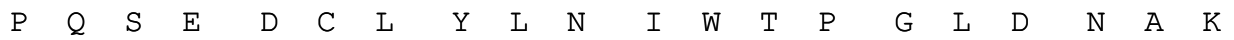

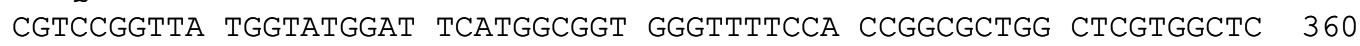
$\begin{array}{llllllllllllllllllll}R & P & V & M & V & W & I & H & G & G & G & F & S & T & G & A & G & S & W & L\end{array}$ ATCTATAACG GACGTCGGCT GGCAACCCGT GGCGATGTAG TGGTGGTCAC CATAAACTAC $\begin{array}{llllllllllllllllllll}I & Y & N & G & R & R & L & A & T & R & G & D & V & V & V & V & T & I & N & Y\end{array}$ CGGCTCAACG TTTTCGGTTT TATCAATCTG AAGGACGTCA CCAAAGGCAA AATCCCGGCC $\begin{array}{lllllllllllllllllllll}R & L & N & V & F & G & F & I & N & L & K & D & V & T & K & G & K & I & P & A\end{array}$ ACCGGTAACG AgGgGCTGCT TGACCAgGtg TTtgCCCTGC AgTGGgtgCG GGACAAtATC 540 $\begin{array}{lllllllllllllllllllll}T & G & N & E & G & L & L & D & Q & V & F & A & L & Q & W & V & R & D & N & I\end{array}$ tCAAACTTCG GCGgTGACCC TAACAATGTG ACCATAtTtg GCGAATCTGC CGgGgGCATG 600 $\begin{array}{llllllllllllllllllll}S & N & F & G & G & D & P & N & N & V & T & I & F & G & E & S & A & G & G & M\end{array}$ AgCGTGGgGA CGCtACtgGC CATGCCGAGg GCGAAAgGgC TGTTtCACAA GgCtATtTtg $\begin{array}{lllllllllllllllllllll}S & V & G & T & L & L & A & M & P & R & A & K & G & L & F & H & K & A & I & L\end{array}$ CAGAGTGGTG CCGGACACCA TGTGAGCTCG ACTGAGCGGG CTGTGAAAGT GGCGAGTATG $\begin{array}{lllllllllllllllllllll}Q & S & G & A & G & H & H & V & S & S & T & E & R & A & V & K & V & A & S & M\end{array}$ TTCCTTGACA TCTTGgGgGt tAAGCCCGAT GAAGCAGAGA GGCTGTGGTC ACTGACTGCG 780 $\begin{array}{lllllllllllllllllllll}F & L & D & I & L & G & V & K & P & D & E & A & E & R & L & W & S & L & T & A\end{array}$ GAgCAgCtTT TGgAgGCTTA CAAGgAgCtT GCCAACAgGg CACGTGACCC TAgGtCAgGg 840 $\begin{array}{lllllllllllllllllllll}E & Q & L & L & E & A & Y & K & E & L & A & N & R & A & R & D & P & R & S & G\end{array}$ CTGGCTGACC TGCCGTTGA ACCTGTGGTG GATGgCTCtg TGCTTCCTGA CATGCCCCCG 900 $\begin{array}{llllllllllllllllllll}\mathrm{L} & \mathrm{A} & \mathrm{D} & \mathrm{L} & \mathrm{P} & \mathrm{L} & \mathrm{R} & \mathrm{P} & \mathrm{V} & \mathrm{V} & \mathrm{D} & \mathrm{G} & \mathrm{S} & \mathrm{V} & \mathrm{L} & \mathrm{P} & \mathrm{D} & \mathrm{M} & \mathrm{P} & \mathrm{P}\end{array}$ CATGCCGTTG CCAGCGGTTC CGCCGACGAT GTTGCTATCA TGGTGGGCAC CAACCTTGAT 960 $\begin{array}{llllllllllllllllllllll}\mathrm{H} & \mathrm{A} & \mathrm{V} & \mathrm{A} & \mathrm{S} & \mathrm{G} & \mathrm{S} & \mathrm{A} & \mathrm{D} & \mathrm{D} & \mathrm{V} & \mathrm{A} & \mathrm{I} & \mathrm{M} & \mathrm{V} & \mathrm{G} & \mathrm{T} & \mathrm{N} & \mathrm{L} & \mathrm{D}\end{array}$

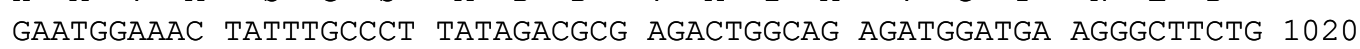

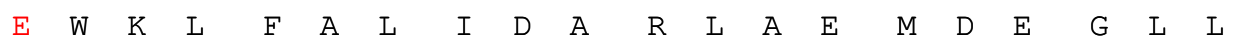
TTACGTCGCT GTCAGCGGCT GATTCCGgGt GTGGATGCGg CGGCACTTGT CGAGACTtAC 1080 $\begin{array}{llllllllllllllllllll}\mathrm{L} & \mathrm{R} & \mathrm{R} & \mathrm{C} & \mathrm{Q} & \mathrm{R} & \mathrm{L} & \mathrm{I} & \mathrm{P} & \mathrm{G} & \mathrm{V} & \mathrm{D} & \mathrm{A} & \mathrm{A} & \mathrm{A} & \mathrm{L} & \mathrm{V} & \mathrm{E} & \mathrm{T} & \mathrm{Y}\end{array}$ CGCAAGGCGC GTGCTAAGCG CGGCTGGTCA GTCGTGCCGG CGGATATTTT CATAGCCATT 1140 $\begin{array}{lllllllllllllllllllll}R & K & A & R & A & K & R & G & W & S & V & V & P & A & D & I & F & I & A & I\end{array}$ CAgtCAgACA GAATTTTCCG TATCCCGgCG ATCCGgCTTA CTGAgGCCCA CCGCAGTCGC 1200 $\begin{array}{llllllllllllllllllll}Q & S & D & R & I & F & R & I & P & A & I & R & L & T & E & A & H & R & S & R\end{array}$ CGCAAgACAA GCtAtAtgtA tCtAtTCGAC TGgGtTtCAC CGCtgAgGgA AgGtgCCCtg 1260 $\begin{array}{lllllllllllllllllllll}R & K & T & S & Y & M & Y & L & F & D & W & V & S & P & L & R & E & G & A & L\end{array}$ GGTTCGTGCC ATGCACTGGA GCTGGGCTTC GTCTTCGGTA CCCTGGACGA CAATTTTACC 1320 $\begin{array}{llllllllllllllllllll}G & S & C & H & A & L & E & L & G & F & V & F & G & T & L & D & D & N & F & T\end{array}$ GGCACTAGTg AgGAgGCTAG AgCCCTAGCG GAgAAAATGC AgGATGCCTG GACGGCTTTT 1380

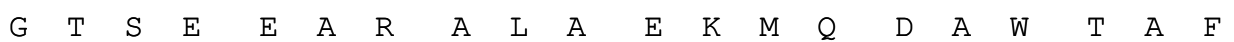
GCCCGCAAGg GTGACCCCAg TTGCCCCAGC CTTGgCAACT GGAAGACCTA CAGCGAGCGC 1440 $\begin{array}{llllllllllllllllllll}A & R & K & G & D & P & S & C & P & S & L & G & N & W & K & T & Y & S & E & R\end{array}$ AGgGAgACCA TGATCCTGGg CAgGAATtgT CGCCTCATGg AAGCCCCTTA CGACGAgGAA 1500 $\begin{array}{llllllllllllllllllll}R & E & T & M & I & L & G & R & N & C & R & L & M & E & A & P & Y & D & E & E\end{array}$ TGCCAGGCAT GGgAgAaggt CCCCGAtACt GTGCTCGCTg CGTTtTAg 1548

$\begin{array}{llllllllllllllllllllll}C & Q & A & W & E & K & V & P & D & T & V & \text { L } & A & A & F & *\end{array}$

Abb. 38: Nukleotid- und Aminosäuresequenz von estJS3. Die für Esterasen/Lipasen typische Konsensussequenz G-X-S-X-G ist gelb, die für die Esterasen/Lipasen der Familie IV H-G-G-G-X ist grün dargestellt. Die putativen Aminosäuren der katalytischen Triade sind rot unterlegt (ARPIGNY und JÄGER 1999). 


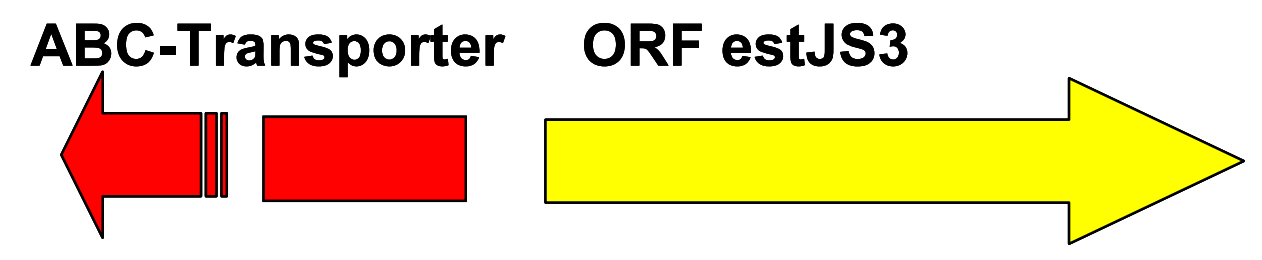

$1 \mathrm{kbp}$

Abb. 39: estJS3 mit Teilsequenz eines mögliche ABC-Transporters. Der Orf EstJS3 ist als gleber Pfeil dargestellt. Der rote Pfeil zeigt die Orientierung eines Orfs, welcher vermutlich für Teile eines ABC Transpoter kodiert.

Im Rahmen des aktivitätsbasierenden Screenings nach Genen welche lipolytische Aktivität vermitteln konnten vier Klone identifiziert werden, welche der Fosmidgenbank entstammen (pFosJS1 bis pFosJS4). Auf drei Fosmiden konnte ein lipolytischer ORF identifiziert werden. Ihre Eigenschaften sind in Tab. 10 zusammengefasst. 
Tab. 10 Aufstellung der identifizierten ORFs estJS1-3 mit ihren nächsten verwandten Proteinen.

Die Identifizierung der verwandten Proteine, sowie die Sequenzähnlichkeitswerte erfolgten mit

Hilfe der BLAST Programme der NCBI.

\begin{tabular}{|c|c|c|c|c|c|c|}
\hline ORF & $\begin{array}{l}\text { Größe des } \\
\text { ORFs }\end{array}$ & $\begin{array}{c}\text { Anzahl der AS } \\
\text { des } \\
\text { abgeleiteten } \\
\text { Genproduktes }\end{array}$ & $\begin{array}{l}\text { Nächst verwandtes } \\
\text { Protein und } \\
\text { Accession Nummer }\end{array}$ & Organismus & E-value & $\begin{array}{c}\text { Identität } \\
\text { (Aminosäurebereich) }\end{array}$ \\
\hline estJS1 & $814 \mathrm{bp}$ & $271 \mathrm{AS}$ & $\begin{array}{c}\text { BioH } \\
\text { BAB39459.1 }\end{array}$ & $\begin{array}{l}\text { Kurthia sp. } \\
\text { 538-KA26 }\end{array}$ & $3 e^{-64}$ & $\begin{array}{c}45 \% \\
1 \text { bis } 264\end{array}$ \\
\hline estJS2 & 1503 bp & 500 AS & $\begin{array}{c}\text { Carboxylesterase } \\
\text { Typ B } \\
\text { ZP_1385717.1 }\end{array}$ & $\begin{array}{l}\text { Chlorobium } \\
\text { ferrooxidans } \\
\text { DSM13031 }\end{array}$ & $4 e^{-73}$ & $\begin{array}{c}36 \% \\
31 \text { bis } 490\end{array}$ \\
\hline estJS3 & 1548 bp & 515 AS & $\begin{array}{c}\text { Carboxylesterase } \\
\text { Typ B } \\
\text { ZP_01696734.1 }\end{array}$ & $\begin{array}{l}\text { Bacillus } \\
\text { coagulans } \\
36 D 1\end{array}$ & $2 e^{-108}$ & $\begin{array}{c}42 \% \\
7 \text { bis } 504\end{array}$ \\
\hline
\end{tabular}




\subsection{Screening der Standort-Genbanken auf proteolytische Aktivität}

Das Screening der Metagenombanken nach Genen mit proteolytischer Aktivität wurde mit Hilfe eines Plattentestverfahrens durchgeführt. Die verwendeten LBSkim-Milk-Agarplatten (s. 2.3.4) weisen eine starke Trübung auf. Die hydrolytische Spaltung von Peptidbindungen führt zur Bildung eines klaren Hofes um die Kolonie mit proteolytischer Aktivität (s. Abb. 40). Als Wirtsstämme dienten die E. coli-Stämme TOP10 bzw. DH5a für Plasmid-Genbanken und E. coli EPI300-T1 ${ }^{R}$ für Fosmide.

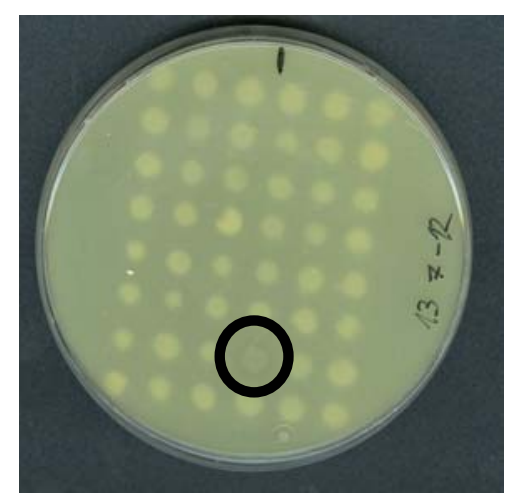

Abb. 40: Plattentestverfahren zur Erkennung proteolytischer Aktivität (s. 2.16.6). Der Kreis markiert einen rekombinanten E. coli Stamm der Fosmidgenbank FosA, welcher proteolytische Aktivität zeigt.

Nach Screening aller in dieser Arbeit konstruierten Metagenombanken konnte schließlich drei positive Klone identifiziert werden, welche alle der Fosmidgenbank des Standortes Avachinsky entstammen. Nach Präparation und Retransformation wiesen alle Klone einen stabilen Phänotyp auf. Sie wurden fortlaufend als pFosJS5 bis pFosJS7 bezeichnet. Nach Restriktionsverdau konnte für das Fosmid pFosJS5 eine Insertgröße von ca. 40 $\mathrm{kbp}$, für pFosJS6 von ca. $20 \mathrm{kbp}$ und für pFosJS7 von ca. $35 \mathrm{kbp}$ ermittelt werden. 


\subsubsection{Identifizierung der proteolytischen ORFs aus pFosJS5 und pFosJS6 durch Subklonierung und Sequenzierung}

Zur Identifizierung der proteolytischen ORFs aus pFosJS5 und pFosJS6 war es nötig sogenannte „shotgun“-Genbanken zu konstruieren, da eine direkte Sequenzierung über „Primer-walking“ aufgrund der zu großen Inserts nicht möglich war. Dazu wurden zwei verschiedene Ansätze verfolgt. pFosJS5 wurde zunächst mit dem Restriktionsenzym BamHI geschnitten. Der gesamte Ansatz wurde dephosporyliert um eine Religation zu verhindern und schließlich in den Vektor pBlueskript IISK+ kloniert. Nach Transformation in E. coli TOP10 und Screening der erhaltenen Subklone auf proteolytische Aktivität konnte zunächst ein proteolytisch aktiver Subklon identifiziert werden. Dieser Klon wies allerdings nach Restriktionanalyse seines Plasmides eine Insertgröße von ca. $15 \mathrm{kbp}$ auf. Durch weitere Subklonierung des Subklones mit dem Restriktionsenzym EcoRI konnte ein weiterer Subklon mit einem Insert von 4,5 kbp nach Screening auf LB-Skim-Milk-Agarplatten identifiziert werden. Mittels „Primer-walking“ konnte ein proteolytischer ORF von 3030 bp mit einem GCGehalt von 51,9 \% identifiziert werden, der für 1009 Aminosäuren kodiert. Es wurde eine Molekularmasse von 107,32 kDa für das abgeleitete Protein berechnet. $\mathrm{Er}$ wurde fortlaufend als pepJS1 bezeichnet. Nach Datenbankvergleich mit blastp der NCBI (s. oben) ergab sich eine Identität von $86 \%$ über die gesamte Aminosäuresequenz zu einer S8 Peptidase aus Chloroflexus aggregans DSM 9485. Es wurde mit Hilfe des Programms „SignalP 3.0“ (http://www.cbs.dtu.dk/services/SignalP/) ein Signapeptid von Aminosäure 1 bis 30 festgestellt. In Abb. 41 ist die Aminosäuresequenz von pepJS1 gezeigt. 


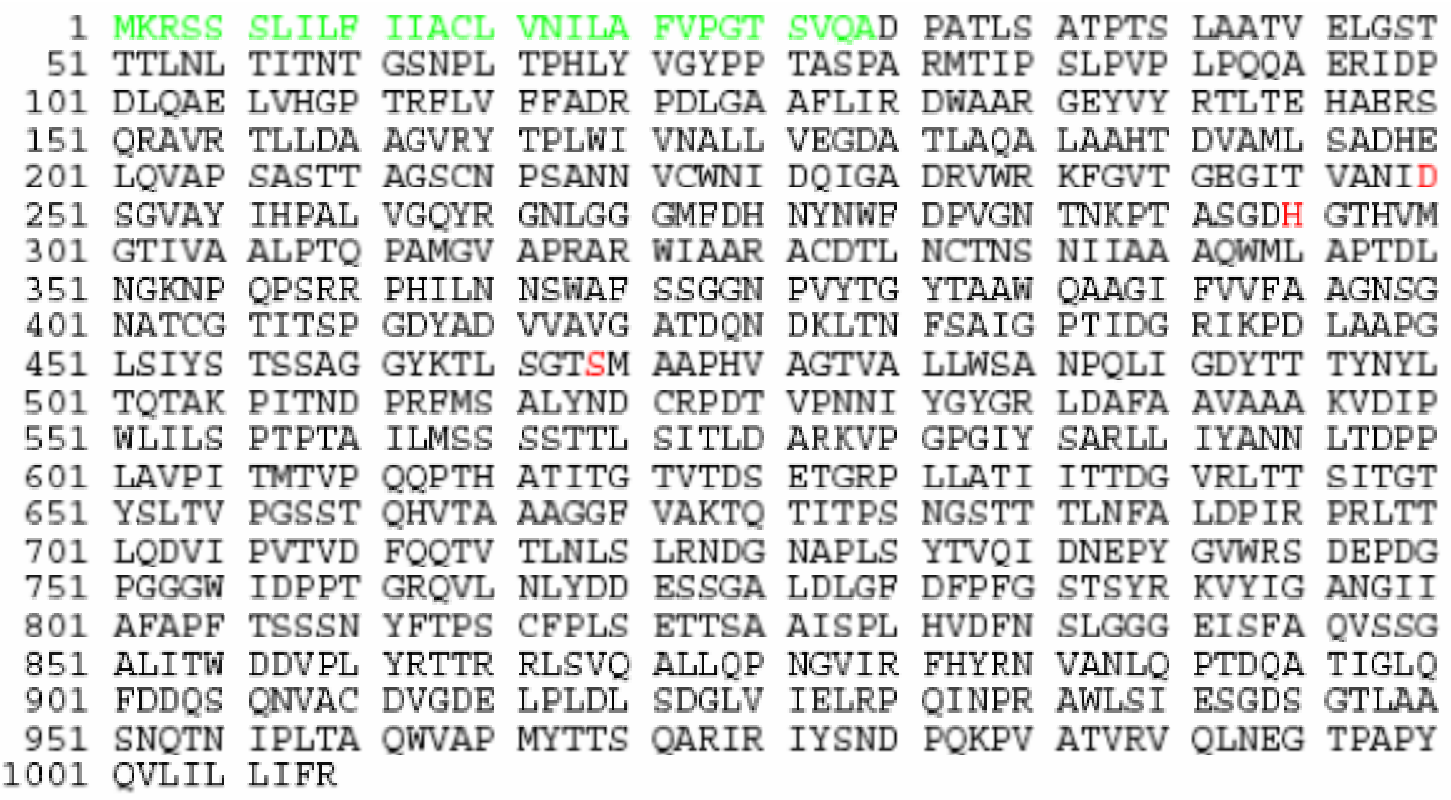

Abb. 41: Aminosäuresequenz von PepJS1. Das Signalpeptid ist grün unterlegt, Die Aminosäuren der katalytischen Triade rot

Ein Vergleich mit der Datenbank MEROPS (http://merpos.sanger.ac.uk/) ergab eine Identität von 80,79 \% auf Aminosäureebene zu der Peptidase S8A aus Chloroflexus aggregans. Diese S8A-Peptidasen gehören zu den Subtilisinähnlichen Peptidasen (RAWLINGS 1993).

Die Identifizierung des proteolytischen ORFs aus pFosJS6 erfolgte auf andere Weise. Dazu wurde pFosJS6 partiell mit dem Restriktionsenzym Bsp143I verdaut (s. 2.11.1). Anschließend erfolgte eine Größenfraktionierung über Agarosegelelektrophorese. Fragmente zwischen 3 und $5 \mathrm{kbp}$ wurden zur Klonierung eingesetzt. Die Klonierung erfolgte durch TA-Klonierung (s. 2.11.2/3) in den Vektor pCR-XL-TOPO. Die anschließende Transformation in E. coli TOP10 brachte etwa 600 Klone. Diese wurden in Mikrotiterplatten konserviert (s. 2.4.4) und erneut auf proteolytische Aktivität untersucht. Es konnten zwei positive Subklone mit einer Plasmidinsertgröße von 2,8 und $4 \mathrm{kbp}$ identifiziert werden. Das Plasmid mit dem Insert von 2,8 kbp wurde durch das „Göttinger Genomics Laboratory" komplett sequenziert. Es konnte ein ORF von 1179 bp und einem GC Gehalt von $85 \%$ identifiziert werden. Dieser ORF pepJS2 kodiert damit für 392 Aminosäuren. Das Protein hat eine Molekularmasse von 41,26 kDa. Ein Datenbankvergleich durch blastp der NCBI Datenbank ergab 61 \% Identität im Bereich der Aminosäuren 78 bis 389 zu der S1 Peptidase aus 
Chloroflexus aurantiacus J-10. S1-Proteasen gehören zu den Trypsinen. Es konnte ein Signalpeptid von Aminosäure 1 bis 24 identifiziert werden. In Abb. 42 ist die Aminosäuresequenz von pepJS2 dargestellt.

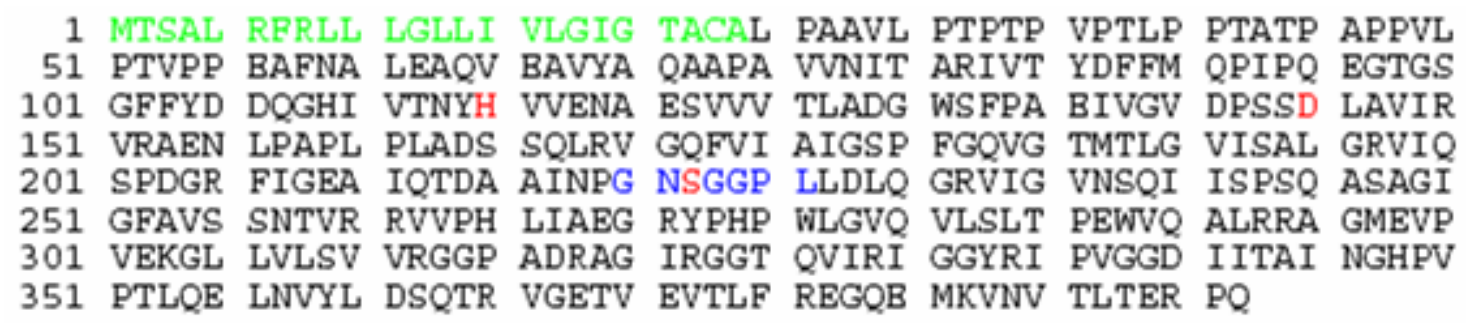

Abb. 42: Aminosäuresequenz von PepJS2. Grün ist das Signalpeptid, rot die Aminosäuren der katalytischen Triade, blau die Konsensus-Sequenz G-X-S-X-G der Trypsin Peptidasen dargetellt.

Mit Hilfe der MEROPS Datenbank (http://merpos.sanger.ac.uk/) erfolgte eine weitere Eingruppierung. PepJS2 zeigt eine Identität von 51,85 \% auf Aminosäureebene zu einer S1B Peptidase aus Roseiflexus castenholzii. Zu den S1B Peptidasen zählen auch die HtrA-Proteasen. Es handelt sich bei dieser Gruppe um Hitzeschock-induzierte Serin-Proteasen. (PALLEN et al. 1997; CLAUSEN et al. 2002), welche im Periplasma aktiv sind. Sie bestehen aus einer proteolytischen und mindestens einer C-terminalen PDZ-Domäne. Eine PDZ Domäne ist ein Teil eines Proteins, welcher mit anderen Proteinen interagieren kann. PDZ-Domänen spielen bei der Substratbindung eine entscheidene Rolle. In Abb. 43 ist ein Domänenvergeich der HtrA-Protease aus E. coli und PepJS2 dargestellt. Bis auf eine weitere PDZ Domäne bei Escherichia coli liegt eine identische Domänenstruktur vor.
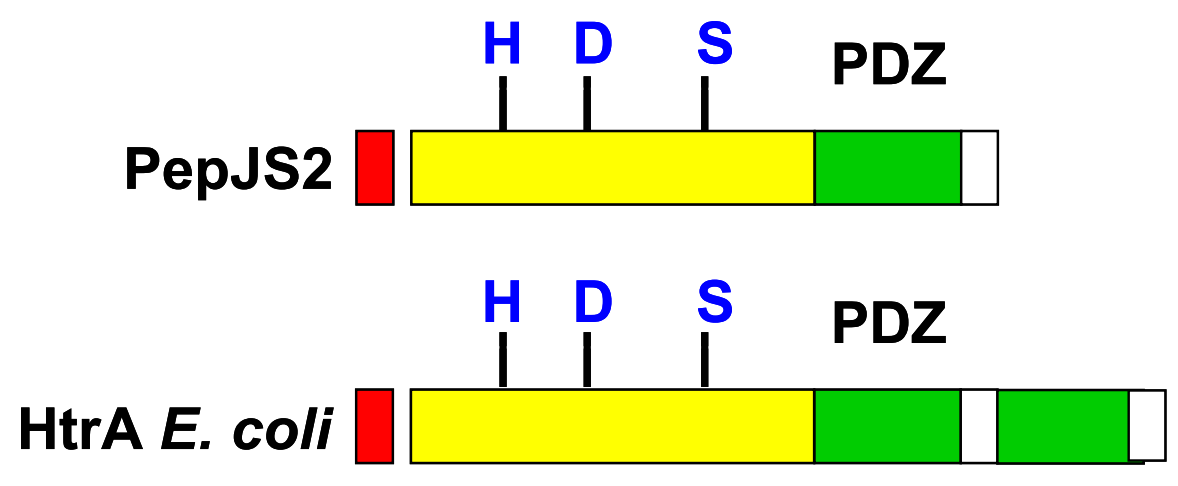

Abb. 43: Vergleich der Domänenstrukturen von PepJS2 und HtrA aus Escherichia coli. Rot ist das Signalpeptid, gelb die katalytische Domäne) und grün die PDZ Domänen dargestellt. Blau sind die Aminosäuren der katalytischen Triade 


\subsubsection{Heterologe Expression von PepJS1 und PepJS2}

Zur Charakterisierung wurden zunächst pepJS1 und pepJS2 jeweils in den Expressionsvektor pET101/D-TOPO kloniert werden. Die Klonierung wurde so gewählt, dass die Genprodukte nach erfolgter heterologer Produktion in dem Wirt E. coli mit einem C-terminalen V5-Epitop und einem $\mathrm{His}_{6}{ }^{-T a g}$ versehen waren. Die Expression des Proteins konnte dann durch spezifische His $6^{-}$bzw. V5-Antikörper in Western-Blot Analysen nachgewiesen werden. Die Reinigung sollte schließlich über Nickel-TED-Affinitätschromatographie erfolgen. Mittels PCR und den Einsatz der Pfu-Polymerase wurden die entsprechenden Gene amplifiziert und nach dem Schema der pET Directional TOPOß-Klonierung (s. 2.4.3) kloniert. Die entsprechenden Konstrukte wurden zunächst in $E$. coli TOP10 transformiert und anschließend die richtige Orientierung der Fragmente im Vektor durch Restriktionsanalyse überprüft. Zusätzlich wurden die Klonierungen durch Sequenzierung der Inserts bestätigt. Zur Expression wurden die Vektoren pET101::pepJS1 und pET101::pepJS2 in den Expressionsstamm BL21 transformiert. Eine $1 \mathrm{~L}$ Hauptkultur wurde mit einer Vorkultur angeimpft und bis zu einer $\mathrm{OD}_{600} 0,6-0,8$ bei $37^{\circ} \mathrm{C}$ unter Schütteln inkubiert (s. 2.4.1). Dann erfolgte die Induktion mittels IPTG $(0,1 \mathrm{mM})$ für 5-6 h bei $37^{\circ} \mathrm{C}$. Da es sich bei Subtilisin-ähnliche Proteasen überwiegend um extrazelluläre Proteasen handelt (GUPTA et al. 2002) wurde bei PepJS1 der Kulturüberstand zur weiteren Reinigung verwendet. Mittels Vivaflow 200 (s. 2.17.3) wurde dieser konzentriert und umgepuffert. Bei HtrA-Proteasen hingegen handelt es sich um periplasmatische Enzyme. Deshalb erfolgte für PepJS2 die Isolierung des Periplasmas (s. 2.17.2.3). Die so erhaltenen Rohextrakte aus dem Kulturüberstand bzw. dem Periplasma wurden dann über Nickel-TED-Affinitätschromatographie (s. 2.17.5.1) durch den vorhandenen Cterminalen $\mathrm{His}_{6}$-Tag gereinigt. Die Aufreinigungsschritte wurden mittels SDSPAGE (s. 2.17.6) analysiert und schließlich eine Aktivitätsfärbung nach SDSPAGE durchgeführt (s. 2.17.8). Die einzelnen Schritte der Aufreinigung von PepJS2 sind in Abb. 44 dargestellt. 


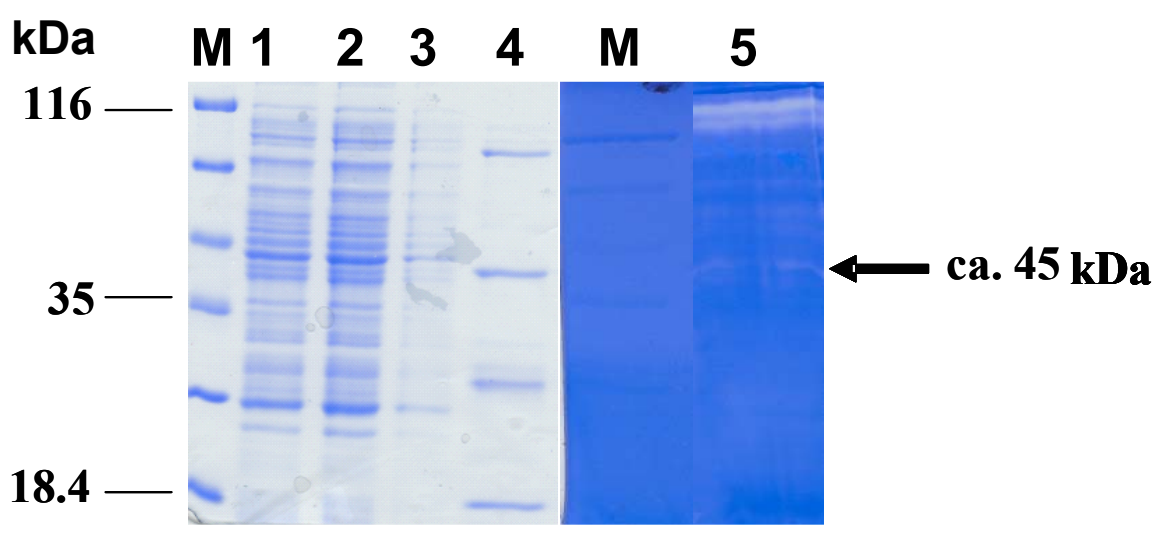

\begin{abstract}
Abb. 44: Aufreinigungsschritte von PepJS2 mit anschließender Aktivitätsfärbung. M: Molekularmassenmarker in $\mathrm{kDa}, 1$ : Rohextrakt, 2: Säulendurchlauf, 3: Waschfraktion, 4: Elutionsfraktion, 5: Aktivitätsfärbung von PepJS2. Eluiert wurde mit $50 \mathrm{mM}$ Phosphatpuffer und einer Imidazolkonzentration von $250 \mathrm{mM}$.
\end{abstract}

Wie in Abb. 44 zu erkennen ist, ist keine spezifische Aufreinigung von PepJS2 gelungen. Allerdings zeigt sich eine deutliche Bande bei ca. $45 \mathrm{kDa}$, was der theoretischen Molekularmasse von von PepJS2 addiert mit dem C-terminalen His6-Tag und dem V5-Epitop entspricht. Diese Bande zeigt sich auch nach Aktivitätsfärbung durch eine Aufklarung. Dies deutete darauf hin, dass es sich bei dieser Bande um PepJS2 handelt. Zur Überprüfung wurde eine WesternBlot-Analyse durchgeführt (s. 2.17.8). Das Ergebnis zeigt Abb. 45. 


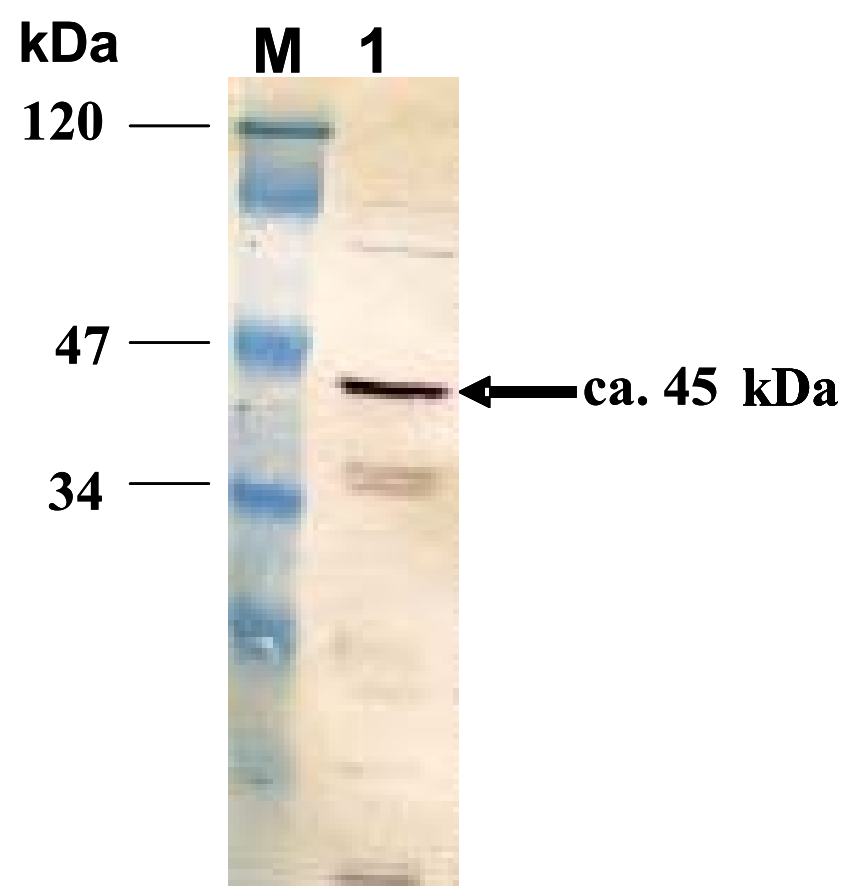

Abb. 45: Western-Blot-Analyse nach Aufreinigung von PepJS2 über Nickel-TEDAffinitätschromatographie $\mathrm{M}$ : Molekularmassenmarker in $\mathrm{kDa}, 1$ : Elutionsfraktion. Ein Rohextrakt von E. coli/BL21/pepJS2 wurde elektrophoretisch durch SDS-PAGE (s. 2.17.6) aufgetrennt, auf Nitocellulose-Membran geblottet und durch Immunodetektion mittels Anti-V5Antikörper nachgewiesen (s. 2.17.8). Der Pfeil markiert die Detektion von PepJS1.

Die heterologe Expression von PepJS2 konnte also durch Immunodetektion nachgewiesen werden (s. Abb. 45). Es zeigte sich eine deutliche Bande bei ca. $45 \mathrm{kDa}$, was PepJS2 nach heterolger Expression in E. coli BL21 entspricht. Mit den verschiedenen Fraktionen der Reinigung wurden nun Aktivitätstests durchgeführt (s. 2.17.4.2). Allerdings konnte in keiner der Fraktionen eine signifikante proteolytische Aktivität bestimmt werden.

Die Aufreingung von PepJS1 aus dem Kulturüberstand mittels Nickel-TEDAffinitätschromatographie (s. 2.17.5.1) brachte keinen Erfolg. Nach SDS-PAGE konnte in keiner der Elutionsfraktionen eine spezifische Bande im Bereich von ca. $110 \mathrm{kDa}$ nachgewiesen werden. Diese $110 \mathrm{kDa}$ entsprechen der Molekularmasse von PepJS1 (107,32 kDa) und den C-terminal gebundenem His6-Tag und V5 Epitop.

Im Rahmen des aktivitätsbasierenden Screenings nach Genen welche proteolytische Aktivität vermitteln konnten 3 Kolne identifiziert werden. Sie entstammen der Fosmidgenbank und wurden mit pFosJS5 bis pFosJS7 
bezeichnet. Auf pFosJS5 und pFosJS6 konnte ein proteolytischer ORF identifiziert und beschrieben werden. Ihre Eigenschaften sind in Tab. 11 zusammengefasst. 
Tab. 11: Aufstellung der identifizierten ORFs PepJS1 und PepJS2 mit ihren nächst verwandten Proteinen. Die Identifizierung der verwandten Proteine, sowie die Sequenzähnlichkeitswerte erfolgten mit. Hilfe der BLAST Programme der NCBI.

\begin{tabular}{|c|c|c|c|c|c|c|}
\hline ORF & $\begin{array}{c}\text { Größe des } \\
\text { ORFs }\end{array}$ & $\begin{array}{l}\text { Anzahl der AS } \\
\text { des abgeleiteten } \\
\text { Genproduktes }\end{array}$ & $\begin{array}{l}\text { Nächst verwandtes } \\
\text { Protein und } \\
\text { Accession Nummer }\end{array}$ & Organismus & E-value & $\begin{array}{c}\text { Identität } \\
\text { (Aminosäurebereich) }\end{array}$ \\
\hline pepJS1 & 3030 bp & 1009 AS & $\begin{array}{c}\text { Peptidase S8 } \\
\text { ZP_01514699.1 }\end{array}$ & $\begin{array}{l}\text { Chloroflexus } \\
\text { aggregans } \\
\text { DSM } 9485\end{array}$ & 0,0 & $\begin{array}{c}86 \% \\
1 \text { bis } 1009\end{array}$ \\
\hline pepJS2 & 1179 & 392 AS & $\begin{array}{c}\text { Peptidase S1 } \\
\text { ZP_00768469.1 }\end{array}$ & $\begin{array}{c}\text { Chloroflexus } \\
\text { aurantiacus J- } \\
10\end{array}$ & $2 e^{109}$ & $\begin{array}{c}61 \\
78 \text { bis } 389\end{array}$ \\
\hline
\end{tabular}




\subsection{Isolierung von Mikroorganismen unter anaeroben Bedingungen und Glycerin als einzige Kohlenstoff und Energiequelle}

Zur Charakterisierung des Metagemoms Kamtschatka Avachinsky wurde ein zweiter Ansatz verfolgt: Den der Isolierung von Mikroorganismen. Dazu wurden Anreicherungsschritte unter anaeroben Bedingungen mit Glycerin als einziger Kohlenstoff und Energiequelle durchgeführt.

Die anaeroben Anreicherungen erfolgten in einem Kulturvolumen von $50 \mathrm{ml}$ in $125 \mathrm{ml}$ Serumflaschen („Hypovials“, Fa. Pierce, Rockford, England). Dazu wurde ein anaerobes Mineralmedium ausgewählt (s. 2.3.7) und mit $10 \%$ der Probe aus dem Standort Avachinsky beimpft. Als einzige Kohlenstoff- und Energiequelle wurde Glycerin in einer Endkonsentration von $100 \mathrm{mM}$ hinzugegeben. Es folgte eine Inkubation für 6 Tage bei $65^{\circ} \mathrm{C}$. Danach erfolgten mehrere Verdünnungsausstriche auf Mineralmedium-Agarplatten ebenfalls unter anaeroben Bedingungen und anschließender Inkubation bei $65{ }^{\circ} \mathrm{C}$. Kolonienbildung konnte nach ca. 2 Tagen beobachtete werden. Diese wurden mehrfach erneut vereinzelt, was schließlich zur Isolierung eines Mikroorganismusses führte der fortlaufend als A1 bezeichnet wird. Mittels Kolonie-PCR (s. 2.13) wurde das 16S rRNA-Gen amplifiziert. Als Primer wurden die gegen die 16S rRNA-Genen von Bakterien gerichteten Oligonukleotide 16S-08 und 16S-1504 (s. Tab. 4) eingesetzt. Ein Datenvergleich durch blastn der NCBI Datenbank ergab zu 99 \% eine Identität zu einem 16S rRNA-Gen aus Thermoanaerobacter wiegelii B5. Da der isolierte Mikroorganismus in der Lage war unter anaeroben Bedingungen mit Glycerin als einziger Energie- und Kohlenstoffquelle zu wachsen, war das Ziel, das für diesen Stoffwechsel notwendige Operon zu isolieren. Dazu sollte aus der chromosomalen DNA des Mikroorganismusses eine Fosmid-Genbank konstruiert werden. Der Mikroorganismus wurde in einem Kulturvolumen von $500 \mathrm{ml}$ unter anaeroben Bedingungen angezogen (s. 2.4.2) und die chromosomale DNA isoliert (s. 2.8.1). Die Fosmid-Genbank wurde laut Protokoll (s. 2.16.3.1) angefertigt. Sie umfasst 1200 Klone mit einer durchschnittlichen Insertgröße zwischen 20 und $35 \mathrm{kbp}$. Zur Identifizierung des für die Glycerinfermentation zuständigen Operon, wurde ein anaerobes Screening auf M9-Mineralmedium und Glycerin als Kohlenstoff- und Energiequelle durchgeführt. Als Wirtsstamm wurde E. coli 
ECL707 (SPRENGER et al. 1989), welcher nicht in der Lage ist, aerob mit Glycerin, zu wachsen ausgewählt. Dadurch sollte ausgeschlossen werden, dass durch eventuelle mikroaerophile Bedingungen ein Hintergrundrasen auf den Platten erscheint. Die Fosmide wurden in E. coli ECL707 transformiert (s. 2.16.2) und unter anaeroben Bedingungen auf die Screeningplatten aufgebracht. Es folgte eine Inkubation von 6 Tagen bei $37^{\circ} \mathrm{C}$. Mittels dieser Methode konnte allerdings kein positiver Klon, welcher in der Lage ist unter anaeroben Bedingungen mit Glycerin als einziger Energie- und Kohlenstoffquelle zu wachsen, gefunden werden

\subsubsection{Screening der Fosmid-Genbank des isolierten Theromoanaerobacter auf lipolytische, proteolytische und amyolytische Aktivität}

Die 1200 Fosmid Klone der Genbank des Thermoanaerobacter wurden auf das Vorhandensein verschiedener biotechnologisch relevanter Enzymaktivitäten Lipasen, Protease oder Amylase hin untersucht. Dies erfolgte mittels aktivitätsbasierender Plattentests. Zunächst wurde auf das vorhandensein lipolytischer Aktivität gescreent (s. 2.16.5). Es konnte ein positiver Klon identifiziert werden, welcher nach Isolierung des Fosmides und Retransformation einen positiven Phänotyp zeigte. Er wurde FosA1 genannt. Zur Isolierung des für die lipolytische Aktivität verantwortlichen ORFs erfolgte eine Subklonierung. Das Fosmid wurde erneut präpariert (s. 2.8.4.4) und mit dem Restriktionsenzym Hindlll geschnitten (s. 2.11.1). Der gesamte Ansatz wurde dephosphoryliert (s. 2.11.2.3), um Religationen zu verhindern. Es folgte schließlich die Klonierung in den zuvor mit HindIII linearisierten Vektor pBSKII ${ }^{+}$ Nach Transformation in E. coli TOP10 wurden die erhaltenen Subklone erneut auf lipolytische Aktivität überprüft, was zu einem positiven Subklon führte. Das Plasmid hat eine Insertgröße von 2,8 kbp. Es konnte ein lipolytischer ORF von 780 bp identifiziert werden, der für 259 Aminosäuren kodiert. Die abgeleitete Molekularmasse beträgt 29,19 kDa und der isoelektrischen Punkt liegt bei 5,45. Er wird als lipA1 bezeichnet. Nach blastp gegen die Datenbank der NCBI konnte eine $100 \%$ Identität im gesamten Aminosäurebereich zu einer 
Dienlacton-Hydrolase aus Thermoanaerobacter pseudoethanolicus festgestellt werden. Abb. 46 zeigt die Aminosäuresequenz.

1 MOKAV BITYN GKTLR GMMHL PDDVK GKVPM VIMEH GETGN KVBSH FIFVK

51 MSRAL BKVGI GSVRF DFYGS GESDG DESEM TFSSE LEDAR QILKF VKEQP

101 TTDPE RIGLL GLSMG GAIAG IVARE YKDEI KALVL WAPAF NMPEL IMHBS

151 VKQYG AIMEQ LGFVD IGGHK LSKDF VEDIS KLNIF BLSKG YDKKV LIVHG

201 TNDEA VEYKV SDRIL KEVYG DNATR VTIEN ADHTF KSLEW EKKAI EESVE

251 FFKKE LLKG

Abb. 46: Aminosäuresequenz der putativen Dienlacton-Hydrolase aus dem Isolat A1. Grün: Konservierter Breich für Lipasen/Esterasen. Rot Mögliche Aminosäuren der katalytischen Triade.

Des Weiteren konnte ein ORF von 1245 bp stromabwärts des lipolytischen ORFs identifiziert werden, welcher für eine Peptidase T kodiert. Nach einem Datenbankvergleich durch blastp der NCBI Datenbank konnte eine Peptidase T aus Thermoanaerobacter pseudoethanolicus mit einer Identität von $99 \%$ auf Aminosäureebene identifiziert werden. Das Genprodukt kodiert für 414 Aminosäuren und hat eine Molekularmasse von 46,68 kDa und einen isolelektrischen Punkt von 5,16. Abb. 47 zeigt einen Überblick über die Organisation der ORFs.

\section{ORFlip ORFpep}

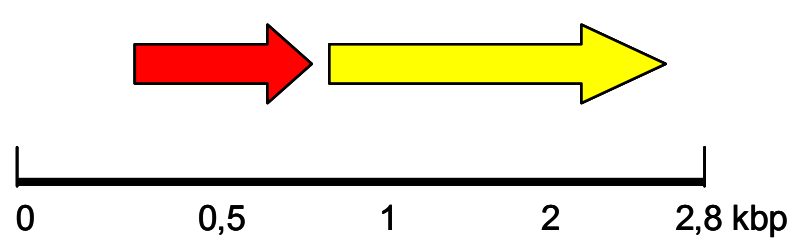

Abb. 47: Organisation der ORFs im Fosmid der Genbank A1. Rot: lipolytischer ORF, gelb: proteolytischer ORF.

Das Screening nach amyolytischer Aktivität der Fosmid-Genbank A1 wurde wie unter 2.16.7 beschrieben durchgeführt und ergab zwei positive Klone. Abb. 48 zeigt einen amyolytisch aktiven Klon. 


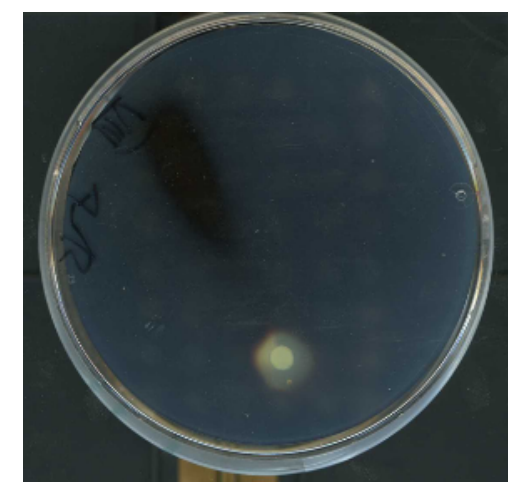

Abb. 48: Amyolytisch aktiver Klon der Fosmid Genbank des Isolates A1. Nachweis der amyolytischen Aktivität durch Abbau der in den Agarplatten solubilisierten Stärke und Anfärbung mit Lugolscher Lösung.

Zur Ermittlung der molekularen Masse des amyolytisch aktiven Proteins konnte eine aktivitätsbasierende SDS-PAGE (s. 2.17.6) durchgeführt werden. Dazu wurde der amyolitisch aktive Fosmid-Klon in einer $5 \mathrm{ml}$ LB-Cm-Kultur angezogen und ein Rohextrakt erstellt (s. 2.17.2.2). Dieser wurde durch SDSPAGE aufgetrennt und anschließend in Phosphat-Puffer (50 mM) für $2 \mathrm{~h}$ gewaschen. Erst dann erfolgte eine Inkubation in Phosphat-Puffer (50 mM) und $1 \%(w / v)$ löslicher Stärke ü. $\mathrm{N}$ bei $60^{\circ} \mathrm{C}$. Am nächsten Morgen wurde das Gel mit Lugolscher Lösung angefärbt. Die amyolytische Aktivität macht sich durch eine ungefärbte klare Bande bemerkbar. Das Ergebnis ist in Abb. 49 dargestellt. Es zeigt bei 50 -55 kDa die amyolytische Aktivität des Rohextraktes durch eine klare Bande 


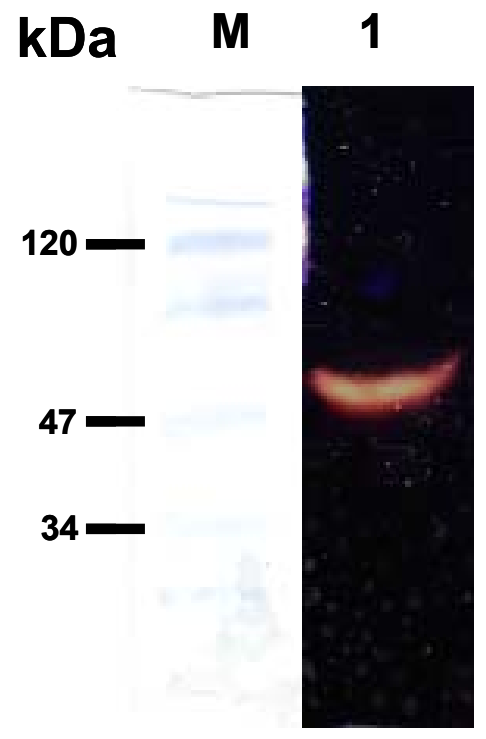

Abb. 49: Aktivitätsfärbung nach SDS-PAGE des amyolytisch aktiven Rohextraktes. M: Molekularmassenstandard, 1: amyolytische Aktivität des Rohextraktes in Form einer aufgeklarten Bande bei 50 - $55 \mathrm{kDa}$. Der Rohextrakt wurde durch SDS-PAGE aufgetrennt und anschließend in Phosphat-Puffer (50 $\mathrm{mM}$ ) für $2 \mathrm{~h}$ gewaschen. Dann erfolgte eine Inkubation in Phosphat-Puffer $(50 \mathrm{mM})$ und $1 \%(\mathrm{w} / \mathrm{v})$ löslicher Stärke ü. $\mathrm{N}$ bei $60{ }^{\circ} \mathrm{C}$. Anschließend wurde das Gel mit Lugolscher-Lösung gefärbt (s. 2.17.6). 


\section{Diskussion}

Die Untersuchung der mikrobiellen Diversität von Habitaten mittels kultivierungsunabhängigen Methoden, wie der 16S rRNA-Genanalyse, geben Einblicke in die tatsächliche mikrobielle Vielfalt (DANIEL 2005, STREIT und SCHMITZ 2004). Durch die Methode der Metagenomanalyse erschließt sich das genetische Potential von bisher unkultivierten Mikroorganismen. Die Konstruktion von sogenannten Metagenombanken stellt dabei einen wichtigen Teil bei der Konservierung der metagenomischen Information dar. Verschiedenste DNA-Isolierungsmethoden, welche es erlauben, DNA direkt aus einer Umweltprobe zu isolieren, spielen eine entscheidene Rolle bei der Erschließung der gesamten genetischen Information eines Habitates. Die in Metagenombanken konservierte metagenomische DNA steht somit für die Identifizierung neuartiger Biokatalysatoren und Wirkstoffe zur Verfügung.

Im Rahmen dieser Arbeit wurden DNA-Isolierungsmethoden zur Erschließung der metagenomischen Information aus thermophilen Habitaten der Kamtschatka-Region entwickelt und optimiert. Es wurde die mikrobielle Diversität des Standortes Avachinsky mittels 16S rRNA-Genanalysen untersucht, sowie Metagenombanken der Standorte Avachinsky und Dachnie für die Identifizierung und Charakterisierung neuartiger Biokatalysatoren konstruiert.

\subsection{DNA-Isolierung aus Umweltproben}

Bei der phylogenetischen Charakterisierung eines Habitates durch 165 rRNAGenanalysen sowei bei der Konstruktion von Metagenombanken spielt der Erhalt der mikrobiellen Diversität bei der Isolierung der Umwelt-DNA eine entscheidene Rolle. Zahlreiche Untersuchungen zur DNA-Isolierung aus Umweltproben sind bisher veröffentlicht worden (ROCHELLE 2001, COURTOIS et al. 2001, KRSEK 1999). Dabei können grundsätzlich zwei Ansätze verfolgt werden: Zum einen die vorherige Abtrennung der Mikroorganismen von der Matrix mit anschließender Lyse der Zellen (COURTOIS 2001, LINDAHL 1995) 
oder der Ansatz der direkten Lyse der Zellen in der Probe (ZHOU et al. 1996). Die Methode der Abtrennung der Mikroorganismen von der Matrix wird bevorzugt bei der DNA-Isolierung aus wässrigen Habitaten oder Biofilmen angewendet. Insgesamt besteht der Vorteil der vorherigen Trennung von Zellen und Matrixbestandteilen in der Konzentrierung des Zellmaterials, was besonders bei Habitaten mit geringer Biomasse von Vorteil ist (KIMURA et al. 2007, GIOVANNONI et al. 1990). Bei den Habitaten Avachinsky und Dachnie handelte es sich allerdings um terrestrische Proben die in ausreichender Menge zur Verfügung standen, so dass diese Methode nicht in Frage kam. Des Weiteren spielt die Reinheit der isolierten DNA für spätere Amplifizierungen durch PCR oder Klonierungen der DNA eine entscheidene Rolle. In Abhängigkeit des Ausgangsmaterials kommt es bei der Isolierung von UmweltDNA zur Mitisolierung von Humin- und Flavinsäuren, welche in Habitaten mit hohem Anteil an organischem Material, wie z. B. Boden, besonders stark auftreten (TEBBE 1993, YEATES 1998). Diese Verunreinigungen traten auch bei der DNA-Isolierung aus den Habitaten Avachinsky und Dachnie auf und konnten mit Hilfe der Caesiumchlorid-Dichtegradientenzentrifugation (s. 2.12.2) (OGRAM et al. 1987) weitestgehend beseitigt werden, so dass sie für weitere molekularbiologische Verfahren zugänglich war (s. 3.2 und 3.3). Der Ansatz der direkten Lyse der Zellen in der Probe hat generell den Vorteil, dass auch frei in der Probe vorliegende DNA mit erfasst wird (KNIETSCH et al. 2003, HENNE et al. 2000). Außerdem entfallen aufwendige Trennverfahren durch Homogenisierung oder Gradientenzentrifugation (LINDAHL 1995, COURTOIS et al. 2001). Ein weiterer Faktor, welcher einen großen Einfluß auf die Ausbeute an DNA bei der Isolierung aus Umweltproben hat, ist die Methode des Zellaufschlusses (COWAN et al. 2005) Für den Zellaufschluß besonders stabiler Zellwände wie die der Grampositiven Bakterien oder der besonders für extreme Standorte bekannten Archaeen finden mechanische Zellaufschlussmethoden größere Anwendung. Unter den Begriff „mechanischer Zellaufschluß“ fallen Methoden wie „Bead-Beating“ (HAMAMURA et al. 2005, NIEMI et al 2001, YEATES et al. 1998), die „Freeze-Thaw“-Methode (BLANK et al. 2002, BARNS et al. 1994, LEE et al. 1996), der Zellaufschluß durch Ultraschall (DEGRANGE und BARDIN 1995), die Verwendung der Mikrowelle oder die Kombination von flüssigem Stickstoff und Homogenisator (JOHNSTON 
und AUST 1996). Die „Bead-Beating“-Methode fand bereits zahlreiche Anwendung bei der Isolierung von Umwelt-DNA aus thermophilen Habitaten (HAMAMURA et al. 2005, NORRIS et al. 2002, WILKINSON et al. 2002). YEATES et al. (1998) untersuchten verschiedene Umwelt-DNAIsolierungsmethoden. Trotz des Einsatzes des „Bead Beaters“ gelang es ihnen hochmolekulare DNA aus Umweltproben $\mathrm{zu}$ isolieren. Der Erhalt der hochmolekularen Struktur der Umwelt-DNA ist Vorraussetzung für die Konstruktion von „large-Insert“-Genbanken (BERRY et al. 2003). Im Rahmen dieser Arbeit sollten ebenfalls „large-Insert“-Metagenombanken in Form einer Fosmidgenbank konstruiert werden, was Umelt-DNA ab einer Größe von 25 kbp zur Vorraussetzung hatte (s. 3.3.2). In dieser Arbeit kam die Methode des „Bead-Beating“ in Kombination mit der direkten Lyse der Zellen nach ZHOU et al. (1996) zur Anwendung (s. 2.8.2). Durch den kurzen (30 Sekunden) Einsatz der „Bead-Beating“-Methode, konnten zu starke Scherkräfte gegen die DNA vermieden werden, so dass die hochmolekulare Struktur weitgehend erhalten blieb. So konnte eine Fosmid-Genbank mit einer durchschnittlichen Insertgröße von $35 \mathrm{kbp}$ aus Umwelt-DNA des Stanortes Avachinsky konstruiert werden (s. Tab. 9), was ein Beleg für die hochmolekulare Struktur der isolierten Umwelt-DNA darstellt. Zusätzlich konnten umfangreiche phylogenetische Untersuchungen des Standortes Avachinsky durchgeführt werden.

\subsection{Phylogenetische Untersuchung des thermophilen Habitates Avachinsky}

Die phylogenetische Untersuchung der mikrobiellen Diversität von Umweltproben ist ein wichtiger Teil der Metagenomforschung. Lange Zeit war die Kultivierbarkeit von Mikroorganismen Voraussetzung für deren phylogenetische Einordnung. Erst wenn es gelungen war, den Mikroorganismus anzureichern und zu isolieren, konnte sein genetisches Potential ausgeschöpft werden und eine phylogenetische Einordnung erfolgen. Durch neuartige molekularbiologische Methoden, wie die Isolierung der metagenomischen DNA aus Umweltproben, die Entwicklung der Polymerase-Kettenreaktion sowie der Sequenzanalyse, traten mikrobielle Kultivierungstechniken zur phylogenetischen Charakterisierung von Habitaten in den Hintergrund. Die 
phylogentische Untersuchung der mikrobiellen Diversität beruht auf der Sequenzanalyse von sogenannten Markergenen. Diese sollten ubiquitär vorhanden sein und hochkonservierte Bereiche aufweisen, welche sich im Laufe der Evolution nur wenig verändert haben. Die 16S rRNA-Genanalyse steht dabei im Vordergrund. Das 16S rRNA-Gen kodiert für die $16 \mathrm{~S}$ rRNA der kleinen 30S-Untereinheit der Ribosomen von Prokaryoten. Hochkonservierte Genbereiche erlauben die Ableitung von Oligonukeotiden zur vollständigen oder partiellen Amplifikation dieser Gene mittels PCR. Weniger konservierte oder variable Regionen der 16S rRNA-Gene erlauben die phylogentische Zuordnung. Eine Vielzahl von Untersuchungen beruht auf der phylogenetischen Einordnung von 16S rRNA-Genen (HUGENHOLTZ 1998, BARNS 1994, LI 2006, LI 2007). Carl Woese konstruierte 1987 anhand der Untersuchung von 16S rRNA-Genen den ersten phylogenetischen Stammbaum. Dieser setzte sich aus 12 Phyla bereits kultivierter Mikroorganismen zusammen. Viele Phyla blieben jedoch lange Zeit unentdeckt. Erst durch die Erweiterung von Datenbanken durch neue kultivierungsunabhängige Methoden der $16 S$ rRNAGenanalysen machte es möglich neuartige Phyla zu beschreiben. Der durch Woese und Mitarbeiter entwickelte Stammbaum wurde 2003 auf 52 Phyla erweitert (PACE 1985, RAPPE und GIOVANNONI 2003, HUBER 2002). 14 Phyla von kultivierbaren Bakterien sind dazugekommen und weitere 26 Phyla werden nur durch 16S rRNA-Gensequenzen bisher unkultivierter Mikroorganismen repräsentiert. Inzwischen sind über 100 bakterielle Phyla bekannt (DESANTIS et al. 2006). Schon in den 70er Jahren entdeckten Woese und Mitarbeiter anhand von ribosomalen Untersuchungen, dass sich das Leben in drei Domänen einteilen lässt. Die Eukaryoten, die Bakterien und schließlich die Archaeen. Zunächst teilte man die Archaeen in zwei Phyla. Die Crenarchaeota und die Euryarchaeota. BARNS et al. (1996) leitete anhand 16S rRNA-Genanalysen von unkultivierten Mikroorganismen einer heißen Quelle des Yellowstone Nationalparks, dem sogenannten „Obsidian Pool“, ein weiteres Phylum der Archaeen, die Korarchaeota ab. Bis heute wird dieses Phylum nur durch 16S rRNA-Gensequenzen von unkultivierten Mikroorganismen repräsentiert. Ein möglicherweise weiteres Phylum der Archaeen, die Nanoarchaeota, entdeckten HUBER et al. 2002 durch die Identifizierung eines mit dem Archaeon Ignicoccus pacificus (HUBER 2000) in einer Art Symbiose 
lebenden Mikroorganismus. Abb. 50 zeigt einen phylogenetischen Stammbaum der verschiedenen Phyla und Ordnungen der Archaeen, konstruiert anhand von 16S rRNA-Gensequenzen kultivierter und unkultivierter Archaeen (SCHLEPER et al. 2005). Im Vergleich mit den Bakterien zeigen die Archaeen eine sehr geringe Anzahl verschiedener Ordnungen innerhalb der Phyla. Insgesamt sind bei den Archaeen 12 Ordnungen bereits kultivierter Archaeen bekannt (GRIBALDO und BROCHIER-ARMANET 2006). In Abb. 50 sind sie als schwarze Dreiecke markiert. Die leeren Dreiecke zeigen die Ordnungen innerhalb der Phyla der Archaeen von bisher unkultivierten Archaeen. Sterne markieren hyperthermophile Ordnungen.

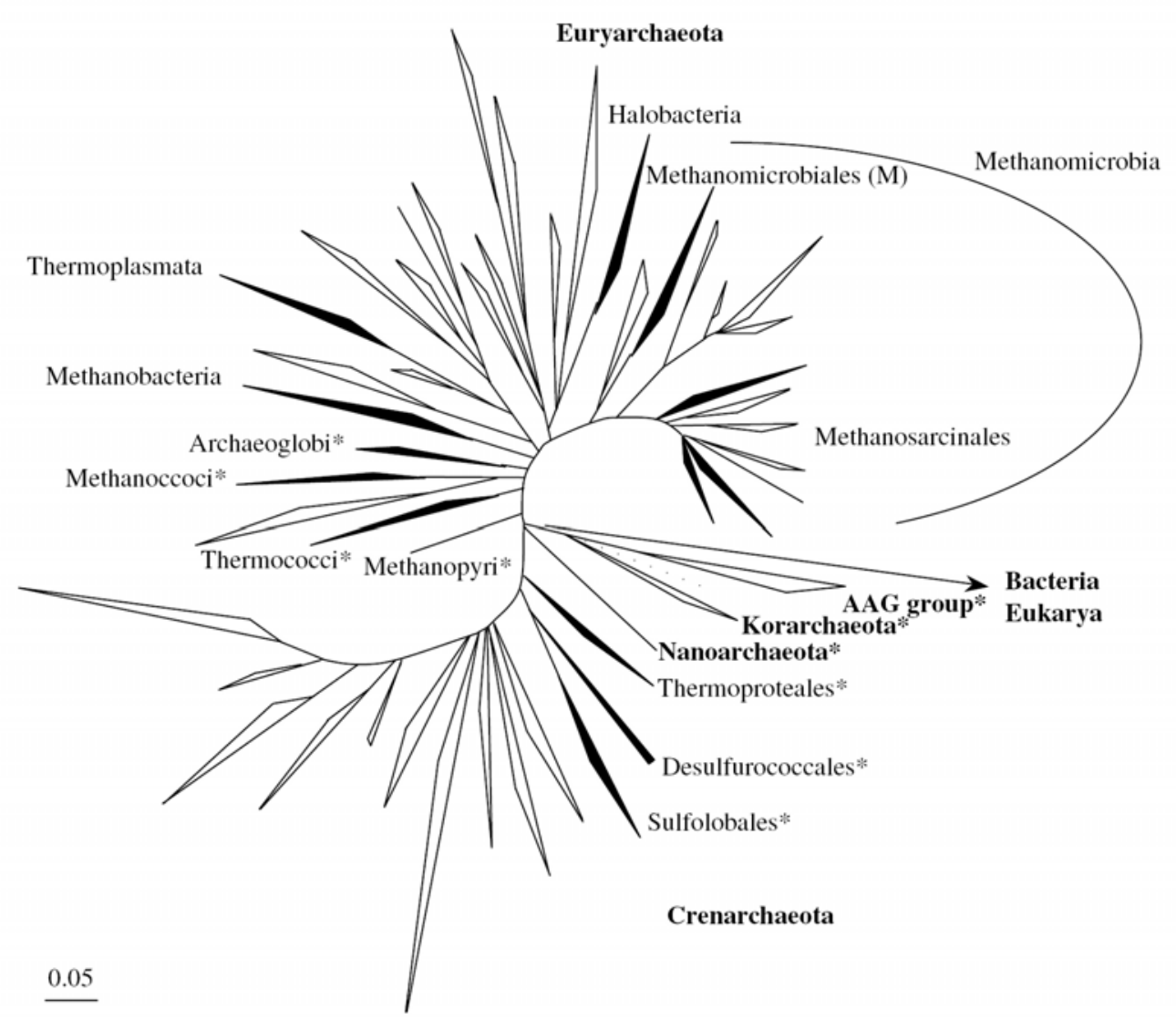

Abb. 50: Phylogentischer Stammbaum der Archaeen (SCHLEPER et al., 2005). Schwarze Dreiecke repräsentieren Ordnungen bereits kultivierter Mikroorganismen. Leere Dreiecke zeigen Ordnungen die nur durch $16 \mathrm{~S}$ rRNA Gensequenzen unkultivierter Mikroorganismen repräsentiert werden. Sterne zeigen Ordnungen oder Phyla hyperthermophiler Archaeen. 
Im Rahmen dieser Arbeit wurde die mikrobielle Diversität eines thermoalkaliphilen Habitates der Kamtschaka-Region anhand von bakteriellen als auch archaellen 16S rRNA-Gensequenzen untersucht. In einer Diplomarbeit konnten bereits erste Eindrücke in die mikrobielle Diversität verschiedener Habitate der Kamtschatka-Region vermittelt werden (s. Diplomarbeit Jörg Schuldes). Die Untersuchung der mikrobiellen Diversität und die Analyse phylogenetischer Beziehungen wurden in den letzten Jahren an den unterschiedlichsten Habitaten, wie z. B. Boden (COURTOIS et al. 2001, LIESACK und STACKEBRANDT 1992), Seen (MA et al. 2004), der Tiefsee (LEPAGE et al. 2004, VETRIANI et al. 1999), Biofilme (BOND et al. 2000) oder heißen Quellen (HAMAMURA et al. 2005, KANOKRATANA et al. 2004, GOSH et al. 2003, BLANK et al. 2002) durchgeführt. Besonders die mikrobielle Diversität thermophiler Standorte wurde in den letzten Jahren in zahlreichen Arbeiten beschrieben ( $\mathrm{LI}$ et al. 2006, KIMURA et al. 2007, MARTEINSSON et al. 2001, YAMAMOTO et al. 1998). Da es sich bei dem Standort Avachinsky um einen thermophilen, alkaliphilen und terrestrischen Standort handelt, wurden im Rahmen dieser Arbeit Vergleiche mit möglichst ähnlichen Standorten vorgenommen. Dabei spielen Parameter wie Standortbeschaffenheit, $d . h$. flüssiges oder terrestrisches Habitat, pH-Wert und Temperatur oder die Zusammnestzung des Substrates eine entscheidene Rolle.

Insgesamt wurden im Rahmen dieser Arbeit 594 16S rRNA-Gensequenzen aus dem Habitat Avachinsky untersucht. Davon konnte 393 Sequenzen den Bakterien und 201 den Archaeen zugeordnet werden. Eine Analyse der 594 Sequenzen mit dem Programm DOTUR (s. 2.14.4) (SCHLOSS und HANDLSMAN 2004), welche die gegeneinander alignten $16 S$ rRNAGensequenzen in sogenannte OTUs (operational taxonomic units) umrechnet, ergab 186 OTUs der bakteriellen 16S rRNA-Gensequenzen und 28 OTUs für die archaellen 16S rRNA-Gensequenzen. 1 OTU umfasst dabei alle 16S rRNAGensequenzen, welche sich untereinander nicht mehr als $3 \%$ in ihrer Sequenz unterscheiden. Die hohe Zahl der OTUs von insgesamt 214 zeigt die potentielle mikrobielle Diversität des Standortes Avachinsky. 234 bakterielle und 42 archelle 16S rRNA-Gensequenzen wurden zur phylogentischen Untersuchung und schließlich für die Konstruktion von phylogentischen Stammbäumen genutzt. Es konnten 16S rRNA-Gensequenzen aus insgesamt 20 
verschiedenen bakteriellen Phyla amplifiziert und zugeordnet werden (s. Abb. 25).

Obwohl es sich bei dem Habitat Avachinsky um ein thermophiles Habitat handelt, konnten viele 16S rRNA-Gensequenzen Phyla zugeordnet werden, welche vorwiegend in mesophilen Standorten vertreten sind, wie z. B. die Proteobakterien (s. Abb. 14 bis Abb. 19). Dies konnte schon in anderen Untersuchungen thermophiler Habitate gezeigt werden (LI et al. 2006, HAMAMURA et al. 2005). Auch in phylogenetischen Untersuchungen anderer Habitate der Kamtschatka-Region (s. Diplomarbeit Jörg Schuldes) konnten verschiedene Klassen der Proteobakterien identifiziert werden. $55 \%$ der amplifizierten bakteriellen 16S rRNA-Gensequenzen des Habitates Avachinsky wurden den Proteobakterien zugeordnet. Davon gehören 24 \% den AlphaProteobakterien an. Auffällig bei den Alpha-Proteobakterien ist hier die Ordnung Sphingomonadales, bei der die direkten Nachbarn von 13 der insgesamt 18 aus dem Habitat Avachinsky amplifizierten 16S rRNA-Gensequenzen kultivierte Mikroorganismen sind. Diese zeigen zudem Identitäten zwischen 99,4 und $100 \%$ zu den nächsten Nachbarn. Dabei stammen die Isolate aus metallkontaminierten Böden [AY162053, AF105023] oder der Tiefsee [DQ396092]. Die Beta-Proteobakterien sind mit 13,5\%, die DeltaProteobakterien mit 10,5 \% und die Gamma-Proteobakterien schließlich noch mit $7 \%$ vertreten. 13 von 33 im Rahmen dieser Arbeit amplifizierten 16S rRNAGensequenzen der Beta-Proteobakterien zeigen mehr als $97 \%$ Identität zur 16S rRNA-Gensequenz ihres direkten Nachbarn. Bei den GammaProteobakterien zeigen 8 von 16 16S rRNA-Gensequenzen aus Avachinsky über $97 \%$ Identität zu ihrem direkten Nachbarn. Nur zwei 16S rRNAGensequenzen der Delta-Proteobakterien zeigen mehr als $97 \%$ Identität zu ihren direkten Nachbarn. Auffällig ist, dass den Epsilon-Proteobakterien keine 16S rRNA-Gensequenzen zugeordnet werden konnte. Schon bei den Proteobakterien ist $\mathrm{zu}$ erkennen, dass sich der überwiegende Teil der amplifizierten 16S rRNA-Gensequenzen zwar in Phyla eingruppieren lassen, aufgrund ihrer geringen Identitäten von unter $97 \%$ zu ihren direkten Nachbarn handelt es sich aber vermutlich um neue Arten innerhalb der Ordnungen. Abb. 51 vergleicht die bakterielle Diversität des Standortes Avachinsky mit verschiedenen Habitaten des Yellowstone Nationalparks, heißen Quellen in 
Japan, Indien und Thailand, sowie einem Natronsee in der Mongolei. In Tab. 12: Umweltbedingungen verschiedener mittels 16S rRNA-Genanalysen untersuchten Habitate angegeben.

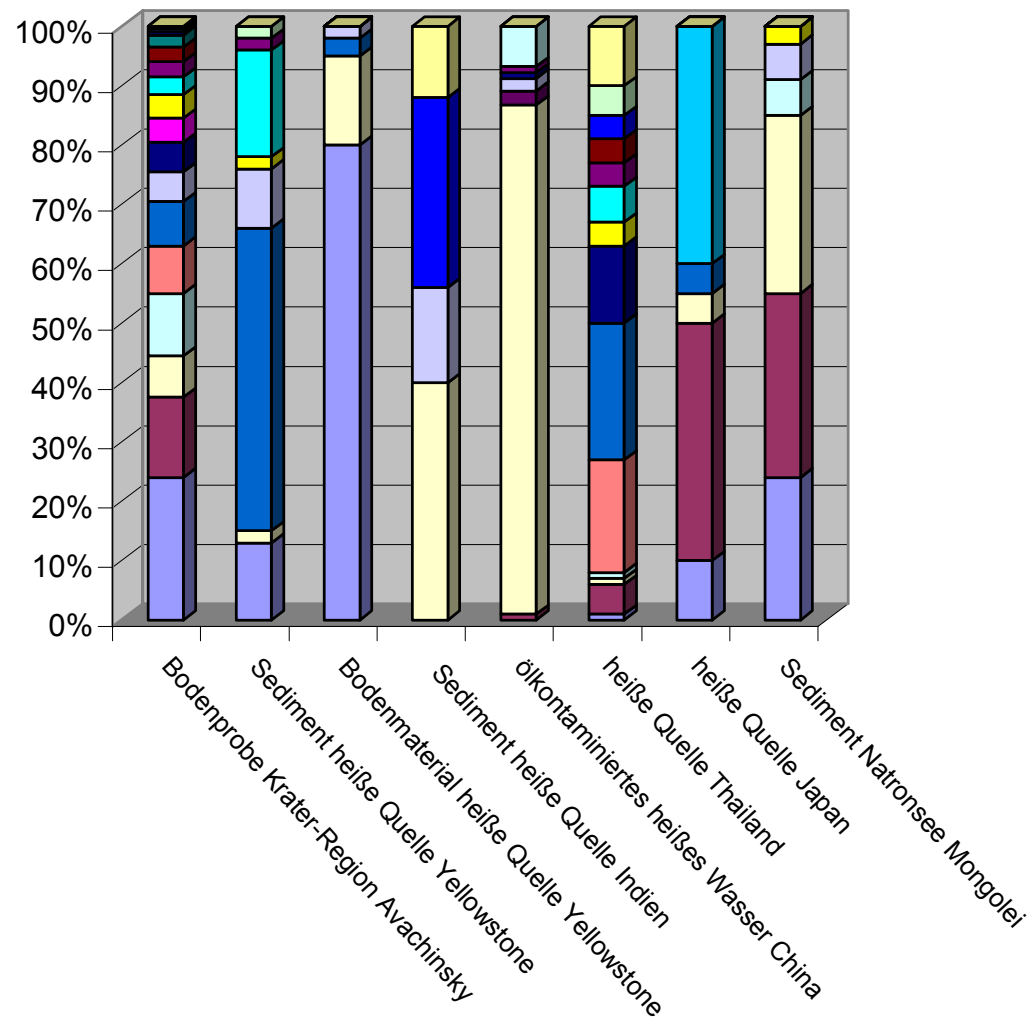

$\square$ Thermus
$\square$ Verrucomicrobia
$\square$ Thermotogae
$\square$ Aquificae
$\square$ Cyanobacteria
$\square$ Gemmatimonadetes
$\square$ Chloroflexi
$\square$ Grampositive Bakterien mit
hohem GC-Gehalt
$\square$ Planctomycetes
$\square$ OP,TM,BRC
$\square$ Chlorobi
$\square$ Nitrospirae
$\square$ Grampostive Bakterien mit
niedrigem GC-Gehalt
$\square$ Acidobacteria
$\square$ CFB
$\square \varepsilon$-Proteobacteria
$\square \delta$-Proteobacteria
$\square y$-Proteobacteria
$\square \beta$-Proteobacteria
$\square \alpha-$ Proteobacteria

Abb. 51: Prozentuale Verteilung von 16S rRNA-Gensequenzen in die bakteriellen Phyla, amplifiziert aus verschiedenen Habitaten. Bodenprobe Avachinsky (diese Arbeit), Sediment heiße Quelle,Yellowstone Nationalpark (NORRIS et al. 2001), Bodenmaterial heiße Quelle, Yellowstone Nationalpark (HAMAMURA et al. 2005), Sediment heiße Quelle, Indien (GOSH et al. 2003), ölkontaminiertes heißes Wasser, China (Li et al. 2006), heiße Quelle, Thailand (KANOKRATANA et al. 2005), heiße Quelle, Japan (YAMAMOTO et al. 1998), Sediment Natronsee, Mongolei (MA et al. 2004). 
Tab. 12: Umweltbedingungen verschiedener mittels $16 S$ rRNA-Genanalysen untersuchten Habitate

\begin{tabular}{|c|c|c|c|c|}
\hline Standort & $\begin{array}{c}\text { Art des } \\
\text { Habitates }\end{array}$ & $\mathrm{T}\left[{ }^{\circ} \mathrm{C}\right]$ & $\mathrm{pH}$ & Referenz \\
\hline Avachisnky & Kraterregion & 67 & $9-9,3$ & diese Arbeit \\
\hline $\begin{array}{l}\text { Yellowstone } \\
\text { N. (USA) }\end{array}$ & Sediment & $35-65$ & $3,7-5,1$ & $\begin{array}{l}\text { NORRIS et al. } \\
2001\end{array}$ \\
\hline $\begin{array}{l}\text { Yellowstone } \\
\text { N. (USA) }\end{array}$ & $\begin{array}{l}\text { Bodenmaterial } \\
\text { an heißer Quelle }\end{array}$ & $\begin{array}{l}\text { nicht } \\
\text { bestimmt }\end{array}$ & $2,8-3,8$ & $\begin{array}{l}\text { HAMAMURA et } \\
\text { al. } 2005\end{array}$ \\
\hline Japan & $\begin{array}{l}\text { Sediment heiße } \\
\text { Quelle }\end{array}$ & $52-72$ & $7,2-8$ & $\begin{array}{l}\text { YAMAMOTO et } \\
\text { al. } 1998\end{array}$ \\
\hline China & $\begin{array}{l}\text { Öl- } \\
\text { kontaminiertes } \\
\text { heißes Wasser }\end{array}$ & 180 & nicht bestimmt & LI et al. 2006 \\
\hline Thailand & Heiße Quelle & 55 & 6,6 & $\begin{array}{l}\text { KANOKRATANA } \\
\text { et al. } 2005\end{array}$ \\
\hline Indien & Heiße Quelle & $60-69$ & $9,1-9,3$ & GOSH et al. 2003 \\
\hline Mongolei & Natronsee & $\begin{array}{l}\text { Nicht } \\
\text { bestimmt }\end{array}$ & 10 & MA et al. 2004 \\
\hline
\end{tabular}

Die phylogenetischen Untersuchungen der verschiedenen Habitate zeigen, dass Proteobakterien ubiquitär sind, was Habitate mit zu Avachinsky vergleichbaren Umweltparametern betrifft. Wenigstens eine Ordnung der Proteobakterien konnte in den oben genannten Habitaten (s. Tab. 12) sowie den anderen Habitaten der Kamtschatka-Region (s. Diplomarbeit Jörg Schuldes) identifiziert werden. Im Vergleich zu den anderen Habitaten (Tab. 12) zeigt der Standort Avachinsky die größte Diversität, was die Identifizierung von Vertretern verschiedener Phyla betrifft. Nur die Untersuchungen einer heißen Quelle in Thailand (KANOKRATANA et al. 2005) zeigen eine ähnlich hohe bakterielle Diversität auf Phylumebene. Dort konnten 14 bakterielle Phyla identifiziert werden. $12 \%$ der amplifizierten 16S rRNA-Gensequenzen entfallen hier auf die Proteobakterien. Auf das Phylum der Bacteroidetes entfallen in Avachinsky insgesamt 19 16S rRNA-Gensequenzen (s. Abb. 20). Sie zeigen Identitäten zu den $16 \mathrm{~S}$ rRNA-Gensequenzen ihrer direkten Nachbarn zwischen 
92,4 bis 100 \%. Eine Gruppe von sechs Sequenzen (A03_kab08, B06_kab08, D05_kab08, H01_kab08, F07_kab07, B10_kab07) zeigt dabei eine hohe Identität von 99,7 bis $100 \%$ zu einer $16 \mathrm{~S}$ rRNA-Gensequenz amplifiziert aus einem Truthahndarm [EF025213]. Bei dem Phylum Bacteroidetes oder der Ordnung Bacteroides handelt es sich um überwiegend um zuckerabbauende obligat anaerobe Darmbakterien. Sie konnten aber auch schon in anderen Habitaten nachgewiesen werden, z. B. in Uranabfallhalden in Johanngeorgenstadt (Sachsen) [AM084894] oder taiwanesischem Waldboden [DQ451493]. ANITORI et al. (2002) untersuchten eine heiße Quelle in Australien und konnten ebenfalls das Phylum Bacteroidetes nachweisen. Bacteroidetes konnten auch noch in der heißen Quelle Thailands nachgewiesen werden. Erste phylogenetische Untersuchungen des Habitates Dachnie (s. Diplomarbeit Jörg Schuldes) identifizierten ebenfalls das Phylum Bacteroidetes. Auf das Phylum Acidobacteria entfallen in Thailand (KONAKRATANA et al. 2005) mit $23 \%$ der 16S rRNA-Gensequenzen deutlich mehr als beim Habitat Avachinsky, dort sind es 7,5 \% (Abb. 23). Davon zeigen mit einer Ausnahme alle mehr als $3 \%$ Unterschied zu ihrem nächsten Nachbarn. Klon C11_kab06 aus dieser Arbeit zeigt mit $98.9 \%$ die höchste Identität zu seinem direkten Nachbarn. Dieser entstammt einem thermalen Bereich des australischen artesischen Beckens. NORRIS et al. (2001) konnten $51 \%$ ihrer $16 S$ rRNAGensequenzen den Acidobacteria zuorden. In den beiden alkaliphilen Habitaten Indien und Mongolei konnten keine Acidobacteria identifiziert werden. Im Natronsee der Mongolei konnten wie in Avachinsky 24 \% der amplifizierten 16S rRNA-Gensequenzen den Gamma-Proteobakterien zugeordnet werden. Aufgrund der Umweltbedingungen lässt sich der alkaliphile Standort in Indien am Besten mit Avachinsky vergleichen. Er zeigt mit pH 9,1 bis 9,3 und einer Temperatur von 60 bis $69{ }^{\circ} \mathrm{C}$ ähnliche Umweltbedingungen. Dieser Standort zeigt mit vier identifizierten mikrobiellen Phyla allerdings die geringste bakterielle Diversität auf Phylumebene aller hier vorgestellten Habitate. Ein großer Teil der amplifizierten 16S rRNA-Gensequenzen wird hier den Cyanobakterien zugeordnet Dies steht im Gegensatz zu Avachinsky, wo es unter 0,5\% sind bzw. drei 16S rRNA-Gensequenzen. G03_kab06 zeigt mit 84,1 \% die größte Identität zu Trichormus doliolium [AJ630455] und A05_kab11 und B09_kab11 mit etwa $95 \%$ zu einer 16S rRNA-Gensequenz isoliert aus 
filtriertem Grundwasser in Japan [AB179670]. Aufgrund des großen phylogenetischen Abstandes könnte es sich auch hier um neue Cluster innerhalb dieses Phylums handeln. WIEGEL et al. (2003) untersuchten die mikrobielle Diversität alkalithermophiler Habitate und kamen zu dem Ergebnis, dass sich die Mehrzahl der Prokaryoten in diesen Habitaten den Grampostiven Bakterien, wie z. B den Bacilli oder den Actinobacteria zuordnen lassen. Grampositive Bakterien konnten mit einer Ausnahme in allen hier gezeigten Habitaten nachgewiesen werden. Auch in ersten phylogenetischen Untersuchungen anderer Habitate der Kamtschatka-Region (s. Diplomarbeit Jörg Schuldes) konnten Grampositive Bakterien identifiziert werden und überwiegend den Bacilli und Clostridia zugeordnet werden. YAMAMOTO et al. (1998) konnten keine Grampositiven Bakterien in der heißen Quelle in Japan identifizieren. GOSH et al. (2003) konnten 16 \% ihrer amplifizierten 16 S rRNAGensequenzen den Grampositiven Bakterien zuordnen. In Avachinsky sind es 7,5 \%. Davon entfallen 5 \% auf die Grampositiven mit niedrigem GC-Gehalt, wie die Clostridia oder die Bacilli und 2,5\% auf die Grampositiven mit hohem GC-Gehalt, den Actinobacteria. Insgesamt zeigen alle $16 \mathrm{~S}$ rRNAGensequenzen der Grampositiven mit niedrigem GC-Gehalt des Habitates Avachinsky eine Identität von unter $95 \%$ zu den $16 \mathrm{~S}$ rRNA-Gensequenzen ihrer direkten Nachbarn. Im Rahmen der Anreicherungen (s. 3.6) konnte ein Mikroorganismus isoliert werden, der zu der Gruppe der Thermoanaerobacter gehört. Dieser zeigt mit 99 \% eine hohe Identität zu seinem phylogenetisch direkten Nachbarn. Die Grampositiven mit hohem GC-Gehalt zeigen insgesamt höhere Identitäten. Die 16S rRNA-Gensequenz des Klons D04_kab08 stimmt sogar zu 100 \% mit der Sequenz eines Klons isoliert aus einem hypersalinen See auf Hawaii überein [AF513962]. Von den hier verglichenden Habitaten konnte nur in Avachinsky und in Thailand das Phylum Chlorofexi nachgewiesen werden. Außerdem konnten Vertreter der Chloroflexi in einem thermophilen Habitat bei Mutnovsky (s. Diplomarbeit Jörg Schuldes) identifiziert werden. Die Chlorflexi kommen in neutralen bis alkalischen heißen Quellen vor, aber auch in marinen nichtthermophilen Habitaten konnten sie nachgewiesen werden. Klon C07_kab11 zeigt mit 99,4\% die höchste Identität zu der $16 S$ rRNAGensequenz seines direkten Nachbarn. Dieser wird nur durch seine 16S rRNAGensequenz repräsentiert und entstammt einem Silagebunker [AY921738]. 
Insgesamt konnten nur sechs Sequenzen, bzw. 2,5\% aller 16S rRNAGensequenzen des Habitates Avachinsky den Chloroflexi zugeordnet werden. In Thailand sind es mit $4 \%$ ähnlich viele wie in Avachinsky. Die Nitrospirae werden in Avachinsky durch $5 \%$ aller 16S rRNA-Gensequenzen repräsentiert, sie konnten in anderen vergleichbaren Habitaten (s. Tab. 12) wiederum nur in Thailand nachgewiesen werden. Dort werden sie von $13 \%$ aller $16 \mathrm{~S}$ rRNAGensequenzen vertreten. In Avachinsky zeigen 9 von 12 16S rRNAGensequenzen des Phylums Nitrospirae eine Identität von über $97 \%$ zu der 16S rRNA-Gensequenzen des direkten Nachbarn. Mit 99,7 \% Identität zu einer 16S rRNA Gensequenz einer thermalen Region des australischen großen artesischen Beckens [AB183860] zeigt F04_kab20 die höchste Identität zu seinem direkten Nachbarn. Das Phylum Chlorobi konnte unter allen hier verglichenen Habitaten nur in Avachinsky nachgewiesen werden. Bei Chlorobi handelt es sich um Grüne Schwefelbakterien welche unter anderem in sulfidhaltigen warmen Quellen vorkommen. Die hier amplifizierten 16S rRNAGensequenzen zeigen zwischen 87,5 und $94,7 \%$ Identität zu $16 \mathrm{~S}$ rRNA Gensequenzen amplifiziert aus Seesedimenten [DQ066981-3, AB179535,6]. Die Planctomycetes konnten neben KANOKRATANA et al. (2005) auch von NORRIS et al. (2001) im Yellowstone Nationalpark nachgewiesen werden. Bei den Planctomycetes handelt es sich um ein noch sehr unerforschtes Phylum. Die Mehrzahl der bekannten Gattungen ist aquatisch. Die Gattung Isosphaera steht für thermophile Vertreter dieses Phylums. Die 16S rRNA-Gensequenzen des Habitates Avachinsky zeigen zwischen 77,9 und 95,8 \% Identität zu ihren direkten Nachbarn. Vier 16S rRNA-Gensequenzen (D12_kab19, G11_kab19, G12_kab11, B06_kab06) zeigen erstaunlicher Weise direkte phylogenetische Verwandtschaft zu einer 16S rRNA-Gensequenz amplifiziert aus einem extrem acidophilen Habitat [DQ499298] in Pennsylvania (USA). Die Identitäten liegen allerdings unter 90 \%. Die Phyla Aquificae, Thermotogae, sowie die „candidate divisions" OP, TM und BRC konnten nur in geringem Umfang im Habitat Avachinsky nachgewiesen werden. Sie sind mit weniger als $1 \%$ aller amplifizierten 16S rRNA-Gensequenzen vertreten. Dabei handelt es sich bei den Phyla Thermotogae und Aquificae um hyperthermophile Vertreter der Bakterien. Der Standort Avachinsky gehört mit $67^{\circ} \mathrm{C}$ allerdings eher zu den thermophilen und nicht zu den hyperthermophilen Habitaten, so dass diese 
Phyla vermutlich nicht so stark vertreten sind. Außerdem gehört das Habitate Avachinsky aufgrund seines $\mathrm{pH}$ Wertes (9 bis 9,3) nicht zu den bevorzugten Habitaten dieser hyperthermophilen Bakterien. Die „candidate divisions“ OP8, OP10 und OP11 sind insgesamt mit 7 16S rRNA-Gensequenzen im Habitat Avachinsky vertreten. Die „Obsidian Pool“ Divisionen entstammen den phylogenetischen Untersuchungen einer heißen Quelle des Yellowstone Nationalparks durch HUGENHOLTZ et al. (1997), die $30 \%$ ihrer amplifizierten bakteriellen 16S rRNA-Gensequenzen aufgrund von Sequenzidentitäten zu den nächst verwandten Sequenzen von unter 85 \% in diese „candidate divisions" OP (Obsidian Pool) einteilten. Zwei Sequenzen aus Avachinsky konnten der TM6 Division zugeordnet werden (D01_kab06, C07_kab01). Sie zeigen etwa 87 \% Identität zu einer $16 \mathrm{~S}$ rRNA-Gensequenz amplifiziert aus einem Waldboden [AY043958]. Die BRC Division ist nur durch die Sequenz E08_kab01 in Avachinsky vertreten. Sie zeigt 90 \% Identität zu einer 16S rRNA-Gensequenz aus einem Sediment des "Loch Duich“ in Schottland. Insgesamt kann man sagen, dass die Einteilung der amplifizierten bakteriellen 165 rRNAGensequenzen aus Avachinsky aufgrund der sehr geringen Identitäten zu den direkten Nachbarn sehr schwierig ist. Durch die geringen Identitäten bilden sich neue Cluster völlig unbekannter Mikroorganismen.

Bei der Untersuchung der archaellen Diversität des Habitates Avachinsky konnten insgesamt 201 16S rRNA-Gensequenzen untersucht werden. Aufgrund hoher Identitäten (99 bis 99,5 \%) vieler archaeller 16S rRNA-Gensequenzen untereinander wurden schließlich 42 Sequenzen zur Konstruktion phylogenetischer Stammbäume verwendet. Die Crenarchaeota werden in den phylogenetischen Stammbäumen dieser Arbeit von 27 16S rRNAGensequenzen vertreten (s. Abb. 12). Insgesamt konnten jedoch 186 16S rRNA-Gensequenzen aus diesem Phylum untersucht werden, was insgesamt $92 \%$ aller in dieser Arbeit untersuchten archaellen 16S rRNAGensequenzen entspricht. Dabei werden alle direkten Nachbarn nur durch $16 \mathrm{~S}$ rRNA-Gensequenzen unkultivierter Crenarchaeota repräsentiert und zeigen weniger als $97 \%$ Identität zu den im Rahmen dieser Arbeit untersuchten 16S rRNA-Gensequnezen. Dies deutet auf völlig neue Arten von Mikroorganismen innerhalb der verschiedenen Phyla hin. KIMURA et al. (2007) untersuchten die archaelle Diversität einer hydrothermalen Tiefseeprobe. Auch hier konnten 
$79,2 \%$ aller untersuchten 16S rRNA-Gensequenzen den Crenarchaeota zugeordnet werden. Die Crenarchaeota sind für ihre hyperthermophilen Mitglieder wie die Thermoproteales oder Pyrodictiales bekannt. Es konnten allerdings auch schon Vertreter der Crenarchaeota an mesophilen Standorten, wie z. B. verschiedenen Seen nachgewiesen werden (SCHLEPER 1997, DELONG 1992). Auch in dieser Arbeit zeigten neun 16S rRNA-Gensequenzen (H09_kaa05, G07_kaa05, D07_kaa10, H03_kaa10, G04_kaa18, F09_kaa05, B08_kaa05, A11_kaa05, E04_kaa01) des Phylums Crenarchaeota Identitäten zwischen 93,5 und 95,8 \% zu einer 16S rRNA-Gensequenz amplifiziert aus einer Ackerprobe in Wisconsin (USA). Der Yellowstone Nationalpark hingegen ist bekannt für seine thermalen Regionen, unzählige heiße Quellen und Geysire. Viele 16S rRNA-Genanalysen zur Untersuchung der mikrobiellen Diversität von thermophilen Habitaten wurden anhand von Habitaten des Yellowstone Nationalparks durchgeführt (BLANK et al. 2002, NORRIS et al. 2002, HUGENHOLTZ et al. 1997, REYSENBACH 1994). Die 16S rRNAGensequenz des Klons D01_kaa07 zeigt 83,5 \% Identität zu einer 16S rRNAGensequenz amplifiziert aus einer heißen Quelle des Yellowstone Nationalparks (SPEARS et al. 2004). Zwei 16S rRNA-Gensequenzen (B06_kaa10, C02_kaa10) zeigen Ähnlichkeit zu einer 16S rRNA-Gensequenz amplifiziert aus Proben einer Kraterregion auf Honolulu (Hawaii) [EF032790]. Bei der Untersuchung der Diversität der Euryarchaeota des Habitates Avachinsky (s. Abb. 11) fiel auf, dass 11 der insgesamt $1516 S$ rRNAGensequenzen Ähnlichkeit zu $16 S$ rRNA-Gensequenzen amplifiziert aus Proben einer Goldmine in Südafrika zeigen (TAKAl et al. 2001). Die Identitäten liegen zwischen 82,8 und 97,6 \%. Bei diesen Proben handelt es sich überwiegend um Wasserproben dessen pH-Wert im Bereich 9,5 bis 10 liegt, was in etwa mit dem $\mathrm{pH}$-Wert des Habitates Avachinsky übereinstimmt. Die Temperatur der Wasserproben wurde nicht gemessen.

Von insgesamt 276 bakteriellen und archaellen 16S rRNA-Gensequenzen des Habitates Avachinsky zeigen $68 \%$ weniger als $97 \%$ Identität zu ihren direkten Nachbarn. D. h. es handelt sich vermutlich um völlig unbekannte Mikroorganismen neuer Ordnungen in den entsprechenden Phyla, welche z. T. völlig eigenständige Cluster bilden. 95,5 \% der direkten Nachbarn werden nur durch 16S rRNA-Gensequenzen unkultivierter Mikroorganismen repräsentiert. 
Dieser Wert unterstreicht, dass trotz zahlreicher phylogenetischer Untersuchungen in den letzten Jahren und die stetig wachsende Zahl an 16S rRNA-Gensequenzen in den Datenbanken die mikrobielle Diversität im Allgemeinen noch sehr unerforscht ist. Es bedarf weiterer phylogenetischer Untersuchungen bzw. Sequenzdaten, um 16S rRNA-Gensequenzen mit geringen Identitäten gegenüber anderen 16S rRNA-Gensequenzen zu klassifizieren oder phylogenetisch einzuordnen.

\subsection{Konstruktion von Metagenombanken.}

Die isolierte metagenomische DNA der Standorte Avachinsky und Dachnie wurde neben phylogenetischen Untersuchungen durch 16S rRNA-Genanalysen auch zur Konstruktion von Genbanken verwendet. Dafür stehen verschiedene Vektorsysteme zur Verfügung. Plasmide zur Konstruktion von „small-insert“Metagenombanken (YUN et al. 2004, GABOR et al. 2004, HENNE et al. 2000) und Cosmide bzw. Fosmide und BACs (bacterial artificial chromosome) für die Konstruktion von „large-insert“-Metagenombanken (GINOLHAC 2004, BERRY et al. 2003, MACNEIL 2001, BRADY 2004). Für welches System man sich entscheidet, hängt dabei von der gewünschten Insertgröße, der Kopienzahl, dem Wirtsorganismus sowie von der Qualität der isolierten DNA ab. Stark verunreinigte oder bereits im größeren Umfang gescherte DNA eignet sich eher zur Herstellung von „small-insert“-Metagenombanken. Dabei finden „smallinsert"-Metagenombanken vorwiegend Verwendung bei der Identifizierung einzelner Gene durch aktivitätsbasierende Screening-Techniken (LÄMMLE et al. 2007, RANJAN et al. 2005, GUPTA 2002). „high-copy“-Plasmide erlauben dabei auch die Detektion nur schwach exprimierter Genprodukte. Die Identifizierung der entsprechenden Gene ist auf Grund der geringeren Insertgröße von Plasmiden durch wenige Sequenzierungsschritte relativ unkompliziert. Die geringere Insertgröße führt allerdings dazu, dass eine größere Menge an Klonen für die Durchmusterung nach bestimmten Zielgenen zur Verfügung stehen muß (DANIEL 2005, SCHLOSS und HANSELSMAN 2003). Um die Trefferquote zu erhöhen können vor der Extraktion der DNA aus der Probe verschiedene Anreicherungschritte durchgeführt werden, wie sie 
auch bei klassischen Anreicherungen von Mikroorganismen durchgeführt werden. Durch Kultivierung der Probe in Anwesenheit eines selektiven Substrates wird ein Selektionvorteil erzeugt (REES et al. 2004, KNIETSCH et al. 2003a und 2003b). Es werden Organismen angereichert, die das entsprechende Substrat verwerten können. Werden Genbanken aus diesen Anreicherungskulturen konstruiert, wird die Trefferquote bei der Durchmusterung nach entsprechenden Zielgenen erhöht und der Umfang der zu konstruierenden Genbanken kann reduziert werden. Ein Nachteil dieser Anreicherungsschritte ist allerdings der Verlust an mikrobieller Diversität (COWAN et al 2005). Außerdem eignet sich die Genbank nicht mehr zur Durchmusterung nach anderen Zielgenen. „large-insert“-Metagenombanken hingegen stellen durch ihre umfangreichen Insertgrößen ein weitaus größeres Potential an genetischer Information und eignen sich deshalb zur Identifizierung ganzer Gencluster oder Stoffwechselwege (SCHMEISSER et al. 2007, COWAN et al. 2005). Tab. 13 gibt einen Überblick über aus Metagenombanken identifizierte funktionale Gene und Enzyme.

Tab. 13: Beispiele für funktionale Gene und Enzyme, die in Metagenombanken identifiziert werden konnten

\begin{tabular}{ll}
\hline Funktionale Gene/Enzyme & Referenz \\
\hline Lipasen/Esterasen & VOGET et al. 2003; ELEND und \\
& SCHMEISSER 2006; LEE et al. 2004; \\
& SCHMEISSER et al. 2003; BELL et al. \\
& 2002, HENNE et al. 2000 \\
& SANTOSA 2001 \\
Proteasen & DESANTIS et al. 2002 \\
Nitrilasen & HOSTER et al. 2005 \\
Chitinasen & HEALY et al. 1995, REES et al. 2004 \\
Cellulasen & YUN et al. 2004 \\
a-Amylasen & KNIETSCH et al. 2003a \\
Alkohol-Oxidoreduktasen & RIESENFELD et al. 2004 \\
Antibiotikaresistenzen & HENNE et al. 1999 \\
4-Hydroxybutyrat-Dehydrogenasen & GINOLHAC et al. 2004 \\
Polyketid - Synthasen & BRADY et al. 2004 \\
Langkettige N-Acyltyrosine &
\end{tabular}


In dieser Arbeit wurden sowohl „small“- als auch „large-insert“Metagenombanken konstruiert. Neben verschiedenen Plasmid-Genbanken konnte eine aus 5200 Klonen bestehende Fosmid-Genbank konstruiert werden (s. 3.3). Diese Metagenombanken wurden für die Durchmusterung nach biotechnologisch relevanten Biokatalysatoren verwendet.

Prinzipiell können zwei Ansätze bei der Durchmusterung von Metagenombanken verfolgt werden (HANDELSMAN 2004, SCHLOSS und HANDELSMAN 2003). Zum einen können sequenzabhängige Screeningverfahren genutzt werden. Diese beruhen auf Sequenzähnlichkeiten oder konservierten Bereichen in den entsprechenden Zielgenen. Dabei werden z. B. DNA-Sonden konstruiert, welche für Koloniehybridisierungen eingesetzt werden oder zur Amplifikation der entsprechenden Zielgene mittels PCR dienen (BELL et al. 2002, HENCKEL et al. 2000). Dabei ist man jedoch auf das Vorhandensein spezifischer Sequenzdaten angewiesen. Die Identifizierung völlig neuer unbekannter Gene und Genprodukte ist nicht möglich (STREIT et al. 2004). Außerdem besteht die Möglichkeit der Identifizierung von unvollständigen Genen und Genprodukten bzw. katalytisch inaktiven Genprodukten (LORENZ et al. 2002). Der zweite Ansatz zur Durchmusterung von Metagenombanken sind auf Enzymaktivitäten beruhende Screeningverfahren. Dabei können verschiedene Plattentests zum Einsatz kommen, welche heterolog produzierte Genprodukte durch den Umsatz. bzw. Abbau von z. B. farbmarkierten Substraten identifizieren (RONDON et al. 2000). Im Gegensatz zum sequenzabhängigen Screening bietet dies die Möglichkeit der Identifizierung und Erforschung völlig neuartiger und katalytisch aktiver Genprodukte (KOWALCHUK et al. 2007). Eine unabdingbare Vorraussetzung beim Screening auf Enzymaktivitäten ist die aktive Expression des Zielgens (SCHMEISSER et al. 2007). Viele Faktoren können dies jedoch verhindern. Z. B. ein zu hoher GC-Gehalt des Fremdgens in E. coli oder die Nicht Erkennung des fremden Promotors durch die RNA-Polymerase von E. coli (GABOR et al. 2004), toxische Eigenschaften des Fremdproteins, die Bildung von Einschlusskörpern in E. coli durch Überexpression des Fremdgens, fehlende Co-Faktoren oder fehlende posttranslationale Modifikationen. 


\subsection{Identifizierung von Genen aus Metagenombanken, die lipolytische Aktivität vermitteln}

Im Rahmen dieser Arbeit wurde nach Enzymen gesucht, welche lipolytische Aktivität vermitteln. Sie gehören der Enzymgruppe der alpha/beta-Hydrolasen an. Diese Enzyme katalysieren die Spaltung und Bildung von Esterbindungen. Dabei spalten Lipasen (EC 3.1.1.3), welche auch als Triglycerol-Hydrolasen bezeichnet werden, bevorzugt wasserunlösliche, langkettige Substrate. Esterasen (EC 3.1.1.1), auch Carboxylesterasen genannt, hingegen spalten wasserlösliche, kurzkettige Substrate. Die zu den Serin-Hydrolasen zählenden Enzyme zeigen eine charakteristische katalytische Triade (JÄGER 1994). Sie wurde in Lipasen, Esterasen und Serin-Proteasen gefunden (ARPIGNY und JÄGER 1999) und besteht aus drei Resten: Serin, Histidin und Aspartat bzw. Glutamat. Dabei ist der Histidinrest zur Stabilisierung über Wasserstoffbrückenbindungen mit den anderen Resten verbunden. JÄGER und WOHLFARTH (1994) beschrieben den Reaktionsmechnismus, bei dem es zur Aktivierung des Serins kommt, was schließlich zur hydrolytischen Spaltung der Esterbindung führt. Zahlreiche Arbeiten zeigten bereits, dass sich diese Enzyme heterolog in E. coli produzieren lassen (ELEND et al. 2006, LEE et al. 2004, HENNE et al. 2000). Die Screenings wurden mit Hilfe eines Plattentests durchgeführt (s. 2.16.5). Die Transformationsansätze der Plasmidgenbanken bzw. die in Mikrotiterplatten konservierten Fosmidklone wurden auf tributyrinhaltige LB-Agarplatten transferiert. Nach Durchmusterung aller konstruierten Metagenombanken sowie der Genombank des Thermoanaerobacter (s. 3.6) konnten fünf lipolytisch aktive Fosmidklone identifiziert werden. Diese wurden mit pFosJS1 bis pFosJS4 und pFosA1 bezeichnet. pFosA1 entstammt der Fosmidgenbank, welche aus chromosmaler DNA des Thermoanaerobacter (s. 3.6) konstruiert wurde.

\subsubsection{Charakterisierung der lipolytischen ORFs}

Die für die lipolytische Aktivität verantwortlichen ORFs konnten auf den Fosmiden pFosJS1 bis pFosJS3 identifiziert werden und wurden mit estJS1 bis estJS3 bezeichnet. Ein weiterer lipolytischer ORF konnte aus der 
Fosmidgenbank des Thermoanaerobacter (s. 3.6) identifiziert und mit lipA1 bezeichnet werden. Ein Vergleich auf Aminosäureebene der vier ORFs zeigte nur geringe Ähnlichkeit untereinander, was die hohe Diversität der konstruierten Fosmidgenbank bestätigt. Durch Vergleich der Aminosäuresequenzen der ORFs mit in Datenbanken hinterlegten Sequenzdaten und Untersuchungen der vorhandenen konservierten Bereiche konnten die Genprodukte in verschiedene Familien der lipolytischen Enzyme eingeteilt werden. BRENNER et al. zeigten bereits 1988 eine für lipolytische Enzyme hochkonservierte Aminosäuresequenz, weches ein aktives Serin enthält. In allen vier ORFs konnte dieses charakteristische Pentapeptid G-X-S-X-G identifiziert werden. Inzwischen ist eine erweiterte Konsensussequenz für Lipasen um das aktive Serin beschrieben worden. Es wurde zu fogendem Motiv erweitert: [LIV]-X[LIVFY]-[LIVMST]-G-[HYWV]-S-x-G-[GSTAC] (PROSITE Eintrag PS00120: LIPASE_SER, SIGRIST et al. 2002). Abb. 52 zeigt ein Alignment der identifizierten lipolytischen Genprodukte im Bereich des an der Katalyse beteiligten Serins.

$\begin{array}{lcccccccccccc}\text { EstJS1 } & 87 & \text { A } & \text { H } & \text { V } & \text { F } & \text { G } & \text { V } & \text { S } & \text { M } & \text { G } & \text { G } & 96 \\ \text { EstJS2 } & 212 & \text { V } & \text { T } & \text { I } & \text { F } & \text { G } & \text { E } & \text { S } & \text { G } & \text { G } & \text { A } & 221 \\ \text { EstJS3 } & 190 & \text { V } & \text { T } & \text { I } & \text { F } & \text { G } & \text { E } & \text { S } & \text { A } & \text { G } & \text { G } & 199 \\ \text { LipA1 } & 107 & \text { I } & \text { G } & \text { L } & \text { L } & \text { G } & \text { L } & \text { S } & \text { M } & \text { G } & \text { G } & 116\end{array}$

Abb. 52: Alignment der identifizierten lipolytischen Genprodukte im Bereich des an der Katalyses beteiligten Serins. Übereinstimmungen mit dem in der PROSITE Datenbank hinterlegtem Lipase Motiv ([LIV]-x-[LIVFY]-[LIVMST]-G-[HYWV]-S-x-G-[GSTAC] (PROSITE Eintrag PS00120: LIPASE_SER, SIGRIST et al. 2002) um das aktive Serin sind gelb unterlegt. Dunkelgelb sind die Übereinstimmungen in den Aminosäuresequenzen der vier Esterasen bzw. Lipasen unterlegt.

Vollständig konnte dieses Konsensusmotiv für keines der abgeleiteten lipolytischen Genprodukte identifiziert werden. EstJS1 bis EstJS3 und LipA1 zeigen leichte Abweichungen. Im Folgenden werden die identifizierten offenen Leserahmen estJS1, estJS2 und estJS3 sowie lipA1 und die an der Katalyse beteiligten Bereiche der Genprodukte dikutiert.

Die abgeleitete Aminosäuresequenz des auf dem Fosmid pFosJS1 identifizierten lipolytischen ORFs estJS1 zeigte nach Ableich mit der Datenbank der NCBI eine Identität von $45 \%$ im Bereich der Aminosäuren 1 bis 264 zu dem Protein BioH aus dem Organismus Kurthia sp. 538-KA26 (s. 3.4.1). BioH kodiert vermutlich für ein Protein, welches für die Synthese von Pimeloeyl-CoA 
verantwortlich ist, einem Zwischenprodukt der Biotin-Biosynthese (KIYASU et al. 2001). Die genaue Funktion ist allerdings noch unbekannt. In mehreren Arbeiten konnte allerdings die lipolytische Aktivität von BioH aus E. coli, Serratia marcescens und $\mathrm{BioH}$ isoliert aus Metagenombanken anhand von aktivitätsbasierenden Plattentests (s. 2.16.5) beschrieben werden (RANJAN et al. 2005, AKATSUKA et al. 2002, TOMCZYK et al. 2002). Neben der lipoytischen Aktivität identifizierten sie in dem jeweiligem BioH-Protein das für Serin-Hydrolasen typische Konsensusmotiv um das aktive Serin (G-X-S-X-G) (s. Abb. 52). Die Übereinstimmungen in den Aminosäuresequenzen von BioH Proteinen und Serin-Hydrolasen lassen vermutlich auf einen gemeinsamen Ursprung schließen (AKATUSKA et al. 2002). EstJS1 konnte bereits in die Familie $\mathrm{V}$ der lipolytischen bakteriellen Enzyme eingeordnet (s. 3.4.1). In Abb. 29 wurde bereits gezeigt, dass auch das Protein BioH aus Kurthia sp. 538KA26 die Konsensussequenz nach BRENNER et al. 1988 aufweist. Das konservierte Motiv der PROSITE Datenbank (s. Abb. 52) konnte hingegen nicht vollständig identifiziert werden. EstJS1 zeigt an der ersten Stelle der Konsensussequenz ein Alanin anstelle der beschriebenen Reste Leucin, Isoleucin und Valin. Dieser Alaninrest konnte auch für Yersinia pestis $\mathrm{BioH}$, [AJ414141]; Salmonalla typhimurium BioH, [AE008861]; E. coli K-12 BioH, [X15587]; Vibrio cholerae BioH, [AE004337] nachgewiesen werden (AKATSUKA et al. 2003). Abb. 53 zeigt ein Alignment im Bereich des aktiven Serins von EstJS1 und BioH aus Kurthia sp. 538-KA26 gegen zwei lipolytische Enzyme der Familie V (ARPIGNY und JÄGER 1999). Verglichen mit der Konsensussequenz der Datenbank PROSITE ([LIV]-X-[LIVFY]-[LIVMST]-G[HYWV]-S-X-G-[GSTAC] (PROSITE Eintrag PS00120: LIPASE_SER, SIGRIST et al. 2002) zeigen sie sechs Übereinstimmungen die bei allen vier Proteinen vorkommen. Alle vier Genprodukte zeigen im Bereich der dritten Position der Konsensussequenz ein Valin, sowie an der achten, variablen Position der Konsensussequenz weisen alle drei Lipasen ein Methioninrest auf. Die Übereinstimmungen in der Aminosäuresequenz um das aktive Serin von typischen Vertretern der Familie $V$ der lipolytischen Enzyme mit verschiedenen BioH Proteinen deutet auf die Zugehörigkeit der BioH Proteine zu den SerinHydrolasen hin (AKATSUKA et al. 2002) 


$\begin{array}{lcccccccccccc}\text { EstJS1 } & 87 & \text { A } & \text { H } & \text { V } & \text { F } & \text { G } & \text { V } & \text { S } & M & \text { G } & G & 96 \\ \text { SAL } & 138 & \text { L } & \text { N } & \text { V } & \text { L } & \text { G } & \text { W } & \text { S } & M & \text { G } & \text { G } & 147 \\ \text { Lip3 } & 136 & \text { T } & \text { H } & \text { V } & \text { G } & \text { G } & \text { N } & \text { S } & M & \text { G } & \text { G } & 145 \\ \text { BioH } & 87 & \text { A } & \text { H } & \text { V } & \text { Y } & \text { G } & \text { I } & \text { S } & \text { M } & \text { G } & \text { G } & 96\end{array}$

Abb. 53: Alignment von EstJS1 mit Lipasen der Familie V. im Bereich des aktiven Serins [LIV]-X-[LIVFY]-[LIVMST]-G-[HYWV]-S-X-G-[GSTAC] (PROSITE Eintrag PS00120: LIPASE_SER, SIGRIST et al. 2002) SAL: Lipase aus Sulfolobus acidocalarius [AF071233]. Lip3: Lipase aus Moraxella sp. [X53869].BioH: BioH aus Kurthia sp. 538-KA26. Dargestellt ist der Bereich um das aktive Serin der katalytischen Triade. Gelb unterlegt sind die Übereinstimmungen mit der PROSITE Konsensussequenz, Dunkelgelb die Übereinstimmungen der Aminosäuren der drei Lipasen, bzw. Esterase

ARPIGNY und JÄGER unterteilten 1999 die lipolytischen Enzyme aufgrund konservierter Bereiche in den Aminosäuresequenzen in acht Familien. Eine Reihe von lipolytischen Enzymen konnte bisher der Familie $\mathrm{V}$ zugeordnet werden. Die biochemischen Eigenschaften sind jedoch nur für wenige dieser Enzyme bekannt. Mittels Aktivtätsscreening (s. 2.16.5) einer zuvor konstruierten Metagenombank identifizierten TIRAWONGSAROJ et al. (2008) eine Esterase (Est1) der Familie V aus einer heißen Quelle in Thailand. Diese heiße Quelle untersuchte KANOKRATANA et al. 2004 mittels 16S rRNA-Genalysen (s. 4.2). Über $80 \%$ seiner 16S rRNA-Gensequenzen zeigten phylogenetische Verwandtschaft zu 16S rRNA-Gensequenzen unkultivierter Mikroorganismen. Aufgrund dieser Daten sollte das Habitat als Quelle zu Identifizierung völlig neuartiger Enzyme dienen (TIRAWONGSAROJ et al. 2008). Est1 [EF413637] wurde über Homologien in der Aminosäuresequenz konservierter Bereiche in die Familie V der lipolytischen Enzyme eingeordnet. Est1 zeigte die höchste Aktivität bei Temperaturen zwischen 50 und $70^{\circ} \mathrm{C}$ und einem pH-Wert zwischen 9 und 10. Bei diesen Parametern zeigte die Esterase ebenfalls eine hohe Thermostabilität gemessen über einen Zeitraum von 2 h. EstJS1 zeigt hingegen, obwohl aus einem thermophilen Habitat stammend, ein Temperaturoptimum bei etwa $37^{\circ} \mathrm{C}$, allerdings ebenfalls eine hohe Thermostabilität im Bereich zwischen 50 und $60^{\circ} \mathrm{C}$. Ähnlich wie Est1 zeigt auch EstJS1 ein pH-Optimum im alkalischen Bereich. Est1 und EstJS1 weisen ein breites Substratspektrum auf. Sie sind in der Lage, sowohl kurzkettige als langkettige Acylester zu spalten. Aufgrund des Substratspektrums mit einem Aktivitätsoptimum gegenüber pNP-Butyrat lassen sich beide Enzyme eher den Esterasen zuordnen. Im Gegensatz zur hohen Thermostabilität von Est1, zeigte Lip3 aus Moraxella TAl144 ein Temperaturoptimum bei unter $25{ }^{\circ} \mathrm{C}$ mit einer 
sehr geringen Thermostabilität (FELLER et al. 1990). Da es sich bei Moraxella TAI144 jedoch um einen psychrophilen Mikroorganismus handelt, erklärt sich diese geringe Thermostabilität. Es untermauert aber auch das breite Spektrum der Familie V der lipolytischen Enzyme. Es konnten Lipasen oder Esterasen dieser Familie aus psychrophilen, mesophilen und thermophilen Mikroorganismen identifiziert werden (TIRAWONGSAROJ et al. 2008, KASHIMA et al. 1999, APRIGNY et al. 1998, FELLER et al. 1990).

Die identifizierten lipolytischen ORFs estJS2 und estJS3 konnten nach ARPIGNY und JÄGER (1999) in die Familie IV der lipolytischen Enzyme eingeordnet werden (s. 3.4.2). Beide zeigen das für lipolytische Enzyme konservierte Pentapeptid G-X-S-X-G (s. Abb. 52). Ein erweitertes Motiv um das aktive Serin, welches typisch für Carboxylesterasen vom Typ B ist, lautet:

F-[GR]-G-x(4)-[LIVM]-x-[LIV]-x-G-x-S-[STAG]-G.

(s. PROSITE Eintrag PS00122 CARBOXYLESTERASE_B_1, SIGRIST et al. 2002)

Abb. 54 zeigt ein Alignment um das aktive Serin der katalytischen Triade von EstJS1 und 2 mit den Carboxylesterasen aus Chlorobium ferrooxidans und Bacillus coagulans (s. 3.4.2), GCL aus Geotrichum candidum (Pilz) und AChE aus Torpedo californica (Fisch).

$\begin{array}{llllllllllllllllllll}\text { EstJS2 } & 205 & \text { F } & \text { G } & \text { G } & \text { N } & \text { P } & \text { D } & \text { C } & \text { V } & \text { T } & \text { I } & \text { F } & \text { G } & \text { E } & \text { S } & \text { G } & \text { G } & 220 \\ \text { Chl. Fer. } & 201 & \text { F } & \text { G } & \text { G } & \text { D } & \text { P } & \text { G } & \text { R } & \text { V } & \text { T } & \text { L } & \text { F } & \text { G } & \text { Q } & \text { S } & \text { A } & \text { G } & 216 \\ \text { EstJS3 } & 183 & \text { F } & \text { G } & \text { G } & \text { D } & \text { P } & \text { N } & \text { N } & \text { V } & \text { T } & \text { I } & \text { F } & \text { G } & \text { E } & \text { S } & \text { A } & \text { G } & 198 \\ \text { B. coa. } & 179 & \text { F } & \text { G } & \text { G } & \text { D } & \text { P } & \text { D } & \text { C } & \text { V } & \text { T } & \text { I } & \text { F } & \text { G } & \text { E } & \text { S } & \text { A } & \text { G } & 194 \\ \text { AchE } & 187 & \text { F } & \text { G } & \text { G } & \text { D } & \text { P } & \text { K } & \text { T } & \text { V } & \text { T } & \text { I } & \text { F } & \text { G } & \text { E } & \text { S } & \text { A } & \text { G } & 202 \\ \text { GCL } & 204 & \text { F } & \text { G } & \text { G } & \text { D } & \text { P } & \text { D } & \text { K } & \text { V } & \text { M } & \text { I } & \text { F } & \text { G } & \text { E } & \text { S } & \text { A } & \text { G } & 219\end{array}$

Abb. 54: Alignment von EstJS2 und EstJS3 mit bekannten Carboxylesterasen im Bereich des Konsensusmotiv des aktiven Serins. Carboxylesterasen aus Chlorobium ferrooxidans (Chl. fer.)[ZP_01385717] und Bacillus coagulans (B. coa.)[ZP_01696734], AChE aus Torpedo californica und GCL aus Geotrichum candidum (SCHRAG et al. 1991). Hellgelb sind die Übereinstimmungen in der Aminosäuresequenz zu dem konservierten Motiv aus der PROSITE Datenbank (F-[GR]-G-x(4)-[LIVM]-x-[LIV]-x-G-x-S-[STAG]-G) hinterlegt. Die dunkelgelben Bereiche markieren die Aminosäuren, welche in allen Sequenzen vorhanden sind.

Wie anhand Abb. 54 zu erkennen ist, zeigen alle Esterasen bzw. Lipasen eine vollständige Übereinstimmung zu dem Konsensusmotiv aus der PROSITE Datenbank (s. PROSITE Eintrag PS00122 CARBOXYLESTERASE_B_1, SIGRIST et al. 2002). Die Abfolge der Aminosäuren der katalytischen Triaden 
verläuft jedoch bei EstJS2 und EstJS3 nach dem Schema Ser-Glu-His. Das Aspartat wurde also durch Glutamat ersetzt, was typisch für sogenannte Acetylcholinesterasen (E.C. 3.1.1.7) ist. Die Acetylcholinesterasen gehören wie auch die Carboxylesterasen zu den alpha/beta Hydrolasen. SCHRAG et al. (1991) untersuchten eine Lipase aus dem Pilz Geotrichum candidum (s. Abb. 54). Diese zeigte ebenfalls die Aminosäureabfolge der Katalytischen Triade Ser-Glu-His, wie sie auch schon bei einer Lipase aus Candida cylindracea und einer Acetylcholinesterase aus dem Fisch Torpedo californica beschrieben wurde. Außerdem konnte für EstJS2 und EstJS3 das für die Familie IV der lipolytischen Enzyme, auch „hormone-sensitive-lipase“-Familie, kurz HSL genannt, stark konservierte His-Gly-Gly-Gly Motiv im N-terminalen Bereich identifiziert werden (s. 3.4.2) (ARPIGNY und JÄGER 1999). Dieses Motiv ist vermutlich für die Stabilisierung des Übergangszustandes durch Wasserstoffbrücken während der Katalyse verantwortlich (s. Einleitung) (WEI et al 1999). Eine erweiterte Aminosäureabfolge dieses konservierten Bereiches lautet:

[LIVMF](2)-x-[LIVMF]-H-G(2)-[SAG]-[FYW]-x(3)-[STDN]-x(2)-[STYA]-[HAGFT]

(s. PROSITE Eintrag PS01173: LIPASE_GDXG_HIS, SIGRIST et al. 2002). Abb. 55 zeigt ein Alignment von EstJS2 und EstJS3 mit bekannten lipolytischen Enzymen der Familie IV aus Archaeoglobus fulgidus und Escherichia coli in diesem Bereich.

$\begin{array}{lrllllllllllllllllll}\text { EstJS2 } & 125 & \text { M } & \text { V } & \text { W } & \text { F } & \text { H } & \text { G } & \text { G } & \text { G } & \text { Y } & \text { S } & \text { I } & \text { G } & \text { S } & \text { G } & \text { G } & \text { M } & \text { A } & 141 \\ \text { EstJS3 } & 104 & \text { M } & \text { V } & \text { W } & \text { I } & \text { H } & \text { G } & \text { G } & \text { G } & \text { F } & \text { S } & \text { T } & \text { G } & \text { A } & \text { G } & \text { S } & \text { W } & \text { L } & 117 \\ \text { Arch EstA } & 87 & \text { L } & \text { V } & \text { X } & \text { Y } & \text { H } & \text { G } & \text { G } & \text { G } & \text { F } & \text { V } & \text { I } & \text { C } & \text { S } & \text { I } & \text { E } & \text { S } & \text { H } & 103 \\ \text { E. coli } & 82 & \text { L } & \text { F } & \text { X } & \text { L } & \text { H } & \text { G } & \text { G } & \text { G } & \text { F } & \text { I } & \text { L } & \text { G } & \text { N } & \text { L } & \text { D } & \text { T } & \text { H } & 98\end{array}$

Abb. 55: Alignment von EstJS2 und EstJS3 mit bekannten Carboxylesterasen. Archaeoglobus fulgidus (Arch EstA) [AE000985] und Escherichia coli (E. coli) [AE000153] im Bereich des für die Familie IV typischen Konsensusbereiches. Dunkelgelb markiert ist der hochkonservierte Bereich. Hellgelb sind die Aminosäuren des Motives der PROSITE Datenbank markiert. Weiß sind die Abweichungen zum konservierten Motiv unterlegt.

Bis auf wenige Abweichung (Weiß) stimmen die Aminosäuresequenzen mit der des Motives der PROSITE Datenbank (s. PROSITE Eintrag PS01173: LIPASE_GDXG_HIS, SIGRIST et al. 2002) überein. HEMILÄ et al. (1993) sowie CONTRERAS et al. (1996) untersuchten die strukturellen Gemeinsamkeiten 
von lipolytischen Enzymen der Familie IV bzw. der sogenannten HSL-Familie und mehrerer Acetylcholinesterasen und fanden zahlreiche Übereinstimmungen. Sowohl viele bakterielle als auch archaelle thermostabile Esterasen bzw. Lipasen, welche zu der HSL-Familie zählen, konnten bereits erfolgreich gereinigt und charakterisiert werden (DE SIMONE 2000, RHEE 2006). MORANA et al. (2002) isolierten und charakterisierten eine HSLähnliche Carboxylesterase aus dem hyperthermophilen Archaeon Sulfolobus solfataricus. RHEE et al. (2006) hingegen gelang die Identifizierung einer thermostabilen Esterase der Familie IV aus einer Metagenombank, konstruiert aus einem thermalen Habitat in Indonesien. Wie in Abb. $39 \mathrm{zu}$ sehen ist, befinden sich stromaufwärts von estJS3 Sequenzbereiche eines möglichen ABC-Transporters. ABC-Transporter spielen unter anderem eine Rolle bei der sogenannten Typl-Sekretion (BINET et al. 1997). Die Typll-Sekretion setzt das Vorhandensein eines N-terminalen Signalpeptids voraus, welches bei EstJS1 bis EstJS3 nicht identifiziert werden konnte. Bei der Typl-Sekretion handelt es sich um ein Dreikomponentensystem bestehend aus einer ATPase, einem Membranfusionsprotein und einem Protein in der äußeren Membran. Der ABCabhängige Transport ist für Lipasen der Familie I.3 bekannt (ARPIGNY und JÄGER 1999), und unter anderem für die Lipasen aus Pseudomaonas fluorescens und Serratia marcescens beschrieben worden (DUONG et al. 1994, AKATSUKA et al. 1995). Zur weiteren Beschreibung bzw. Charakterisierung und Einordnung der lipolytischen Enzyme EstJS2 und EstJS3 bedarf es jedoch umfangreicher biochemischer Untersuchungen. Diese sind zurzeit Teil einer Diplomarbeit.

Der lipolytische ORF lipA1 wurde aus der Fosmidgenbank des angereicherten Thermoanaerobacter isoliert (s. 3.6). Blastp gegen die Datenbank der NCBI ergab eine 100 \%ige Identität zu einer Dienlacton-Hydrolase aus Thermoanaerobacter pseudoethanolicus, welche im Rahmen der Genomsequenzierung von Thermoanaerobacter pseudoethanolicus [NC_010321] identifiziert aber nicht näher charakterisiert wurde. DienlactonHydrolasen (EC 3.1.1.45) spielen eine Rolle beim bakteriellen Abbau von Chloraromaten und gehören zu den Alpha/Beta-Hydrolasen. Wie Abb. 52 zeigt, weist LipA1 die Konsesussequenz um das aktive Serin G-X-S-X-G auf. In Dienlacton-Hydrolasen ist die Aminosäureabfolge in der katalytischen Triade 
Cis-His-Asp (BEVERIDGE und OLLIS 1995). Diese Abfolge konnte für LipA1 nicht identifiziert werden. Abb. 56 zeigt ein Alignment um das aktive Serin der katalytischen Triade von LipA1 und putativen Dienlacton-Hydrolasen und zeigt einen weiteren konservierten Bereich. Dieses HG-Motiv dient vermutlich der Stabilisierung des Übergangszustandes während der Katalyse durch Wasserstoffbrücken (PARK et al. 2007).

\begin{tabular}{|c|c|c|c|}
\hline ibrio spenc & 6 & KDAEIQSGT-------FPVVLLSHGYRGNWRNQNWLA & \\
\hline ibrio sp. GMD5 & 56 & AQIQSGT--------FPVILLSHGYRGNWRNQNWLA & \\
\hline nomonas sp. & & LQTSKAGGTQKRPLVLLSHGYRGSWRN & \\
\hline hella chejuensis & & VPDAEPAQGA--------HS LVVLSHGYGGNWRNLNWLA & \\
\hline $\mathrm{PA \perp}$ & 19 & LPDDVKGK----------VPMVIMFHGFT GNKVESHF IF & \\
\hline & & ILPDDVKGK----------VPMVIMFHGFT GNKVESHF IF & \\
\hline & & $.::::^{\star} *{ }^{\star}, \quad: \quad:::$ & \\
\hline spendidus & & IVAATDHPGTTSFDQSPEQAAKWWERPRDITR & \\
\hline o sp. GMD & & PEQAEKWWERPRDVSR & \\
\hline monas sp. & & RPKDIKH & \\
\hline chejuensis & & RPHDLSR & \\
\hline & & VKMS-RALEKVGIGSVRFDFYG & \\
\hline & & VKMS-RALEKVGIGSVRFDFYGSGESDGDFSEMTFSSELE & \\
\hline & & $\begin{array}{llllllll}: & : . & \ldots & . & : & : . & & .\end{array}$ & \\
\hline & & TIDYLLSEVQWKQAVNA & \\
\hline ID509 & & QLAGAKI & 7 \\
\hline as sp. & & LDYLLNDS IWQQDIL & 9 \\
\hline a chejuensis & & RIAAVGHSLGGWTVMALAGARF & 8 \\
\hline & & ERIGLLGLSMGGAIAGIVAREYK & \\
\hline & & ARQILKFVKEQPTTDPERIGLLGLSMGGAIAGIVAREYK & \\
\hline & & $: .: \quad: * \star: * \star$ & \\
\hline
\end{tabular}

Abb. 56: Alignment von LipA1 im Bereich des aktiven Serins mit bereits bekannten Dienlacton Hydrolasen. [ABS72371.1] Vibrio sp. GMD509, [ZP_00990521] Vibrio spendidus 12B01, [YP_434199] Hahella chejuensis KCTC 2396, [ZP_01074102] Marinomonas spMED121, [ZP_00778935] Thermoanaerobacter pseudoethanolicus (T. pseudo). Rot ist das aktive Serin gekennzeichnet, gelb sind konservierte Bereiche unterlegt.

PARK et al. (2007) isolierten ein lipolytisch aktives Protein (Vlip509) aus dem Organismus Vibrio sp. GMD509 [ABS72371.1], welche Ähnlichkeiten zu putativen Dienlacton-Hydrolase (bis zu 82 \% auf Aminosäureebene) sowie verschiedenen Esterasen und Lipasen zeigte. LipA1 zeigt eine Identität von 19 \% auf Aminosäurebene im Bereich von Aminosäure 1 bis 259 zu Vlip509. Durch biochemische Untersuchungen konnte Vlip509 eindeutig den Esterasen zugeordnet werden. Eine Dienlacton-Hydrolase-Aktivität wurde nicht bestimmt. Weitere biochemische Untersuchungen sind nötig um auch LipA1 genauer in die Familien der lipolytischen Enzyme einzuteilen. 


\subsection{Identifizierung von Genen aus Metagenombanken, die proteolytische Aktivität vermitteln}

Proteasen kommen in jeder Zelle vor und sind an zahlreichen Prozessen beteiligt innerhalb und außerhalb der Zelle beteiligt (GUPTA et al. 2002a). Proteasen sind aufgrund ihres großen Wirkungsspektrums von großer Bedeutung in der Waschmittel-, Nahrungsmittel- und Pharmaindustrie. Proteasen katalysieren die Hydrolyse von Proteinen zu Aminosäuren und Peptiden. Sie sind die Enzymklasse mit der bei weitem höchsten wirtschaftlichen Bedeutung (GUPTA et al. 2002a, OUTRUP et al. 1990). Gerade die alkalischen Serinproteasen finden breite Anwendung als Additive in Wasch- und Geschirrspülmitteln. Sie zeigen Stabilität gegenüber hohen Temperaturen, hohen $\mathrm{pH}$-Werten und in Gegenwart von Detergenzien. Proteasen werden darüber hinaus in der Ledergerbung, bei der Sojaproduktion oder der Herstellung von Süßstoff eingesetzt. In der Pharmaindustrie sind sie von Bedeutung, da sie viele Toxine durch spezifische Spaltung von einer inaktiven Proform in eine katalytisch aktive Form verwandeln (GORDON und LEPPLA 1994). Die größte Bedeutung haben mikrobielle Proteasen. Sie werden überwiegend von Vertretern der Bacilli produziert (GUPTA et al. 2002b, RAO et al 1998). In der vorliegenden Arbeit wurden die konstruierten Metagenombanken auf das Vorhandensein von Genen, welche proteolytische Aktivität vermitteln, untersucht. Ein auf Enzymaktivität beruhendes Screeningverfahren (s. 2.16.6) diente zur Identifizierung dieser Gene.

\subsubsection{Charakterisierung der proteolytischen ORFs}

Der auf pFosJS5 identfizierte proteolytischer ORF pepJS1 zeigte eine hohe Identität von $86 \%$ auf Aminosäureebene im gesamten Bereich zu einer S8 Peptidase aus Chloroflexus aggregans DSM948 festgestellt werden. Ein Vergleich mit der Datenbank MEROPS ergab eine Identität von 80,8 \% auf Aminosäureebene zu der Peptidase S8A aus Chloroflexus aggregans. Chloroflexus gehört zu den Grünen Nichtschwefelbakterien und kommt in neutralen bis alkalischen heißen Quellen vor. Das Phylum Chloroflexus konnte 
mittels 16S rRNA-Genanalysen im Habitat Avachinsky identifiziert werden (s Abb. 24). Chloroflexus aggregans DSM948 wurde in Japan aus einer ca. $60{ }^{\circ} \mathrm{C}$ heißen Quelle isoliert. Die Serin-Proteasen der Subfamilie S8A sind die sogenannten subtilisinähnlichen Proteasen (MEROPS). Im Allgemeinen handelt es sich bei innen um extrazelluläre, bakterielle Proteasen (SIEZEN und LEUNISSEN 1997, GUPTA 2002). Mit Hilfe des Programms „SignalP 3.0“ konnte ein Signapeptid von Aminosäure 1 bis 30 festgestellt werden. Die Aminosäureabfolge in der kataytischen Triade der Serin-Proteasen ist Aspartat, Histdin und Serin. Ein erweitertes Motiv der Aminosäuren der katalytischen Triade der Subfamilie S8A liefert die MEROPS Datenbank. Es lautet:

D-[TS]-Gly, H-G-T-H und T-S-M-A-X-P. PepJS1 besitzt diese Abfolge der Aminosäuren der katalytischen Triade. Abb. 57 zeigt ein Alignment von PepJS1 mit bekannten S8 Serin Proteasen im Bereich der Aminosäuren der katalytischen Triade. 


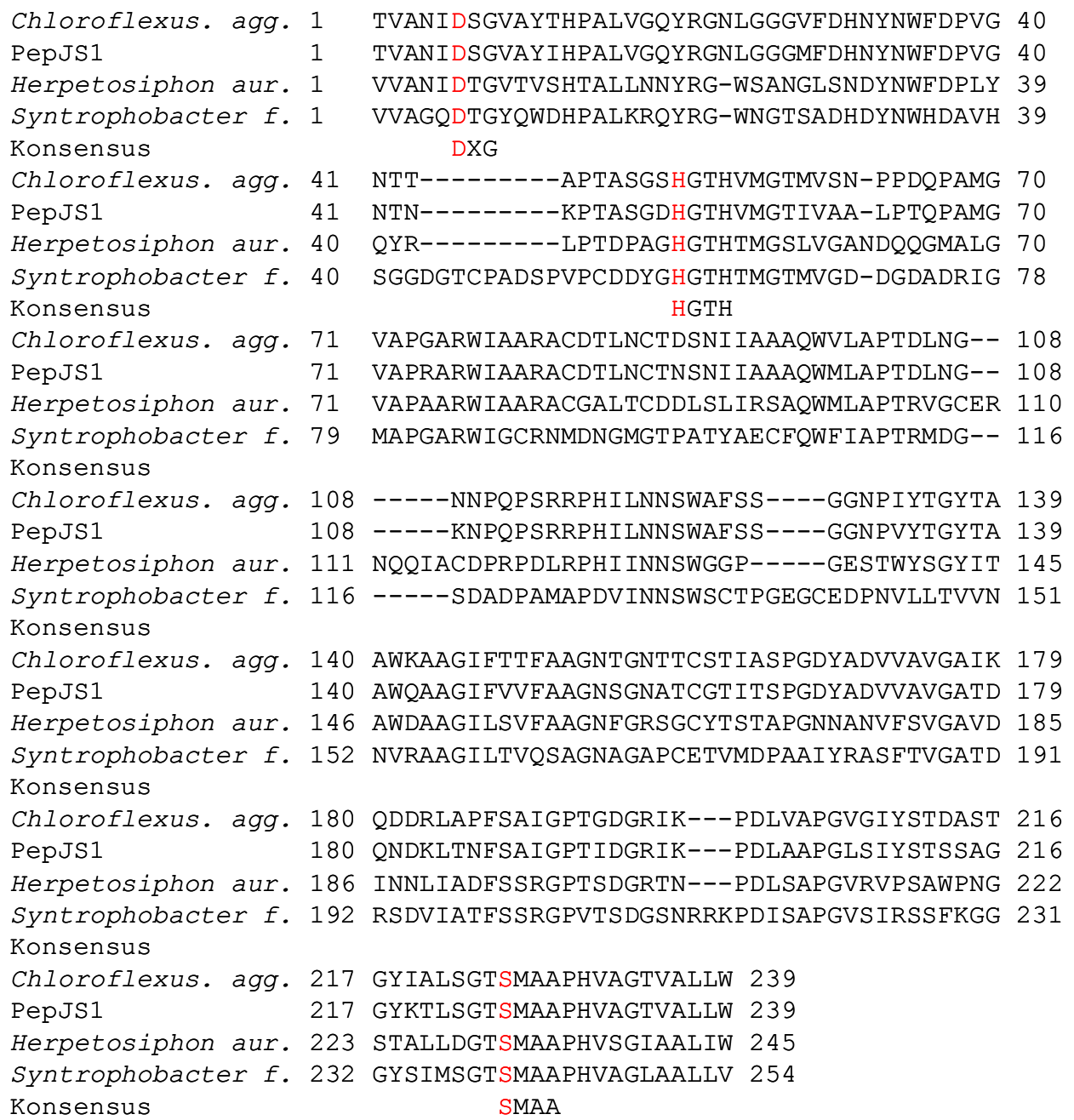

Abb. 57: Aligment von PepJS1 im Bereich der Aminosäuren der katalytischen Triade mit bereits bekannten S8 Serin Proteasen. Rot sind die Aminosäuren der katalytischen Triade gekennzeichnet. Chloroflexus aggregans. S8 Peptidase [ZP_01514699.1], Herpetosiphon auranticus. S8 Peptidase [YP_001547411], Syntrophobacter fumfumaroxidans S8 Peptidase [YP_846396.1].

GÖDDE et al. (2005) isolierten eine subtilisinähnliche Protease aus dem extrem thermophilen Organismus Fervidobacterium islandicum und produzierten sie heterolog in E. coli. Aufgrund der Sequenzhomologien im Bereich der katalytischen Triade (D-[TS]-Gly, H-G-T-H und T-S-M-A-X-P, MEROPS Datenbank) und biochemischen Analysen teilten sie die Protease den Thermitasen zu, einer Untergruppe der subtilisinähnlichen Proteasen. Erst weitere biochemische Analysen von PepJS1 lassen eine genauere Einteilung in die Untergruppen der Proteasen zu.

Das Genprodukt von pepJS2 zeigte nach BLASTp mit der Datenbank der NCBI eine 61 \%ige Identität im Bereich der Aminosäuren 78 bis 389 zu einer S1 
Peptidase aus Chloroflexus auranticus J-10-fl. Chloroflexus auranticus J-10-fl. wurde aus einer alkalischen heißen Quelle in Japan isoliert (PIERSON 1974). Beim Standort Avachinsky handelt es sich ebenfalls um ein thermoalkaliphiles Habitat (s.3.1 und 3.2.1). Aus dem Organismus konnten bereit drei thermostabile Proteasen isoliert werden (WATANABE et al. 1993). Die MEROPS Datenbank zeigt hingegen eine 51,85 \%ige Identität zu einer S1B Peptidase aus Roseiflexus castenholzii. S1 Peptidasen oder auch Chymotrypsine genannt sind Endopeptidasen und gehören zu den Serin Peptidasen. Die katalytische Triade der S1 Peptidasen folgt dem Schema Asp, His und Ser. Zu den S1 Peptidasen gehören auch viele nicht proteolytisch aktive Proteine (RAWLINGS und BARRETT 1993). Die überwiegende Mehrheit der S1 Peptidasen besitzt ein N-terminales Signalpeptid und wird sekretiert. Sie werden durch Spaltung im N-terminalen Bereich von einem inaktiven Propeptid in eine aktive Form überführt. Auch für PepJS2 konnte ein Signalpeptid identifiziert werden. Es reicht von Aminosäure 1 bis 24. Zu den S1B Peptidasen gehören auch die sogenannten HtrA-Proteasen. Dabei handelt es sich um periplasmatisch verankerte, oligomere Strukturen bildende und Hitzeschockinduzierte Serin Proteasen. HtrA-Proteasen treten als eine Art Qualitätskontrollfaktor auf indem sie mißgefaltete Proteine abbauen. Ausführlich wurden HtrA-Proteasen am Beispiel von DegP aus E. coli beschrieben (LIPINSKY et al. 1989, STRAUCH 1989). DegP tritt als Hexamer auf. Neben seiner Proteaseaktivität tritt DegP auch als Chaperon in Erscheinung (BASS et al. 1996, SPIESS et al. 1999). HtrA-Proteasen sind Hitzeschock- bzw. Stressinduziert. Bei hohen Temperaturen zeigt HtrA Proteaseaktivität und unter für den jeweiligen Organismus optimalen Temperaturen überwiegt die Chaperonaktivität (BETTON et al. 1999, CLAUSEN et al. 2002). Auch in verschiedenen anderen Proteobakterien, grampostiven Bakterien, Cyanobakterien sowie Pilzen und dem Menschen konnten HtrA-Proteasen identifiziert werden. Abb. 58 zeigt ein Alignment im Bereich der katalytischen Triade von PepJS2 mit einigen HtrA Proteasen. 


\begin{tabular}{|c|c|c|}
\hline PepJs2 & 07 & QGHIVTNYHVVENAESVVVTLADGWSFPAEIVGVDPSSDLAVI \\
\hline HtrA ChI. aur. & 10 & QGHIVTNYHVIADADELQVTLADGQTVPARIVGSDPSNDLAVI \\
\hline ItrA E. COli & 23 & YVVTNNHVVDNA TVIKVQLSDGRKFDAKMVGKDPRSDIAI \\
\hline HrtA Leg. pneu. & 103 & NG I I ITNDHV IRNANL ITI TLQDGRRLKARLIGGDSETDLAV \\
\hline HtrA Lac. hel. & 142 & KGYIVTNNHVISGSDAVQVLLANGKTVNAKVVGKDSTTDLA \\
\hline onsensus & & G $\quad \mathrm{TN} H V$ \\
\hline epJs2 & 157 & PA-PLPLADSSQLRVGQFVIAIGSPFGQVG-----TMTLGV \\
\hline HtrA ChI. aur. & 160 & TIRPLPIGDSTQVYVGQFVLAIGNPFGLER-----TLTFGI \\
\hline ItrA E. COIi & 173 & LT-AIKMADSDALRVGDYTVAIGNPFGLG-----ETVTSGI \\
\hline ArtA Leg. pneu. & 152 & LK-SLVIGDSDKLEVGDYVVAIGNPFGLNSFGNSQSATFGIV \\
\hline $\begin{array}{l}\text { HtrA Lac. hel. } \\
\text { Konsensus }\end{array}$ & 192 & TQ-TAQFGDSKHLEAGQTVIAVGSPLGSEYAS---TVTQGI J \\
\hline PepJs2 & 201 & SPDGRFIGEAIQTDAAINPGNSGGPLLDLQGRVIGVNSQ 2 \\
\hline HtrA Chl. aur. & 205 & SPNQRFIGEVIQSDVAINPGNSGGPLLDLSGRVIGVNSA 2 \\
\hline HtrA E. COli & 217 & NAEN--YENFIQTDAAINRGNSGGALVNLNGELIGINTA 2 \\
\hline rtA Leg. pneu. & 201 & NIEG--VENFIQTDAAINPGNSGGALVNAKGELIGINTA 23 \\
\hline $\begin{array}{l}\text { HtrA Lac. hel. } \\
\text { Konsensus }\end{array}$ & 238 & $\begin{array}{c}\text { TSSGN-QQTVIQTDAAINPGNSGGALVNSAGQVIGINSM } 2 \\
\text { GNSGG L }\end{array}$ \\
\hline
\end{tabular}

Abb. 58: Alignment von PepJS2 im Bereich der Aminosäuren der katalytischen Triade mit bekannten HtrA Proteasen. Rot sind die Aminosäuren der katalytischen Triade gekennzeichnet. HtrA Chl. aur. (Chloroflexus auranticus J-10-fl.)[ZP_00768469.1], HtrA E. coli [ABI99646.1], HtrA Leg. pneu. (Legionella pneumophila) [YP_126634.1], HtrA Lactobacillus. helveticus [CAA06668.1].

PALLEN und WREN verglichen 1997 die Aminosäuresequenzen im Bereich der katalytischen Triade von verschiedenen HtrA-Proteasen und konnten schließlich eine Konsensussequenz ableiten. Diese konservierten Motive im Bereich der aktiven Aminosäuren konnten auch für PepJS2 nachgewiesen werden (s. Abb. 58). HtrA-Proteasen besitzen mindestens eine sogenannte PDZ Domäne am C-terminalen Ende (CLAUSEN 2002). PDZ steht für die eukaryotischen Proteine „post-synaptic density“, „disc-large“ und „zo-1“, in denen diese Domänen zuerst entdeckt wurden und auch als DHR oder GLGF Domänen bekannt sind. Sie umfassen 80 bis 100 Aminosäuren. PDZ Domänen spielen eine wichtige Rolle bei der Interaktion von Enzym und Substrat. Für E. coli DegQ konnten zwei PDZ Domänen identifiziert werden (PONTING et al. 1997). PDZ1 ist wichtig für die Erkennung des Substrates und PDZ2 für die Bildung der hexameren Struktur von DegP. Auch für PepJS2 konnte eine PDZ Domäne im Bereich der Aminosäuren 275 bis 378 identifiziert werden (s. Abb. 43). Aufgrund der Übereinstimmungen im Bereich der Aminosäuren der katalytischen Triade sowie der strukturellen Ähnlichkeiten in der Primärstruktur von bereits bekannten HtrA Proteasen, lässt sich PepJS2 eindeutig in die Familie der HtrA Proteasen einordnen. 
Beide im Rahmen dieser Arbeit untersuchten Proteasen (PepJS1 und PepJS2) konnten den Serin-Proteasen zugeordnet werden. Eine weitere Einteilung konnte nur in Form von Sequenzhomologien in der Aminosäureabfolge im Bereich konservierter Motive erfolgen, da eine Reinigung bzw. biochemische Charakterisierung nur partiell möglich war. 


\section{$5 \quad$ Zusammenfassung}

1. Die mikrobielle Diversität des alkalithermophilen Habitates Avachinsky (Kamtschatka) wurde mittels $16 \mathrm{~S}$ rRNA-Genanalysen untersucht. Insgesamt wurden 594 16S rRNA-Gensequenzen analysiert, von denen 393 den Bakterien und 201 den Archaeen zugeordnet werden konnten. Sie konnten in 186 „operational taxonomic units“ (OTUs) eingeteilt werden. 276 16S rRNA-Gensequenzen wurden zur Konstruktion von phylogentischen Stammbäumen verwendet. Sie konnten in 18 bakterielle und 2 archaelle Phyla eingeordnet werden. Etwa $50 \%$ aller bakteriellen $16 S$ rRNA-Gensequenzen konnten den Proteobakterien zugeordnet werden. Davon entfallen $24 \%$ auf die Alpha-Proteobakterien. Weitere dominierende Phyla sind die Bacteroidetes (8\%), und die Acidobacteria (7,5\%). Alle anderen bakteriellen Phyla sind mit weniger als $5 \%$ der $16 \mathrm{~S}$ rRNA-Gesequenzen vertreten. Zwei Drittel der archaellen 16S rRNAGensequenzen konnten Ordnungen von bisher unkultivierten Crenarchaeota zugeordnet werden. Die Euryarchaeota werden durch die Ordnungen Thermoplasmatales und Halobacteriales repräsentiert. Insgesamt zeigen 95,5 \% der 16S rRNA-Gensequenzen keinerlei Identität zu 16S rRNA-Gensequenzen bereits kultivierter Mikroorganismen und bilden zum Teil neue Cluster innerhalb der verschiedenen Phyla.

2. Zur Herstellung von Metagenombanken konnte Umwelt-DNA aus Proben der extremen Standorte Avachinsky und Dachnie (Kamtschatka) durch Kombination von chemischer Zelllyse und mechanischem Zellaufschluss durch „Bead-Beating“ isoliert werden. Die DNA wurde mittels Caesiumchlorid-Dichtegradienten-Zentrifugation gereingt und anschließend zur Konstruktion von „small-insert“- und „large-insert“Genbanken in Plasmidvektoren bzw. Fosmidvektoren ligiert. Es wurden insgesamt vier Plasmid-Genbanken bestehend aus 139000 rekombinanten Plasmiden konstruiert, die insgesamt 391,5 Mbp an 
klonierter Umwelt-DNA enthalten. Die Fosmid-Genbank umfasst 5200 Klone mit $182 \mathrm{Mbp}$ an klonierter Umwelt-DNA.

3. Zur Identifizierung von Genen in den Metagenombanken, die lipolytische Aktivität vermitteln, wurde ein auf Enzymaktivität basierendes Plattentestverfahren verwendet. Im Rahmen der Durchmusterung der Plasmid- und Fosmid-Genbanken konnten vier lipolytische E.coli-Klone identifiziert werden. Sie entstammen alle der Fosmidgenbank. Die Fosmide wurden mit pFosJS1 bis pFosJS4 bezeichnet.

4. Insgesamt konnten drei Gene identifiziert werden, die für Esterasen bzw. Lipasen kodieren. Diese wurden mit estJS1 bis estJS3 bezeichnet. Das Gen estJS1 umfasst 816 bp. Die Aminosäuresequenz des abgeleiteten Genprodukts zeigte $45 \%$ Identität zu BioH, einem vermutlich an der Biotin-Biosynthese beteiligten Enzym mit Esterasefunktion aus dem Organismus Kurthia sp. 538-KA26. Das estJS1-Gen wurde in den Expressionsvektor pET101/D-TOPO kloniert und das Genprodukt heterolog in E. coli BL21 produziert. EstJS1 konnte gereinigt und durch biochemische Charakterisierung und Sequenzanalysen in die Familie IV der lipolytischen Enzyme eingeordnet werden. Die Gene estJS2 und estJS3 kodieren für 500 bzw. 515 Aminosäuren und zeigen signifikante Ähnlichkeit zu den Carboxylesterasen Typ B aus Chlorobium ferrooxidans DSM13031 und Bacillus coagulans 36D1. Durch Sequenzanalysen und durch die Identifizierung konservierter Bereiche konnten sie in die Familie $\mathrm{V}$ (hormone-sensitive-lipase-Familie) der lipolytischen Enzyme eingeordnet werden.

5. Zur Identifizierung von Genen, die proteolytische Aktivität vermitteln, wurde ein auf Enzymaktivität basierendes Screening-Verfahren durchgeführt. Insgesamt konnten drei proteolytisch aktive E. coli-Klone identifiziert werden. Die Fosmide wurden mit pFosJS5 bis pFosJS7 bezeichnet. 
6. Auf den Fosmiden pFosJS5 und pFosJS6 konnte jeweils ein Gen identifiziert werden, das für eine Protease kodiert (pepJS1 bzw. pepJS2). Das Gen pepJS1 kodiert für eine Protease von 1009 Aminosäuren, die hohe Identität (86 \%) zu einer S8 Peptidase aus Chloroflexus aggregans DSM 9485 zeigt. PepJS1 besitzt ein N-terminales Signalpeptid für den Proteinexport. Durch die Identifizierung konservierter Motive im Bereich der katalytischen Triade konnte PepJS1 den Subtilisin-ähnlichen Proteasen zugeordnet werden. Das Genprodukt von pepJS2 (392 Aminosäuren) zeigte $61 \%$ Identität zu einer S1 Peptidase aus Chlorflexus aurantiacus J-10-fl. PepJS2 besitzt ebenfalls ein Nterminales Signalpeptid. Es konnten konservierte Motive, welche typisch für Proteasen der HtrA-Familie sind identifiziert werden. Außerdem konnte eine C-terminale PDZ-Domäne, die für die Enzym-SubstratBindung bzw. für die Bildung von oligomere Strukturen verantwortlich ist, gefunden werden. Die Gene pepJS1 und pepJS2 wurden in den Expressionvektor pET101/D-TOPO kloniert, heterolog in E. coli BL21 produziert und partiell gereinigt. 
Akatsuka, H., Kawai, E., Omori, K., Komatsubara, S., Shibatani, T. and Tosa, T. (1994). The lipA gene of Serratia marcescens which encodes an extracellular lipase having no N-terminal signal peptide. J Bacteriol 176, 194956.

Amann, R. I., Ludwig, W. and Schleifer, K. H. (1995). Phylogenetic identification and in situ detection of individual microbial cells without cultivation, vol. 59, pp. 143-169.

Anitori, R. P., Trott, C., Saul, D. J., Bergquist, P. L. and Walter, M. R. (2002). A culture-independent survey of the bacterial community in a radon hot spring. Astrobiology 2, 255-70.

Arpigny, J. L. and Jaeger, K. E. (1999). Bacterial lipolytic enzymes: classification and properties. Biochem J 343 Pt 1, 177-83.

Barns, S. M., Fundyga, R. E., Jeffries, M. W. and Pace, N. R. (1994). Remarkable archaeal diversity detected in a Yellowstone National Park hot spring environment. Proc Natl Acad Sci U S A 91, 1609-13.

Bell, P. J., Sunna, A., Gibbs, M. D., Curach, N. C., Nevalainen, H. and Bergquist, P. L. (2002). Prospecting for novel lipase genes using PCR. Microbiology 148, 2283-91.

Berry, A. E., Chiocchini, C., Selby, T., Sosio, M. and Wellington, E. M. (2003). Isolation of high molecular weight DNA from soil for cloning into BAC vectors. FEMS Microbiol Lett 223, 15-20.

Binet, R., Letoffe, S., Ghigo, J. M., Delepelaire, P. and Wandersman, C. (1997). Protein secretion by gram-negative bacterial ABC exporters. Folia Microbiol (Praha) 42, 179-83.

Blank, C. E., Cady, S. L. and Pace, N. R. (2002). Microbial composition of near-boiling silica-depositing thermal springs throughout Yellowstone National Park. Appl Environ Microbiol 68, 5123-35.

Bond, P. L., Druschel, G. K. and Banfield, J. F. (2000). Comparison of acid mine drainage microbial communities in physically and geochemically distinct ecosystems. Appl Environ Microbiol 66, 4962-71. 
Bonfield, J. K., Smith, K. and Staden, R. (1995). A new DNA sequence assembly program. Nucleic Acids Res 23, 4992-9.

Bonfield, J. K. and Staden, R. (1996). Experiment files and their application during large-scale sequencing projects. DNA Seq 6, 109-17.

Bradford, M. M. (1976). A rapid and sensitive method for the quantitation of microgram quantities of protein utilizing the principle of protein-dye binding. Anal Biochem 72, 248-54.

Brady, S. F., Chao, C. J. and Clardy, J. (2004). Long-chain N-acyltyrosine synthases from environmental DNA. Appl Environ Microbiol 70, 6865-70.

Brady, S. F. and Clardy, J. (2003). Synthesis of long-chain fatty acid enol esters isolated from an environmental DNA clone. Org Lett 5, 121-4.

Brady, S. F. and Clardy, J. (2005). Cloning and heterologous expression of isocyanide biosynthetic genes from environmental DNA. Angew Chem Int Ed Engl 44, 7063-5.

Clausen, T., Southan, C. and Ehrmann, M. (2002). The HtrA family of proteases: implications for protein composition and cell fate. Mol Cell 10, 44355.

COSTILOW, R.N., (1981). Biophysical factors in growth. In: Gerhardt P., Murray G. E., Costilow N., Nester E. W., Wood W. A., Krieg R., Philips G. B. (Hrsg.) Manual of methods for general bacteriology, 66-78. American Society for Microbiology, Washington D.C., USA.

Courtois, S., Frostegard, A., Goransson, P., Depret, G., Jeannin, P. and Simonet, P. (2001). Quantification of bacterial subgroups in soil: comparison of DNA extracted directly from soil or from cells previously released by density gradient centrifugation. Environ Microbiol 3, 431-9.

Cowan, D., Meyer, Q., Stafford, W., Muyanga, S., Cameron, R. and Wittwer, P. (2005). Metagenomic gene discovery: past, present and future. Trends Biotechnol 23, 321-9.

Daniel, R. (2004). The soil metagenome--a rich resource for the discovery of novel natural products. Curr Opin Biotechnol 15, 199-204.

Daniel, R. (2005). The metagenomics of soil. Nat Rev Micro 3, 470-478.

Danser, A. H. (2007). Renin academy in focus. $J$ Renin Angiotensin Aldosterone Syst 8, 212. 
Degrange, V. and Bardin, R. (1995). Detection and counting of Nitrobacter populations in soil by PCR. Appl Environ Microbiol 61, 2093-8.

DeLong, E. F. (1992). Archaea in coastal marine environments. Proc Natl Acad Sci U S A 89, 5685-9.

DeSantis, G., Zhu, Z., Greenberg, W. A., Wong, K., Chaplin, J., Hanson, S. R., Farwell, B., Nicholson, L. W., Rand, C. L., Weiner, D. P. et al. (2002). An enzyme library approach to biocatalysis: development of nitrilases for enantioselective production of carboxylic acid derivatives. J Am Chem Soc 124, 9024-5.

DeSantis, T. Z., Hugenholtz, P., Larsen, N., Rojas, M., Brodie, E. L., Keller, K., Huber, T., Dalevi, D., Hu, P. and Andersen, G. L. (2006). Greengenes, a Chimera-Checked 16S rRNA Gene Database and Workbench Compatible with ARB, vol. 72, pp. 5069-5072.

Dower, W. J., Miller, J. F. and Ragsdale, C. W. (1988). High efficiency transformation of E. coli by high voltage electroporation. Nucleic Acids Res 16, 6127-45.

Duong, F., Soscia, C., Lazdunski, A. and Murgier, M. (1994). The Pseudomonas fluorescens lipase has a C-terminal secretion signal and is secreted by a three-component bacterial ABC-exporter system. Mol Microbiol $11,1117-26$.

Elend, C., Schmeisser, C., Hoebenreich, H., Steele, H. L. and Streit, W. R. (2007). Isolation and characterization of a metagenome-derived and cold-active lipase with high stereospecificity for (R)-ibuprofen esters. J Biotechnol 130, 3707.

Elend, C., Schmeisser, C., Leggewie, C., Babiak, P., Carballeira, J. D., Steele, H. L., Reymond, J. L., Jaeger, K. E. and Streit, W. R. (2006). Isolation and biochemical characterization of two novel metagenome-derived esterases. Appl Environ Microbiol 72, 3637-45.

Feller, G., Thiry, M. and Gerday, C. (1990). Sequence of a lipase gene from the antarctic psychrotroph Moraxella TA144. Nucleic Acids Res 18, 6431.

Gabor, E. M., de Vries, E. J. and Janssen, D. B. (2004). Construction, characterization, and use of small-insert gene banks of DNA isolated from soil and enrichment cultures for the recovery of novel amidases. Environ Microbiol 6, 948-58. 
Gilbert, E. J. (1993). Pseudomonas lipases: biochemical properties and molecular cloning. Enzyme Microb Technol 15, 634-45.

Gillespie, D. E., Brady, S. F., Bettermann, A. D., Cianciotto, N. P., Liles, M. R., Rondon, M. R., Clardy, J., Goodman, R. M. and Handelsman, J. (2002). Isolation of antibiotics turbomycin a and B from a metagenomic library of soil microbial DNA. Appl Environ Microbiol 68, 4301-6.

Ginolhac, A., Jarrin, C., Gillet, B., Robe, P., Pujic, P., Tuphile, K., Bertrand, H., Vogel, T. M., Perriere, G., Simonet, P. et al. (2004). Phylogenetic analysis of polyketide synthase I domains from soil metagenomic libraries allows selection of promising clones. Appl Environ Microbiol 70, 5522-7.

Giovannoni, S. J., Britschgi, T. B., Moyer, C. L. and Field, K. G. (1990). Genetic diversity in Sargasso Sea bacterioplankton. Nature 345, 60-3.

Gordon, V. M. and Leppla, S. H. (1994). Proteolytic activation of bacterial toxins: role of bacterial and host cell proteases. Infect Immun 62, 333-40.

Gribaldo, S. and Brochier-Armanet, C. (2006). The origin and evolution of Archaea: a state of the art. Philos Trans R Soc Lond B Biol Sci 361, 1007-22.

Gupta, R., Beg, Q. K., Khan, S. and Chauhan, B. (2002). An overview on fermentation, downstream processing and properties of microbial alkaline proteases. Appl Microbiol Biotechnol 60, 381-95.

Gupta, R., Beg, Q. K. and Lorenz, P. (2002). Bacterial alkaline proteases: molecular approaches and industrial applications. Appl Microbiol Biotechnol 59, 15-32.

Hamamura, N., Olson, S. H., Ward, D. M. and Inskeep, W. P. (2005). Diversity and functional analysis of bacterial communities associated with natural hydrocarbon seeps in acidic soils at Rainbow Springs, Yellowstone National Park. Appl Environ Microbiol 71, 5943-50.

Hamamura, N., Olson, S. H., Ward, D. M. and Inskeep, W. P. (2006). Microbial population dynamics associated with crude-oil biodegradation in diverse soils. Appl Environ Microbiol 72, 6316-24.

Hanahan, D. (1983). Studies on transformation of Escherichia coli with plasmids. J Mol Biol 166, 557-80.

Handelsman, J. (2004). Metagenomics: application of genomics to uncultured microorganisms. Microbiol Mol Biol Rev 68, 669-85. 
Healy, F. G., Ray, R. M., Aldrich, H. C., Wilkie, A. C., Ingram, L. O. and Shanmugam, K. T. (1995). Direct isolation of functional genes encoding cellulases from the microbial consortia in a thermophilic, anaerobic digester maintained on lignocellulose. Appl Microbiol Biotechnol 43, 667-74.

Henckel, T., Jackel, U., Schnell, S. and Conrad, R. (2000). Molecular analyses of novel methanotrophic communities in forest soil that oxidize atmospheric methane. Appl Environ Microbiol 66, 1801-8.

Henne, A., Daniel, R., Schmitz, R. A. and Gottschalk, G. (1999). Construction of environmental DNA libraries in Escherichia coli and screening for the presence of genes conferring utilization of 4-hydroxybutyrate. Appl Environ Microbiol 65, 3901-7.

Henne, A., Schmitz, R. A., Bomeke, M., Gottschalk, G. and Daniel, R. (2000). Screening of environmental DNA libraries for the presence of genes conferring lipolytic activity on Escherichia coli. Appl Environ Microbio/ 66, 31136.

Holmes, D. S. and Quigley, M. (1981). A rapid boiling method for the preparation of bacterial plasmids. Anal Biochem 114, 193-7.

Hong, K. S., Lim, H. K., Chung, E. J., Park, E. J., Lee, M. H., Kim, J. C., Choi, G. J., Cho, K. Y. and Lee, S. W. (2007). Selection and characterization of forest soil metagenome genes encoding lipolytic enzymes. J Microbiol Biotechnol 17, 1655-60.

Hoster, F., Schmitz, J. E. and Daniel, R. (2005). Enrichment of chitinolytic microorganisms: isolation and characterization of a chitinase exhibiting antifungal activity against phytopathogenic fungi from a novel Streptomyces strain. Appl Microbiol Biotechnol 66, 434-42.

Huber, H., Burggraf, S., Mayer, T., Wyschkony, I., Rachel, R. and Stetter, K. O. (2000). Ignicoccus gen. nov., a novel genus of hyperthermophilic, chemolithoautotrophic Archaea, represented by two new species, Ignicoccus islandicus $\mathrm{sp}$ nov and Ignicoccus pacificus sp nov. and Ignicoccus pacificus $\mathrm{sp}$. nov. Int J Syst Evol Microbiol 50 Pt 6, 2093-100.

Huber, H., Hohn, M. J., Rachel, R., Fuchs, T., Wimmer, V. C. and Stetter, K. O. (2002). A new phylum of Archaea represented by a nanosized hyperthermophilic symbiont. Nature 417, 63-7. 
Hugenholtz, P. (2002). Exploring prokaryotic diversity in the genomic era. Genome Biol 3, REVIEWS0003.

Hugenholtz, P., Pitulle, C., Hershberger, K. L. and Pace, N. R. (1998). Novel division level bacterial diversity in a Yellowstone hot spring. J Bacteriol 180, 366-76.

Inoue, H., Nojima, H. and Okayama, H. (1990). High efficiency transformation of Escherichia coli with plasmids. Gene 96, 23-8.

Itoh, T. (2003). Taxonomy of nonmethanogenic hyperthermophilic and related thermophilic archaea. J Biosci Bioeng 96, 203-12.

Itoh, T., Nomura, N. and Sako, Y. (2003). Distribution of $16 \mathrm{~S}$ rRNA introns among the family Thermoproteaceae and their evolutionary implications. Extremophiles 7, 229-33.

Jaeger, K. E., Adrian, F. J., Meyer, H. E., Hancock, R. E. and Winkler, U. K. (1992). Extracellular lipase from Pseudomonas aeruginosa is an amphiphilic protein. Biochim Biophys Acta 1120, 315-21.

Jaeger, K. E., Dijkstra, B. W. and Reetz, M. T. (1999). Bacterial biocatalysts: molecular biology, three-dimensional structures, and biotechnological applications of lipases. Annu Rev Microbiol 53, 315-51.

Jaeger, K. E., Ransac, S., Dijkstra, B. W., Colson, C., van Heuvel, M. and Misset, O. (1994). Bacterial lipases. FEMS Microbiol Rev 15, 29-63.

Kanokratana, P., Chanapan, S., Pootanakit, K. and Eurwilaichitr, L. (2004). Diversity and abundance of Bacteria and Archaea in the Bor Khlueng Hot Spring in Thailand. J Basic Microbiol 44, 430-44.

Kashima, Y., Nakajima, Y., Nakano, T., Tayama, K., Koizumi, Y., Udaka, S. and Yanagida, F. (1999). Cloning and characterization of ethanol-regulated esterase genes in Acetobacter pasteurianus. J Biosci Bioeng 87, 19-27.

Kimura, H., Ishibashi, J.-I., Masuda, H., Kato, K. and Hanada, S. (2007). Selective Phylogenetic Analysis Targeting 16S rRNA Genes of Hyperthermophilic Archaea in the Deep-Subsurface Hot Biosphere, vol. 73, pp. 2110-2117.

Knietsch, A., Bowien, S., Whited, G., Gottschalk, G. and Daniel, R. (2003). Identification and characterization of coenzyme B12-dependent glycerol dehydratase- and diol dehydratase-encoding genes from metagenomic DNA libraries derived from enrichment cultures. Appl Environ Microbiol 69, 3048-60. 
Knietsch, A., Waschkowitz, T., Bowien, S., Henne, A. and Daniel, R. (2003). Construction and screening of metagenomic libraries derived from enrichment cultures: generation of a gene bank for genes conferring alcohol oxidoreductase activity on Escherichia coli. Appl Environ Microbiol 69, 1408-16.

Knietsch, A., Waschkowitz, T., Bowien, S., Henne, A. and Daniel, R. (2003). Metagenomes of complex microbial consortia derived from different soils as sources for novel genes conferring formation of carbonyls from short-chain polyols on Escherichia coli. J Mol Microbiol Biotechnol 5, 46-56.

Kolganova, T. V., Kuznetsov, B. B. and Turova, T. P. (2002). [Designing and testing oligonucleotide primers for amplification and sequencing of archaeal $16 \mathrm{~S}$ rRNA genes]. Mikrobiologiia 71, 283-6.

Kowalchuk, G. A., Speksnijder, A. G., Zhang, K., Goodman, R. M. and van Veen, J. A. (2007). Finding the needles in the metagenome haystack. Microb Ecol 53, 475-85.

Krsek, M. and Wellington, E. M. (1999). Comparison of different methods for the isolation and purification of total community DNA from soil. J Microbiol Methods 39, 1-16.

Laemmli, U. K. (1970). Cleavage of structural proteins during the assembly of the head of bacteriophage T4. Nature 227, 680-5.

Lawrence, R. C., Fryer, T. F. and Reiter, B. (1967). The production and characterization of lipases from a micrococcus and a pseudomonad. $J$ Gen Microbiol 48, 401-18.

Lee, S. W., Won, K., Lim, H. K., Kim, J. C., Choi, G. J. and Cho, K. Y. (2004). Screening for novel lipolytic enzymes from uncultured soil microorganisms. Appl Microbiol Biotechnol 65, 720-6.

Leff, L. G., Dana, J. R., McArthur, J. V. and Shimkets, L. J. (1995). Comparison of methods of DNA extraction from stream sediments, vol. 61, pp. 1141-1143.

Lepage, E., Marguet, E., Geslin, C., Matte-Tailliez, O., Zillig, W., Forterre, P. and Tailliez, P. (2004). Molecular diversity of new Thermococcales isolates from a single area of hydrothermal deep-sea vents as revealed by randomly amplified polymorphic DNA fingerprinting and 16S rRNA gene sequence analysis. Appl Environ Microbiol 70, 1277-86. 
Li, H., Yang, S. Z., Mu, B. Z., Rong, Z. F. and Zhang, J. (2006). Molecular analysis of the bacterial community in a continental high-temperature and water-flooded petroleum reservoir. FEMS Microbiol Lett 257, 92-8.

Li, H., Yang, S. Z., Mu, B. Z., Rong, Z. F. and Zhang, J. (2007). Molecular phylogenetic diversity of the microbial community associated with a hightemperature petroleum reservoir at an offshore oilfield. FEMS Microbiol Ecol 60, 74-84.

Li, H. and Zhang, X. (2005). Characterization of thermostable lipase from thermophilic Geobacillus sp. TW1. Protein Expr Purif 42, 153-9.

Liesack, W. and Stackebrandt, E. (1992). Occurrence of novel groups of the domain Bacteria as revealed by analysis of genetic material isolated from an Australian terrestrial environment. J Bacteriol 174, 5072-8.

Lindahl, V., Bakken, L. R. (1995). Evaluation of methods for extraction of bacteria from soil. FEMS Microbiol Ecol 16, 135-142.

Lorenz, P., Liebeton, K., Niehaus, F. and Eck, J. (2002). Screening for novel enzymes for biocatalytic processes: accessing the metagenome as a resource of novel functional sequence space. Curr Opin Biotechnol 13, 572-7.

Luan, X., Chen, J., Zhang, X. H., Li, Y. and Hu, G. (2007). Expression and characterization of a metalloprotease from a Vibrio parahaemolyticus isolate. Can J Microbiol 53, 1168-73.

Ma, Y., Zhang, W., Xue, Y., Zhou, P., Ventosa, A. and Grant, W. D. (2004). Bacterial diversity of the Inner Mongolian Baer Soda Lake as revealed by $16 \mathrm{~S}$ rRNA gene sequence analyses. Extremophiles 8, 45-51.

MacNeil, I. A., Tiong, C. L., Minor, C., August, P. R., Grossman, T. H., Loiacono, K. A., Lynch, B. A., Phillips, T., Narula, S., Sundaramoorthi, R. et al. (2001). Expression and isolation of antimicrobial small molecules from soil DNA libraries. J Mol Microbiol Biotechnol 3, 301-8.

Marteinsson, V. T., Hauksdottir, S., Hobel, C. F., Kristmannsdottir, H., Hreggvidsson, G. O. and Kristjansson, J. K. (2001). Phylogenetic diversity analysis of subterranean hot springs in Iceland. Appl Environ Microbiol 67, 4242-8.

Messing, J. and Vieira, J. (1982). A new pair of M13 vectors for selecting either DNA strand of double-digest restriction fragments. Gene 19, 269-76. 
MILLER, J.H. (1972). Experiments in molecular genetics. Cold Spring Habor Laboratory, Cold Spring Habor, New York

Morana, A., Di Prizito, N., Aurilia, V., Rossi, M. and Cannio, R. (2002). A carboxylesterase from the hyperthermophilic archaeon Sulfolobus solfataricus: cloning of the gene, characterization of the protein. Gene 283, 107-15.

Moreira, D. (1998). Efficient removal of PCR inhibitors using agaroseembedded DNA preparations. Nucleic Acids Res 26, 3309-10.

Moussard, H., Henneke, G., Moreira, D., Jouffe, V., Lopez-Garcia, P. and Jeanthon, C. (2006). Thermophilic Lifestyle for an Uncultured Archaeon from Hydrothermal Vents: Evidence from Environmental Genomics, vol. 72, pp. 2268-2271.

Muyzer, G., de Waal, E. C. and Uitterlinden, A. G. (1993). Profiling of complex microbial populations by denaturing gradient gel electrophoresis analysis of polymerase chain reaction-amplified genes coding for $16 \mathrm{~S}$ rRNA. Appl Environ Microbiol 59, 695-700.

Myers, M., Richmond, R. C. and Oakeshott, J. G. (1988). On the origins of esterases, vol. 5, pp. 113-119.

Niehaus, F., Bertoldo, C., Kahler, M. and Antranikian, G. (1999). Extremophiles as a source of novel enzymes for industrial application. Appl Microbiol Biotechnol 51, 711-29.

Norris, T. B., Wraith, J. M., Castenholz, R. W. and McDermott, T. R. (2002). Soil microbial community structure across a thermal gradient following a geothermal heating event. Appl Environ Microbiol 68, 6300-9.

OGRAM, A., SAYLER, G.S., BARKAY, T., (1987). The extraction and purification of microbial DNA from sediments. J. Microbiol. Methods 7: 57-66.

Ollis, D. L., Cheah, E., Cygler, M., Dijkstra, B., Frolow, F., Franken, S. M., Harel, M., Remington, S. J., Silman, I., Schrag, J. et al. (1992). The alpha/beta hydrolase fold. Protein Eng 5, 197-211.

Pace, N. R. and Marsh, T. L. (1985). RNA catalysis and the origin of life. Orig Life Evol Biosph 16, 97-116.

Pallen, M. J. and Wren, B. W. (1997). The HtrA family of serine proteases. Mol Microbiol 26, 209-21.

Park, S. E., Li, M. H., Kim, J. S., Sapkota, K., Kim, J. E., Choi, B. S., Yoon, Y. H., Lee, J. C., Lee, H. H., Kim, C. S. et al. (2007). Purification and 
characterization of a fibrinolytic protease from a culture supernatant of Flammulina velutipes mycelia. Biosci Biotechnol Biochem 71, 2214-22.

Pattanop Kanokratana, S. C. K. P. L. E. (2004). Diversity and abundance of Bacteria and Archaea in the Bor Khlueng Hot Spring in Thailand, vol. 44, pp. 430-444.

PFENNIG, N., LIPPERT, K.D. (1966). Über das Vitamin B12-Bedürfnis phototropher Schwefelbakterien. Arch. Mircobiol. 55: 245-256.

Pierson, B. K. and Castenholz, R. W. (1974). A phototrophic gliding filamentous bacterium of hot springs, Chloroflexus aurantiacus, gen. and sp. nov. Arch Microbiol 100, 5-24.

Polgar, L. (2005). The catalytic triad of serine peptidases. Cell Mol Life Sci 62, 2161-72.

Ponting, C. P. (1997). Evidence for PDZ domains in bacteria, yeast, and plants. Protein Sci 6, 464-8.

Ranjan, R., Grover, A., Kapardar, R. K. and Sharma, R. (2005). Isolation of novel lipolytic genes from uncultured bacteria of pond water. Biochem Biophys Res Commun 335, 57-65.

Rao, M. B., Tanksale, A. M., Ghatge, M. S. and Deshpande, V. V. (1998). Molecular and biotechnological aspects of microbial proteases. Microbiol Mol Biol Rev 62, 597-635.

Rappe, M. S. and Giovannoni, S. J. (2003). The uncultured microbial majority. Annu Rev Microbiol 57, 369-94.

Rawlings, N. D. and Barrett, A. J. (1993). Evolutionary families of peptidases. Biochem J 290 ( Pt 1), 205-18.

Rawlings, N. D. and Barrett, A. J. (1994). Families of cysteine peptidases. Methods Enzymol 244, 461-86.

Rawlings, N. D. and Barrett, A. J. (1994). Families of serine peptidases. Methods Enzymol 244, 19-61.

Rawlings, N. D. and Barrett, A. J. (1995). Families of aspartic peptidases, and those of unknown catalytic mechanism. Methods Enzymol 248, 105-20.

Rawlings, N. D., Tolle, D. P. and Barrett, A. J. (2004). Evolutionary families of peptidase inhibitors. Biochem J 378, 705-16.

Rawlings, N. D., Tolle, D. P. and Barrett, A. J. (2004). MEROPS: the peptidase database. Nucleic Acids Res 32, D160-4. 
Rees, H. C., Grant, S., Jones, B., Grant, W. D. and Heaphy, S. (2003). Detecting cellulase and esterase enzyme activities encoded by novel genes present in environmental DNA libraries. Extremophiles 7, 415-21.

Reysenbach, A. L., Wickham, G. S. and Pace, N. R. (1994). Phylogenetic analysis of the hyperthermophilic pink filament community in Octopus Spring, Yellowstone National Park. Appl Environ Microbiol 60, 2113-9.

Rhee, J. K., Kim, D. Y., Ahn, D. G., Yun, J. H., Jang, S. H., Shin, H. C., Cho, H. S., Pan, J. G. and Oh, J. W. (2006). Analysis of the thermostability determinants of hyperthermophilic esterase EstE1 based on its predicted threedimensional structure. Appl Environ Microbiol 72, 3021-5.

Rhee, J.-K., Ahn, D.-G., Kim, Y.-G. and Oh, J.-W. (2005). New Thermophilic and Thermostable Esterase with Sequence Similarity to the Hormone-Sensitive Lipase Family, Cloned from a Metagenomic Library, vol. 71, pp. 817-825.

Riesenfeld, C. S., Goodman, R. M. and Handelsman, J. (2004). Uncultured soil bacteria are a reservoir of new antibiotic resistance genes. Environ Microbiol 6, 981-9.

Riesenfeld, C. S., Schloss, P. D. and Handelsman, J. (2004). Metagenomics: genomic analysis of microbial communities. Annu Rev Genet 38, 525-52.

Rondon, M. R., August, P. R., Bettermann, A. D., Brady, S. F., Grossman, T. H., Liles, M. R., Loiacono, K. A., Lynch, B. A., MacNeil, I. A., Minor, C. et al. (2000). Cloning the Soil Metagenome: a Strategy for Accessing the Genetic and Functional Diversity of Uncultured Microorganisms, vol. 66, pp. 2541-2547.

Rosenberg, A. H., Lade, B. N., Chui, D. S., Lin, S. W., Dunn, J. J. and Studier, F. W. (1987). Vectors for selective expression of cloned DNAs by T7 RNA polymerase. Gene 56, 125-35.

SAMBROOK, J., FRITSCH, E., MANIATIS, T., (1989). Molecular cloning: a laboratory manual (2.Aufl.). Cold Spring Harbor Laboratory, Cold Spring Habor, New York, USA

Santosa, D. A. (2001). Rapid extraction and purification of environmental DNA for molecular cloning applications and molecular diversity studies. Mol Biotechnol 17, 59-64.

Sassoon, N., Arie, J. P. and Betton, J. M. (1999). PDZ domains determine the native oligomeric structure of the DegP (HtrA) protease. Mol Microbiol 33, 5839. 
Schleper, C., Holben, W. and Klenk, H. P. (1997). Recovery of crenarchaeotal ribosomal DNA sequences from freshwater-lake sediments. Appl Environ Microbiol 63, 321-3.

Schleper, C., Jurgens, G. and Jonuscheit, M. (2005). Genomic studies of uncultivated archaea. Nat Rev Microbiol 3, 479-88.

Schloss, P. D. and Handelsman, J. (2003). Biotechnological prospects from metagenomics. Curr Opin Biotechnol 14, 303-10.

Schloss, P. D. and Handelsman, J. (2005). Introducing DOTUR, a computer program for defining operational taxonomic units and estimating species richness. Appl Environ Microbiol 71, 1501-6.

Schmeisser, C., Steele, H. and Streit, W. R. (2007). Metagenomics, biotechnology with non-culturable microbes. Appl Microbiol Biotechnol 75, 95562.

Schmeisser, C., Steele, H. and Streit, W. R. (2007). Metagenomics, biotechnology with non-culturable microbes. Appl Microbiol Biotechnol 75, 95562.

Schmeisser, C., Stockigt, C., Raasch, C., Wingender, J., Timmis, K. N., Wenderoth, D. F., Flemming, H. C., Liesegang, H., Schmitz, R. A., Jaeger, K. E. et al. (2003). Metagenome survey of biofilms in drinking-water networks. Appl Environ Microbiol 69, 7298-309.

Schrag, J. D., Vernet, T., Laramee, L., Thomas, D. Y., Recktenwald, A., Okoniewska, M., Ziomek, E. and Cygler, M. (1995). Redesigning the active site of Geotrichum candidum lipase. Protein Eng 8, 835-42.

STRICKEBERGER, M.W., (1996). In: Evolution. Johnes \& Bartlett Publishers, Boston, USA

Shuman, S. (1991). Site-specific DNA cleavage by vaccinia virus DNA topoisomerase I. Role of nucleotide sequence and DNA secondary structure. $J$ Biol Chem 266, 1796-803.

Shuman, S. (1994). Novel approach to molecular cloning and polynucleotide synthesis using vaccinia DNA topoisomerase. J Biol Chem 269, 32678-84.

Siezen, R. J. and Leunissen, J. A. (1997). Subtilases: the superfamily of subtilisin-like serine proteases. Protein Sci 6, 501-23. 
Siezen, R. J., Renckens, B. and Boekhorst, J. (2007). Evolution of prokaryotic subtilases: genome-wide analysis reveals novel subfamilies with different catalytic residues. Proteins 67, 681-94.

Sigrist, C. J., Cerutti, L., Hulo, N., Gattiker, A., Falquet, L., Pagni, M., Bairoch, A. and Bucher, P. (2002). PROSITE: a documented database using patterns and profiles as motif descriptors. Brief Bioinform 3, 265-74.

Sliwinski, M. K. and Goodman, R. M. (2004). Comparison of crenarchaeal consortia inhabiting the rhizosphere of diverse terrestrial plants with those in bulk soil in native environments. Appl Environ Microbiol 70, 1821-6.

Sommer, P., Bormann, C. and Gotz, F. (1997). Genetic and biochemical characterization of a new extracellular lipase from Streptomyces cinnamomeus. Appl Environ Microbiol 63, 3553-60.

Spear, J. R., Walker, J. J., McCollom, T. M. and Pace, N. R. (2005). Hydrogen and bioenergetics in the Yellowstone geothermal ecosystem. Proc Natl Acad Sci U S A 102, 2555-60.

Sprenger, G. A., Hammer, B. A., Johnson, E. A. and Lin, E. C. (1989). Anaerobic growth of Escherichia coli on glycerol by importing genes of the dha regulon from Klebsiella pneumoniae. J Gen Microbiol 135, 1255-62.

Staden, R., Beal, K. F. and Bonfield, J. K. (2000). The Staden package, 1998. Methods Mol Biol 132, 115-30.

Strauch, K. L., Johnson, K. and Beckwith, J. (1989). Characterization of degP, a gene required for proteolysis in the cell envelope and essential for growth of Escherichia coli at high temperature. J Bacteriol 171, 2689-96.

Streit, W. R., Daniel, R. and Jaeger, K. E. (2004). Prospecting for biocatalysts and drugs in the genomes of non-cultured microorganisms. Curr Opin Biotechnol 15, 285-90.

Streit, W. R. and Schmitz, R. A. (2004). Metagenomics--the key to the uncultured microbes. Curr Opin Microbiol 7, 492-8.

Studier, F. W. and Moffatt, B. A. (1986). Use of bacteriophage T7 RNA polymerase to direct selective high-level expression of cloned genes. $\mathrm{J} \mathrm{Mol} \mathrm{Biol}$ $189,113-30$.

Studier, F. W., Rosenberg, A. H., Dunn, J. J. and Dubendorff, J. W. (1990). Use of T7 RNA polymerase to direct expression of cloned genes. Methods Enzymol 185, 60-89. 
Takai, K., Moser, D. P., DeFlaun, M., Onstott, T. C. and Fredrickson, J. K. (2001). Archaeal diversity in waters from deep South African gold mines. Appl Environ Microbiol 67, 5750-60.

Tebbe, C. C. and Vahjen, W. (1993). Interference of humic acids and DNA extracted directly from soil in detection and transformation of recombinant DNA from bacteria and a yeast. Appl Environ Microbiol 59, 2657-65.

Tirawongsaroj, P., Sriprang, R., Harnpicharnchai, P., Thongaram, T., Champreda, V., Tanapongpipat, S., Pootanakit, K. and Eurwilaichitr, L. (2008). Novel thermophilic and thermostable lipolytic enzymes from a Thailand hot spring metagenomic library. J Biotechnol 133, 42-9.

Tomczyk, N. H., Nettleship, J. E., Baxter, R. L., Crichton, H. J., Webster, S. P. and Campopiano, D. J. (2002). Purification and characterisation of the $\mathrm{BIOH}$ protein from the biotin biosynthetic pathway. FEBS Lett 513, 299-304.

Towbin, H., Staehelin, T. and Gordon, J. (1992). Electrophoretic transfer of proteins from polyacrylamide gels to nitrocellulose sheets: procedure and some applications. 1979. Biotechnology 24, 145-9.

Vetriani, C., Jannasch, H. W., MacGregor, B. J., Stahl, D. A. and Reysenbach, A. L. (1999). Population structure and phylogenetic characterization of marine benthic Archaea in deep-sea sediments. Appl Environ Microbiol 65, 4375-84.

Vieille, C. and Zeikus, G. J. (2001). Hyperthermophilic enzymes: sources, uses, and molecular mechanisms for thermostability. Microbiol Mol Biol Rev 65, $1-43$.

Vieira, J. and Messing, J. (1982). The pUC plasmids, an M13mp7-derived system for insertion mutagenesis and sequencing with synthetic universal primers. Gene 19, 259-68.

Voget, S., Leggewie, C., Uesbeck, A., Raasch, C., Jaeger, K. E. and Streit, W. R. (2003). Prospecting for novel biocatalysts in a soil metagenome. Appl Environ Microbiol 69, 6235-42.

Wang, G. C. and Wang, Y. (1996). The frequency of chimeric molecules as a consequence of PCR co-amplification of 16S rRNA genes from different bacterial species. Microbiology 142 ( Pt 5), 1107-14. 
Watanabe, A., Kamio, Y., Kimura, W. and Izaki, K. (1993). Purification and characterization of a thermostable neutral metalloprotease I from Chloroflexus aurantiacus J-10-fl. Biosci Biotechnol Biochem 57, 2160-5.

Whitman, W. B., Coleman, D. C. and Wiebe, W. J. (1998). Prokaryotes: the unseen majority. Proc Natl Acad Sci U S A 95, 6578-83.

WILSON, E.O., (1992). In: The diversity of life, pp. 131-162: W.W. Norton \& Co. New York, USA.

WILKINSON, D.E., JEANICKE, T., COWAN, D.A., (2002). Efficient molecular cloning of environmental DNA from geothermal sediments. Biotechnol. Lett. 24:155-161.

Winkler, U. K. and Stuckmann, M. (1979). Glycogen, hyaluronate, and some other polysaccharides greatly enhance the formation of exolipase by Serratia marcescens. J Bacteriol 138, 663-70.

Wohlfarth, S., Hoesche, C., Strunk, C. and Winkler, U. K. (1992). Molecular genetics of the extracellular lipase of Pseudomonas aeruginosa PAO1. J Gen Microbiol 138, 1325-35.

Wolin, E. A., Wolfe, R. S. and Wolin, M. J. (1964). Viologen dye inhibition of methane formation by Methanobacillus omelianskii. J Bacteriol 87, 993-8.

Yamamoto, H., Hiraishi, A., Kato, K., Chiura, H. X., Maki, Y. and Shimizu, A. (1998). Phylogenetic evidence for the existence of novel thermophilic bacteria in hot spring sulfur-turf microbial mats in Japan. Appl Environ Microbiol 64, 16807.

Yanisch-Perron, C., Vieira, J. and Messing, J. (1985). Improved M13 phage cloning vectors and host strains: nucleotide sequences of the M13mp18 and pUC19 vectors. Gene 33, 103-19.

Yeates, C., Gillings, M. R., Davison, A. D., Altavilla, N. and Veal, D. A. (1998). Methods for microbial DNA extraction from soil for PCR amplification. Biol Proced Online 1, 40-47.

Yun, J., Kang, S., Park, S., Yoon, H., Kim, M. J., Heu, S. and Ryu, S. (2004). Characterization of a novel amylolytic enzyme encoded by a gene from a soilderived metagenomic library. Appl Environ Microbiol 70, 7229-35. 


\section{$7 \quad$ Anhang}

>estJS1

ATGCCCAGGGTGAAGGTTAACGATATAAATATCTACTATGATGAGCACGGGCACGGGGAA CCACTGCTATTGATAATGGGCTTCGGTTCCTATTCTGCTCACTGGTCGCCCATAATACCA CATCTCTCAAAGGAGTTCCGTGTCATCGCCTTTGACAATCGTGGCACGGGACAGAGCGAT AAACCGGATTATCCCTACACCTTGCCGATGATGGCTGGTGATGCTAGGGGGCTACTTGAT GTGCTTGGTATAGACAGGGCACATGTCTTTGGCGTCTCCATGGGCGGGATGATAGCGCAG GAGTTTACCCTTAACTATCCGGGAAGGGTGCGCAGCCTTATCCTGGGATGCACCAACTGC GGCGGTAAGAACGCCGTGCCACCCTCTGAGGAAGCACTCCGTTTCCTTTTCGGTCCTGAG ATGGCGAAGCTGTCTGTGGAGGAGCGGGCACGTCTGACCGCCCCCTGGCTGTGGACGAAA GAGTTTATCGAGAAACACCCGGAGGCAGTGGAGTTTTATGTGACCATTACTTCGCGCTAC CCCACGCCGGTACACGGCTTCAGAAGCCAGGCACAGGCGATAGCCGGGCACGATACCTAC GATAGGTTGCCACAGATAAAGGCACCCACACTGGTGATAACCGGGGATGCCGATAGACTT ATCCCGCCGGAAAACTCGAAGATATTAGCCTCCAGAATACCGGGTGCTGAGTTAGTTGTA CTGAAAAATGCTGGACACGGCTTTATTACGGATGCTACCGAGGATGCGGCGAAGGTGATA CTCGACTTCTTAAGACGGCATTCCGGCAGGGACTGA

>estJS2

ATGGGCTCACCGACCCTTGAACTGCCCACACGGTGGTGGTACAATCAGCCAAAACCGCAA AAGGAGAATGAAATGGCACTGAGTGACCCCATAATGACCGATTCCGGACCCGTGTCCGGC GTGGTGCTGGGGGAGCCGGGGAAGGAGGTTCATGTCTACCGCTCCATCCCCTACGCCGCC CCGCCCCTGGGCGAGCTGCGCTGGAAGCCGCCGCAGCCGCTTTCGCCATGGAGGCGCATC CGCGATTGCACCCCACCCTCCAAGCCCTGCCCGCAGGTGGAGAGGCCGTTCTGCCCCGGT CCCTACAGCGAGGACTGCCTCTATCTGGTGGTGATGACGCCGGCAAAGAAAGCGAACGAG CGGCTGCCGGTGATGGTCTGGTTCCACGGCGGCGGCTATAGCATCGGCAGCGGCGGCATG GCGCCCTGGGGCACCTCGCTGGCGCTGGCACAGCAGGGCGTGGTGCTGGTCAGCGTCACC CACCGCCTTGGTCCCCTGGGCTGCCTGGCACTGCCGGCGCTCTCTAAGGAGTCGCCCGAA GGCGTCTCCGGGAACTACCTGTTCCTCGATTGCATCGCTGCCCTCAAGTGGGTGCAGCGC AACATCGCCAACTTCGGCGGCAACCCCGACTGCGTCACCATCTTCGGCGAGTCCGGCGGC GCCGGCAAGTGCGATGCCCTGATGGCTTCCCCCATGGCTAAGGGCTTGTTCCACCGCGTC ATCCTGGAGAGCGGCGCCAACGGCGGCACAGGCGAGCAGGCACGCCTGGTGGTCACCCTC AAGGACGCCGAGGCGCTGGGCGAAAGGCTGGTCACCCAGTATTTGAATATGGATCCCAGC GACCTGGCGGCACTGCGCAAACTCCCCGCCGAGCAACTGGTCAGGGCGGCAGCCAAGCTC ACCCAGGACATGGCGGTGGAGCGCCCCGAGGGCGTCACCGCCACCGATACCTTGAAGGTG GACGGCTACTTCATGCCCGACTTCCCCGACAACATCTTCCGCGCCGGCAGGCAGAACAAC GTCCCGCTGATAACCTGCGCCAACCTCGGCGAGCTCATCGCCGAGAAGACGCTCCTCAAG ATGCCCGGCATCATCAAGGCATATGTCACCAGGCTGGAGAGCTGCCACAGGCTGGGCACC AAGGGCTTCGGCTGCATCTTCAGCCACGTGCCCACAAAGTGGCGGGCTGAGGGGGTGATG GCATACCACGGCATCGAGCTGATGTACCTGTTCGGCGTCTATAAGGTCATCGGCAACCCG GCGCACTTCATCGGCTTCGCCCAGCCCTCGGGCGCCTCCTCGCCCGATGCCGGCATCACC GATGAGGACAGGCTGGTCTCCGAGGCGATGATGGCGATGTGGGTGCAGTTTGCCAGGAGC GGCGACCCCAATGTCAAGGGGTTAATCAAATGGCCCACCTGGGAGCCGGCAAGCGACCAG TACCTCGATATCGCCTGGCCCCTGCAGGTGAGGTCGGGCTATTCCAGGGTCGCCGGTGGC TAA

>estJS3

ATGGTTGAAGCTACACCAGCAATCGTCGAGACTACTGCAGGGAAAATCGAGGGTGTTTTC AGAAAAGGGCTGTATATCTTCAGGGGTGTTCCTTTTGCAGCACCGCCTGTGGGAAAGAAG CGCTGGTTGCCACCTGAGCCAGTCCAGCCGTGGAGTGGTGTTAAAAGAACCGTGGAGTTC GGGGCCACCTGCCCTCAGGTGCCCATGGAAGTGGCGTTACTTAATCCACCCGAGCAACAG CCACAGAGCGAGGACTGCCTCTATCTCAACATCTGGACGCCAGGGCTTGACAATGCCAAA CGTCCGGTTATGGTATGGATTCATGGCGGTGGGTTTTCCACCGGCGCTGGCTCGTGGCTC ATCTATAACGGACGTCGGCTGGCAACCCGTGGCGATGTAGTGGTGGTCACCATAAACTAC CGGCTCAACGTTTTCGGTTTTATCAATCTGAAGGACGTCACCAAAGGCAAAATCCCGGCC ACCGGTAACGAGGGGCTGCTTGACCAGGTGTTTGCCCTGCAGTGGGTGCGGGACAATATC TCAAACTTCGGCGGTGACCCTAACAATGTGACCATATTTGGCGAATCTGCCGGGGGCATG 
AGCGTGGGGACGCTACTGGCCATGCCGAGGGCGAAAGGGCTGTTTCACAAGGCTATTTTG CAGAGTGGTGCCGGACACCATGTGAGCTCGACTGAGCGGGCTGTGAAAGTGGCGAGTATG TTCCTTGACATCTTGGGGGTTAAGCCCGATGAAGCAGAGAGGCTGTGGTCACTGACTGCG GAGCAGCTTTTGGAGGCTTACAAGGAGCTTGCCAACAGGGCACGTGACCCTAGGTCAGGG CTGGCTGACCTGCCGTTGAGACCTGTGGTGGATGGCTCTGTGCTTCCTGACATGCCCCCG CATGCCGTTGCCAGCGGTTCCGCCGACGATGTTGCTATCATGGTGGGCACCAACCTTGAT GAATGGAAACTATTTGCCCTTATAGACGCGAGACTGGCAGAGATGGATGAAGGGCTTCTG TTACGTCGCTGTCAGCGGCTGATTCCGGGTGTGGATGCGGCGGCACTTGTCGAGACTTAC CGCAAGGCGCGTGCTAAGCGCGGCTGGTCAGTCGTGCCGGCGGATATTTTCATAGCCATT CAGTCAGACAGAATTTTCCGTATCCCGGCGATCCGGCTTACTGAGGCCCACCGCAGTCGC CGCAAGACAAGCTATATGTATCTATTCGACTGGGTTTCACCGCTGAGGGAAGGTGCCCTG GGTTCGTGCCATGCACTGGAGCTGGGCTTCGTCTTCGGTACCCTGGACGACAATTTTACC GGCACTAGTGAGGAGGCTAGAGCCCTAGCGGAGAAAATGCAGGATGCCTGGACGGCTTTT GCCCGCAAGGGTGACCCCAGTTGCCCCAGCCTTGGCAACTGGAAGACCTACAGCGAGCGC AGGGAGACCATGATCCTGGGCAGGAATTGTCGCCTCATGGAAGCCCCTTACGACGAGGAA TGCCAGGCATGGGAGAAGGTCCCCGATACTGTGCTCGCTGCGTTTTAG

$>$ I ipA I

ATGCAAAAGGCTGTTGAAATTACATATAACGGCAAAACTTTAAGAGGAATGATGCATTTG CCTGATGATGTTAAGGGTAAAGTGCCTATGGTAATAATGTTTCACGGTTTTACAGGCAAT AAAGTAGAGTCTCACTTTATTTTTGTGAAGATGTCAAGAGCTTTAGAAAAAGTAGGTATT GGGAGTGTAAGGTTTGACTTTTATGGTTCTGGAGAAAGTGATGGGGACTTTAGTGAAATG ACATTTAGCAGTGAATTGGAAGATGCAAGACAAATTTTAAAGTTTGTGAAAGAGCAACCT ACGACTGACCCTGAGAGAATAGGACTACTTGGTTTGAGTATGGGAGGAGCTATTGCAGGG ATTGTAGCAAGGGAATATAAAGATGAAATAAAGGCGTTGGTGCTATGGGCTCCAGCTTTT AATATGCCTGAGCTTATAATGCACGAAAGTGTAAAGCAATACGGAGCTATTATGGAACAA TTGGGCTTTGTAGACATAGGAGGACATAAACTGAGTAAAGATTTTGTTGAGGATATTTCA AAATTAAATATATTGAGCTGTCAAAAGGATACGATAAAAAAGTGCTTATAGTTCATGgG ACAAATGATGAAGCGGTTGAATATAAAGTTTCTGATAGAATCTTAAAAGAGGTTTATGGG GATAACGCTACAAGAGTGACAATCGAAAATGCAGACCATACTTTTAAGAGTTTAGAATGG GAGAAAAAGGCGATTGAGGAGTCAGTAGAGTTTTTCAAAAAGGAATTGTTAAAGGGATAG

$>$ pepJS1

ATGAAACGATCTAGTTCACTTATCCTCTTCATCATTGCTTGCTTGGTCAACATACTGGCA TTCGTGCCGGGTACCTCAGTGCAGGCCGATCCGGCTACACTCTCCGCTACCCCAACCAGC CTTGCAGCCACTGTCGAACTTGGCAGTACAACCACCCTCAACCTCACTATCACCAATACC GGCAGTAATCCATTAACACCTCACCTCTATGTTGGCTATCCACCAACAGCCAGTCCGGCT CGCATGACGATTCCATCACTGCCGGTGCCACTCCCCCAACAAGCCGAGCGGATCGATCCT GACCTACAAGCCGAGTTGGTGCACGGACCAACTCGCTTCCTCGTCTTCTTCGCCGACCGA CCCGATCTCGGTGCAGCATTCTTGATTCGCGATTGGGCGGCCCGCGGTGAGTACGTTTAC CGTACTTTGACCGAACATGCCGAACGCAGCCAACGCGCCGTGCGCACGCTGCTCGATGCT GCCGGTGTGCGTTACACTCCGCTCTGGATCGTCAACGCCTTGCTGGTTGAAGGGGACGCA ACCCTGGCCCAAGCCCTTGCTGCTCACACCGACGTTGCAATGCTGAGTGCCGACCACGAG CTGCAAGTAGCTCCGTCGGCTTCGACAACAGCCGGTAGTTGCAATCCATCTGCCAATAAC GTCTGCTGGAATATTGATCAAATCGGCGCTGACCGAGTCTGGCGCAAGTTCGGTGTCACC GGTGAGGGGATTACCGTCGCAAATATCGATAGTGGCGTTGCGTATATCCATCCGGCGCTC GTCGGCCAATACCGTGGTAACCTTGGCGGTGGTATGTTTGACCACAACTATAACTGGTTC GACCCAGTAGGTAACACCAACAAACCAACTGCCTCAGGTGATCACGGCACCCACGTGATG GGGACAATAGTTGCCGCTCTACCTACCCAACCGGCGATGGGTGTGGCACCGCGAGCACGC TGGATCGCAGCCCGAGCCTGTGATACGCTCAACTGTACCAATAGCAATATCATTGCCGCA GCCCAATGGATGTTGGCTCCAACCGATCTCAACGGTAAAAATCCGCAACCGAGTCGTCGT CCGCATATCCTCAATAATTCATGGGCATTTAGCAGTGGTGGTAACCCGGTCTATACCGGT TATACGGCAGCGTGGCAAGCCGCCGGCATCTTCGTCGTCTTTGCTGCCGGTAACTCTGGC AATGCGACGTGTGGGACGATTACATCACCCGGTGATTATGCCGATGTGGTAGCAGTAGGG GCAACCGATCAAAATGATAAACTGACAAACTTTAGCGCTATCGGTCCAACAATTGATGGT CGGATCAAACCTGATCTGGCCGCGCCGGGACTGAGTATCTATTCAACTTCATCTGCGGGT GGCTACAAAACCCTCTCAGGTACTTCAATGGCAGCACCTCACGTGGCCGGTACGGTTGCC CTGCTCTGGTCGGCTAACCCACAGTTGATCGGTGATTATACTACCACCTACAACTACCTT ACCCAGACCGCAAAACCGATTACTAATGACCCACGGTTTATGAGTGCACTCTATAACGAC 
TGCCGTCCTGACACTGTTCCCAATAATATCTACGGTTATGGACGGCTCGATGCCTTTGCT GCGGTAGCCGCGGCTAAGGTTGATATTCCATGGCTGATTCTTTCCCCAACACCTACGGCA ATCCTAATGAGTAGTAGCAGTACGACACTGTCTATTACACTTGACGCCCGTAAAGTGCCT GGACCGGGTATCTACTCGGCACGTCTTTTGATCTACGCCAACAATCTGACCGACCCACCG CTGGCTGTACCAATAACGATGACTGTACCACAGCAACCTACACACGCGACGATTACCGGT ACAGTGACCGATAGTGAGACCGGTCGGCCATTACTGGCGACGATAATAACGACTGACGGT GTGCGCCTGACGACCAGCATTACCGGAACTTATAGCTTGACAGTGCCCGGCAGTTCTACC CAACACGTGACCGCTGCTGCCGGTGGCTTTGTTGCAAAAACCCAAACAATCACACCAAGC AATGGGAGCACGACAACCCTTAACTTTGCTCTTGACCCGATTCGCCCCCGCTTGACCACA TTACAAGATGTGATACCGGTTACCGTTGATTTTCAGCAAACCGTCACGCTCAATTTGTCG TTGCGTAATGATGGCAATGCCCCTCTCTCCTACACCGTCCAGATTGATAACGAGCCTTAT GGCGTCTGGCGAAGTGACGAACCGGATGGGCCGGGCGGTGGTTGGATCGATCCACCAACC GGTAGACAGGTGCTCAACTTGTATGATGATGAGAGTAGTGGTGCCCTCGATCTCGGCTTT GATTTTCCATTTGGCAGCACGTCTTACCGCAAAGTCTACATTGGAGCAAATGGGATTATC GCCTTCGCTCCCTTTACTTCCAGTTCGAACTACTTCACTCCATCATGCTTTCCATTATCT GAAACTACCTCGGCGGCGATTAGCCCACTTCACGTCGATTTTAATAGTCTTGGTGGCGGT GAAATCAGCTTTGCCCAGGTGAGCAGCGGCGCACTTATCACATGGGATGATGTGCCATTA TACCGTACAACTCGCCGGCTCAGTGTGCAAGCCCTCTTACAACCCAATGGTGTCATTCGC TTCCATTACCGGAATGTAGCCAATTTGCAGCCCACCGATCAGGCTACAATTGGTCTCCAG TTTGACGATCAAAGCCAGAACGTGGCTTGTGATGTCGGGGATGAGCTACCACTCGATCTG AGCGATGGATTGGTCATCGAGCTACGACCTCAGATCAATCCACGGGCATGGCTCAGTATT GAGTCCGGTGACAGTGGCACGCTAGCCGCTTCCAATCAGACGAATATCCCGCTCACTGCG CAGTGGGTCGCCCCAATGTATACGACCTCACAGGCACGGATACGGATTTACAGCAATGAT CCGCAGAAACCGGTTGCCACTGTACGTGTACAACTGAACGAAGGTACCCCTGCTCCCTAT CAAGTGCTCATTTTGCTAATATTCCGGTAA

$>$ pepJS2

ATGACATCCGCGCTGCGTTTTCGGCTTCTGCTGGGATTGCTCATCGTGCTGGGAATCGGG ACCGCCTGTGCCCTGCCCGCGGCGGTCCTGCCCACCCCCACGCCGGTACCGACCCTTCCC CCCACGGCGACCCCCGCGCCGCCGGTCCTGCCCACCGTCCCCCCAGAAGCATTCAACGCG CTGGAAGCCCAGGTGGAAGCGGTCTACGCGCAGGCCGCCCCTGCCGTCGTCAACATCACC GCCCGCATCGTCACCTACGACTTCTTCATGCAGCCCATCCCGCAGGAGGGGACCGGCTCC GGTTTCTTCTACGATGACCAGGGGCACATCGTCACCAACTATCACGTGGTGGAGAATGCC GAATCGGTGGTGGTGACGCTGGCCGACGGATGGTCGTTCCCGGCGGAGATTGTGGGGGTG GACCCCTCGTCGGACCTGGCGGTGATTCGCGTTCGGGCGGAGAATCTGCCGGCCCCTCTG CCCCTGGCGGACTCCAGCCAGTTGCGGGTGGGGCAGTTTGTCATCGCCATCGGCAGCCCT TTCGGGCAGGTGGGGACGATGACACTGGGGGTCATCAGCGCGCTGGGGCGGGTCATCCAG AGCCCCGACGGTCGCTTCATCGGCGAGGCCATCCAGACCGACGCGGCCATCAACCCCGGC AACTCCGGCGGGCCGCTGCTGGACCTGCAGGGGCGGGTGATCGGCGTCAACTCCCAGATC ATCAGCCCCAGTCAGGCATCGGCGGGCATCGGGTTTGCAGTCTCTTCCAACACGGTGCGG CGGGTGGTGCCGCATCTGATTGCGGAAGGACGGTATCCTCACCCCTGGCTGGGCGTCCAG GTCCTCTCCCTGACCCCGGAGTGGGTACAGGCCCTGCGGCGGGCCGGCATGGAAGTGCCG GTGGAGAAGGGACTGCTGGTGCTGAGCGTGGTCCGGGGCGGGCCCGCAGACCGGGCTGGC ATCCGGGGCGGAACTCAGGTCATCCGTATCGGGGGATACCGGATTCCGGTGGGCGGCGAC ATTATTACCGCGATCAACGGCCACCCGGTGCCGACCCTCCAGGAACTGAACGTCTACCTG GACTCGCAGACGCGGGTGGGGGAGACCGTGGAAGTGACCCTTTTCCGGGAAGGGCAGGAG ATGAAGGTGAACGTCACGCTGACGGAGAGACCCCAGTAA 


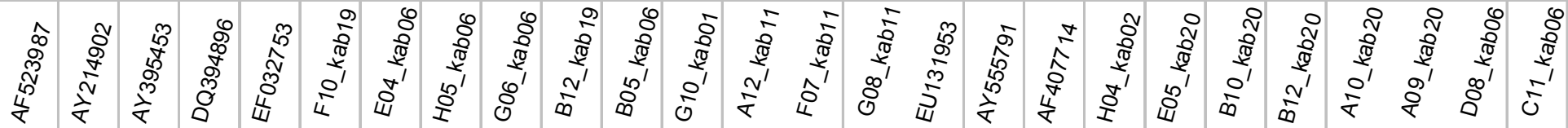

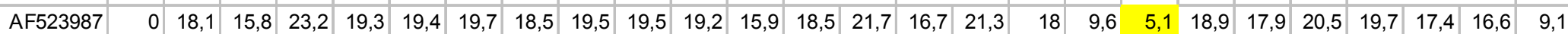

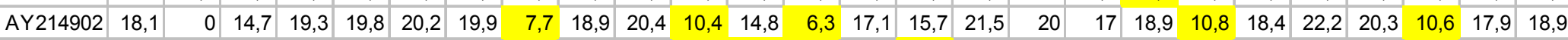

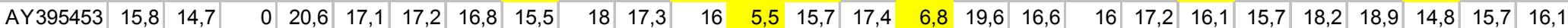

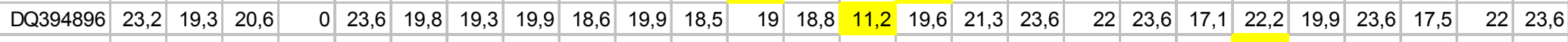

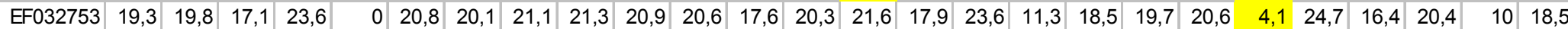

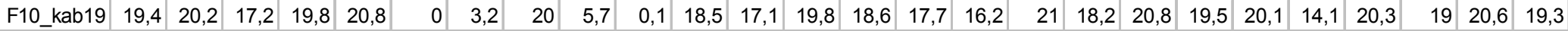

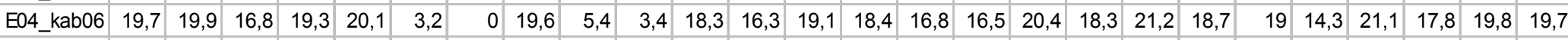

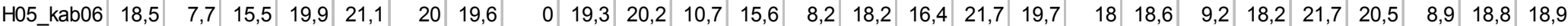

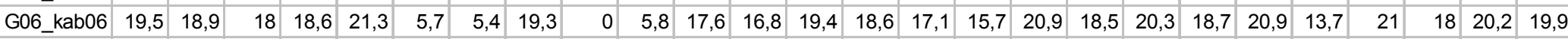

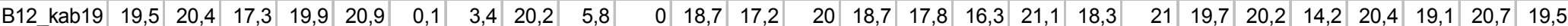

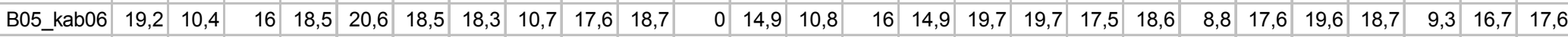

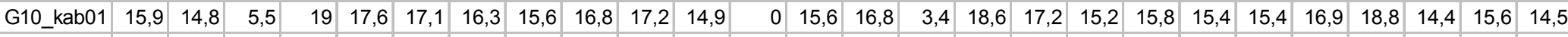

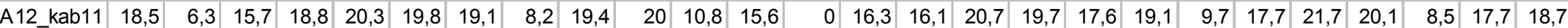

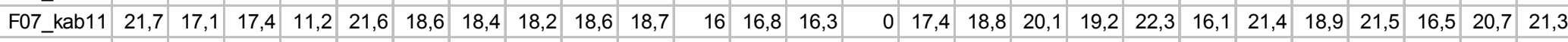

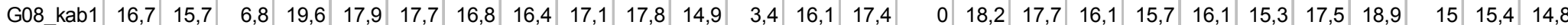

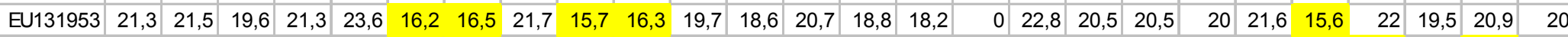

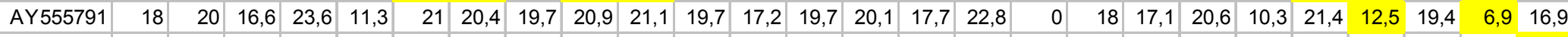
\begin{tabular}{|l|r|r|r|r|r|r|r|r|r|r|r|r|r|r|r|r|r|r|r|r|r|r|r|r|r|r|}
\hline AF407714 & 9,6 & 17 & 16 & 22 & 18,5 & 18,2 & 18,3 & 18 & 18,5 & 18,3 & 17,5 & 15,2 & 17,6 & 19,2 & 16,1 & 20,5 & 18 & 0 & 8,8 & 19,3 & 17,3 & 19 & 18,9 & 18,3 & 16,9 & 1,1 \\
\hline
\end{tabular}

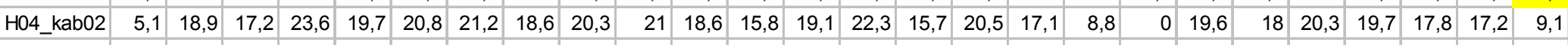
\begin{tabular}{|l|r|r|r|r|r|r|r|r|r|r|r|r|r|r|r|r|r|r|r|r|r|r|r|r|r|r|}
\hline E05 kab20 & 18,9 & 10,8 & 16,1 & 17,1 & 20,6 & 19,5 & 18,7 & 9,2 & 18,7 & 19,7 & 8,8 & 15,4 & 9,7 & 16,1 & 16,1 & 20 & 20,6 & 19,3 & 19,6 & 0 & 18,7 & 21 & 20,1 & 5,8 & 17,4 & 19,6 \\
\hline
\end{tabular}

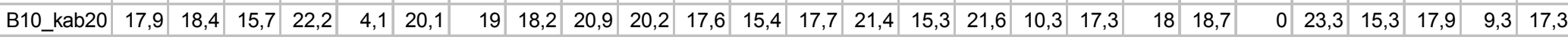

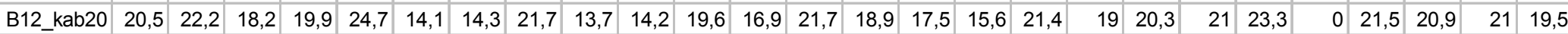

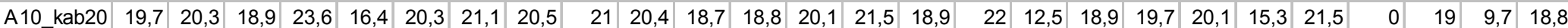

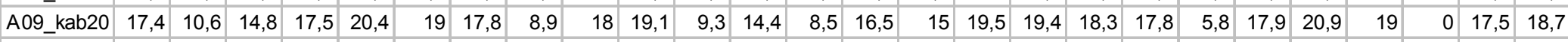

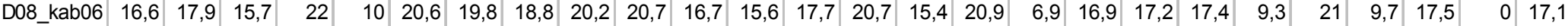

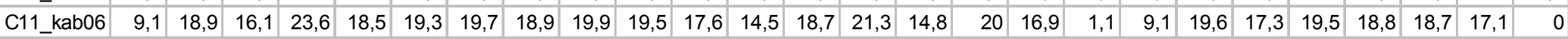

\section{Distance Matrix Acidobacteria}




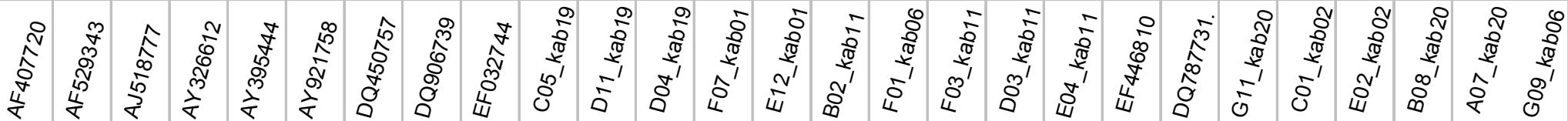

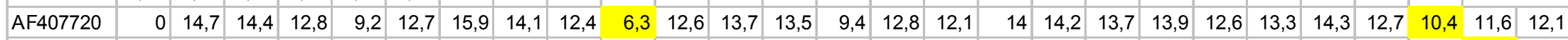

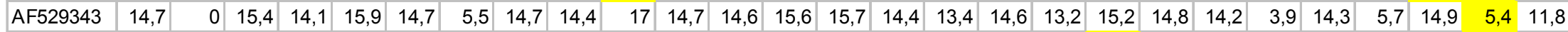

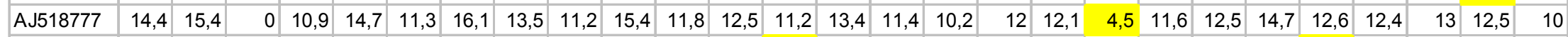

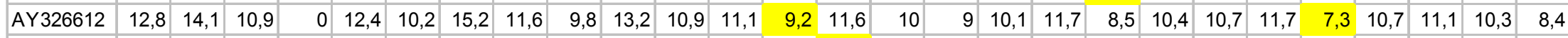

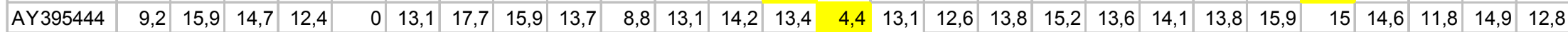

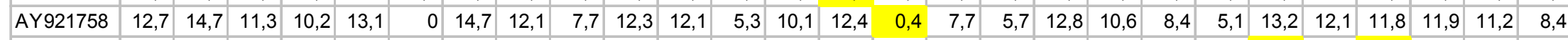

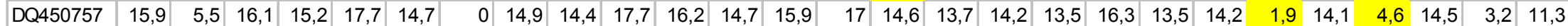

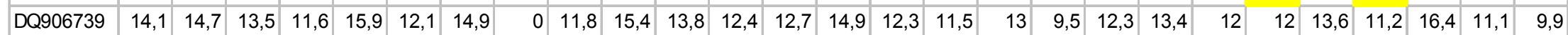

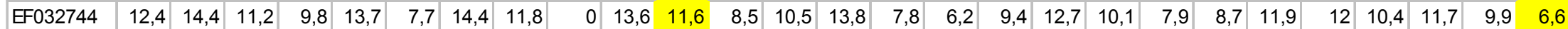
\begin{tabular}{|l|r|r|r|r|r|r|r|r|r|r|r|r|r|r|r|r|r|r|r|r|r|r|r|r|r|r|r|r|r|r|r|r|r|}
\hline C05_kab19 & 6,3 & 17 & 15,4 & 13,2 & 8,8 & 12,3 & 17,7 & 15,4 & 13,6 & 0 & 12,3 & 13,6 & 13,6 & 9 & 12,3 & 12,8 & 13,5 & 16,2 & 14,2 & 13,9 & 12,8 & 15,2 & 15 & 14,6 & 10,9 & 13,5 & 13 \\
\hline
\end{tabular}

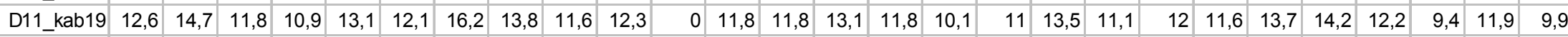

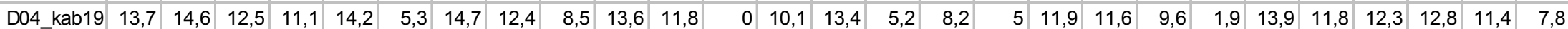

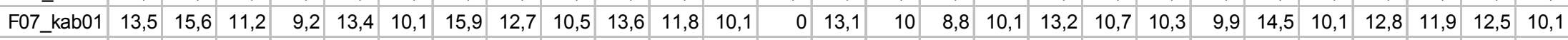

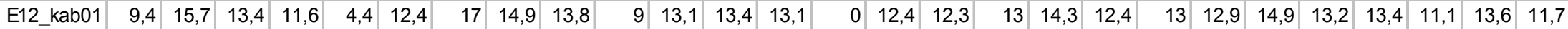

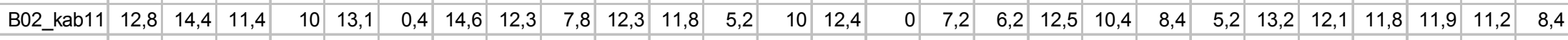

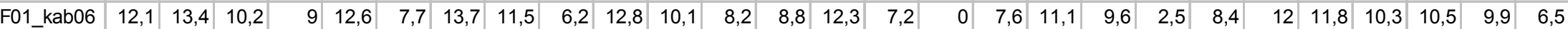

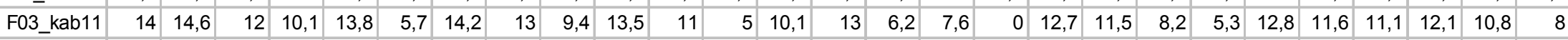
\begin{tabular}{|r|r|r|r|r|r|r|r|r|r|r|r|r|r|r|r|r|r|r|r|r|r|r|r|r|r|r|r|r|r|r|}
\hline D03_kab11 & 14,2 & 13,2 & 12,1 & 11,7 & 15,2 & 12,8 & 13,5 & 9,5 & 12,7 & 16,2 & 13,5 & 11,9 & 13,2 & 14,3 & 12,5 & 11,1 & 12,7 & 0 & 11,2 & 13,1 & 11,5 & 12,1 & 14 & 11,3 & 15,2 & 11,8 & 10,5 \\
\hline
\end{tabular}

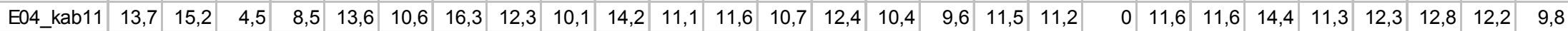

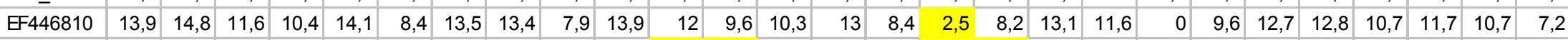

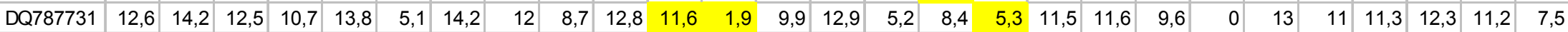

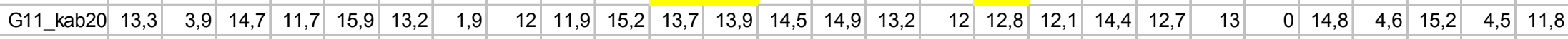
\begin{tabular}{|l|l|l|l|l|l|l|l|l|l|l|l|l|l|l|l|l|l|l|l|l|l|l|l|l|l|l|l|}
\hline C01 kab02 & 14,3 & 14,3 & 12,6 & 7,3 & 15 & 12,1 & 14,1 & 13,6 & 12 & 15 & 14,2 & 11,8 & 10,1 & 13,2 & 12,1 & 11,8 & 11,6 & 14 & 11,3 & 12,8 & 11 & 14,8 & 0 & 14,1 & 14,3 & 13,3 & 12,5 \\
\hline
\end{tabular}

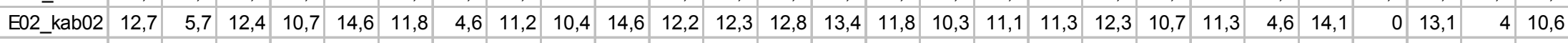

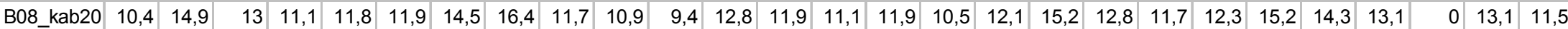

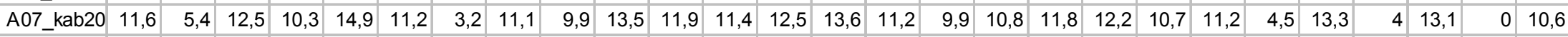

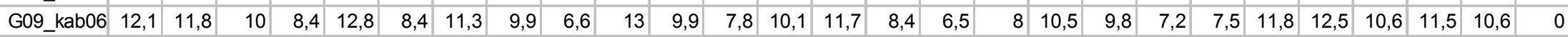

\section{Distance-Matrix Alpha-Proteobacteria unklassifiziert}




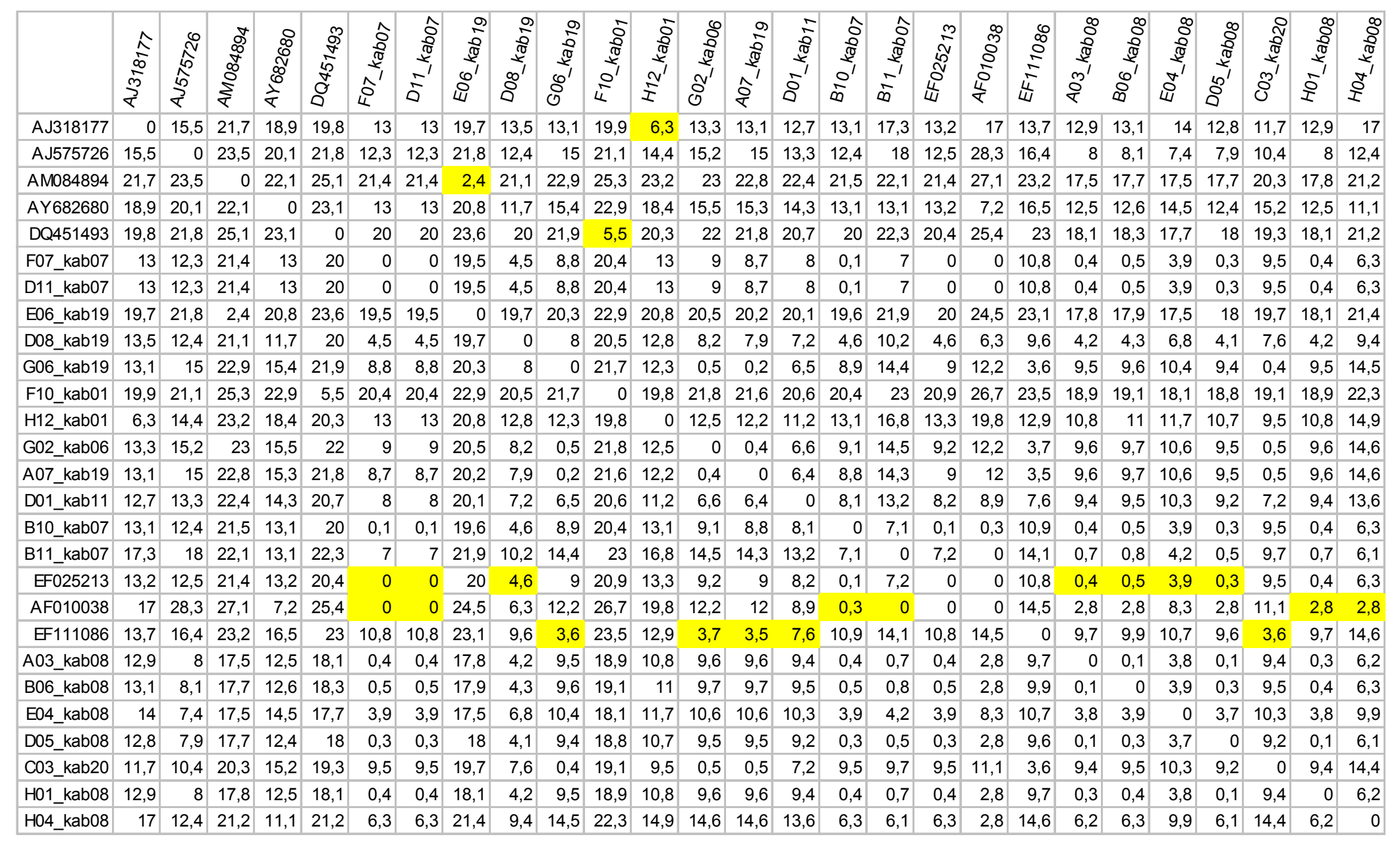

Distance Matrix Bacteroidetes 


\begin{tabular}{|c|c|c|c|c|c|c|c|c|c|c|c|c|c|c|c|c|c|c|c|c|c|}
\hline & 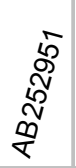 & 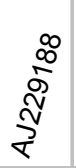 & $\begin{array}{c}\hat{D} \\
\frac{D}{5} \\
\frac{5}{7}\end{array}$ & 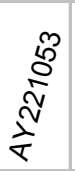 & $\begin{array}{l}\infty \\
8 \\
8 \\
8 \\
0 \\
0\end{array}$ & $\begin{array}{c}\infty \\
\infty \\
\varnothing \\
8 \\
8\end{array}$ & $\begin{array}{l}\text { m } \\
\text { के } \\
8 \\
8 \\
0 \\
0\end{array}$ & $\underset{\frac{\infty}{2}}{\stackrel{2}{\frac{0}{2}}}$ & 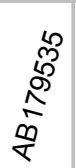 & 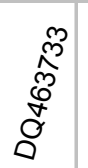 & $\begin{array}{l}\hat{N} \\
\hat{0} \\
\infty \\
\stackrel{0}{0} \\
\mathbb{u}\end{array}$ & 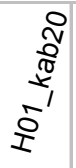 & 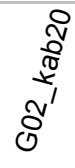 & 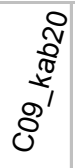 & 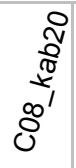 & 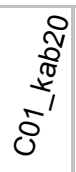 & 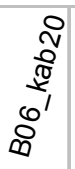 & 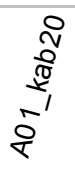 & 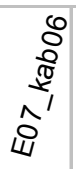 & 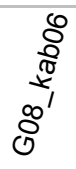 & $\frac{8}{\frac{8}{\pi}}$ \\
\hline AB252951 & 0 & 16,9 & 12,8 & 13,9 & 8,1 & 12,9 & 12,6 & 12,5 & 14,3 & 14,5 & 13,2 & 15,8 & 15 & 13,7 & 8,2 & 5,8 & 13,3 & 16,5 & 13,4 & 16,4 & 15,6 \\
\hline AJ229188 & 16,9 & 0 & 17,4 & 17,5 & 14,8 & 13,6 & 17,2 & 17,1 & 8,4 & 16,3 & 17,4 & 14,8 & 16,9 & 15,7 & 15 & 15 & 15,1 & 17,2 & 15 & 14,3 & 8,8 \\
\hline AJ519407 & 12,8 & 17,4 & 0 & 16,4 & 14,3 & 14,8 & 7,1 & 8,8 & 14,8 & 14,7 & 5,7 & 14,1 & 10,8 & 9,3 & 14,6 & 13,6 & 11,8 & 16,1 & 6,2 & 17,5 & 15,2 \\
\hline AY221053 & 13,9 & 17,5 & 16,4 & 0 & 9,2 & 14,7 & 16,8 & 17 & 16 & 18,8 & 16,7 & 18,4 & 16,7 & 15,9 & 9,3 & 8,7 & 15,9 & 19,5 & 16,3 & 19,2 & 17,1 \\
\hline DQ066981 & 8,1 & 14,8 & 14,3 & 9,2 & 0 & 10,1 & 14 & 13,1 & 12 & 15,1 & 13,8 & 14,7 & 14,3 & 13,7 & 6 & 3,7 & 12,3 & 15,8 & 12,8 & 15 & 14,4 \\
\hline DQ06 & 12,9 & 13,6 & 14,8 & 14,7 & 10,1 & 0 & 14,5 & 13,9 & 11,5 & 9,3 & 14,5 & 9,6 & 15,4 & 14,2 & 14,5 & 12,6 & 11 & 11 & 15,7 & 12,5 & 13,5 \\
\hline DQ066983 & 12,6 & 17,2 & 7,1 & 16,8 & 14 & 14,5 & 0 & 8,4 & 15,8 & 12,7 & 6,3 & 15,9 & 8,3 & 6,9 & 16,8 & 14,4 & 13,8 & 17,1 & 10,6 & 18,3 & 17,4 \\
\hline AB179529 & 12,5 & 17,1 & 8,8 & 17 & 13,1 & 13,9 & 8,4 & 0 & 14,3 & 14,5 & 9,3 & 15,7 & 12,5 & 11 & 14,9 & 12,7 & 13,7 & 16,9 & 5,3 & 18,1 & 17,2 \\
\hline AB179535 & 14,3 & 8,4 & 14,8 & 16 & 12 & 11,5 & 15,8 & 14,3 & 0 & 13,9 & 15 & 13 & 16 & 14,5 & 14,1 & 13,6 & 13,2 & 15,4 & 14,1 & 13,1 & 6,4 \\
\hline DQ463733 & 14,5 & 16,3 & 14,7 & 18,8 & 15,1 & 9,3 & 12,7 & 14,5 & 13,9 & 0 & 14 & 11,5 & 13,6 & 13,1 & 17,5 & 16,2 & 12,6 & 12,8 & 17 & 11,9 & 14,2 \\
\hline EF01 & 13,2 & 17,4 & 5,7 & 16,7 & 13,8 & 14,5 & 6,3 & 9,3 & 15 & 14 & 0 & 13,7 & 10,7 & 9,2 & 16,1 & 14,8 & 11,3 & 17,4 & 7,8 & 16,9 & 16,7 \\
\hline H01_kab20 & 15,8 & 14,8 & 14,1 & 18,4 & 14,7 & 9,6 & 15,9 & 15,7 & 13 & 11,5 & 13,7 & 0 & 15,9 & 14,6 & 15,7 & 15,2 & 3,4 & 5 & 14,3 & 10,2 & 13,6 \\
\hline G02_kab20 & 15 & 16,9 & 10,8 & 16,7 & 14,3 & 15,4 & 8,3 & 12,5 & 16 & 13,6 & 10,7 & 15,9 & 0 & 2 & 17,1 & 14,6 & 14,4 & 17 & 13,4 & 17 & 16 \\
\hline C09_kab20 & 13,7 & 15,7 & 9,3 & 15,9 & 13,7 & 14,2 & 6,9 & 11 & 14,5 & 13,1 & 9,2 & 14,6 & 2 & 0 & 14,8 & 14,1 & 13,1 & 15,8 & 11,8 & 16 & 14,7 \\
\hline C08_kab20 & 8,2 & 15 & 14,6 & 9,3 & 6 & 14,5 & 16,8 & 14,9 & 14,1 & 17,5 & 16,1 & 15,7 & 17,1 & 14,8 & 0 & 6,1 & 13,4 & 17 & 14,7 & 16,5 & 15 \\
\hline C01_kab20 & 5,8 & 15 & 13,6 & 8,7 & 3,7 & 12,6 & 14,4 & 12,7 & 13,6 & 16,2 & 14,8 & 15,2 & 14,6 & 14,1 & 6,1 & 0 & 11,8 & 16,3 & 13,5 & 15,9 & 14,8 \\
\hline B06_kab20 & 13,3 & 15,1 & 11,8 & 15,9 & 12,3 & 11 & 13,8 & 13,7 & 13,2 & 12,6 & 11,3 & 3,4 & 14,4 & 13,1 & 13,4 & 11,8 & 0 & 8,5 & 12,7 & 11,3 & 13,8 \\
\hline A01_kab20 & 16,5 & 17,2 & 16,1 & 19,5 & 15,8 & 11 & 17,1 & 16,9 & 15,4 & 12,8 & 17,4 & 5 & 17 & 15,8 & 17 & 16,3 & 8,5 & 0 & 16,3 & 12,2 & 15,7 \\
\hline E07_kab06 & 13,4 & 15 & 6,2 & 16,3 & 12,8 & 15,7 & 10,6 & 5,3 & 14,1 & 17 & 7,8 & 14,3 & 13,4 & 11,8 & 14,7 & 13,5 & 12,7 & 16,3 & 0 & 17,2 & 15,3 \\
\hline G08_kab06 & 16,4 & 14,3 & 17,5 & 19,2 & 15 & 12,5 & 18,3 & 18,1 & 13,1 & 11,9 & 16,9 & 10,2 & 17 & 16 & 16,5 & 15,9 & 11,3 & 12,2 & 17,2 & 0 & 10,9 \\
\hline G10_kab06 & 15,6 & 8,8 & 15,2 & 17,1 & 14,4 & 13,5 & 17,4 & 17,2 & 6,4 & 14,2 & 16,7 & 13,6 & 16 & 14,7 & 15 & 14,8 & 13,8 & 15,7 & 15,3 & 10,9 & 0 \\
\hline
\end{tabular}

\section{Distance Matrix Chlorobi}




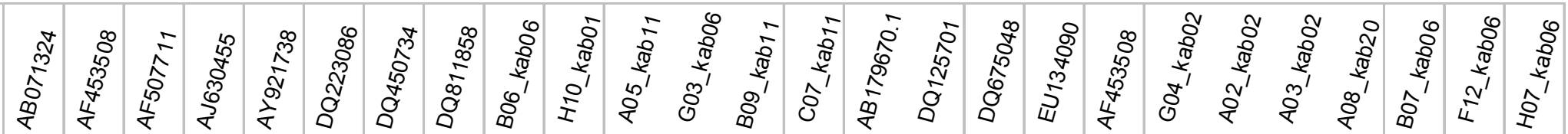

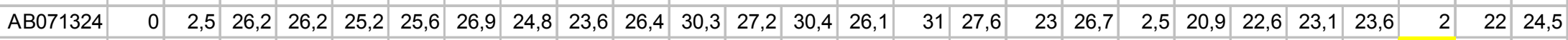

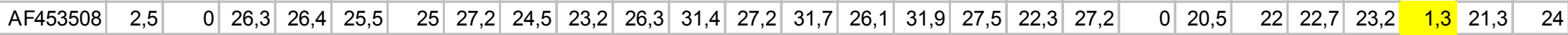

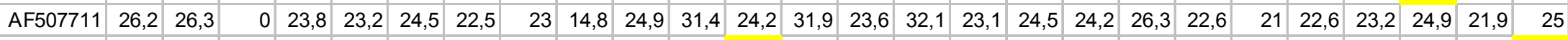

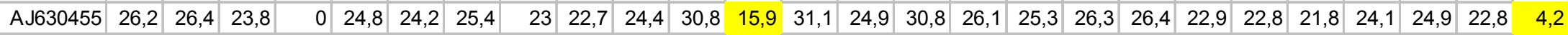

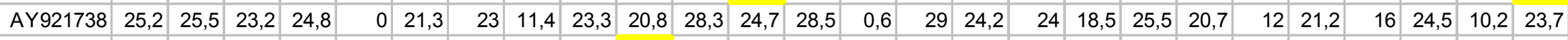

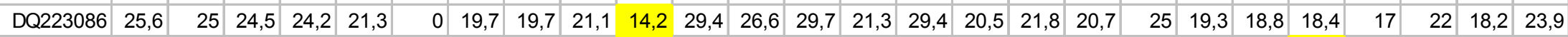

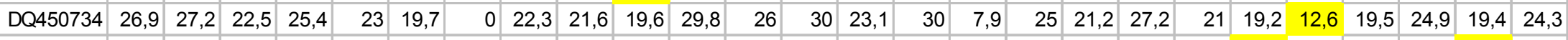

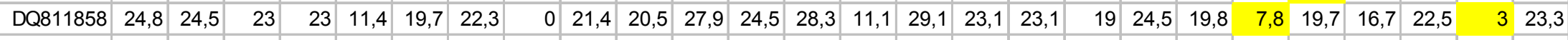

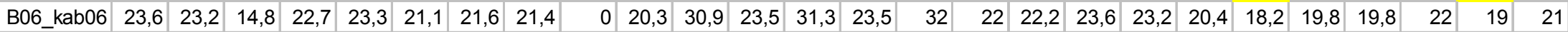

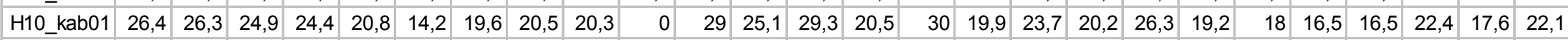

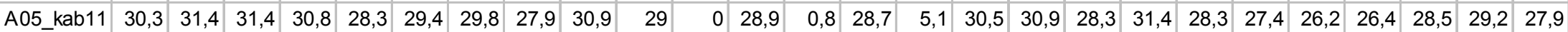

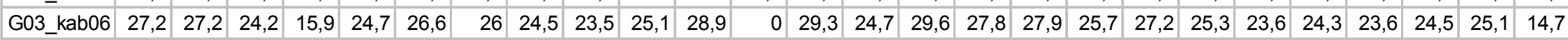

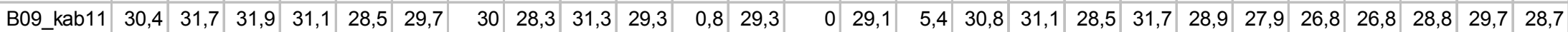

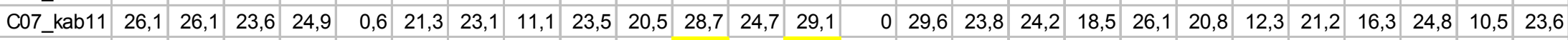

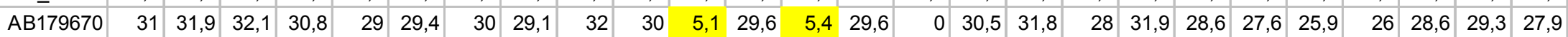

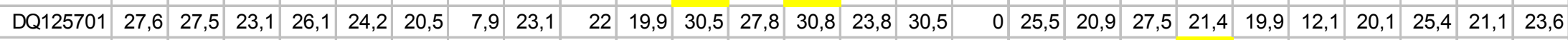

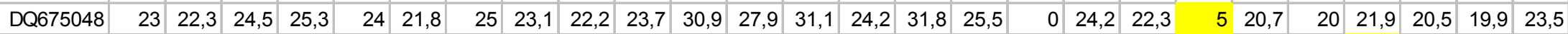

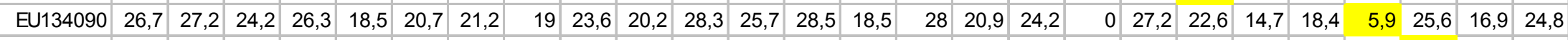

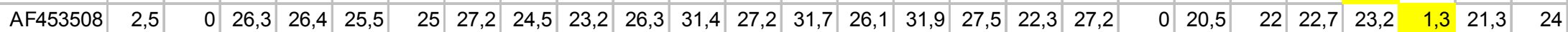

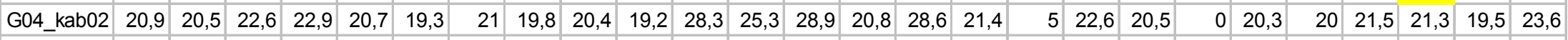

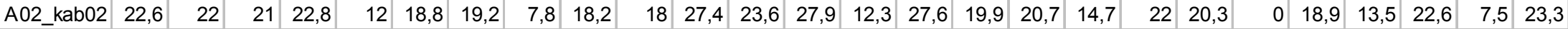

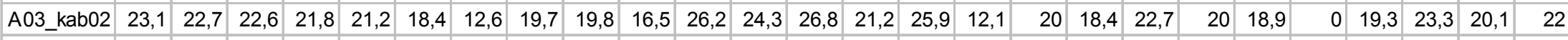

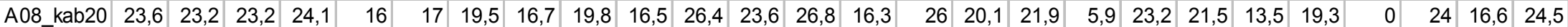

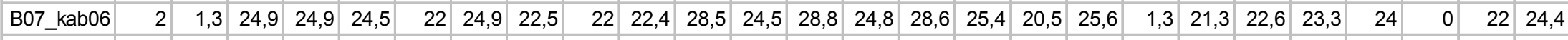

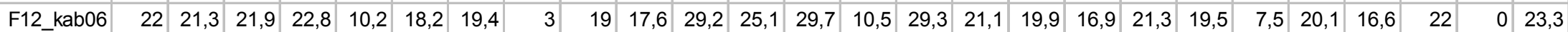

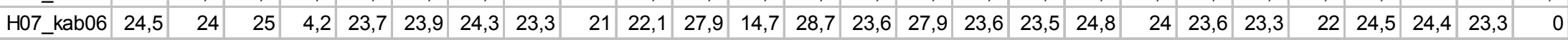

Distance Matrix Cyanobacteria, Thermotogae,Aquificae, Chloroflexi, OP11 


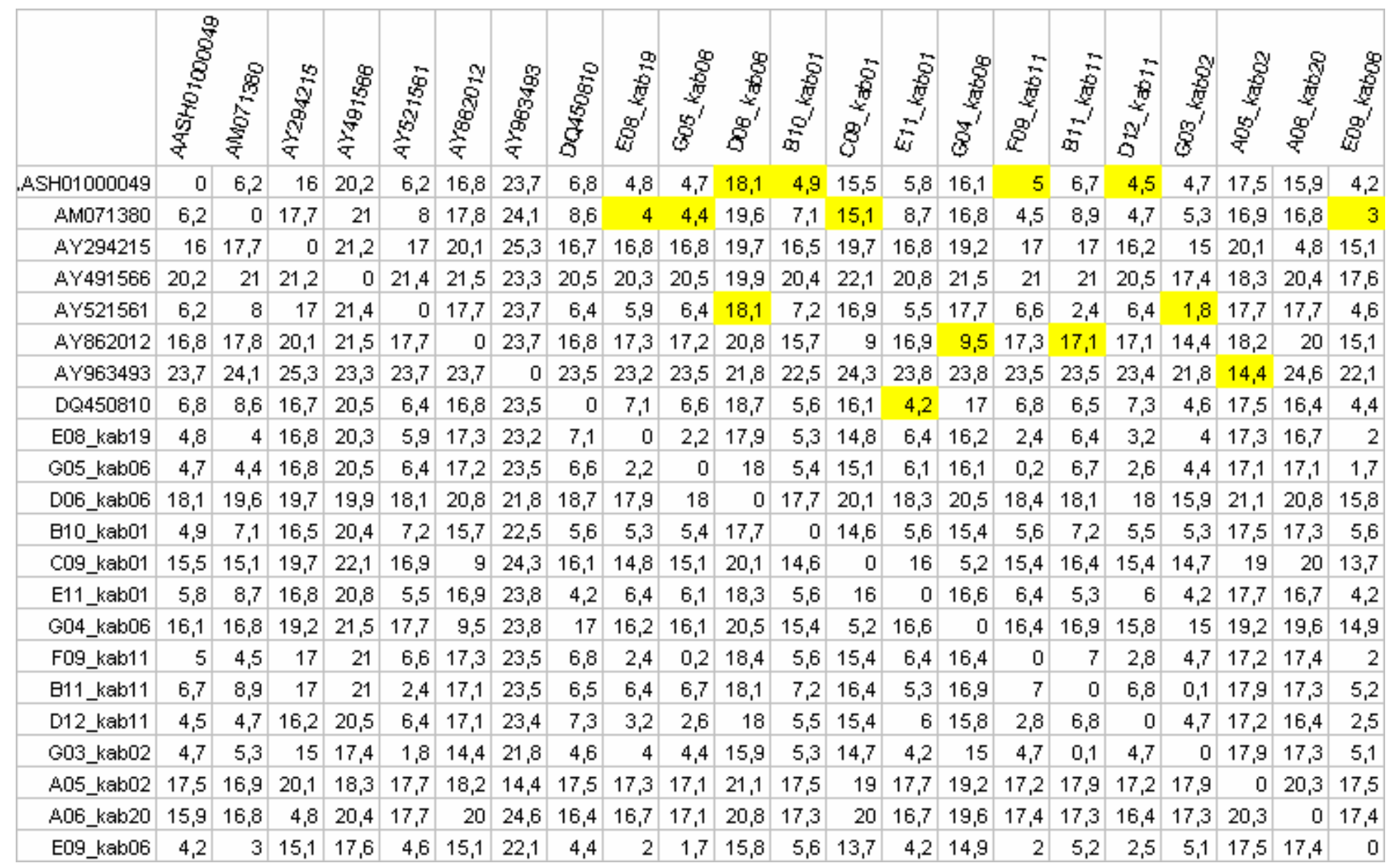

Distance Matrix Desulfovibtionales 


\begin{tabular}{|c|c|c|c|c|c|c|c|c|c|c|c|c|c|c|c|c|c|c|c|c|}
\hline & $\begin{array}{c}\stackrel{+}{\infty} \\
\stackrel{\infty}{\infty} \\
\frac{\infty}{\infty}\end{array}$ & 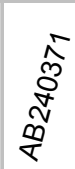 & 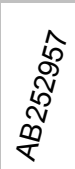 & 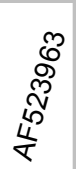 & 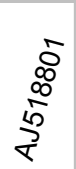 & $\begin{array}{l}\infty \\
\stackrel{\infty}{\infty} \\
\infty \\
\frac{\infty}{\infty}\end{array}$ & 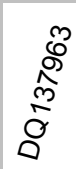 & 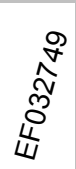 & $\underset{\frac{w}{w}}{\stackrel{2}{\frac{\pi}{\pi}}}$ & 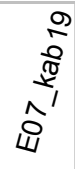 & 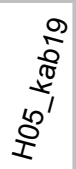 & $\frac{\frac{n}{\pi}}{\frac{\pi}{2}}$ & $\frac{\sqrt{\pi}}{\infty^{\infty}}$ & $\frac{\frac{\pi}{2}}{\frac{\pi}{2}}$ & $\frac{\frac{\pi}{\sigma^{\prime}}}{\frac{\pi}{\pi}}$ & 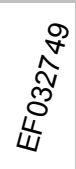 & 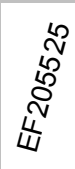 & 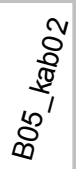 & 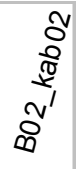 & 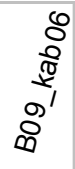 \\
\hline AB187 & 0 & 14 & 14 & 16,8 & 11,4 & 13,7 & 17 & 10,3 & 14,2 & 10,2 & 16,6 & 14,9 & 12,9 & 16,9 & 10,9 & 10,3 & 17,4 & 14 & 4,8 & 14,7 \\
\hline AB240371 & 14 & 0 & 12,8 & 14,3 & 12,8 & 12,4 & 17 & 10,9 & 12,3 & 10,6 & 15,2 & 11,5 & 11 & 14,9 & 12 & 10,9 & 16,4 & 6,2 & 11,4 & 16,1 \\
\hline AB25295 & 14 & 12,8 & 0 & 16 & 9,1 & 10,2 & 17,5 & 10,1 & 4,8 & 9,1 & 15,9 & 10 & 9,3 & 16,5 & 10,2 & 10,1 & 16 & 11,9 & 9,3 & 15,4 \\
\hline AF523963 & 16,8 & 14,3 & 16 & 0 & 15,4 & 15,2 & 20,2 & 15,2 & 16,5 & 14,5 & 14,3 & 16,7 & 15,5 & 4,2 & 14,6 & 15,2 & 14,6 & 14,4 & 14,4 & 16,3 \\
\hline AJ51 & 11,4 & 12,8 & 9,1 & 15,4 & 0 & 10,3 & 16,8 & 6,7 & 9,5 & 6,4 & 14,9 & 11,5 & 9,6 & 15,9 & 6,8 & 6,7 & 15,2 & 10,6 & 6,3 & 13,8 \\
\hline $\mathrm{AJ}$ & 3,7 & 12,4 & 10,2 & 15,2 & 10,3 & 0 & 16,8 & 11,3 & 11,4 & 10,9 & 15,9 & 10,6 & 6,2 & 15,6 & 9,8 & 1,3 & 16,2 & 1,6 & 8,2 & 15,2 \\
\hline DQ137963 & 17 & 17 & 17,5 & 20,2 & 16,8 & 16,8 & 0 & 17,2 & 18,2 & 17,3 & 18,9 & 12,4 & 16,8 & 19,9 & 17 & 17,2 & 19,2 & 15,6 & 14,2 & 16,3 \\
\hline EF03 & 0,3 & 10,9 & 10,1 & 15,2 & 6,7 & 11,3 & 17,2 & 0 & 10,6 & 2,5 & 14,7 & 11,8 & 9,8 & 15,5 & 6,7 & 0 & 15,7 & 11,5 & 5,8 & 14,3 \\
\hline E12_kab19 & 14,2 & 12,3 & 4,8 & 16,5 & 9,5 & 11,4 & 18,2 & 10,6 & 0 & 9,8 & 15,7 & 10,5 & 9,4 & 16 & 11,4 & 10,6 & 15,8 & 11,7 & 9,7 & 16,1 \\
\hline E07_kab19 & 10,2 & 10,6 & 9,1 & 14,5 & 6,4 & 10,9 & 17,3 & 2,5 & 9,8 & 0 & 14,5 & 11,6 & 9,3 & 14,6 & 6,1 & 2,5 & 15,8 & 11 & 5,5 & 14 \\
\hline H05_kab19 & 16,6 & 15,2 & 15,9 & 14,3 & 14,9 & 15,9 & 18,9 & 14,7 & 15,7 & 14,5 & 0 & 15,3 & 15,4 & 14 & 14,9 & 14,7 & 5,2 & 14,4 & 12,8 & 15,6 \\
\hline E11_kab11 & 14,9 & 11,5 & 10 & 16,7 & 11,5 & 10,6 & 12,4 & 11,8 & 10,5 & 11,6 & 15,3 & 0 & 9,7 & 16,4 & 11,3 & 11,8 & 16,1 & 12,4 & 11,6 & 16,1 \\
\hline F08_k & 12,9 & 11 & 9,3 & 15,5 & 9,6 & 6,2 & 16,8 & 9,8 & 9,4 & 9,3 & 15,4 & 9,7 & 0 & 15,8 & 9,7 & 9,8 & 16,2 & 10,8 & 7,6 & 14,9 \\
\hline A09_kab19 & 16,9 & 14,9 & 16,5 & 4,2 & 15,9 & 15,6 & 19,9 & 15,5 & 16 & 14,6 & 14 & 16,4 & 15,8 & 0 & 14,9 & 15,5 & 15,3 & 14,9 & 14,9 & 15,8 \\
\hline A10_kab19 & 10,9 & 12 & 10,2 & 14,6 & 6,8 & 9,8 & 17 & 6,7 & 11,4 & 6,1 & 14,9 & 11,3 & 9,7 & 14,9 & 0 & 6,7 & 15,7 & 12,3 & 5,2 & 13,1 \\
\hline EF03? & 10,3 & 10,9 & 10,1 & 15,2 & 6,7 & 11,3 & 17,2 & 0 & 10,6 & 2,5 & 14,7 & 11,8 & 9,8 & 15,5 & 6,7 & 0 & 15,7 & 11,5 & 5,8 & 14,3 \\
\hline EF205525 & 17,4 & 16,4 & 16 & 14,6 & 15,2 & 16,2 & 19,2 & 15,7 & 15,8 & 15,8 & 5,2 & 16,1 & 16,2 & 15,3 & 15,7 & 15,7 & 0 & 15,1 & 14,4 & 16,6 \\
\hline B05_kab02 & 14 & 6,2 & 11,9 & 14,4 & 10,6 & 11,6 & 15,6 & 11,5 & 11,7 & 11 & 14,4 & 12,4 & 10,8 & 14,9 & 12,3 & 11,5 & 15,1 & 0 & 12,7 & 16,8 \\
\hline B02_kab02 & 4,8 & 11,4 & 9,3 & 14,4 & 6,3 & 8,2 & 14,2 & 5,8 & 9,7 & 5,5 & 12,8 & 11,6 & 7,6 & 14,9 & 5,2 & 5,8 & 14,4 & 12,7 & 0 & 15,2 \\
\hline B09_kab06 & 14,7 & 16,1 & 15,4 & 16,3 & 13,8 & 15,2 & 16,3 & 14,3 & 16,1 & 14 & 15,6 & 16,1 & 14,9 & 15,8 & 13,1 & 14,3 & 16,6 & 16,8 & 15,2 & \\
\hline
\end{tabular}

Distance Matrix Delta-Proteobacteria unklassifiziert 


\begin{tabular}{|c|c|c|c|c|c|c|c|c|c|c|c|c|c|c|c|c|c|c|c|c|c|}
\hline & 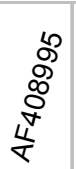 & $\begin{array}{c}\hat{6} \\
\hat{\infty} \\
\frac{\infty}{5} \\
\vec{T}\end{array}$ & 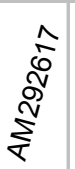 & 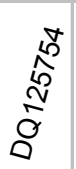 & 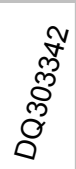 & 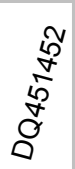 & $\begin{array}{c}\hat{\hat{D}} \\
\hat{\operatorname{\rho }}\end{array}$ & 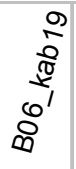 & 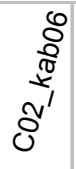 & $\frac{\sqrt{0}}{\pi^{\frac{\pi}{0}}}$ & 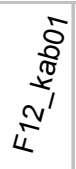 & 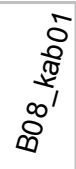 & $\frac{T^{\frac{\pi}{d}}}{i^{\prime}}$ & 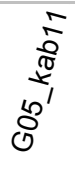 & 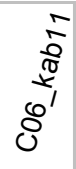 & $\frac{\sqrt[T]{\infty}}{\hat{\mathbb{D}}^{\prime}}$ & $\frac{i}{\frac{\pi}{\pi}}$ & $\begin{array}{c}\hat{\hat{N}} \\
\hat{0} \\
\hat{0} \\
\hat{\sigma}\end{array}$ & 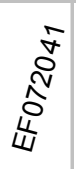 & $\begin{array}{l}\stackrel{i}{N} \\
\stackrel{\infty}{\infty} \\
\stackrel{\infty}{<}\end{array}$ & 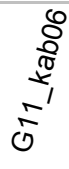 \\
\hline & 0 & 8,9 & 0,4 & 7,7 & 0,8 & 9,3 & 101 & 8,4 & 6,5 & 7,8 & 0,9 & 8,1 & 9,5 & 3,2 & 6,7 & 0,3 & 0,9 & 9,9 & 7,5 & & 13 \\
\hline ונה & & 0 & 9 & 5,8 & 8,8 & & 8,6 & 3,6 & & 5,1 & 8, & & 8,3 & 9 & & 0, & & & & 11,2 & 11,2 \\
\hline & & 0 & & & 0,8 & & 0,5 & $\sqrt{3}$ & & 8,3 & & & 9,8 & 3,2 & 7,2 & & 0 , & & & & 3,2 \\
\hline & & 5,8 & & & 7 & & & 5,7 & 4,4 & 4,6 & 7,7 & & & 7, & & & 7, & & & & 0,4 \\
\hline & & 8,8 & 0 & 76 & 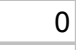 & 9,2 & 0,1 & 8,2 & 6,4 & 7,6 & 1 & 7,8 & 9,4 & 3,1 & 6,5 & 0,8 & 0, & 9,5 & 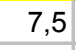 & 0 , & 13 \\
\hline & & 8,6 & & & 9,2 & & & & & 9,2 & & & 5,2 & & & & & & & & 4,1 \\
\hline$\times 97$ & & 8,6 & 0,5 & 9,6 & 0,1 & 4,6 & 0 & 8,6 & 9,3 & 9,5 & 10,3 & 1 & 4 & 0,2 & 9,1 & 10 & 0,1 & 3,3 & 9 & 10,7 & 14,3 \\
\hline & & 3,6 & & & 8 & & 8,6 & 0 & 6,4 & & & & 8,3 & 8,2 & 4,4 & 8,1 & & & & & 10,4 \\
\hline $\mathrm{CO}$ & & 7 & 7 & & 6,4 & & 9,3 & 6,4 & 0 & 4,6 & 6,2 & 5,8 & 9,3 & 6,1 & 4,7 & & 6, & 8,9 & & & 11,6 \\
\hline G11_ & 7,8 & 5,1 & & 4, & 7,6 & 9,2 & 9,5 & 6 & 4,6 & 0 & 7,3 & 4,8 & 9,1 & 7,9 & 5,8 & 7,6 & 7, & $y$ & 4,8 & 10, & 10 \\
\hline & & & & & & & & 8 & & 7,3 & & & & & 6,4 & & & & & & 13,2 \\
\hline & & 5,1 & & & 7,8 & 9,4 & 01 & 4,4 & 5,8 & 4,8 & 7,5 & & 9.3 & 8,2 & 4 & & & 9,6 & & & 10,3 \\
\hline & & 8, & & & & & & 8 & 9,3 & , 1 & 9 & & & 8,8 & 8,5 & & & & & & 4,1 \\
\hline & & & & & & & 10,2 & 8,2 & & 7,9 & & & & & 6,6 & & & & & & 13,8 \\
\hline $\mathrm{C} 06$ & & 5 & 7,2 & & 6,5 & 8,8 & 9,1 & 4,4 & 4,7 & 5,8 & 6,4 & & 85 & 6,6 & & 63 & & 8,9 & & 9,1 & 11,2 \\
\hline & & & & & 0 , & & 10 & 8,1 & 6,1 & 7,6 & 0, & & & 0,1 & 0,0 & & 0,8 & & & & 13,1 \\
\hline D07_ & & & & & & 9,5 & 101 & 8 & & 7,5 & & & & 2,7 & 64 & & & 9,7 & & & 13,2 \\
\hline & & 8,3 & & & 9 & 0 & 3 & 8,5 & 8,9 & 9 & 9 , & 9,6 & & 8,8 & 8,9 & 9,6 & 9, & 0 & 9,6 & 10,9 & 13,9 \\
\hline & & & & & & & & 6,6 & 0,7 & 4,8 & & & 9,7 & 7,4 & 5,4 & 7,6 & 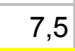 & 9,6 & &, 0 & 8,5 \\
\hline & & & & & & & & & 8,1 & 10,6 & & & & & 9,1 & & & & & & 9,5 \\
\hline G11_kab06 & 13 & 11,2 & 3,2 & 10,4 & 13 & 14,1 & 14,3 & 10,4 & 11,6 & 10 & 13,2 & 10,3 & 14,1 & 13,8 & 11,2 & 13,1 & 13,2 & 13,9 & 8,5 & 9,5 & \\
\hline
\end{tabular}

\section{Distance Matrix Rhizobiales}




\begin{tabular}{|c|c|c|c|c|c|c|c|c|c|c|c|c|c|c|c|c|c|c|c|c|c|c|c|c|c|c|}
\hline & 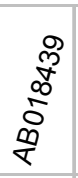 & 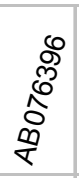 & 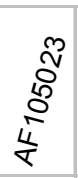 & 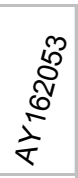 & 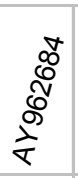 & 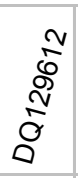 & 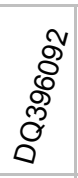 & 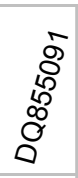 & 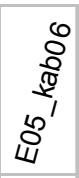 & 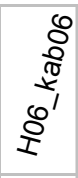 & 离 & 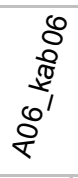 & 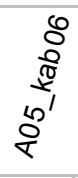 & 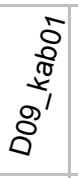 & 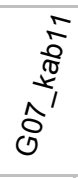 & $\frac{\sqrt{0}}{\frac{\pi}{2}}$ & 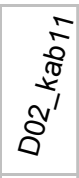 & 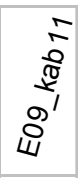 & $\overbrace{}^{\frac{N}{\pi}}$ & 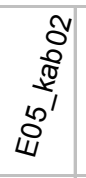 & 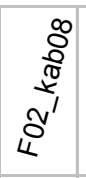 & 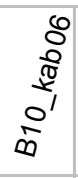 & 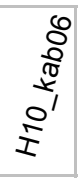 & 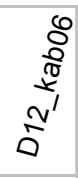 & 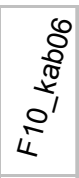 & 要 \\
\hline & 0 & 6,8 & 3,2 & 2,8 & 1,7 & 2,7 & 13,9 & 3,2 & 6,1 & 2,8 & 1,8 & 2,9 & 3,1 & 3,2 & 3,2 & 3 & 1,9 & 3,1 & 1,8 & 14,7 & 3,4 & 0,8 & 1,5 & 0,8 & 0,7 & \\
\hline & 68 & c & 7 & & & & & & & & & & & & & 6,8 & & & & & & & & & & \\
\hline & & 7 & c & & & 3,3 & 14 & 0,9 & & & & & 0, & & 0,6 & 3,3 & 3,8 & 0,7 & & & & & & & & \\
\hline & & 6,5 & 3,2 & & 4, & & 14 & & & & & & 2, & & & 0,2 & 4, & & & 1 & & & & & & \\
\hline & & 7,6 & 3,8 & 4,1 & & 4,3 & 13,6 & 3,8 & & 4,2 & 0. & 4,2 & 3,7 & 3,8 & 3,8 & 4,3 & 0,3 & & & & & & & & & \\
\hline & & 7,1 & 3, & & 4,3 & & & 3,7 & 6,3 & & 4,2 & 3,6 & 3,5 & 3,4 & 3,4 & 3,6 & 4,8 & 3,4 & 4,1 & 14,3 & 4, & & & & 3, & \\
\hline & & 4,3 & 14,5 & 14 & 13,6 & 3,8 & 0 & 4,8 &, 7 &, 9 &, 2 & 15,4 & 15,4 & 14,8 & 14,8 & 14,1 & 13,8 & 14,7 & 13,2 & 16,3 & 14,8 & 4,8 & 4,8 & 4,8 & $4, I$ & \\
\hline & & 7, & 0,9 & 3 & & & 14,8 & & & & & 3,3 & , & 0,6 & 0,0 & 2,9 & & & 3 & $4, \mathrm{~S}$ & & & & & & \\
\hline & & 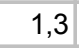 & 6,4 & & & &, 7 & 6,4 & & & & & & & & 0,1 & & & & 72 & & & & & & \\
\hline & & & & & & & & & & & & & & & & & & & & 13, & & & & & & \\
\hline & & & & & & & & & & & & & & & & & & & & $14, \bar{c}$ & & & & & & \\
\hline & & & & & & & & & & & & & & & & & & & & 3, & & & & & & \\
\hline & & & & & & & & & & & & & & & & & & & & & & & & & & \\
\hline & & 6 , & & & & & & & & & & & & & & & & & & & & & & & & \\
\hline & 3,2 & 7 & & & & & & & & & & & & & & 2,8 & & & & 10 & & & & & & \\
\hline & ? & 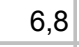 & 3 & & & & & & & & & & & & & & 4, & & & $13, \varepsilon$ & & & & & & \\
\hline & & & & & & & & & & & & & & & & & & & & & & & & & & \\
\hline & & & & & & & & & & & & & & & 3 & & & & & 15 & & & & & & \\
\hline & & & & & & & & & & & & & & & & & & & 0 & 14,8 & & & & & & \\
\hline & 7 & 4 & 14,8 & 3,6 & 4,8 & 14,3 & 16,3 & 14,9 & & 3,6 & 4,8 & 13,8 & $\begin{array}{l}4,7 \\
\end{array}$ & & 15 & 13,8 & & 5 & 14,8 & 0 & 4,4 & 15 & 4,7 & & 4,8 & 15 \\
\hline & & & 3 & & & & & & & & & & 3,5 & & & 3,1 & 4,2 & & 4 & 14,4 & & 4,2 & 3,5 & & 4 & \\
\hline & & & & & & & & & & & & & & & & 2,4 & 0,3 & & & 15 & & & & & & \\
\hline & & & & & & & & & & & & & & & & & & & & 14, & & & & & & \\
\hline & & & & & & & & & & & & & & & & & & & & 10 & & & & & & \\
\hline & & & & & & & & & & & & & & & & & & & & & & & & & & \\
\hline & & & & & & & & & & & & & & & & & & & & 15,1 & 1,3 & & & & 0,3 & \\
\hline
\end{tabular}

\section{Distance Matrix Alpha-Proteobacteria Sphingomonadales}




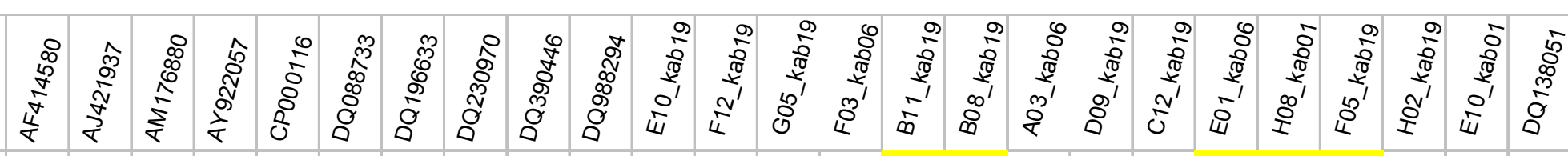

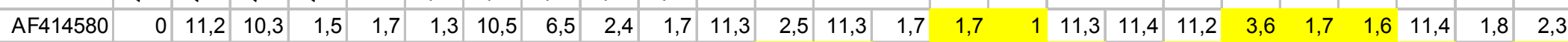

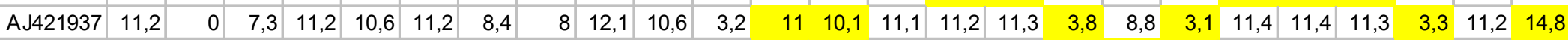

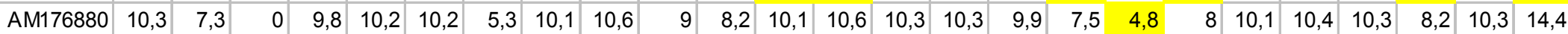

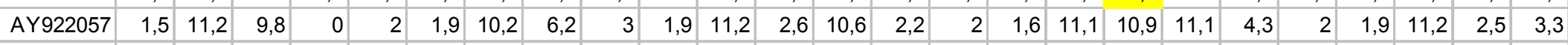
\begin{tabular}{|l|r|r|r|r|r|r|r|r|r|r|r|r|r|r|r|r|r|r|r|r|r|r|r|r|r|r|r|r|r|}
\hline CP00116 & 1,7 & 10,6 & 10,2 & 2 & 0 & 1,9 & 10,2 & 6,1 & 3,3 & 2,5 & 11,1 & 1,9 & 10,3 & 2 & 1,8 & 1,5 & 11,3 & 10,9 & 10,7 & 4,5 & 1,8 & 1,8 & 10,9 & 2,3 & 3,8 \\
\hline
\end{tabular}

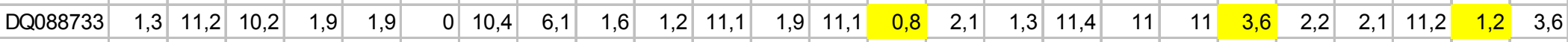

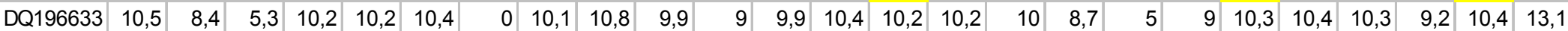

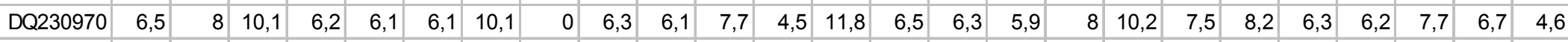

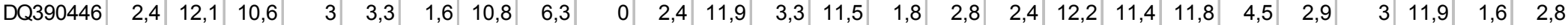

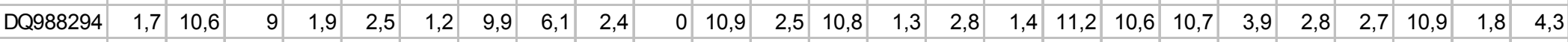

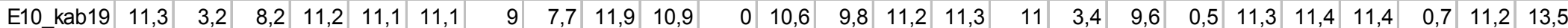

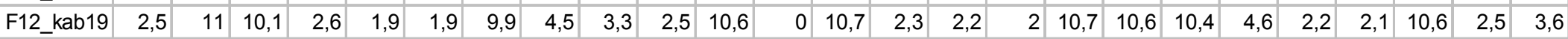

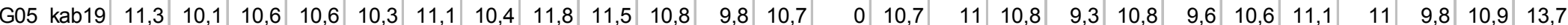

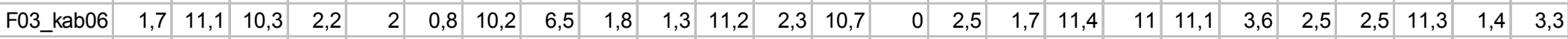
\begin{tabular}{|r|r|r|r|r|r|r|r|r|r|r|r|r|r|r|r|r|r|r|r|r|r|r|r|r|r|}
\hline B11 kab19 & 1,7 & 11,2 & 10,3 & 2 & 1,8 & 2,1 & 10,2 & 6,3 & 2,8 & 2,8 & 11,3 & 2,2 & 11 & 2,5 & 0 & 1,8 & 11,2 & 11 & 11,2 & 4,2 & 0,3 & 0,3 & 11,4 & 2,5 & 2,1 \\
\hline
\end{tabular}

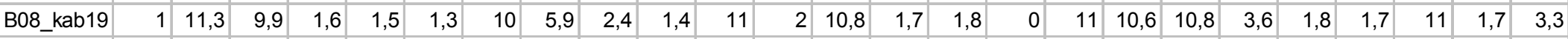

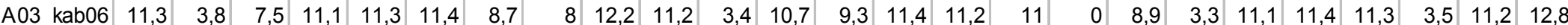

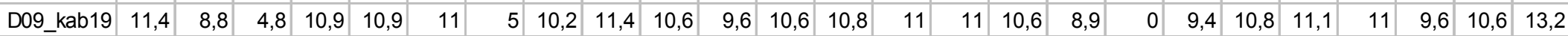

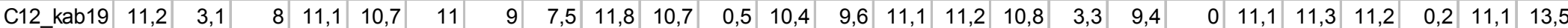

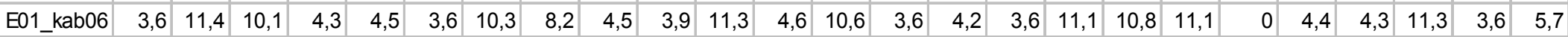

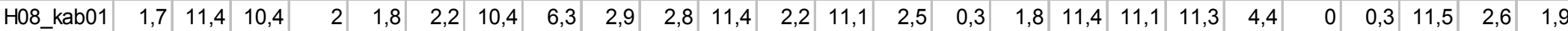

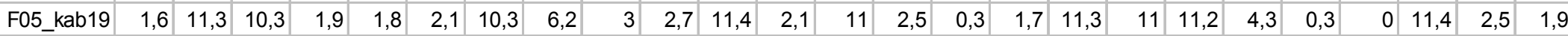

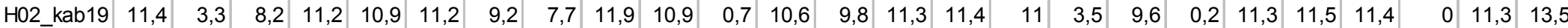

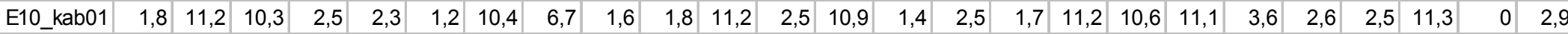

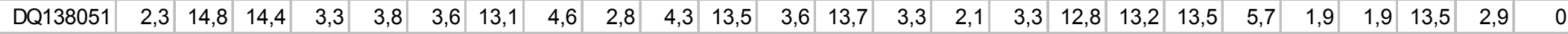

Distance Matrix Beta-Proteobacteria: Nitrosomonadales, Burkholderiales 


\begin{tabular}{|c|c|c|c|c|c|c|c|c|c|c|c|c|c|c|c|c|c|c|c|c|}
\hline & 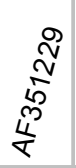 & $\frac{\frac{8}{2}}{\infty}$ & $\begin{array}{c}\frac{0}{6} \\
\hat{5} \\
\hat{\sigma}\end{array}$ & 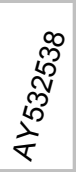 & 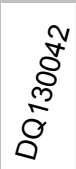 & 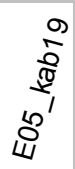 & 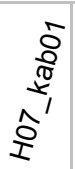 & 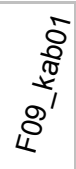 & 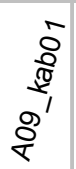 & 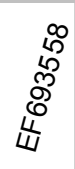 & $\begin{array}{l}0 \\
\frac{6}{6} \\
6 \\
8 \\
\sum^{2}\end{array}$ & 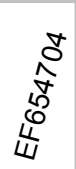 & 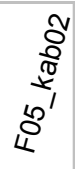 & 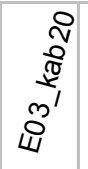 & 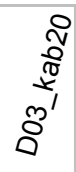 & $\frac{\frac{d}{\mathbb{W}}}{i^{\prime}}$ & 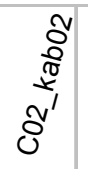 & 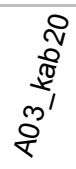 & 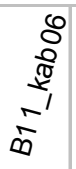 & 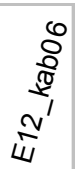 \\
\hline AF351229 & 0 & 9,5 & 8,3 & 9,2 & 10,7 & 8,2 & 8,9 & 9,8 & 9,2 & 11,3 & 9,3 & 9 & 9,4 & 7,4 & 9,9 & 15,4 & 5,1 & 5,6 & 7 & 6,9 \\
\hline AY118150 & 9,5 & 0 & 7,7 & 8,8 & 11,3 & 7,7 & 9,3 & 3,7 & 1,6 & 12,1 & 2,4 & 1,3 & 2,6 & 2,3 & 9,2 & 10,6 & 5,5 & 6,2 & 3 & 3 \\
\hline AY171616 & 8,3 & 7,7 & 0 & 9 & 10,4 & 5,4 & 9,2 & 9,2 & 8,4 & 12 & 8,6 & 8,2 & 8,3 & 8,1 & 10,5 & 15,3 & 6,9 & 7,6 & 7,9 & 7,8 \\
\hline AY532538 & 9,2 & 8,8 & 9 & 0 & 10 & 8,4 & 7,4 & 10,4 & 9,2 & 9,6 & 9,5 & 8,9 & 10 & 9,8 & 10,3 & 17,5 & 8,6 & 9 & 9,8 & 9,7 \\
\hline DQ130042 & 10,7 & 11,3 & 10,4 & 10 & 0 & 10,8 & 8,7 & 11,6 & 11,8 & 11,5 & 11,9 & 11,5 & 12,9 & 12,2 & 6 & 17 & 10 & 10,3 & 11,2 & 11,1 \\
\hline & 8,2 & 7,7 & 5,4 & 8,4 & 10,8 & 0 & 10,3 & 7,6 & 7,9 & & 8,2 & 7,6 & 7,2 & 6,8 & 10,4 & 15 & 7 & 7,3 & 6,4 & 6,3 \\
\hline H07_kab01 & 8,9 & 9,3 & 9,2 & 7,4 & 8,7 & 10,3 & 0 & 10,2 & 9,8 & 1,8 & 9,5 & 9,4 & 10,2 & 10,2 & 9,9 & 15,2 & 8,6 & 9,3 & 10,3 & 10,2 \\
\hline F09_kab01 & 9,8 & 3,7 & 9,2 & 10,4 & 11,6 & 7,6 & 10,2 & 0 & 3,2 & 12,8 & 2,9 & 2,7 & 3,1 & 1,7 & 9,5 & 10,7 & 6,6 & 7,9 & 0,3 & 0,3 \\
\hline A09_kab01 & 9,2 & 1,6 & 8,4 & 9,2 & 11,8 & 7,9 & 9,8 & 3,2 & 0 & 12,8 & 2,1 & 0,7 & 2,9 & 0,5 & 9,5 & 10,5 & 6,4 & 7,2 & 1,4 & 1,4 \\
\hline EF693558 & 11,3 & 12,1 & 12 & 9,6 & 11,5 & 14 & 1,8 & 12,8 & 12,8 & 0 & 11,8 & 12,4 & 11 & 11,4 & 11,2 & 18,8 & 8,8 & 9,6 & 10,7 & 10,5 \\
\hline AM086156 & 9,3 & 2,4 & 8,6 & 9,5 & 11,9 & 8,2 & 9,5 & 2,9 & 2,1 & 11,8 & 0 & 1,8 & 2,5 & 2,5 & 9,8 & 10,9 & 7,5 & 8,7 & 1,3 & 1,3 \\
\hline EF654704 & 9 & 1,3 & 8,2 & 8,9 & 11,5 & 7,6 & 9,4 & 2,7 & 0,7 & 12,4 & 1,8 & 0 & 2,6 & 0,5 & 9,2 & 10,3 & 6,1 & 7,2 & 1,2 & 1,2 \\
\hline F05_k & 9,4 & 2,6 & 8 & 10 & 12,9 & 7,2 & 10,2 & 3,1 & 2,9 & 11 & 2,5 & 2,6 & 0 & 3,1 & 10,1 & 10,7 & 7,2 & 8,1 & 3,1 & 3,1 \\
\hline E03_kab20 & 7,4 & 2,3 & 8,1 & 9,8 & 12,2 & 6,8 & 10,2 & 1,7 & 0,5 & 11,4 & 2,5 & 0,5 & 3,1 & 0 & 9,8 & 10,5 & 6,6 & 7,4 & 1,7 & 1,7 \\
\hline D03_kab20 & 9,9 & 9,2 & 10,5 & 10,3 & 6 & 10,4 & 9,9 & 9,5 & 9,5 & 11,2 & 9,8 & 9,2 & 10,1 & 9,8 & 0 & 16,1 & 9,9 & 10 & 9,5 & 9,4 \\
\hline E01_kab02 & 15,4 & 10,6 & 15,3 & 17,5 & 17 & 15 & 15,2 & 10,7 & 10,5 & 18,8 & 10,9 & 10,3 & 10,7 & 10,5 & 16,1 & 0 & 14,6 & 15,7 & 10,5 & 10,8 \\
\hline C02_kab02 & 5,1 & 5,5 & 6,9 & 8,6 & 10 & 7 & 8,6 & 6,6 & 6,4 & 8,8 & 7,5 & 6,1 & 7,2 & 6,6 & 9,9 & 14,6 & 0 & 2,3 & 6,6 & 6,5 \\
\hline A03_kab20 & 5,6 & 6,2 & 7,6 & 9 & 10,3 & 7,3 & 9,3 & 7,9 & 7,2 & 9,6 & 8,7 & 7,2 & 8,1 & 7,4 & 10 & 15,7 & 2,3 & 0 & 7,9 & 7,8 \\
\hline B11_kab06 & 7 & 3 & 7,9 & 9,8 & 11,2 & 6,4 & 10,3 & 0,3 & 1,4 & 10,7 & 1,3 & 1,2 & 3,1 & 1,7 & 9,5 & 10,5 & 6,6 & 7,9 & 0 & 0,3 \\
\hline E12_kab06 & 6,9 & 3 & 7,8 & 9,7 & 11,1 & 6,3 & 10,2 & 0,3 & 1,4 & 10,5 & 1,3 & 1,2 & 3,1 & 1,7 & 9,4 & 10,8 & 6,5 & 7,8 & 0,3 & \\
\hline
\end{tabular}

Distance Matrix Beta-Proteobacteria: Methylophilales 


\begin{tabular}{|c|c|c|c|c|c|c|c|c|c|c|c|c|c|c|c|c|c|c|c|c|}
\hline & 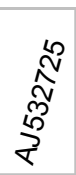 & 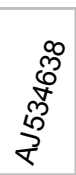 & $\begin{array}{l}\infty \\
\stackrel{0}{\circ} \\
\stackrel{8}{8} \\
8 \\
0\end{array}$ & 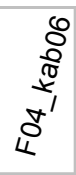 & $\begin{array}{l}8 \\
\frac{8}{\pi} \\
\delta^{\prime} \\
\delta^{\prime}\end{array}$ & 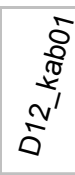 & $\begin{array}{c}\frac{9}{\pi} \\
\frac{\pi}{\pi} \\
0 \\
0\end{array}$ & 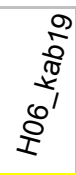 & $\frac{\frac{\pi}{d}}{\frac{\pi}{d}}$ & $\frac{\sqrt{2}}{\frac{\pi}{\pi}}$ & $\frac{\sqrt{0}}{\frac{\pi}{\pi}}$ & $\frac{i}{\sqrt[\pi]{\infty}}$ & 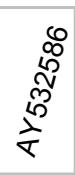 & 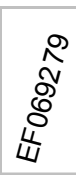 & $\begin{array}{l}\mathscr{\infty} \\
\infty \\
\infty \\
\infty \\
\infty\end{array}$ & $\frac{\hat{\nabla}}{\underset{\nabla}{\sigma}}$ & 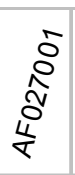 & 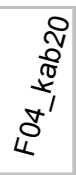 & 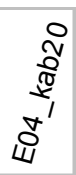 & 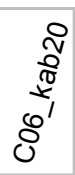 \\
\hline AJ532725 & 0 & 21,3 & 19 & 21,3 & 20,9 & 20 & 1,2 & 1,3 & 21,6 & 21,3 & 21 & 19,1 & 19,7 & 24,8 & 19 & 21,6 & 19,7 & 16 & 17,3 & 18,5 \\
\hline AJ534638 & 21,3 & 0 & 21 & 4,8 & 4 & 21,7 & 21,3 & 21,3 & 5 & 4,9 & 4,1 & 8,5 & 7,4 & 6,2 & 21,6 & 4,2 & 21,2 & 18 & 7,2 & 4,4 \\
\hline DQ097680 & 19 & 21 & 0 & 20,3 & 19,8 & 14,2 & 18,7 & 18,8 & 20,5 & 20,3 & 20 & 19,3 & 19,6 & 25,2 & 2,7 & 20,9 & 13,3 & 2,1 & 15,2 & 16,7 \\
\hline F04_kab06 & 21,3 & 4,8 & 20,3 & 0 & 2,2 & 20,2 & 19,9 & 20 & 0,2 & 0,1 & 2,3 & 8 & 7,3 & 0,8 & 20,6 & 3,9 & 20,3 & 17,3 & 7 & 3,2 \\
\hline $\mathrm{CO3}$ & 20,9 & 4 & 19,8 & 2,2 & 0 & 20 & 19,5 & 19,6 & 2,4 & 2,3 & 0,1 & 7,8 & 6,6 & 2,7 & 20,2 & 2,3 & 20 & 16,9 & 6,5 & 3,2 \\
\hline D12_kab01 & 20 & 21,7 & 14,2 & 20,2 & 20 & 0 & 18,5 & 18,5 & 20,4 & 20,2 & 20,1 & 19,5 & 19,7 & 26,1 & 13,3 & 21,7 & 4,8 & 10,3 & 17,4 & 18,3 \\
\hline G08_kab19 & 1,2 & 21,3 & 18,7 & 19,9 & 19,5 & 18,5 & 0 & 0,1 & 20,1 & 20 & 19,7 & 18,2 & 18 & 24,3 & 18,5 & 20,9 & 18,7 & 15,7 & 17,1 & 18,4 \\
\hline H06_kab19 & 1,3 & 1,3 & 18,8 & 20 & 19,6 & 18,5 & 0,1 & 0 & 20,2 & 20,1 & 19,7 & 18,2 & 18 & 24,5 & 18,5 & 21 & 18,8 & 15,9 & 17,2 & 18,5 \\
\hline A09_kab11 & 21,6 & 5 & 20,5 & 0,2 & 2,4 & 20,4 & 20,1 & 20,2 & 0 & 0,3 & 2,5 & 8,2 & 7,5 & 1,1 & 20,8 & 4,1 & 20,5 & 17,4 & 7,1 & 3,3 \\
\hline B04_kab11 & 21,3 & 4,9 & 20,3 & 0,1 & 2,3 & 20,2 & 20 & 20,1 & 0,3 & 0 & 2,4 & 8,1 & 7,4 & 0,8 & 20,6 & T & 20,3 & 17,3 & & 3,2 \\
\hline C10_kab11 & 21 & 4,1 & 20 & 2,3 & 0,1 & 20,1 & 19,7 & 19,7 & 2,5 & 2,4 & 0 & 7,9 & 6,7 & 2,8 & 20,3 & 2,5 & 20,2 & 17,1 & 6,7 & 3,5 \\
\hline E05_kab11 & 19,1 & 8,5 & 19,3 & 8 & 7,8 & 19,5 & 18,2 & 18,2 & 8,2 & 8,1 & 7,9 & 0 & 5,6 & 9,1 & 19,4 & 7,6 & 19,8 & 15,4 & 0,8 & 5,5 \\
\hline AY532586 & 19,7 & 7,4 & 19,6 & 7,3 & 6,6 & 19,7 & 18 & 18 & 7,5 & 7,4 & 6,7 & 5,6 & 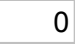 & 7,9 & 19,9 & 5,9 & 19,4 & 15,9 & 3,4 & 4,7 \\
\hline EF069279 & 24,8 & 6,2 & 25,2 & 0,8 & 2,7 & 26,1 & 24,3 & 24,5 & 1,1 & 0,8 & 2,8 & 9,1 & 7,9 & 0 & 25,7 & 5 & 26,6 & 20,4 & 7 & 4,1 \\
\hline AB183860 & 19 & 21,6 & 2,7 & 20,6 & 20,2 & 13,3 & 18,5 & 18,5 & 20,8 & 20,6 & 20,3 & 19,4 & 19,9 & 25,7 & 0 & 21,3 & 12,5 & 0,3 & 15,1 & 16,7 \\
\hline DQ414437 & 21,6 & 4,2 & 20,9 & 3,9 & 2,3 & 21,7 & 20,9 & 21 & 4,1 & 4 & 2,5 & 7,6 & 5,9 & 5 & 21,3 & 0 & 21,7 & 17 & 6,1 & 2 \\
\hline AF027001 & 19,7 & 21,2 & 13,3 & 20,3 & 20 & 4,8 & 18,7 & 18,8 & 20,5 & 20,3 & 20,2 & 19,8 & 19,4 & 26,6 & 12,5 & 21,7 & 0 & 10,1 & 16,5 & 16,8 \\
\hline F04_kab20 & 16 & 18 & 2,1 & 17,3 & 16,9 & 10,3 & 15,7 & 15,9 & 17,4 & 17,3 & 17,1 & 15,4 & 15,9 & 20,4 & 0,3 & 17 & 10,1 & 0 & 15,1 & 16,7 \\
\hline E04_kab20 & 17,3 & 7,2 & 15,2 & 7 & 6,5 & 17,4 & 17,1 & 17,2 & 7,1 & 7 & 6,7 & 0,8 & 3,4 & & 15,1 & 6,1 & 16,5 & 15,1 & & 6 \\
\hline C06_kab20 & 18,5 & 4,4 & 16,7 & 3,2 & 3,2 & 18,3 & 18,4 & 18,5 & 3,3 & 3,2 & 3,5 & 5,5 & 4,7 & 4,1 & 16,7 & 2 & 16,8 & 16,7 & 6 & 0 \\
\hline
\end{tabular}

\section{Distance Matrix Nitrospirae}




\begin{tabular}{|c|c|c|c|c|c|c|c|c|c|c|c|c|c|c|c|c|c|c|c|c|c|}
\hline & 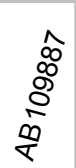 & 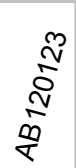 & 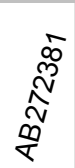 & 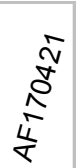 & $\begin{array}{l}\infty \\
\infty \\
\infty \\
\frac{\infty}{\sigma} \\
\frac{1}{6}\end{array}$ & 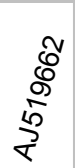 & $\begin{array}{c}\infty^{2} \\
D^{2} \\
\infty^{\infty} \\
7\end{array}$ & 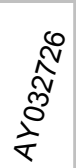 & 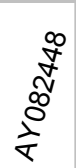 & $\begin{array}{l}\infty \\
\stackrel{\infty}{\infty} \\
\stackrel{\infty}{\Gamma} \\
\frac{1}{\tau}\end{array}$ & 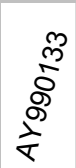 & 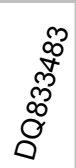 & 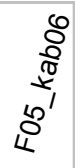 & $\frac{\sqrt{\infty}}{\frac{\pi}{\infty}}$ & 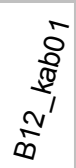 & $\frac{\frac{9}{d}}{\frac{\pi}{2}}$ & 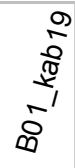 & $\begin{array}{l}\stackrel{9}{\nabla} \\
\stackrel{\tilde{V}}{0} \\
\stackrel{\sim}{u}\end{array}$ & 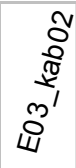 & 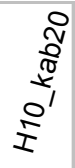 & 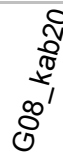 \\
\hline AB109887 & 0 & 14 & 14 & 10,6 & 14,6 & 13,9 & 13,5 & 1,4 & 15,5 & 14 & 16 & 13,1 & 0,1 & 15,7 & 12,9 & 15,7 & 14,3 & 14,8 & 11,5 & 16,3 & 13,9 \\
\hline AB120123 & 14 & 0 & 2,6 & 14,6 & 10,3 & 9,4 & 14,5 & 14,3 & 18,4 & 2,7 & 18,4 & 9,4 & 13,9 & 18,5 & 10,4 & 18,5 & 2,6 & 2,3 & 14,5 & 2,9 & 15,9 \\
\hline AB272381 & 14 & 2,6 & 0 & 14,6 & 8,1 & 8,5 & 14,8 & 14 & 18,7 & 3,9 & 18,6 & 8,3 & 14 & 18,8 & 8,8 & 18,7 & 2,8 & 3 & 14,4 & 2,9 & 16,2 \\
\hline AF170421 & 10,6 & 14,6 & 14,6 & 0 & 14,9 & 13,7 & 5,1 & 11,1 & 14,8 & 13,7 & 15,7 & 13,3 & 10,5 & 14,8 & 12,8 & 15 & 14,4 & 14,7 & 9,5 & 14,9 & 13,1 \\
\hline AF418945 & 14,6 & 10,3 & 8,1 & 14,9 & 0 & 3,1 & 14,8 & 14,3 & 17,7 & 10,9 & 18,3 & 5,7 & 14,3 & 17,7 & 7,3 & 17,6 & 10,3 & 9,9 & 12,5 & 9,1 & 14,5 \\
\hline AJ519662 & 13,9 & 9,4 & 8,5 & 13,7 & 3,1 & 0 & 13,3 & 14 & 17,5 & 10 & 17,4 & 4 & 13,9 & 17,6 & 6,1 & 17,6 & 9,7 & 9,6 & 11,7 & 9,4 & 13,1 \\
\hline AJ810552 & 13,5 & 14,5 & 14,8 & 5,1 & 14,8 & 13,3 & 0 & 14 & 16 & 14,1 & 16,3 & 13,1 & 13,3 & 16,1 & 12,6 & 16,4 & 14,6 & 15,1 & 9 & 14,5 & 9,6 \\
\hline AY032726 & 1,4 & 14,3 & 14 & 11,1 & 14,3 & 14 & 14 & 0 & 15,3 & 13,9 & 16 & 12,6 & 1,5 & 15,2 & 13,2 & 15,2 & 14 & 14,8 & 12,1 & 16,1 & 14 \\
\hline AY082448 & 15,5 & 18,4 & 18,7 & 14,8 & 17,7 & 17,5 & 16 & 15,3 & 0 & 17,8 & 0,3 & 16,9 & 15,4 & 0,6 & 16,9 & 0,6 & 18,1 & 17,6 & 13,1 & 16,2 & 15,4 \\
\hline AY138998 & 14 & 2,7 & 3,9 & 13,7 & 10,9 & 10 & 14,1 & 13,9 & 17,8 & 0 & 17,8 & 9,1 & 13,6 & 17,4 & 11,5 & 17,7 & 1,9 & 1,9 & 14,9 & 2,1 & 16,2 \\
\hline AYS & 16 & 18,4 & 18,6 & 15,7 & 18,3 & 17,4 & 16,3 & 16 & 0,3 & 17,8 & 0 & 17,5 & 16 & 0,6 & 17,5 & 0,3 & 18,3 & 18,2 & 13,2 & 16,1 & 15,7 \\
\hline DQ833483 & 13,1 & 9,4 & 8,3 & 13,3 & 5,7 & 4 & 13,1 & 12,6 & 16,9 & 9,1 & 17,5 & 0 & 12,9 & 16,5 & 5,7 & 16,7 & 9,2 & 9,3 & 12,4 & 8,6 & 14,5 \\
\hline F05_kab06 & 0,1 & 13,9 & 14 & 10,5 & 14,3 & 13,9 & 13,3 & 1,5 & 15,4 & 13,6 & 16 & 12,9 & 0 & 15,2 & 12,7 & 15,2 & 13,8 & 14,8 & 11,5 & 16,3 & 13,9 \\
\hline B09_kab19 & 15,7 & 18,5 & 18,8 & 14,8 & 17,7 & 17,6 & 16,1 & 15,2 & 0,6 & 17,4 & 0,6 & 16,5 & 15,2 & 0 & 16,7 & 0,7 & 17,7 & 17,9 & 13,4 & 16,3 & 15,7 \\
\hline B12_kab01 & 12,9 & 10,4 & 8,8 & 12,8 & 7,3 & 6,1 & 12,6 & 13,2 & 16,9 & 11,5 & 17,5 & 5,7 & 12,7 & 16,7 & 0 & 16,7 & 10,8 & 10,9 & 12,1 & 9,3 & 14,9 \\
\hline H03_kab19 & 15,7 & 18,5 & 18,7 & 15 & 17,6 & 17,6 & 16,4 & 15,2 & 0,6 & 17,7 & 0,3 & 16,7 & 15,2 & 0,7 & 16,7 & 0 & 18 & 17,9 & 13,6 & 16,4 & 15,8 \\
\hline B01_kab19 & 14,3 & 2,6 & 2,8 & 14,4 & 10,3 & 9,7 & 14,6 & 14 & 18,1 & 1,9 & 18,3 & 9,2 & 13,8 & 17,7 & 10,8 & 18 & 0 & 0,8 & 14,4 & 0,3 & 15,6 \\
\hline EF562149 & 14,8 & 2,3 & 3 & 14,7 & 9,9 & 9,6 & 15,1 & 14,8 & 17,6 & 1,9 & 18,2 & 9,3 & 14,8 & 17,9 & 10,9 & 17,9 & 0,8 & 0 & 14,6 & 0,5 & 15,9 \\
\hline E03_kab02 & 11,5 & 14,5 & 14,4 & 9,5 & 12,5 & 11,7 & 9 & 12,1 & 13,1 & 14,9 & 13,2 & 12,4 & 11,5 & 13,4 & 12,1 & 13,6 & 14,4 & 14,6 & 0 & 14,6 & 11,8 \\
\hline H10_kab20 & 16,3 & 2,9 & 2,9 & 14,9 & 9,1 & 9,4 & 14,5 & 16,1 & 16,2 & 2,1 & 16,1 & 8,6 & 16,3 & 16,3 & 9,3 & 16,4 & 0,3 & 0,5 & 14,6 & 0 & 15,7 \\
\hline G08_kab20 & 13,9 & 15,9 & 16,2 & 13,1 & 14,5 & 13,1 & 9,6 & 14 & 15,4 & 16,2 & 15,7 & 14,5 & 13,9 & 15,7 & 14,9 & 15,8 & 15,6 & 15,9 & 11,8 & 15,7 & 0 \\
\hline
\end{tabular}

Distance Matrix Gamma-Proteobacteria: Enterobacteriales, Pseudomonadales 


\begin{tabular}{|c|c|c|c|c|c|c|c|c|c|c|c|c|c|c|c|c|c|c|c|c|c|c|c|c|}
\hline & 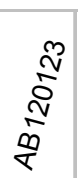 & $\begin{array}{c}\stackrel{\infty}{N} \\
\underset{\sim}{\mathbb{N}} \\
\stackrel{\infty}{x}\end{array}$ & 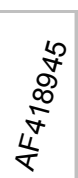 & 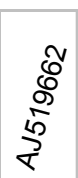 & 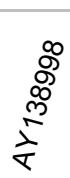 & 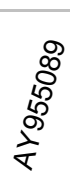 & 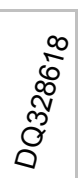 & 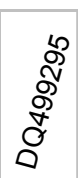 & 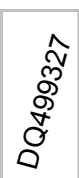 & 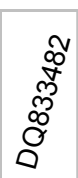 & $\begin{array}{c}\infty \\
\infty \\
\infty \\
\infty \\
\infty \\
\stackrel{0}{0} \\
0\end{array}$ & 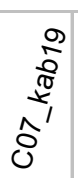 & 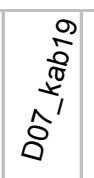 & 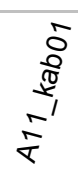 & 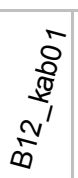 & $\begin{array}{c}\delta \\
\frac{\delta}{\pi} \\
\infty \\
0 \\
0 \\
0\end{array}$ & $\begin{array}{c}\frac{\pi}{\mathbb{\pi}} \\
\underset{\infty}{\infty} \\
\frac{\pi}{\infty}\end{array}$ & $\frac{D^{\infty}}{i^{\infty}}$ & 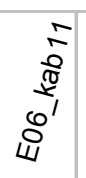 & 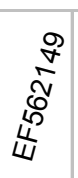 & 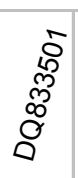 & 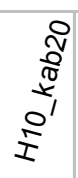 & 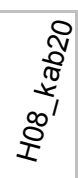 & $\begin{array}{l}0 \\
\frac{\pi}{\mathbb{2}} \\
\frac{1}{2} \\
\frac{1}{1}\end{array}$ \\
\hline AB120123 & 0 & 2,6 & 10,3 & 9,4 & 2,7 & 15,2 & 14,5 & 15,7 & 14,4 & 15,2 & 9,4 & 14,6 & 15,5 & 14,8 & 10,4 & 15,3 & 15,2 & 2,6 & 15,3 & 2,3 & 15,2 & 2,9 & 13,5 & 13,8 \\
\hline AB272381 & 2,6 & 0 & 8,1 & 8,5 & 3,9 & 15,3 & 14,7 & 15,5 & 13,9 & 15,3 & 8,3 & 14,7 & 15,4 & 13,4 & 8,8 & 15 & 15,5 & 2,8 & 15 & 3 & 15,3 & 2,9 & 13,3 & 13,6 \\
\hline AF418945 & 0,3 & 8,1 & 0 & 3,1 & 10,9 & 13,9 & 14 & 13,4 & 13,8 & 14 & 5,7 & 13,7 & 14,5 & 12,6 & 7,3 & 13,9 & 14,2 & 10,3 & 13,8 & 9,9 & 13,9 & 9,1 & 12,4 & 12,6 \\
\hline AJ519662 & 9,4 & 8,5 & 3,1 & 0 & 10 & 13,9 & 14 & 13,7 & 14 & 13,8 & 4 & 13,4 & 14,1 & 12,8 & 6,1 & 13,9 & 14 & 9,7 & 13,8 & 9,6 & 13,9 & 9,4 & 12 & 12,2 \\
\hline AY138998 & 2,7 & 3,9 & 10,9 & 10 & 0 & 14,9 & 14,5 & 15,4 & 14,1 & 14,9 & 9,1 & 14,5 & 15,1 & 14 & 11,5 & 14,4 & 14,7 & 1,9 & 14,4 & 1,9 & 14,9 & 2,1 & 14,1 & 14,4 \\
\hline AY95 & 5,2 & 15,3 & 13,9 & 13,9 & 14,9 & 0 & 6,2 & 1,3 & 6,6 & 0,7 & 13,1 & 1,2 & 5,8 & 11,9 & 12,9 & 4,2 & 4,6 & 14,7 & 4,2 & 15,4 & U & 13,9 & 1,2 & 1,2 \\
\hline DQ3 & 4,5 & 14,7 & 14 & 14 & 14,5 & 6,2 & & 6,9 & $b, 8$ & 6,4 & 13,2 & 5,9 & 6,6 & 11,3 & 12,2 & 7,5 & 6,5 & 14,7 & $(, 5$ & 15,3 & 6,2 & 13,9 & 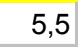 & 5,5 \\
\hline DQ49 & 5,7 & 15,5 & 13,4 & 13,7 & 15,4 & 1,3 & 6,9 & & 7,5 & 1,8 & 13,3 & 2,3 & 6,4 & 12,1 & 12,8 & 5,3 & 5,1 & 14,9 &,, 3 & $10, c$ & 1,0 & 14,2 & & 2,5 \\
\hline DQ4C & ,4 & 13,9 & 13,8 & 14 & 14,1 & 6,6 & 5,8 & 7,5 & & 6,7 & 13,2 & 6,6 & 8,1 & 11,8 & 12,5 & 0,0 & 5,8 & 14,7 & 6,5 & 10,5 & 0,0 & 14,4 & 0,4 & 5,2 \\
\hline & 2 & 5,3 & 14 & 13,8 & 14,9 & 0,7 & 6,4 & 1,8 & 6,7 & 0 & 3,3 & 1,5 & 5,9 & 11,9 & 12,9 & 4,4 & 4,5 & 14,8 & 4,4 & , & $0, r$ & 13,7 & , & 1,2 \\
\hline & 4 & 8,3 & 5,7 & 4 & 9,1 & 13,1 & 13,2 & 13,3 & 13,2 & 13,3 & 0 & 13,1 & 13,5 & 12,4 & 5,7 & 13,8 & 13,5 & 9,2 & 13,7 & 9,3 & 13,1 & 8,6 & 12,3 & 12,4 \\
\hline $\mathrm{CO7}$ & 14,6 & 14,7 & 13,7 & 13,4 & 14,5 & 1,2 & 5,9 & 2,3 & 6,6 & 1,5 & 13,1 & & 5,8 & 11,7 & 12,5 & 3,7 & 4,1 & 14,1 & 3,7 & 1 & 1,2 & 13,7 & 0,3 & 0,3 \\
\hline 019 & 15,5 & 15,4 & 14,5 & 14,1 & 15,1 & 5,8 & 6,6 & 6,4 & 8,1 & 5,9 & 13,5 & 5,8 & 0 & 11 & 12,3 & $\epsilon$ & 7,5 & 15,3 & 6 & 16,2 & 5,8 & 15 & 7,5 & 7,5 \\
\hline & 14,8 & 13,4 & 12,6 & 12,8 & 14 & 11,9 & 11,3 & 12,1 & 11,8 & 11,9 & 12,4 & 11,7 & 11 & 0 & 12 & 11,4 & 12,5 & 14,4 & 11,3 & 15,1 & 11,9 & 15,1 & 11,2 & 11,4 \\
\hline ab01 & 10,4 & 8,8 & 7,3 & 6,1 & 11,5 & 12,9 & 12,2 & 12,8 & 12,5 & 12,9 & 5,7 & 12,5 & 12,3 & 12 & 0 & 13,3 & 12,7 & 10,8 & 13,2 & 10,9 & 12,9 & 9,3 & 11,9 & 12 \\
\hline b01 & 15,3 & 15 & 13,9 & 13,9 & 14,4 & 4,2 & 7,5 & 5,3 & 6,5 & 4,4 & 13,8 & 3,7 & 6 & 11,4 & 13,3 & & & 14,7 & 0,1 & 15,3 & 4,2 & 13,7 & 3,4 & 3,4 \\
\hline A08_kab19 & 15,2 & 15,5 & 14,2 & 14 & 14,7 & 4,6 & 6,5 & 5,1 & 5,8 & 4,5 & 13,5 & 4,1 & 7,5 & 12,5 & 12,7 & 5 & 0 & 14,5 & 5 & 15,7 & 4,6 & 14,2 & 4,4 & 4,4 \\
\hline B01_k & 2,6 & 2,8 & 10,3 & 9,7 & 1,9 & 14,7 & 14,7 & 14,9 & 14,7 & 14,8 & 9,2 & 14,1 & 15,3 & 14,4 & 10,8 & 14,7 & 14,5 & 0 & 14,7 & 0,8 & 14,7 & 0,3 & 13,2 & 13,5 \\
\hline E06_kab11 & 15,3 & 15 & 13,8 & 13,8 & 14,4 & 4,2 & 7,5 & 5,3 & 6,5 & 4,4 & 13,7 & 3,7 & 6 & 11,3 & 13,2 & 0,1 & 5 & 14,7 & 0 & 15,3 & 4,2 & 13,7 & 3,4 & 3,4 \\
\hline EF56 & 2,3 & 3 & 9,9 & 9,6 & 1,9 & 15,4 & 15,3 & 15,6 & 15,3 & 15,3 & 9,3 & 15 & 16,2 & 15,1 & 10,9 & 15,3 & 15,7 & 0,8 & 15,3 & 0 & 5,4 & 0,5 & 13,5 & 13,7 \\
\hline & 15,2 & 15,3 & 13,9 & 13,9 & 14,9 & & 6,2 & 1,3 & 6,6 & 0,7 & 13,1 & 1,2 & 5,8 & 11,9 & 12,9 & 4,2 & 4,6 & 14,7 & 4,2 & 15,4 & & 3,9 & , L & 1,2 \\
\hline & 2 & 2 , & 9 & 9,4 & 2 , & 13,9 & 13,9 & 14,2 & 14,4 & 13,7 & 8,6 & 13,7 & 15 & 15,1 & 9,3 & 13,7 & 14,2 & 0,3 & 13,7 & 0,5 & 13,9 & & 3,5 & 13,7 \\
\hline & & & & 12 & 14 & 1,2 & 5 & 2, & 5, & 1,2 & & & 7,5 & 11,2 & 11,9 & & 4,4 & 3,2 & 4 & 3,5 & & 13,5 & & 0,3 \\
\hline 9_kab06 & 8 & 3,6 & 12,6 & & & 1,2 & 5,5 & 2 & 5 & 1,2 & 12,4 & & 7.5 & 11,4 & & 3,4 & 4.4 & 13,5 & 3,4 & & 12 & 13,7 & 0,3 & \\
\hline
\end{tabular}

Distance Matrix Gamma-Proteobacteria: Xanthomonadales, unklassifiziert 


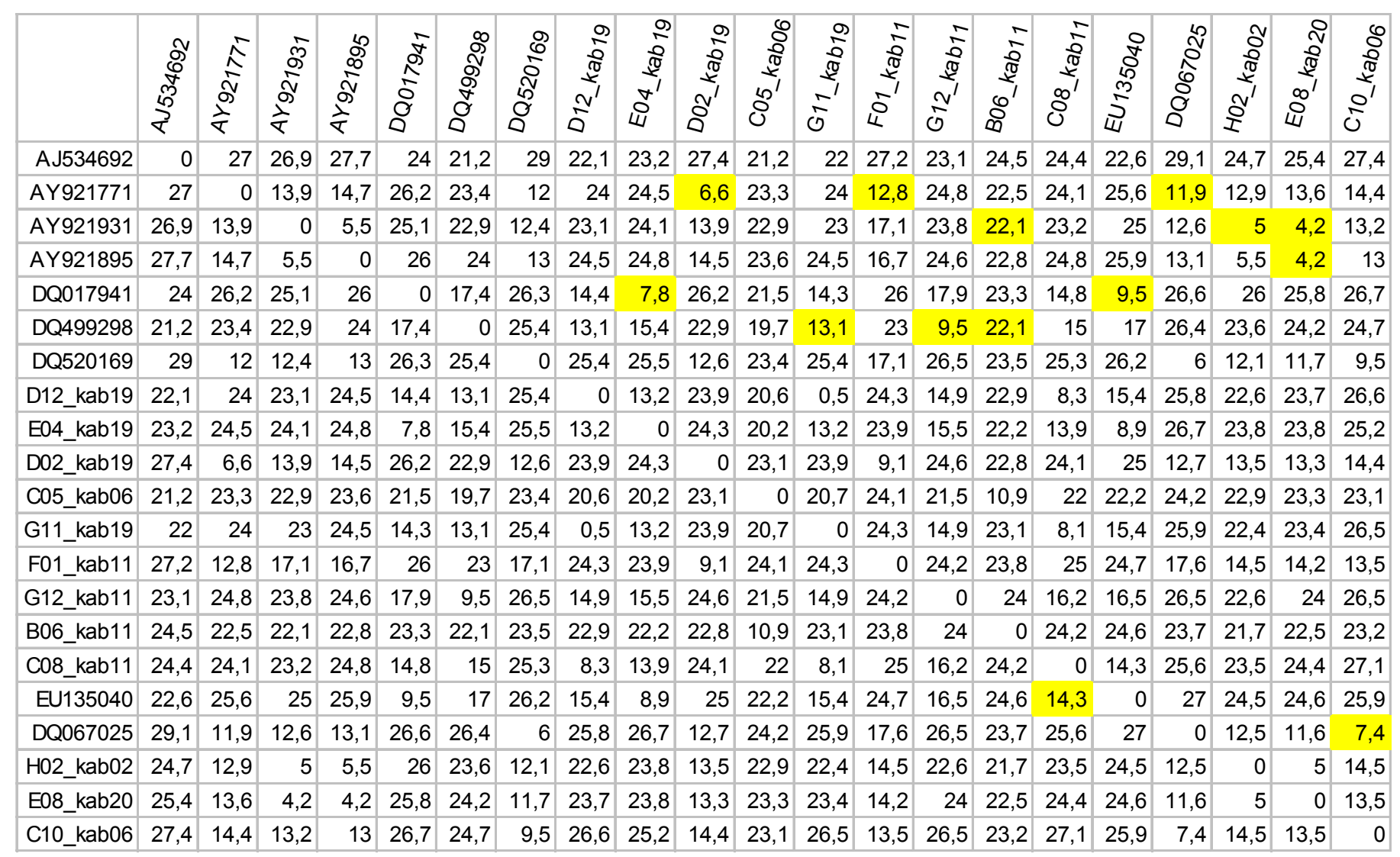

Distance Matrix Planctomycetes, Gemmatimonadetes 


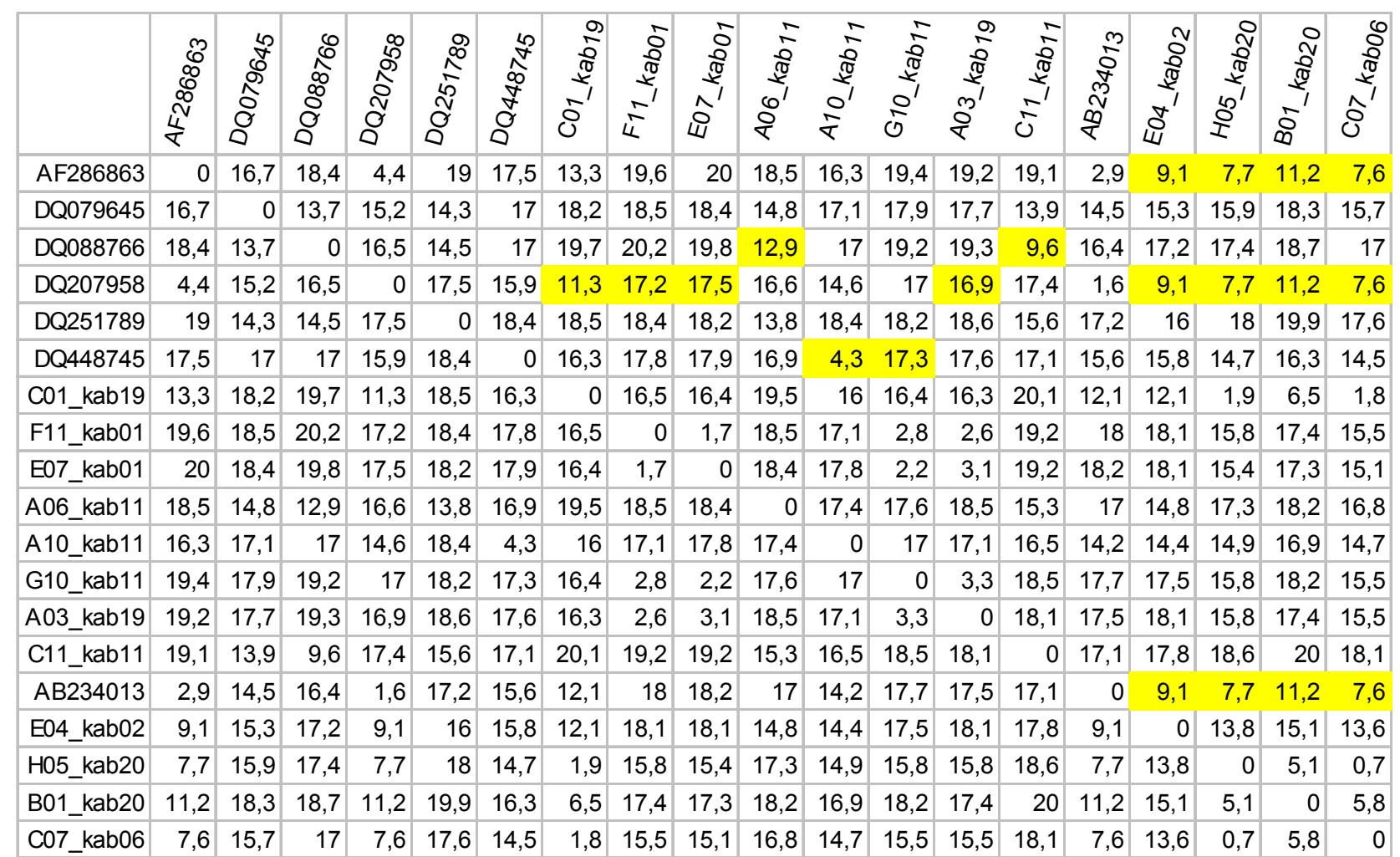

Distance Matrix Firmicutes 


\begin{tabular}{|c|c|c|c|c|c|c|c|c|c|c|c|c|c|c|}
\hline & 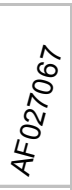 & $\stackrel{\substack{\alpha \\
\stackrel{\sigma}{\delta}}}{\stackrel{\infty}{\delta}}$ & 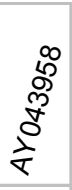 & 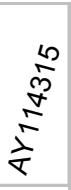 & 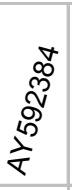 & 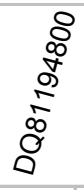 & 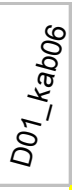 & 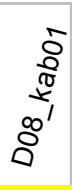 & 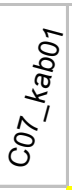 & 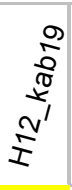 & 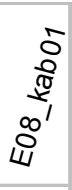 & 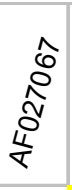 & 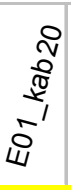 & 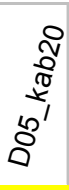 \\
\hline AF027067 & 0 & 12,2 & 23,6 & 23,2 & 22,9 & 13,5 & 23,7 & 3,1 & 23,6 & 0,8 & 22,6 & 0 & 0,9 & 8,3 \\
\hline AJ704718 & 12,2 & 0 & 23,2 & 23,6 & 23,4 & 7,8 & 22,7 & 10,8 & 23,2 & 11,9 & 23 & 12,2 & 10,3 & 10,2 \\
\hline AY043958 & 23,6 & 23,2 & 0 & 26,4 & 13,7 & 25,4 & 12 & 23,3 & 13,6 & 23,2 & 25,1 & 23,6 & 23,5 & 24,4 \\
\hline AY114315 & 23,2 & 23,6 & 26,4 & 0 & 27,6 & 24,9 & 27,4 & 22,9 & 27,4 & 23,2 & 10,4 & 23,2 & 23,2 & 24,3 \\
\hline AY592384 & 22,9 & 23,4 & 13,7 & 27,6 & 0 & 25,3 & 12,5 & 23,2 & 13,9 & 22,8 & 26,7 & 22,9 & 22,9 & 23,4 \\
\hline DQ811948 & 13,5 & 7,8 & 25,4 & 24,9 & 25,3 & 0 & 24,8 & 13,3 & 25,7 & 14,1 & 25,3 & 13,5 & 12 & 10,4 \\
\hline D01_kab06 & 23,7 & 22,7 & 12 & 27,4 & 12,5 & 24,8 & 0 & 23,1 & 14,7 & 23,1 & 25,5 & 23,7 & 23,5 & 23,6 \\
\hline D08_kab01 & 3,1 & 10,8 & 23,3 & 22,9 & 23,2 & 13,3 & 23,1 & 0 & 22,8 & 3,2 & 22,1 & 3,1 & 3 & 8 \\
\hline C07_kab01 & 23,6 & 23,2 & 13,6 & 27,4 & 13,9 & 25,7 & 14,7 & 22,8 & 0 & 22,9 & 26 & 23,6 & 22,1 & 23,1 \\
\hline H12_kab19 & 0,8 & 11,9 & 23,2 & 23,2 & 22,8 & 14,1 & 23,1 & 3,2 & 22,9 & 0 & 22,1 & 0,8 & 0,4 & 8,8 \\
\hline E08_kab01 & 22,6 & 23 & 25,1 & 10,4 & 26,7 & 25,3 & 25,5 & 22,1 & 26 & 22,1 & 0 & 22,6 & 21,1 & 22,8 \\
\hline AF027067 & 0 & 12,2 & 23,6 & 23,2 & 22,9 & 13,5 & 23,7 & 3,1 & 23,6 & 0,8 & 22,6 & 0 & 0,9 & 8,3 \\
\hline E01_kab20 & 0,9 & 10,3 & 23,5 & 23,2 & 22,9 & 12 & 23,5 & 3 & 22,1 & 0,4 & 21,1 & 0,9 & 0 & 8,5 \\
\hline D05_kab20 & 8,3 & 10,2 & 24,4 & 24,3 & 23,4 & 10,4 & 23,6 & 8 & 23,1 & 8,8 & 22,8 & 8,3 & 8,5 & 0 \\
\hline
\end{tabular}

\section{Distance Matrix OP8, TM6, BRC1}

\begin{tabular}{|c|c|c|c|c|c|c|c|c|c|c|c|c|}
\hline & $\underset{\frac{\hat{\sigma}}{\alpha}}{\stackrel{\hat{\sigma}}{\alpha}}$ & $\begin{array}{c}\infty \\
\infty \\
\infty \\
\infty \\
\frac{\infty}{\infty}\end{array}$ & $\begin{array}{c}\hat{a} \\
\stackrel{\hat{N}}{\alpha} \\
\frac{\alpha}{\alpha}\end{array}$ & 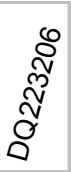 & $\begin{array}{c}8 \\
\frac{8}{\pi} \\
\frac{0}{\pi /} \\
\frac{\pi}{\sigma^{\prime}}\end{array}$ & 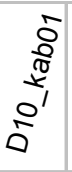 & 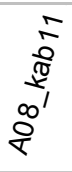 & $\frac{i}{\frac{\pi}{\pi}} \frac{i}{\frac{\pi}{2}}$ & $\frac{\pi}{\infty}$ & 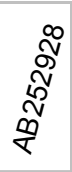 & 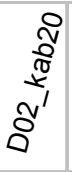 & 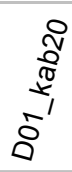 \\
\hline AF407711 & 0 & 14,5 & 13,2 & 13 & 15,2 & 14,3 & 13,7 & 13,7 & 12,3 & 13,9 & 10,6 & 10,3 \\
\hline AJ518782 & 14,5 & 0 & 13,2 & 4,8 & 5,2 & 14,4 & 5,2 & 2,5 & 10,7 & 2,5 & 4,8 & 3,7 \\
\hline AY921701 & 13,2 & 13,2 & 0 & 11,5 & 12 & 4,8 & 12 & 12,1 & 10,6 & 12,4 & 12,6 & 10,8 \\
\hline DQ223206 & 13 & 4,8 & 11,5 & 0 & 3,5 & 11,8 & 3,4 & 4,1 & 9,1 & 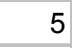 & 4 & 4,9 \\
\hline A04_kab06 & 15,2 & 5,2 & 12 & 3,5 & 0 & 12,1 & 0,1 & 3,8 & 9,3 & 6,3 & 0,1 & 5,2 \\
\hline D10_kab01 & 14,3 & 14,4 & 4,8 & 11,8 & 12,1 & 0 & 12 & 12,8 & 10,3 & 12,9 & 13 & 11,2 \\
\hline A08_kab11 & 13,7 & 5,2 & 12 & 3,4 & 0,1 & 12 & 0 & 3,8 & 9,2 & 4,8 & 0,1 & 5,2 \\
\hline A11_kab11 & 13,7 & 2,5 & 12,1 & 4,1 & 3,8 & 12,8 & 3,8 & 0 & 10 & 1,7 & 2,9 & 3,1 \\
\hline F05_kab11 & 12,3 & 10,7 & 10,6 & 9,1 & 9,3 & 10,3 & 9,2 & 10 & 0 & 9,5 & 10,2 & 8,6 \\
\hline AB252928 & 13,9 & 2,5 & 12,4 & 5 & 6,3 & 12,9 & 4,8 & 1,7 & 9,5 & 0 & 4,8 & 4 \\
\hline D02_kab20 & 10,6 & 4,8 & 12,6 & 4 & 0,1 & 13 & 0,1 & 2,9 & 10,2 & 4,8 & 0 & 5,2 \\
\hline D01_kab20 & 10,3 & 3,7 & 10,8 & 4,9 & 5,2 & 11,2 & 5,2 & 3,1 & 8,6 & 4 & 5,2 & \\
\hline
\end{tabular}

Distance Matrix Beta-Proteobacteria : Rhodocyclales 


\begin{tabular}{|c|c|c|c|c|c|c|c|c|c|c|c|c|c|c|c|c|}
\hline & 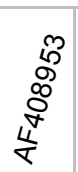 & $\begin{array}{l}\hat{0} \\
\hat{0} \\
0 \\
0 \\
0\end{array}$ & 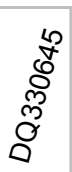 & 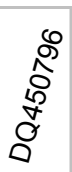 & 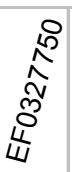 & $\frac{\frac{N}{\pi}}{\frac{\pi}{2}}$ & $\begin{array}{l}\text { సे } \\
\aleph_{0} \\
\infty \\
\sum^{\infty}\end{array}$ & $\begin{array}{l}\hat{\hat{\sigma}} \\
\infty^{\infty} \\
\infty^{\infty} \\
\dot{\sigma}\end{array}$ & 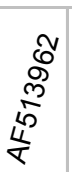 & $\begin{array}{c}\infty \\
\frac{\infty}{\mathbb{T}} \\
\mathbb{J}^{\prime} \\
\mathbb{J}^{\prime}\end{array}$ & 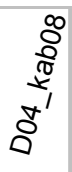 & 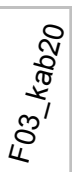 & 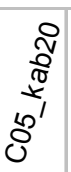 & 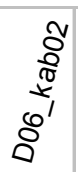 & $\begin{array}{c}\frac{8}{8} \\
\frac{\pi}{2} \\
\delta^{\prime}\end{array}$ & 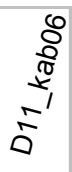 \\
\hline AF40 & 0 & 16,5 & 21,8 & 16,3 & 20,6 & 21,7 & 16,9 & 11,7 & 11,5 & 12 & 11,5 & 15,8 & 20,7 & 2,2 & 14,4 & 11,8 \\
\hline DQ067017 & 16,5 & 0 & 23,3 & 7,3 & 22 & 23,4 & 7,8 & 19,3 & 19,2 & 17,6 & 17,3 & 6,4 & 22,2 & 15,7 & 5,4 & 17,6 \\
\hline DQ330645 & 21,8 & 23,3 & 0 & 23,3 & 12,6 & 12,1 & 22,9 & 22,4 & 22,3 & 21,6 & 21,3 & 21 & 13,8 & 22,1 & 21,7 & 21,6 \\
\hline DQ450796 & 16,3 & 7,3 & 23,3 & 0 & 23 & 23,9 & 4,8 & 19,4 & 19,3 & 17,5 & 17,2 & 3,1 & 21,5 & 15,3 & 5,8 & 17,5 \\
\hline EF032775 & 20,6 & 22 & 12,6 & 23 & 0 & 8,3 & 22,8 & 24,3 & 24,2 & 22,8 & 22,5 & 20,8 & 11,7 & 21,3 & 20,1 & 22,8 \\
\hline F11. & 21,7 & 23,4 & 12,1 & 23,9 & 8,3 & 0 & 24,4 & 24,4 & 24,3 & 24,4 & 24,2 & 22,6 & 14 & 22,8 & 22,2 & 24,3 \\
\hline & & 7,8 & 22,9 & 4,8 & 22,8 & 24,4 & & 20,2 & 20 & 17,6 & 17,5 & 2,4 & 21,4 & 15,9 & 7,3 & 17,7 \\
\hline AY838477 & 11,7 & 19,3 & 22,4 & 19,4 & 24,3 & 24,4 & 20,2 & 0 & 0,3 & 0,5 & 0,1 & 16,9 & 21,7 & 11,8 & 17,1 & 0,1 \\
\hline AF513962. & 11,5 & 19,2 & 22,3 & 19,3 & 24,2 & 24,3 & 20 & 0,3 & 0 & 0,4 & 0 & 16,8 & 21,5 & 11,7 & 16,9 & 0,3 \\
\hline C02_k & 12 & 17,6 & 21,6 & 17,5 & 22,8 & 24,4 & 17,6 & 0,5 & 0,4 & 0 & 0,1 & 16,9 & 21,7 & 11,8 & 17,1 & 0,4 \\
\hline D04_kab08 & 11,5 & 17,3 & 21,3 & 17,2 & 22,5 & 24,2 & 17,5 & 0,1 & U & 0,1 & 0 & 16,8 & 21,5 & 11,7 & 16,9 & 0,3 \\
\hline F03_k & 15,8 & 6,4 & 21 & 3,1 & 20,8 & 22,6 & 2,4 & 16,9 & 16,8 & 16,9 & 16,8 & U & 22,1 & 16,5 & 7,3 & 17,1 \\
\hline C05_ka & 20,7 & 22,2 & 13,8 & 21,5 & 11,7 & 14 & 21,4 & 21,7 & 21,5 & 21,7 & 21,5 & 22,1 & 0 & 21,3 & 21,9 & 21,8 \\
\hline D06_kab02 & 2,2 & 15,7 & 22,1 & 15,3 & 21,3 & 22,8 & 15,9 & 11,8 & 11,7 & 11,8 & 11,7 & 16,5 & 21,3 & & 15,1 & 12 \\
\hline C09_kab06 & 14,4 & 5,4 & 21,7 & 5,8 & 20,1 & 22,2 & 7,3 & 17,1 & 16,9 & 17,1 & 16,9 & 7,3 & 21,9 & 15,1 & 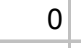 & 17,2 \\
\hline D11_kab06 & 11,8 & 17,6 & 21,6 & 17,5 & 22,8 & 24,3 & 17,7 & 0,1 & 0,3 & 0,4 & 0,3 & 17,1 & 21,8 & 12 & 17,2 & 0 \\
\hline
\end{tabular}

\section{Distance Matrix Actinobacteria, OP10}

\begin{tabular}{|c|c|c|c|c|c|c|c|c|c|c|c|c|c|c|c|c|}
\hline & $\begin{array}{c}\stackrel{9}{\infty} \\
\stackrel{\infty}{\infty} \\
\frac{1}{\sigma}\end{array}$ & 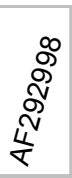 & $\begin{array}{c}\stackrel{8}{\infty} \\
\stackrel{\infty}{\infty} \\
\frac{5}{+}\end{array}$ & $\begin{array}{l}\infty \\
\infty \\
\stackrel{\infty}{\hat{\sigma}} \\
\frac{1}{\sigma}\end{array}$ & 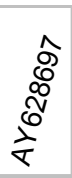 & 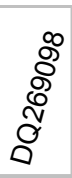 & 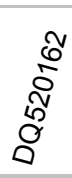 & $\frac{9}{\frac{9}{\pi}}$ & $\frac{i}{\infty}$ & $\begin{array}{c}0 \\
\stackrel{0}{\mathbb{\pi}} \\
\infty \\
\infty \\
\infty^{\prime}\end{array}$ & 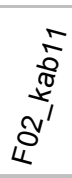 & $\frac{i}{i} \frac{i}{8}$ & 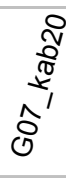 & 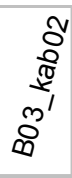 & 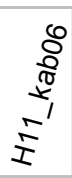 & 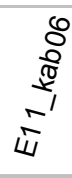 \\
\hline AFOS & 0 & 16,5 & 13,1 & 13,6 & 12,7 & 9,3 & 14,2 & 7 & 11,7 & 12,5 & 13,5 & 14 & 19 & 15,1 & 13 & 15,3 \\
\hline AF2S & 16,5 & 0 & 17,3 & 13,2 & 16,2 & 15,7 & 14,2 & 15,7 & 15,3 & 13,8 & 15,4 & 16,9 & 15 & 14,5 & 14,9 & 16,2 \\
\hline AJ518769 & 13,1 & 17,3 & 0 & 12,1 & 5,5 & 11,8 & 13,7 & 12,9 & 5,2 & 11,9 & 14,5 & 13,3 & 19,2 & 6 & 13 & 15,6 \\
\hline AY178080 & 13,6 & 13,2 & 12,1 & 0 & 10,7 & 13,1 & 9,3 & 13,8 & 10,6 & 6,5 & 13,5 & 10,4 & 16,9 & 12,2 & 9,7 & 16,5 \\
\hline AY628697 & 12,7 & 16,2 & 5,5 & 10,7 & 0 & 12,4 & 13,3 & 12,1 & 5,3 & 10,3 & 12,1 & 12,8 & 18 & 3 & 11,8 & 16 \\
\hline DQ2 & 9,3 & 15,7 & 11,8 & 13,1 & 12,4 & 0 & 15,4 & 10,6 & 12,5 & 13,3 & 16,5 & 13,2 & 19,9 & 13,9 & 13,8 & 14,3 \\
\hline Q5 & 4,2 & 14,2 & 13,7 & 9,3 & 13,3 & 15,4 & 0 & 14,3 & 12,1 & 11,1 & 13,3 & 11,7 & 15,9 & 11,3 & & 16,1 \\
\hline G01_kab19 & 7 & 15,7 & 12,9 & 13,8 & 12,1 & 10,6 & 14,3 & 0 & 11,7 & 12,5 & 12,8 & 14,9 & 19,1 & 13,8 & 14,8 & 15,4 \\
\hline B09_kab01 & 11,7 & 15,3 & 5,2 & 10,6 & 5,3 & 12,5 & 12,1 & 11,7 & 0 & 10 & 11,8 & 12,5 & 18,5 & 3,5 & 11,4 & 15,4 \\
\hline A08_kab01 & 12,5 & 13,8 & 11,9 & 6,5 & 10,3 & 13,3 & 11,1 & 12,5 & 10 & 0 & 12,7 & 9,3 & 15,4 & 10,2 & 9,3 & 15,7 \\
\hline F02_kab11 & 13,5 & 15,4 & 14,5 & 13,5 & 12,1 & 16,5 & 13,3 & 12,8 & 11,8 & 12,7 & 0 & 16,4 & 18,9 & 10,7 & 13,6 & 17,3 \\
\hline C09_kab11 & 14 & 16,9 & 13,3 & 10,4 & 12,8 & 13,2 & 11,7 & 14,9 & 12,5 & 9,3 & 16,4 & 0 & 17,4 & 13,4 & 10,3 & 15,7 \\
\hline G07_k & 19 & 15 & 19,2 & 16,9 & 18 & 19,9 & 15,9 & 19,1 & 18,5 & 15,4 & 18,9 & 17,4 & 0 & 18,8 & 16 & 19,8 \\
\hline B03_kab02 & 15,1 & 14,5 & 6 & 12,2 & & 13,9 & 11,3 & 13,8 & 3,5 & 10,2 & 10,7 & 13,4 & 18,8 & 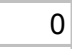 & 12,1 & 15,9 \\
\hline H11_kab06 & 13 & 14,9 & 13 & 9,7 & 11,8 & 13,8 & 3 & 14,8 & 11,4 & 9,3 & 13,6 & 10,3 & 16 & 12,1 & 0 & 16,3 \\
\hline E11_kab06 & 15,3 & 16,2 & 15,6 & 16,5 & 16 & 14,3 & 16,1 & 15,4 & 15,4 & 15,7 & 17,3 & 15,7 & 19,8 & 15,9 & 16,3 & 0 \\
\hline
\end{tabular}

\section{Distance Matrix Caulobacteriales}




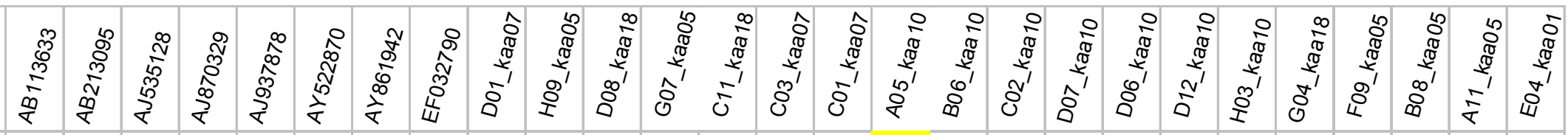

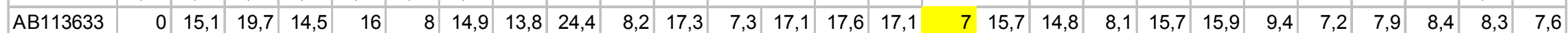

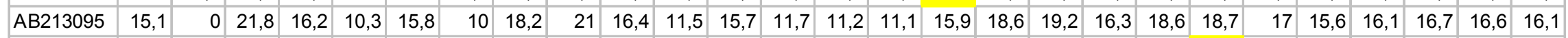

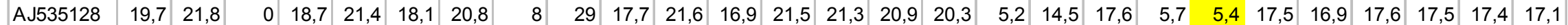

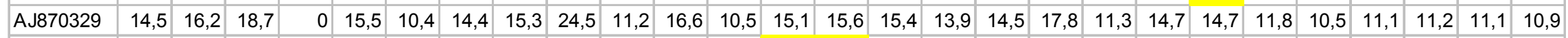

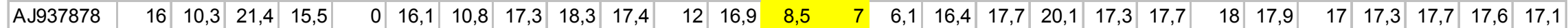

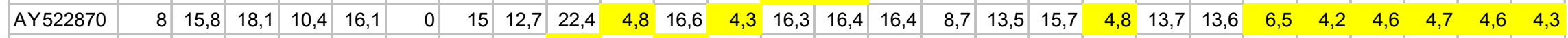
\begin{tabular}{|l|l|l|l|l|l|l|l|l|l|l|l|l|l|l|l|l|l|l|l|l|l|l|l|l|l|l|l|} 
AY861942 & 14,9 & 10 & 20,8 & 14,4 & 10,8 & 15 & 0 & 17,6 & 16,5 & 14,6 & 3,5 & 14,6 & 10,9 & 10,7 & 10,6 & 14,1 & 16,6 & 16,5 & 14,7 & 16,9 & 16,8 & 14,7 & 14,4 & 14,4 & 15 & 14,8 & 14,2 \\
\hline
\end{tabular}

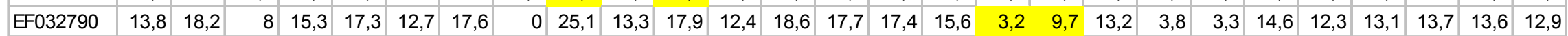

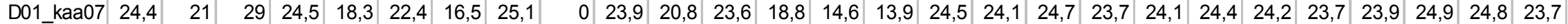

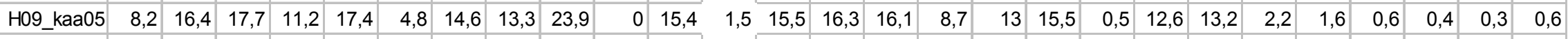

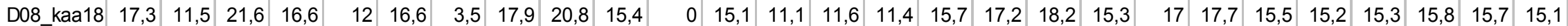

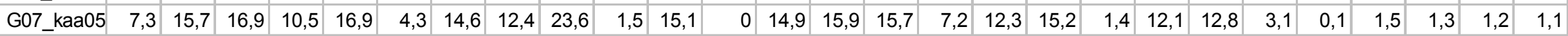

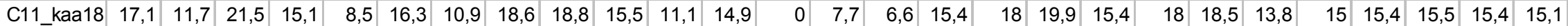

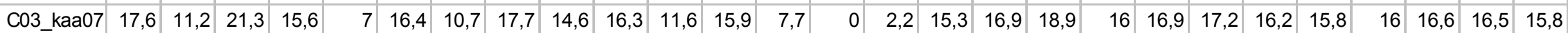

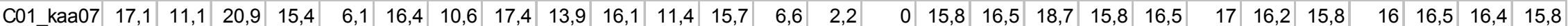

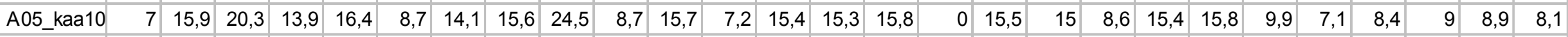
\begin{tabular}{|l|l|l|l|l|l|l|l|l|l|l|l|l|l|l|l|l|l|l|l|l|l|l|l|l|l|l|l|}
\hline B06 kaa10 & 15,7 & 18,6 & 5,2 & 14,5 & 17,7 & 13,5 & 16,6 & 3,2 & 24,1 & 13 & 17,2 & 12,3 & 18 & 16,9 & 16,5 & 15,5 & 0 & 8,4 & 12,9 & 0,6 & 0,4 & 14,4 & 12,5 & 13 & 13,5 & 13,4 & 12,8 \\
\hline
\end{tabular}

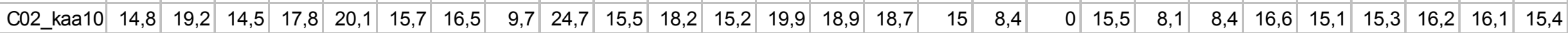

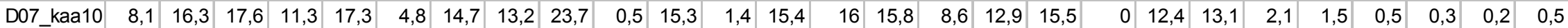

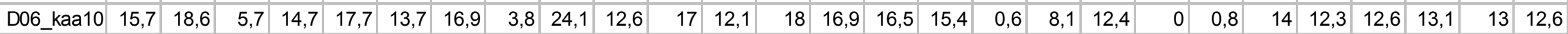

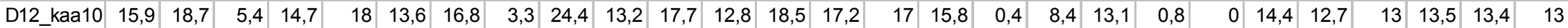

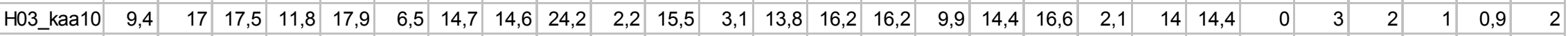

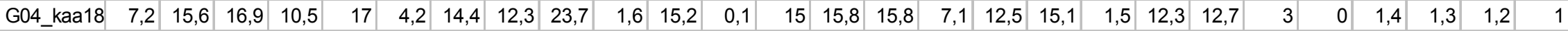

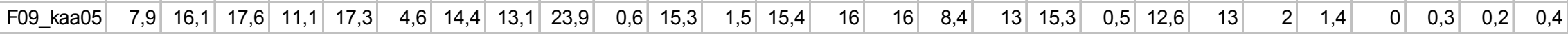

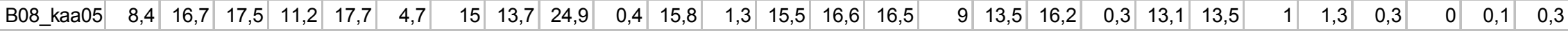

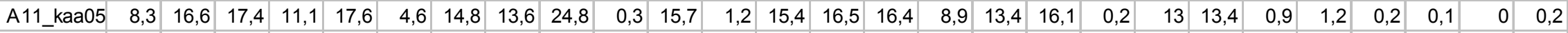

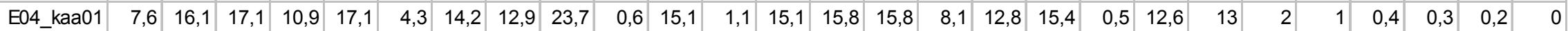

\section{Distance Matrix Crenarchaeota}




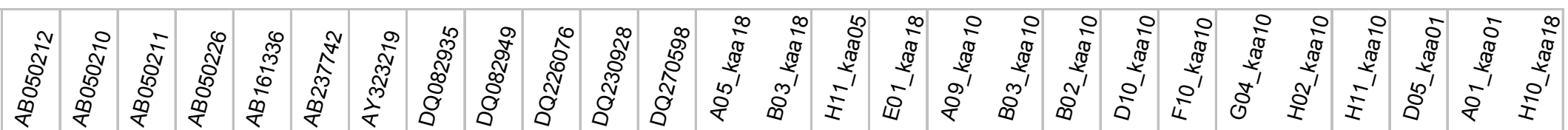

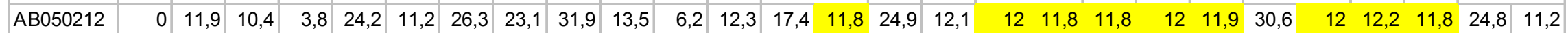

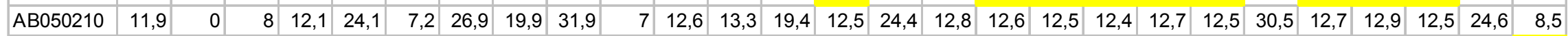

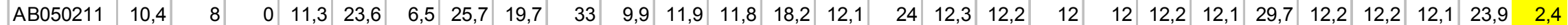

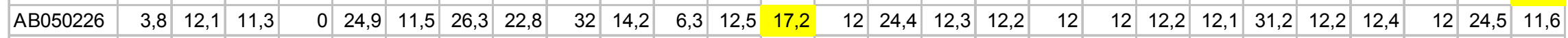

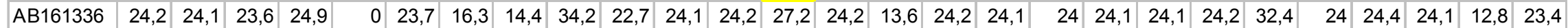

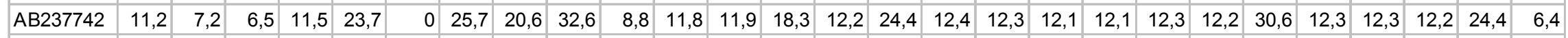
\begin{tabular}{|l|l|l|l|l|l|l|l|l|l|l|l|l|l|l|l|l|l|l|l|l|l|l|l|l|l|l|l|l|l}
\hline AY323219 & 26,3 & 26,9 & 25,7 & 26,3 & 16,3 & 25,7 & 0 & 15,2 & 33,3 & 24,3 & 27,2 & 26,3 & 28,4 & 25,6 & 17,1 & 25,7 & 25,4 & 25,4 & 25,4 & 25,6 & 25,6 & 34,6 & 25,4 & 25,7 & 25,5 & 16,4 & 25,6 \\
\hline
\end{tabular}

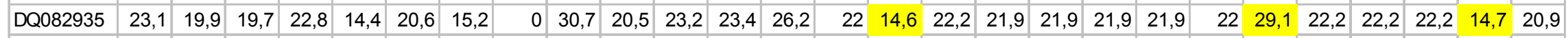

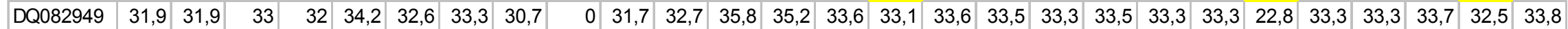

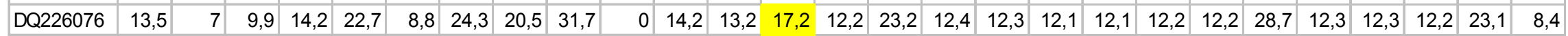

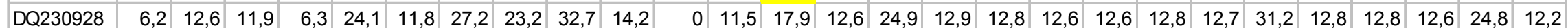

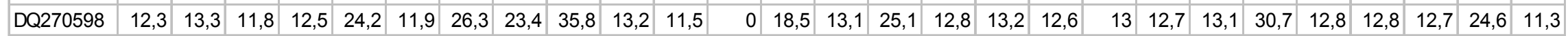

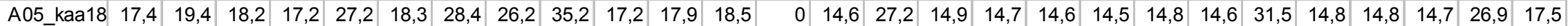

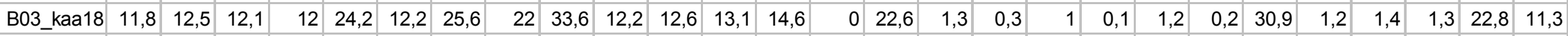

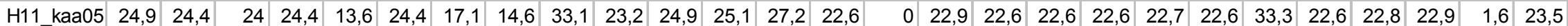

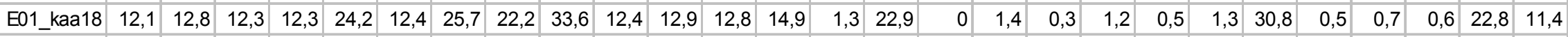

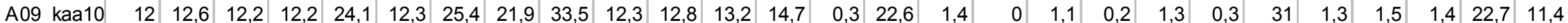

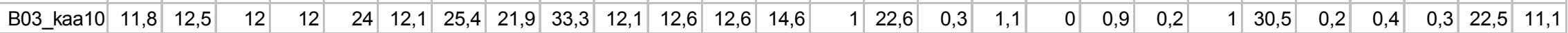

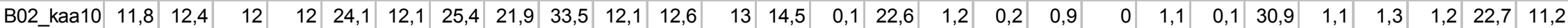
\begin{tabular}{|l|r|r|r|r|r|r|r|r|r|r|r|r|r|r|r|r|r|r|r|r|r|r|r|r|r|r|r|}
\hline D10_kaa10 & 12 & 12,7 & 12,2 & 12,2 & 24,1 & 12,3 & 25,6 & 21,9 & 33,3 & 12,2 & 12,8 & 12,7 & 14,8 & 1,2 & 22,7 & 0,5 & 1,3 & 0,2 & 1,1 & 0 & 1,2 & 30,6 & 0,4 & 0,6 & 0,5 & 22,6 & 11,3 \\
\hline
\end{tabular} \begin{tabular}{|l|r|r|r|r|r|r|r|r|r|r|r|r|r|r|r|r|r|r|r|r|r|r|r|r|r|r|r|r|}
\hline F10kaa10 & 11,9 & 12,5 & 12,1 & 12,1 & 24,2 & 12,2 & 25,6 & 22 & 33,3 & 12,2 & 12,7 & 13,1 & 14,6 & 0,2 & 22,6 & 1,3 & 0,3 & 1 & 0,1 & 1,2 & 0 & 31 & 1,2 & 1,4 & 1,3 & 22,7 & 11,3 \\
\hline
\end{tabular}

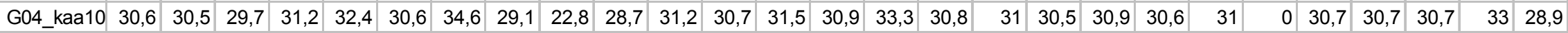

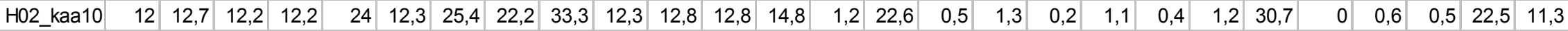

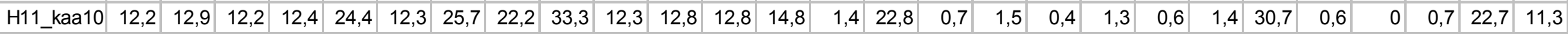

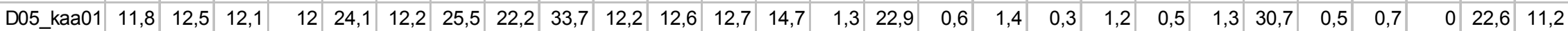

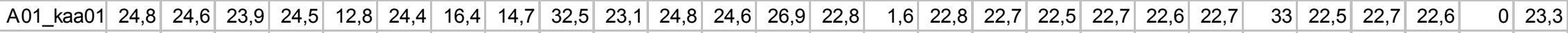

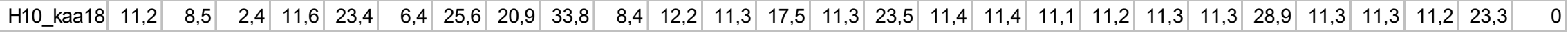

\section{Distance Matrix Euryarchaeota}




\section{DANKSAGUNG}

Ein ganz großes Dankeschön geht an Herrn PD Dr. Rolf Daniel, der mir die Möglichkeit gegeben hat an diesem interessanten Thema zu arbeiten. Vielen Dank für die Betreuung und die vielen hilfreichen Gespräche, die zum Gelingen der Arbeit beigetragen haben.

Prof. G. Gottschalk danke ich für die Übernahme des Korreferates.

Weiterhin möchte ich mich bei meiner Arbeitsgruppe für die nette Arbeitsatmosphäre bedanken. Die Zusammenarbeit mit Carola, Steffi, Christiane, Tanja, Anne und Juli war immer sehr angenehm und hat mir sehr viel Freude bereitet.

Auch allen ehemaligen Labormitgliedern; Jessie, Claudia, Hanna, Söhnke, Michael und Frank, gilt ein großer Dank.

Auch der ehemaligen Arbeitsgruppe von Prof. W. Liebl möchte ich für die sehr nette Zusammenarbeit während der gesamten Zeit danken.

Der Werkstatt, Olaf, Gerd und Patrick, danke ich für die hilfreiche technische Untersützung.

Dem G2L danke ich für die Sequenzierungsarbeiten.

Ein ganz großer Extra-Dank geht an meine Eltern und meinen Bruder, die mich während der gesamten Zeit in jeder Lage unterstütz haben.

Meiner Freundin Andrea danke besonders ... für Alles...! 


\section{Lebenslauf}

\begin{tabular}{|c|c|}
\hline 25.12.1975 & Geburt in Aachen \\
\hline 1982-1986 & $\begin{array}{l}\text { Besuch der Grund- und Hauptschule Wallstraße, } \\
\text { Wolfenbüttel }\end{array}$ \\
\hline 1986-1988 & $\begin{array}{l}\text { Besuch der Orientierungsstufe Wallstraße, } \\
\text { Wolfenbüttel }\end{array}$ \\
\hline 1988-1996 & Besuch des Theodor-Heuss-Gymnasium, Wolfenbüttel \\
\hline 06/1996 & Abitur \\
\hline 1996-1997 & Wehrdienst \\
\hline WS $1997 / 1998$ & $\begin{array}{l}\text { Beginn des Studiums Chemie an der Georg-August- } \\
\text { Universität zu Göttingen }\end{array}$ \\
\hline WS 1998/1999 & $\begin{array}{l}\text { Beginn des Studiums Biologie an der Georg-August- } \\
\text { Universität zu Göttingen }\end{array}$ \\
\hline $10 / 2000$ & $\begin{array}{l}\text { Vordiplom Biologie (Mikrobiologie, Botanik, anorg. } \\
\text { Chemie) }\end{array}$ \\
\hline $11 / 2002$ & $\begin{array}{l}\text { Diplom Biologie (Mikrobiologie, Biochemie, } \\
\text { Immunologie) }\end{array}$ \\
\hline $12 / 2002$ & $\begin{array}{l}\text { Beginn der experimentellen Arbeiten zur vorliegenden } \\
\text { Dissertation }\end{array}$ \\
\hline
\end{tabular}




\section{Erklärung:}

Hiermit erkläre ich, dass ich die vorliegende Arbeit selbstständig und nur unter Angabe der verwendeten Hilfsmittel und Literatur angefertig habe.

Jörg Schuldes

Göttingen, den 18.03.2008 